\title{
How Integrated is Latvian Society? An Audit of Achievements, Failures and Challenges
}

Editor Nils Muižnieks 
UDK 325(474.3)

Ho 930

How Integrated Is Latvian Society? An Audit of Achievements, Failures and Challenges / Editor Nils Muižnieks; University of Latvia Advanced Social and Political Research Institute. - Riga: University of Latvia Press, 2010. - 292 pp. ISBN 978-9984-45-172-5

(C) University of Latvia, 2010

ISBN 978-9984-45-172-5 


\section{Contents}

PART I

Concepts, History, Policy ...................................................................................... 5

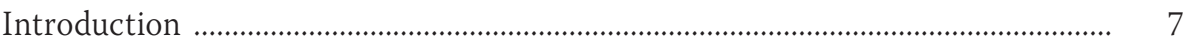

Nils Muižnieks

Social Integration: A Brief History of an Idea ........................................................... 15

Nils Muižnieks

The Soviet Heritage and Integration Policy Development Since the Restoration of Independence

Juris Rozenvalds

The Society Integration Foundation and 'Ethnic Integration'

Ilona Kunda

PART II

INTEgRATION IN VARIOUS LifE REALMS

Citizenship, Participation and Representation

Ilze Brands Kehris

Ethnic Minorities in the Latvian Labour Market, 1997-2009: Outcomes,

Integration Drivers and Barriers

Mihails Hazans

Social Policy and Integration

Feliciana Rajevska

Education for Social Integration

Brigita Zepa

The Media and Integration

Ilze Šulmane

Identity, Ethnic Relations, Language and Culture

Aivars Tabuns

Conclusion

Nils Muižnieks

Draft Integration Indicators

Ilona Kunda and Nils Muižnieks

Contributors 


\section{Part I}

Concepts, History, Policy 


\section{Introduction}

\section{Nils Muižnieks}

Most researchers and policy-makers focus on Russians when discussing the integration of Latvian society. The size of the Russian minority in Latvia and its presumed potential for causing mischief have contributed to this narrow focus, which has been reinforced by the attention of the Russian Federation and various European and international organizations to the status of Russians or "Russian-speakers" (those with Russian as a native language). This book examines the position of Russians and other minorities and their relations with Latvians, but also attempts to measure the integration of Latvian society as a whole. As will be argued below, integration implicates not just minorities, immigrants and refugees, but the majority population as well.

The slightly presumptuous subtitle of this volume - An Audit - was inspired by an earlier effort by colleagues to measure the quality of democracy in Latvia. ${ }^{1}$ The term "audit" suggests a rigorous, systematic evaluation based on accepted standards. The reader will have to determine the extent to which the authors of this volume have fulfilled this promise. According to the Compact Oxford English dictionary, the traditional meaning of an audit is "an official inspection of an organization's accounts." ${ }^{2}$ Usually, if an organization's accounts, procedures or processes are found wanting, the auditor provides recommendations on how to improve performance. While the "auditors" in this volume occasionally enter the realm of the prescriptive, they generally let the analysis speak for itself.

This reluctance to offer a host of policy recommendations derives from a number of considerations. To propose such recommendations, one must make a number of assumptions: that policy-makers want effective policy, that there is a consensus as to what constitutes effective policy, that policy-makers are willing and able to change policy if it is found in some way wanting, and that there are resources available for implementing policy. All of these assumptions are problematic in contemporary Latvia. As will be suggested below in the chapter by Juris Rozenvalds, Latvia's political elite has been very divided

${ }^{1}$ Juris Rozenvalds, ed. (2005), How Democratic Is Latvia: An Audit of Democracy. Riga: University of Latvia Press.

${ }^{2}$ See http://www.askoxford.com/concise_oed/audit?view=uk. 
regarding integration policy, which has resulted in a lukewarm commitment (at best) to implementing even those policy documents that have been adopted. Since a number of key pieces of legislation affecting integration (e.g., the Law on Citizenship, the State Language Law) were adopted or last amended under severe international pressure, the political elite has proven very reluctant to revisit these laws, even when there was a compelling reason for amending them to reflect new circumstances. While government resources for promoting integration have never been plentiful, in the context of a severe economic crisis after 2008, social integration has fallen near the bottom of the government's list of funding priorities and will probably remain there for some time. Despite the absence of an attentive target audience among policy-makers, the authors of the chapters covering integration in various life realms (Part II) do point to the most urgent tasks that need to be addressed.

A strictly policy-oriented approach would also miss much, as the level of integration in a society is undoubtedly affected by a whole range of factors besides government integration policy. Clearly, the inherited experience of inter-ethnic relations shapes current social processes, as does the economic and political situation in general. The analysis below captures only incompletely the impact of the current economic crisis on social integration, as the situation at the time of writing (February 2010) was still very dynamic and some of the available data predate the onset of the crisis in late 2008 or capture only its initial effects. Social integration is also affected by the international situation this was clearly evident immediately after Latvia's accession to the European Union, when naturalization rates briefly jumped and many of Latvia's inhabitants (Latvians and minorities alike) took advantage of their right to free movement within the European Union and migrated, mostly to Ireland and Great Britain. The quality of social integration is also affected by the ups and downs of Latvia's relations with Russia - the "kin-state" of Latvia's largest minority. ${ }^{3}$ Integration policy, which has been contradictory and inconsistent, has been but one, and not always the most important, factor in shaping the integration of Latvian society.

There have been a number of previous efforts to develop integration indicators and to measure integration in Latvia. From 2002 through 2004, first, the Social Integration Department of the Ministry of Justice, then the secretariat of the Special Assignments Minister for Social Integration Affairs (hereafter, simply "integration secretariat") organized a series of inconclusive interministerial discussions with the aim of developing progress indicators for the National Programme on the Integration of Society in Latvia. From 2003 to 2005 , the integration secretariat compiled a sizeable data base of integration projects, an effort that was subsequently abandoned. During its existence from ${ }^{3}$ See Nils Muižnieks, ed. (2006), Latvian-Russian Relations: Domestic and International
Dimensions. Riga: University of Latvia Press. 
2002 to the end of 2008, the integration secretariat commissioned a number of sociological surveys and other studies on various aspects of integration. ${ }^{4}$ In addition, the Society Integration Foundation has funded a number of studies dealing with various aspects of integration or the situation of specific minorities. ${ }^{5}$ International non-governmental organizations and foreign research institutes have also conducted a number of useful studies. ${ }^{6}$ This volume builds on many of these previous efforts, but tries to go further.

Previous efforts were often plagued by a host of problems. Most of the aforementioned efforts were either surveys focusing on attitudes or thematic studies with a focus on one aspect of integration or one minority. No official consensus was ever reached on indicators, so those who commissioned research or carried it out proceeded using various methodologies and approaches. The involvement of stakeholders in society and ministries other than that directly responsible for integration was patchy. It should also be noted that the major funders of the research (the integration secretariat and the Society Integration Foundation) had a certain vested interest in the results. Many of the studies also ignored the academic and policy-oriented work on measuring integration conducted elsewhere.

${ }^{4}$ For commissioned studies on the media, see Sergejs Kruks and Ilze Šulmane (2002), Pilsoniskās sabiedrības attīstība un sabiedrības integrācija. Riga: Komunikācijas studiju nodaļa; Ilze Šulmane and Sergejs Kruks (2006), Neiecietības izpausmes un iecietības veicināšana Latvijāa. Riga: ĪUMSILS. On minorities, see Rīgas Stradina universitāte (2004), Latvijas mazākumtautību sabiedrisko organizāciju dibināšanas mērķi. Riga: RSU; LU FSI and İUMSILS (2007), Mazākumtautības Latvijā. Vēsture un tagadne. Riga: LU FSI; Nils Muižnieks, red. (2007), Nacionālo minoritāšu konvencija - diskriminācijas novēršana un identitātes saglabāšana Latvijā. Riga: LU SPPI. On the role of local governments, see Baltijas Sociālo zinātnu institūts (2004), Pašvaldību loma sabiedrības integrācijas procesā. Riga: BSZI. On civic values at school, see Rīgas Stradiña universitāte, Pilsoniskās vērtības latviešu un mazākumtautību izglìtības programmās: salīdzinājums. Riga: RSU. For the most recent commissioned surveys, see, e.g., SKDS (2006), Sabiedrības integrācijas aktuālākie aspekti. Riga: SKDS (2007), Sabiedrības integrācijas aktuālākie aspekti. Riga; SIA „AC Konsultācijas" (2008), Kvantitatīvs un kvalitatīvs pētījums par sabiedrības integrācijas un pilsonības aktuālajiem aspektiem. On opposition to integration, see Latvijas Universitātes Filozofijas un sociologijas institūts, ĪUMSILS (2007), Pretestība sabiedrības integrācijai: cēloni un sekas. Riga: LU FSI and ĪUMSILS.

${ }^{5}$ See Latvian Centre for Human Rights and Ethnic Studies (2003), The Situation of Roma in Latvia. Riga: LCHRES; Baltic Institute of Social Sciences (2006), Integration practice and perspectives. Riga: BISS; Baltijas sociālo zinātņu institūts (2008), Mēs. Svētki. Valsts. Valsts svētku svinēšanas socioloǵiska izpēte. Riga: BSZI.

${ }^{6}$ See, e.g., the New Baltic Barometer Surveys, available online at www.balticvoices.org; Open Society Institute EU Accession Monitoring Program (2002), Monitoring the EU Accession Process: Minority Protection, Vol. 1, An Assessment of Selected Policies in Candidate States. Budapest: OSI/EU Accession Monitoring Program; and the various seminar reports and studies on Latvia and the other Baltic states available on the web site of the European Centre for Minority Issues in Flensburg, Germany, at www.ecmi.de. 
The effort to measure democracy mentioned above had the luxury of using a ready-made methodology that had already been used elsewhere. The authors of this volume were not so fortunate, as European countries feature a wide range of approaches to integration, none of which can be transferred wholesale to the Latvian context. Most often, discussions about integration elsewhere in the European Union are about immigrants or refugees, called "third country nationals" in EU parlance. ${ }^{7}$ Particularly in many of the new EU member states, integration policy and discourse have focused not on new arrivals, but on the indigenous Roma population. ${ }^{8}$ Latvia does have a small population of recent immigrants whose integration needs should be addressed. ${ }^{9}$ Moreover, Latvia also has a Roma community numbering between 8,000 and 15,000 persons whose situation prompted the Latvian authorities to adopt a Roma integration programme. However, as subsequent chapters demonstrate, Latvia's societal divisions have more to do with other cleavages based on ethnicity and language, with the prime divide being between ethnic Latvians and Russian-speakers, most of whom were either born in Latvia or have lived here for many years.

The initial task of the authors was to come to grips with what we were seeking to measure. As noted in the chapter by Juris Rozenvalds, the official Latvian definition of integration is unsatisfactory for a number of reasons, which prompted the research team to search elsewhere for a more nuanced understanding of social integration that would be firmly based in social science. Thus, the chapter by Nils Muižnieks below seeks to provide a brief intellectual history of the concept of social integration, examining usages over time in the academic and international policy communities and identifying points of consensus. The understanding of social integration resulting from this exercise, in turn, informed the effort to develop a framework for measuring integration in line with best European practices.

This volume represents the outcome of a three-year project generously funded by the Open Society Institute's Think Tank Fund with co-funding from the University of Latvia. At the outset of the project, the project team (Nils Muižnieks, Juris Rozenvalds, Ilona Kunda) conducted an inventory of existing integration research in Latvia, including sociological research, localized studies, analyses of the inter-section of gender and ethnicity, discourse analyses on

7 See the relevant section of the European Commission's web site on immigrant integration at http://ec.europa.eu/justice_home/fsj/immigration/integration/fsj_immigration_integration_ en.htm.

${ }^{8}$ See, e.g., OSI EU Accession Monitoring Program (2002), Monitoring the EU Accession Process: Minority Protection Vol. I, An Assessment of Selected Policies in Candidate States. Budapest: OSI EU Accession Monitoring Program.

9 See, e.g., Centre for Public Policy Providus (2008), Learning to Welcome: The Integration of Immigrants in Latvia and Poland. Riga: Providus; and Advanced Social and Political Research Institute (2009), Immigrant Integration in Latvia. Working Paper No. 1, Riga: ASPRI, available at http://www.szf.lu.lv/files/petnieciba/publikacijas/working_paper/ immig\%20integ\%20final\%20draft.pdf 
topics related to social integration, and more. Many of the chapters below draw on this rich store of data and analysis. Subsequently, the project team organized a series of seminars, conferences and consultations to discuss the emerging research framework with other researchers, outside stakeholders (NGOs, minority groups, gender equality experts, etc.), and the ever dwindling number of civil servants responsible for integration policy. Finally, draft chapters were presented at an international conference on 16-17 November 2009 organized by the Advanced Social and Political Research Institute and the Public Policy Centre Providus in Riga, Latvia, entitled "Inclusion Unaffordable: the Uncertain Fate of Integration and Anti-Discrimination Policies in Central and Eastern Europe."

Before developing concrete indicators, the project team commissioned focus group research to identify perceived barriers to integration. Then the project team developed a set of draft indicators based on the results of the focus group study, our identified points of consensus on the social science understanding of integration, and liberal borrowing from other Europe-wide efforts to measure social cohesion in diverse societies and benchmark integration policies. ${ }^{10}$

To set the context of the current situation, the chapter by Juris Rozenvalds traces the historical legacy of the Soviet and early post-independence years for integration policy, outlining the "everyday habits of mind" acquired by policy-makers and the public at large that continue to impinge on the integration process and integration policy. Rozenvalds also examines the political compromises and disagreements leading up to the adoption of an integration policy framework and the various institutional mechanisms set up to implement this policy. Next, Ilona Kunda takes on the ambitious task of evaluating the policy impact of the Society Integration Foundation - the best-funded, longestlasting institution charged with implementing integration policy by supporting "bottom-up projects".

Subsequent chapters investigate integration in various realms of life. Ilze Brands Kehris examines political and civic integration, focusing on citizenship issues, participation and representation. Mihails Hazans provides an in-depth analysis of integration in and through the labour market, focusing on language and ethnicity. Feliciana Rajevska analyses integration and social policy, focusing on housing, health care and the prison system. Brigita Zepa focuses on integration in the education system, stressing not only ethnic, linguistic and inter-cultural issues, but also the education of various vulnerable social groups. Ilze Šlmane looks at the role of the media and the information environment in integration. Finally, Aivars Tabuns examines language, culture and identity.

${ }^{10}$ Particularly useful were the Council of Europe (2005), Concerted development of social sohesion indicators: Methodological guide. Strasbourg: Council of Europe Publishing, and Migration Policy Group (2005), Setting up a system of benchmarking to measure the success of integration policies in Europe. Brussels: European Parliament, Directorate General Internal Policies of the Union. 
While this volume aims at an all-encompassing approach, a number of important issue areas and target groups are mentioned only in passing, primarily due to the paucity of available disaggregated data. For example, the study does not examine in depth the role of the criminal justice system or the military in social integration. In other contexts, police and border guards are often the first and primary representatives of the state encountered by immigrants and some minority groups. Moreover, as evidenced by numerous recent instances of unrest throughout Europe, misconduct by police or the (perception thereof) can spark social tensions and inter-communal strife. This realization has led to a jump in the amount of attention being paid at international and national level to policing diverse societies. ${ }^{11}$ At the same time, international experience (e.g., the United States) suggests that militaries can be useful promoters of social integration. In Latvia, the changing social role of the military after the transition to a professional army in 2006 has not been analysed by any researcher. Unfortunately, disaggregated data on the criminal justice system (including both personnel and "clients") and the military are fragmented and dated. ${ }^{12}$

Another lacuna is data and analysis on the situation of the Roma. Apart from a 2003 study, there is little recent information and analysis on this, Latvia's most vulnerable minority. After accession to the European Union, a significant number of Latvian Roma migrated elsewhere, primarily to Ireland and Great Britain, though their number is unknown. What is more, the economic crisis has invariably struck the Roma very hard, leading to their further social exclusion. There is clearly a need for an updated study examining all aspects of the situation of Latvia's Roma, including public attitudes towards them and the impact of the Roma integration programme.

The foregoing points to the urgent need for statistics disaggregated by ethnicity, language, religion, citizenship and country of origin. In their enthusiasm to implement EU directives on data protection, some Latvian authorities have gone so far as to declare all ethnic data "sensitive data", thereby depriving researchers and policy-makers of a crucial tool. If the appropriate safeguards are in place and the data are anonymous, voluntary and based on self-identification, they can facilitate combating discrimination and aid those developing policy initiatives to address the needs of vulnerable groups and promote social

${ }^{11}$ See OSCE High Commissioner on National Minorities (2006), Recommendations on Policing in Multi-Ethnic Societies. The Hague: OSCE, available at http://www.osce. org/documents/hcnm/2006/02/17982_en.pdf. See also European Commission against Racism and Intolerance (2007), General Policy Recommendation No. 11, Combating Racism and Racial Discrimination in Policing. Strasbourg: Council of Europe. Available at http://www.coe.int/t/dghl/monitoring/ecri/activities/GPR/EN/Recommendation_N11/ Recommendation_2_en.asp\#TopOfPage.

${ }_{12}$ For suggestive data and analysis, see Anhelita Kamenska and Girts Valdis Kristovskis (2005), 'Civilian Control of the Military and Police,' in Rozenvalds, ed., How Democratic is Latvia, pp. 111-124. 
integration. The forthcoming census in Latvia in 2011 should provide a good opportunity for researchers, integration policy makers and stake-holders in civil society to engage in a dialogue about the data most needed in the realm of social integration.

Several brief notes on terminology are in order. In Latvian, the operative phrase can be translated as the "integration of society" or "society's integration" (sabiedrības integrācija). In this volume, we have chosen to render this as "social integration," reflecting a broad understanding of the word "social" to mean everything pertaining to society (as in the social sciences). This might seem odd to a Latvian reader, as the literal Latvian equivalent (sociā $\bar{l} \bar{a}$ integrācija) refers primarily to social policy, such as the integration of disabled persons, etc. "Social integration" won out over the cumbersome "societal integration" or the odd Latvian-English construction "society integration" for reasons of convenience, as well as its longer academic pedigree.

Another terminological and conceptual issue involves the categories used to describe various groups and identities in society. In the chapters below, the authors most often use the terms "Latvian" and "minority," or "Latvian," "Russian" and "other," or "Latvian" and "Russian-speaking" (usually used to refer to persons whose native language is Russian). These categories do not reflect the many new amalgam identities in Latvian society deriving from ethnically mixed marriages, Europeanization, and the growing importance of other identities. The categories used by the authors below generally reflect those used in the census, the Population Register, sociological surveys and public discourse. The census, which has been based on self-identification, offers respondents only traditional monist categories (e.g., Latvian, Russian, Roma). The Population Register, in turn, uses the voluntary ethnicity entry in passports, which also uses traditional ethnic categories and restricts people's choice of an ethnicity in various ways (e.g., to switch to "Latvian" one must demonstrate a certain level of Latvian language proficiency). Surveys often split respondents into either three big ethnic groups - Latvian, Russian and "other" or by native language - Latvian or Russian-speaker. One barrier to integration is the lingering Soviet essentialist understanding of ethnicity as an immutable, exclusive (one can have only one ethnicity), inherited characteristic. Another barrier is linguistic: there is no single word in Latvian describing a person belonging to Latvia (the Constitution refers to Latvijas tauta - the "people of Latvia"). Calls to use "Latvian" to describe all residents or citizens of Latvia regardless of ethnicity have sparked accusations of assimilationism.

Finally, a few notes of gratitude are in order. First, I would like to take this opportunity to thank the Open Society Institute Think Tank Fund for its support, patience and painless bureaucracy. Second, I would like to thank my colleagues and co-authors for their cooperation, particularly Juris Rozenvalds, now dean of the Faculty of Social Sciences at the University of Latvia, and Ilona Kunda, colleague at the Advanced Social and Political Research Institute. Were it not 
for Ilona's administrative and other talents, this project would never have gotten off the ground, let alone found its way to the reader in the form of a book. Of course, any remaining errors of commission and omission are all mine. 


\section{Social Integration: A Brief History of an Idea Nils Muižnieks}

\section{Introduction}

Researchers and practitioners in Latvia and elsewhere have long debated over the meaning of the concept of "social integration". Participants in these debates have used the term in many, often contradictory, ways. Before attempting to analyse integration policy or measure integration in Latvia, it is useful to sort through this confusion by stepping back and briefly examining the history of the idea itself and the varied meanings it has acquired in the academic and policy literature over time. Having traced the genealogy of the idea, we will be in a better position to present our own understanding of the term, which builds on previous work.

\section{Social Integration in Durkheim and Parsons}

The French sociologist Emile Durkheim (1858-1917) is considered a pioneer in the study of social integration. Durkheim saw social change as a process of increasing differentiation of the social structure. As the division of labour developed, the need for maintaining coherence and unity within the social system grew. Such coherence and unity, which Durkheim termed "integration", could take place in two different ways. In a system characterized by "mechanical solidarity", "integration" relied on common values and beliefs. In a system characterized by "organic solidarity", "integration" relied on interdependence of the parts. Durkheim's "organic solidarity" can be seen as functional integration, stressing reciprocity and social linkages, while "mechanical solidarity" can be seen as normative integration. Durkheim saw "organic solidarity" as increasingly displacing "mechanical solidarity," though feared that the development of norms appropriate to the division of labour could lag behind the rate of social change, creating endemic social strain. ${ }^{1}$

${ }^{1}$ Emile Durkheim (1933), The Division of Labor in Society, trans. George Simpson. Glencoe: The Free Press, pp. 70-132. For an informed discussion of Durkheim's thought that places it in a broader intellectual context, see Andrew C. Janos (1986), Politics and Paradigms: Changing Theories of Change in Social Science. Stanford: Stanford University Press, pp. 23-4. 
Talcott Parsons (1902-1979) was the pre-eminent American sociologist of the $20^{\text {th }}$ century and an avid disciple of the $19^{\text {th }}$ century "classics", especially Durkheim and Max Weber. Like Durkheim, Parsons also saw social change as differentiation, which necessitates "integration" not only through political and institutional change, but also through shared social values and norms, as well as common expectations. Parsons conceived of integration as a process of institutionalizing common values in the social system at various levels.

Parsons described value change in terms of evolution or choice between five different "pattern variables":

1) affectivity versus affective neutrality;

2) self-orientation versus collectivity orientation;

3) universalism versus particularism;

4) ascription versus achievement and

5) specificity versus diffuseness. ${ }^{2}$

Except for the second variable, with which Parsons injected a utopian element into his scheme, the other variables describe a process of rationalization, individuation, and growing impersonalism accompanying the transition from traditional to market societies. This description became influential among those studying "modernization", when interest in various aspects of integration blossomed.

\section{Social Integration in the Modernization and Nationalism Literature}

The concept of "political integration" gained wide currency in the social sciences in the 1960s and 1970s among those examining "modernization" - the social, economic and political changes accompanying industrialization. In 1965, Myron Weiner identified five different usages of the term "integration" among scholars at the time:

1) imposing central control over subordinate political units or regions,

2) linking government to the governed,

3) promoting the capacity of people in a society to organize for a common purpose,

4) developing a value consensus, and

2 Talcott Parsons (1966), Societies: Evolutionary and Comparative Perspectives. Englewood Cliffs, pp. 22-3; Talcott Parsons and Edward A. Shils, eds. (1962), Toward a General Theory of Action, $2^{\text {nd }}$ ed. New York, pp. 76-81. For analysis of Parsons work, see Victor Lidz (2000), 'Talcott Parsons.' In George Ritzer, ed., The Blackwell Companion to Major Social Theorists. Oxford: Blackwell Publishers, pp. 388-431. 
5) bringing together different groups into a single territorial unit and establishing a national identity. ${ }^{3}$

While several of these usages draw on Durkheim's and Parson's legacy, others strike out in new analytical directions.

The first usage focuses on central government control over fragmented territories - a common subject of inquiry among analysts examining the new states of Africa and Asia rent by centrifugal tendencies in the early post-colonial years. While still topical in many parts of the world, this usage is less salient in Latvia. The second usage shifts attention from preventing horizontal territorial fragmentation to generating "vertical" ties between the government and the governed - an imperative that has remained topical in Europe and Latvia to this day. The third and fifth usages include the interaction, exchange and interdependence which are the essence of functional integration, while the fourth usage corresponds with normative integration as outlined above. As Weiner himself noted, "Since there are many ways in which systems may fall apart, there are as many ways of defining "integration". 4

The fifth usage of integration identified by Weiner, that of bringing together groups in one territory and forming a common national identity, became very widespread among students of nationalism, "nation-building" and "national integration". The most influential figure in this literature has been Karl Deutsch, who pioneered the study of what could be termed "communicative integration". Deutsch defined a "community" in terms of "complementary habits and facilities of communication". 5 Two core concepts in Deutsch's approach were "social mobilization" and "assimilation". "Social mobilization" referred to the uprooting of people from their traditional settings (through urbanization, industrialization, government and media penetration of local communities, the development of transport networks) and their availability for mass communication. Deutsch understood "assimilation" in both linguistic and cultural terms. In Deutsch's approach, the two processes were linked:

If assimilation stays ahead of mobilization or keeps abreast of it, the government is likely to remain stable, and eventually everybody will be integrated into one people... On the other hand, where mobilization is fast and assimilation is slow, the opposite happens. ${ }^{6}$

For Deutsch, "integration" often meant assimilation through exposure to intense processes of communication.

${ }^{3}$ Myron Weiner (1965), 'Political Integration and Political Development.' In The Annals of the American Academy of Political and Social Science 358, March 1965, pg. 53.

${ }^{4}$ Ibid., pg. 54.

${ }_{5}^{5}$ Karl W. Deutsch (1953), Nationalism and Social Communication. Cambridge: MIT Press, pg. 70.

${ }^{6}$ Karl W. Deutsch (1969), Nationalism and Its Alternatives. New York: Knopf, pg. 27. 
Treating "integration" as tantamount to "assimilation" is very common in the social science literature on nationalism and "national integration." This trend reflects a number of factors: the assimilationist thrust of state policy in many "nationalizing" polities, a belief in the transitory nature of ethnic identities, and a widespread perception of sub-national identities as being incompatible with the consolidation of an overarching national identity. As Arend Lijphart noted in 1971, "in almost all theories of integration a high degree of cultural homogeneity, and especially a homogenous political culture, is considered a prerequisite for political integration". ${ }^{8}$ Much of the literature of the 1960s and 1970 s is also quite optimistic about the ability of national projects to assimilate indigenous, minority, regional or "low" cultures into a homogenous high culture through standardized education policy, universal conscription, language policy and other instruments available to the modern state. The impetus behind attempts at cultural and linguistic homogenization merits additional attention, as it has been quite persistent.

\section{Common Rationales for Integration qua Assimilation}

Over time, several different rationales for promoting assimilation have been offered by observers and policy-makers. One important rationale that was quite common in the $19^{\text {th }}$ and early $20^{\text {th }}$ centuries was the belief that assimilation was good for minorities. Paternalistic ethnocentrism as a rationale for assimilation can be illustrated through the statements of several prominent $19^{\text {th }}$ century British liberals.

In 1839, Lord Durham sought to justify the Anglicization of Canada in the following terms:

The language, the laws, the character of the North American continent are English; and every race but the English appears there in a condition of inferiority... It is to elevate them from that inferiority that I desire to give to the Canadians our English character. I desire it for the sake of the educated classes, whom the distinction of language and manners keeps apart from the great Empire to which they belong. ${ }^{9}$

In 1861 John Stuart Mill made a similar argument in more general terms: Experience proves that it is possible for one nationality to merge and be absorbed in another; and when it was originally an inferior and

7 This term was popularized by Rogers Brubaker (1996), Nationalism Reframed: nationhood and the national question in the New Europe. Cambridge: Cambridge University Press.

8 Arend Lijphart (1971), 'Cultural Diversity and Theories of Political Integration.' In Canadian Journal of Political Science/Revue canadienne de science politique, Vol. 4, No. 1 (March 1971), pg. 4.

9 Cited in Anthony H. Birch (1989), Nationalism and National Integration. London: Routledge, pg. 38. 
more backward portion of the human race the absorption is greatly to its advantage. Nobody can suppose that it is not more beneficial to a Breton, or a Basque of French Navarre, to be brought into the current of the ideas and feelings of a highly civilized and cultivated people - to be a member of the French nationality, admitted on equal terms to all the privileges of French citizenship, sharing the advantages of French protection, and the dignity of French power - than to sulk on his own rocks, the half-savage relic of past times, revolving in his own little mental orbit, without participation or interest in the general movement of the world, the same remark applies to the Welshman or the Scottish Highlander as members of the British nation. ${ }^{10}$

In the $21^{\text {st }}$ century, such paternalistic ethnocentrism, at least public expression thereof, is rare. Economic and/or political rationales for promoting or accepting assimilation are far more common.

A common argument is that modern economic development necessitates cultural and linguistic homogeneity. As Ernest Gellner, one of the foremost recent theorists of nationalism, has argued, "a modern industrial state can only function with a mobile, literate, culturally standardized, interchangeable population" "11, "its economy depends on mobility and communication between individuals, at a level which can only be achieved if those individuals have been socialized into a high culture, and indeed into the same high culture". ${ }^{12}$ The core mechanism for socialization (and assimilation) in the modern state is mass public education. Will Kymlicka has provided a cogent summary of the argument of those he has labelled "liberal nationalists": "standardized public education in a common language has often been seen as essential if all citizens are to have equal opportunity to work in the modern economy."13

Cultural and linguistic homogeneity are also commonly thought to be an essential prerequisite for attaining a number of political goals as well. Those studying "modernization" in Africa often made an argument about the link between cultural diversity and non-democratic forms of government. As Leo Kuper argued in 1969, "Cultural diversity or pluralism automatically imposes the strictest necessity for domination by one of the cultural sections. It excludes the possibility of consensus ... and necessitates non-democratic regulation of

10 Cited in ibid., pg. 39.

11 Ernest Gellner (1983), Nations and Nationalism. Ithaca: Cornell University Press, pg. 46.

12 Ibid., pg. 140.

13 Will Kymlicka (2001), 'Western Political Theory and Ethnic Relations in Eastern Europe.' In Will Kymlicka and Magda Opalski, eds., Can Liberal Pluralism be Exported? Western Political Theory and Ethnic Relations in Eastern Europe. Oxford: Oxford University Press, pg. 20. 
group relations." 14 In 1970, Dankwart Rostow, the founding father of the discipline of "transitology," made a more general claim, arguing that the crucial prerequisite for the transition to democracy was national unity: "the vast majority of the citizens in a democracy-to-be must have no doubt or mental reservations as to which political community they belong to." 15

Certain contemporary liberals espouse what could be termed "civic assimilationism" - a view that accepts cultural and linguistic diversity in the private sphere, but argues that a shared, homogenous public or societal culture is essential for dialogue and effective communication, conflict resolution and the pursuit of common goals. ${ }^{16}$ While some have argued in favour of homogeneity from the liberal camp, others have done so from a more social democratic perspective. Some have argued that there is a trade-off between cultural heterogeneity and the maintenance of welfare states, as people are often less willing to demonstrate social solidarity with those who are culturally different. ${ }^{17}$

While cultural homogeneity may facilitate social solidarity, render democratization easier, and make democracies more stable, cultural diversity is now an inalienable part of all European societies. Moreover, even if policy-makers were tempted to resurrect the kinds of assimilationist policies common in the $18^{\text {th }}$ and $19^{\text {th }}$ centuries, the effort would be in vain, as insuperable barriers to mass assimilation have emerged in democratic European systems. It is important to understand the nature of these barriers, as they also point to the necessity of pursuing an integration policy that does not set the unrealistic goal of creating culturally and linguistically homogenous societies. Moreover, those barriers constrain the kinds of integration policy that are possible.

\section{Barriers to Assimilation in Contemporary Europe}

Regardless of the frequency and persistence of the arguments of those justifying assimilation as a desirable policy goal, large-scale assimilation of minorities, immigrants and indigenous people in $21^{\text {st }}$ century Europe is highly unlikely for a number of reasons. First of all, both liberal and Marxist ${ }^{18}$ assumptions about the transient nature of ethnic affiliations have proven to be faulty. As

14 Introduction to Leo Kuper and M. G. Smith, eds., (1969), Pluralism in Africa. Berkeley: University of California Press, pg. 14.

15 Dankwart A. Rostow (1970), 'Transitions to Democracy: Toward a Dynamic Model,' Comparative Politics, Vol. 2, No. 3 (1970), pg. 350.

16 Bhiku Parekh calls Rawls and Habermas the most prominent exponents of "civic assimilationism." See Bhiku Parekh (2006), Rethinking Multiculturalism: Cultural Diversity and Political Theory, $2^{\text {nd }}$ ed. New York: Palgrave Macmillan, pg. 200.

17 See Frank Salter (2004), Welfare, Ethnicity and Altruism: New Data and Evolutionary Theory.London: Routledge.

18 For a detailed overview of Marxist approaches to ethnicity, see Walker Connor (1984), The National Question in Marxist-Leninist Theory and Strategy. Princeton: Princeton University Press. 
Walker Connor, a prominent critic of the assimilationist assumptions of writers on "nation-building" noted, "advances in communications and transportation tend also to increase the cultural awareness of the minorities by making their members more aware of the distinctions between themselves and others". ${ }^{19} \mathrm{In}$ the 1970s and 1980s, the re-emergence of Catalan, Corsican, Scottish, Welsh and other West European minority nationalisms shook the positions of those arguing that minority identities had lost their salience in Western Europe. A decade or two later, the disintegration of multinational communist states such as Yugoslavia, the Soviet Union and Czechoslovakia demonstrated that authoritarian systems fare little better than democratic ones in neutralizing or depoliticising sub-national identities.

While minority identities have proven adaptable and resilient in various economic and political systems, they are increasingly protected by the consolidation of a minority rights regime in Europe. ${ }^{20}$ While it remains quite weak, this regime does constrain the room for manoeuvre of states by explicitly forbidding forcible assimilation of national or ethnic, linguistic, and religious minorities and indigenous people. ${ }^{21}$ As Will Kymlicka has noted with regard to assimilating minorities, "France was only successful in the nineteenth century because it employed a level of coercion against the Basques and Bretons that would be inconceivable now". ${ }^{22}$

Not only have "traditional" minorities carved out some political space for preserving and maintaining their identities, Europe has increasingly become host to "new" minorities through the absorption of migrants, asylum-seekers and refugees. The Organisation for Economic Co-operation and Development (OECD) estimated that the documented migrant population in the European Economic Area was more than 20 million foreigners or 5.3\% of the population at the end of the twentieth century. The International Organization for Migration (IOM) placed the figure even higher, at around 56 million or $7.7 \%$ of the entire

19 Walker Connor (1972), 'Nation-Building or Nation-Destroying?' World Politics, Vol. XXIV, No. 3 (April 1972), pg. 329.

${ }^{20}$ There is a large and growing literature on this regime. Among others, see Gabriel N. Toggenberg, ed., (2004), Minority Protection and the Enlarged European Union: the Way Forward. Budapest: OSI/LGI; Marc Weller, ed., (2005), The Rights of Minorities: A Commentary on the Framework Convention for the Protection of National Minorities. Oxford: Oxford University Press.

${ }^{21}$ See, e.g., Art. 32, Document of the Copenhagen Meeting of the Human Dimension of the CSCE (1990); Art. 5, Para. 2, Council of Europe Framework Convention for the Protection of National Minorities (1995); Art. 8, UN Declaration on the Rights of Indigenous Peoples (2007).

${ }^{22}$ Kymlicka, 'Western Political Theory and Ethnic Relations in Eastern Europe,' pg. 26. 
population. ${ }^{23}$ In the medium to long-term, a continued influx is highly likely not only due to traditional "push" factors in Africa and elsewhere, but due to "pull" factors caused in particular by ageing populations. Some demographers predict that Europe will need as many as 50 million immigrants by 2050 to maintain current living standards. ${ }^{24}$

While continued immigration is likely, Europeanization is also beginning to limit the room for manoeuvre of European governments in their treatment of immigrants. Empirical studies suggest that great differences persist as to the extent of Europeanization of domestic immigration policies in various European countries. ${ }^{25}$ However, since the Amsterdam Treaty of 1997, migration is a policy area that has witnessed steady "communitarization." As Christian Joppke has argued, there is now a competition for skilled labour migrants, and EC directives now regulate not only family migration and asylum, but also many issues concerning immigrant integration, in particular anti-discrimination and the residence and free movement rights of non-EU immigrants. ${ }^{26}$ Here, the direction of policy is not uniform, as the trend towards stabilizing the legal status of immigrants and expanding their rights has often been accompanied by policy measures aimed at teaching them, sometimes under compulsion, the national language and local values, a point to which we will return later.

\section{Integration, Multiculturalism and Intercultural Competence}

Attempting to assimilate minorities and immigrants has been a common response of many states in Europe and elsewhere to diversity. However, over the last several decades, several countries have officially foresworn assimilation, acknowledged the persistent nature, legitimacy and equal worth of minority and immigrant cultures and sought to make accommodation for minority cultural needs. While "multiculturalism" in some circles has come to mean purely the separate coexistence of different groups, in other contexts it has

23 Figures cited in Rita Sussmuth and Werner Weidenfeld (2005), 'The Integration Challenge: Living Together in a Europe of Diversity.' In Rita Sussmuth and Werner Weidenfeld, eds., Managing Integration: The European Union's Responsibilities Towards Immigrants. Berlin: Bertelsmann Stifftung, pg. xi.

24 Wolfgang Lutz and Sergei Scherbov (2006), 'Future Demographic Change in Europe: The Contribution of Migration.’ In Demetrios G. Papandreiou, ed., Europe and Its Immigrants in the $21^{\text {st }}$ Century. Washington, D.C./Lisbon: Migration Policy Institute and Luso-American Foundation, pp. 207-222.

25 See, e.g., Thomas Faist and Andreas Ette, eds. (2007), The Europeanization of National Policies and Politics of Immigration: Between Autonomy and the European Union. Hampshire: Palgrave.

${ }^{26}$ Christian Joppke (2007), 'Transformation of Immigrant Integration: Civic Integration and Antidiscrimination in the Netherlands, France, and Germany,' World Politics 59 (January 2007), pg. 247. 
been conceived as a situation in which cultural maintenance is accompanied by intergroup contacts.

The first state to elevate "multiculturalism" to the level of policy was Canada, which in 1971 altered its long-established bicultural policy based on the British and French Charter groups, largely as a result of concern expressed by non-Charter immigrant groups about the preservation of their identities. Sweden declared "multiculturalism" official policy in 1975, while Australia did so in 1978. While diverse in their origins, the policies of all three states, at least at the outset, have shared a number of common features:

1) accepting the maintenance of minority and immigrant cultures,

2) ensuring that children have opportunities to learn both the national language and their mother tongue,

3) overcoming inequities in access to employment, housing and other realms, and

4) combating racism and discrimination. ${ }^{27}$

"Integration" in the context of multicultural policies has often been seen in opposition to assimilation.

One of the most influential analysts of "integration" in the context of multiculturalism is the Canadian social scientist John Berry, who has written widely about "acculturation attitudes" - "the ways people prefer to live in intercultural contact situations" and "acculturation expectations" - "views about how immigrants and other non-dominant ethnocultural groups should acculturate". ${ }^{28}$ According to Berry, two issues are critical: to what extent do individuals from non-dominant groups wish to maintain their cultural attributes and to what extent do they wish to have contacts with other groups. As can be seen in the diagram below, these two issues can be used to portray the stances of individuals belonging to minority groups, as well as those of the broader society. In this formulation, "integration" at the individual level is the maintenance of one's identity accompanied by a willingness to engage in contact with members of other cultural groups. At the societal level, a willingness to permit or even promote the maintenance of minority identities combined with a willingness to engage in or even promote intercultural contacts means "multiculturalism".

27 For a cogent overview of the origins, development and major policy directions of these three countries, see Christine Ingles (1996), Multiculturalism: New Policy Responses to Diversity, MOST Policy Papers 4. Paris: UNESCO, pp. 41-6.

28 This is from a recent formulation of Berry's extensive work in Jean Phoney, John W. Berry, Paul Vader, and Carmella Lie Kind (2006), 'The Acculturation Experience: Attitudes, Identities and Behaviours of Immigrant Youth.' In John W. Berry, Jean Phinney, David L. Sam and Paul Vedder, eds., Immigrant Youth in Cultural Transition: Acculturation, Identity and Adaptation Across National Contexts. Mahwah, NJ: Lawrence Erlbaum Assoc., pg. 73 . 


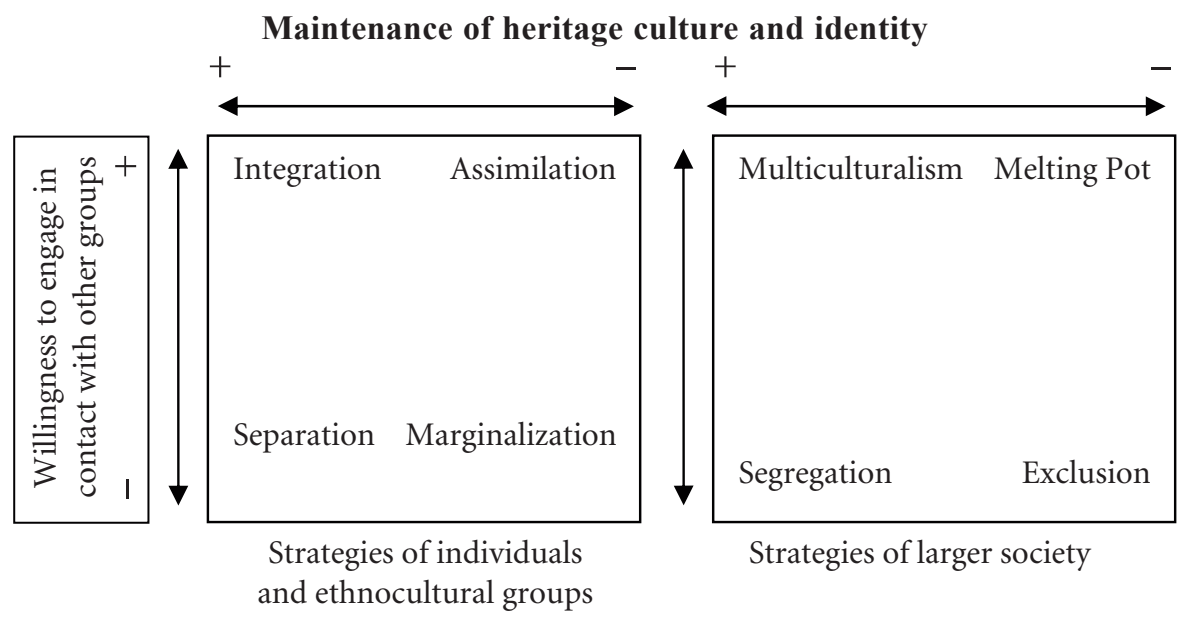

Source: John W. Berry (2006), 'Contexts of acculturation.' In David L. Sam and John W. Berry, eds., The Cambridge Handbook of Acculturation Psychology. Cambridge: Cambridge University Press, pg. 35.

The emphasis on and positive valuation of intercultural contact has its roots in the social psychology of prejudice, a field pioneered by Gordon Allport in the 1950s. Allport hypothesized that intergroup contact would lead to reduced intergroup prejudice if four conditions obtained:

1) the contact participants were of equal status,

2) they shared common goals,

3) there was no competition between the groups,

4) there was authority sanction for the contact. ${ }^{29}$

A recent overview of over 200 studies testing the "Allport contact hypothesis" found strong confirmation that intergoup contact does relate negatively to prejudice, that the largest effects were achieved in work and other organizational contexts, and that majority participants revealed much larger mean effects than minority participants. ${ }^{30}$

Even if all of Allport's conditions obtain, intergroup contact can still result in misunderstanding and even conflict if the contact parties lack what is increasingly called "intercultural competence." "Intercultural competence" has been defined in various ways. Green has argued that it involves "learning how to perceive others through their own cultural lens, knowledge of certain cultural beliefs, personal comfort with differences, willingness to change one's ideas,

${ }^{29}$ Gordon W. Allport (1954), The Nature of Prejudice. Reading, MA: Addison-Wesley.

30 Thomas F. Pettigrew and Linda R. Tropp (2000), 'Does Intergroup Contact Reduce Prejudice? Recent Metanalytical Findings. In Stuart Oskamp, ed., Reducing Prejudice and Discrimination. Mahwah: Lawrence Erlbaum Assoc., pp. 93-114. 
the ability to be flexible". ${ }^{31}$ Manco has argued that it entails "psychosocial capacities that enable individuals and groups to [...] confront the complex situations arising out of contact between cultures in an inegalitarian socio-economic and political context". ${ }^{32}$ Increasingly, it is held that "intercultural competence" can be acquired through education.

In a recent important contribution, the Council of Europe's White Paper on Intercultural Dialogue stressed three core intercultural competence areas:

1) "democratic citizenship" facilitated by education enabling an individual to act as an active and responsible citizen respectful of others;

2) "language", including knowledge of the national language and protection of minority languages, and

3) "history" - a critical, evidence-based approach stressing dialogue and the elimination of stereotypes. ${ }^{33}$

The new emphasis on "interculturalism" is a useful supplement to the stress on cultural maintenance and minority identities in the "multiculturalist" approach. However, a certain tension remains between minority rights as conceived within the discourse on "multiculturalism" and non-discrimination. To avoid the stress on difference of the former and the frequent injustice of "cultural blindness" towards minority groups inherent in the latter, Timo Makonnen has argued for "multicultural integration" in which legislation and policy avoid creating or reifying differences, but reflect them, while seeking to combat prejudice and equalize socioeconomic inequities. ${ }^{34}$

"Integration" as a component of minority rights and/or anti-discrimination strategies is a topic of frequent discussion in the work of regional and international organizations. Thus, it is useful to investigate how "integration" has been conceived in human rights discourse, as this provides a useful supplement to work in the social sciences. Moreover, international and regional organizations have increasingly framed both the policy and academic debates through their standardsetting, country monitoring, and funding of research and programmes.

${ }^{31}$ J. Green (1998), Cultural Awareness in the Human services: A Multi-Ethnic Approach, $3^{\text {rd }}$ ed. Boston: Allyn \& Bacon, pg. 75.

32 Altay Manco (2006), 'Young people of immigrant origin in Europe: how can we make the school an instrument for social mobility and acquisition of intercultural competences?' In Achieving social cohesion in a multicultural Europe: Concepts, situation and developments, Trends in social cohesion, No. 18. Strasbourg: Council of Europe, pg. 161.

${ }^{33}$ Council of Europe (2008), White Paper on Intercultural Dialogue: ,Living Together as Equals in Dignity." Strasbourg: Council of Europe, pp. 28-9.

${ }^{34}$ Timo Makkonen (2004), 'Is Multiculturalism bad for the fight against discrimination?' In Martin Scheinin and Reetta Toivanen, eds., Rethinking non-discrimination and minority rights. Turku: Abo Akademi University, pp. 175-6. 


\section{Integration, Human Rights and International Organizations}

Various international and regional organizations, such as the United Nations (UN), the Organization for Security and Cooperation in Europe (OSCE) and the Council of Europe $(\mathrm{CoE})$ have put the issue of social integration on their agendas, primarily in the context of human rights. These organizations often insert the word "integration" into various international standards and reports governing the treatment of indigenous people, migrants, refugees, and national or ethnic minorities. Though the meaning assigned to the term often differs depending on the mandate of the organization in question and the specific population of concern, certain common usages can be identified.

The term "social integration" gained wide currency in the human rights community at the 1995 UN World Summit for Social Development in Copenhagen. The report of the summit, which uses the term 40 times, notes that:

Social integration, or the capacity of people to live together with full respect for the dignity of each individual, the common good, pluralism and diversity, non-violence and solidarity, as well as their ability to participate in social, cultural, economic and political life, encompasses all aspects of social development and all policies. ${ }^{35}$

A subsequent UN report that continues the work of the Social Summit argues that inclusion, participation and justice are the three main "building blocks of social integration". ${ }^{36}$ The report goes on to claim that "participatory dialogue" is the core instrument to "promote the values and principles of social integration". ${ }^{37}$ In a review of the work of several European human rights organizations on issues of integration, Merja Pentikainen has identified the "participatory dimension of integration - i.e., linking the question of participation and integration" as a frequent common element. ${ }^{38}$

The Council of Europe has focused less on "social integration" but on the similar concept of "social cohesion". Like the UN, it also has focused on participation and achieving "cohesion through human rights." 39 A recent influential publication on Concerted Development of Social Cohesion Indicators defines

${ }^{35}$ United Nations (1995), 'Report of the World Summit for Social Development.', A/ CONF. 166/9, 19 April 1995, 29, available at http://daccessdds.un.org/doc/UNDOC/GEN/ N95/116/51/PDF/N9511651.pdf?OpenElement.

${ }^{36}$ United Nations (2007), Participatory Dialogue: Towards a Stable, Safe and Just Society for All. New York: United Nations Department of Economic and Social Affairs, pg. 11.

${ }^{37}$ Ibid., pg. 61.

${ }^{38}$ Merja Pentikainen (2008), 'Creating an Integrated Society, Managing Diversity and Human Rights in Europe.' European Yearbook of Minority Issues, Vol. 6, 2006/7. Leiden: Martinus Nijhoff Publishers, pg. 349.

${ }^{39}$ Council of Europe (2005), Concerted Development of Social Cohesion Indicators: Methodological Guide. Strasbourg: Council of Europe, pg. 15. 
"social cohesion" as "society's ability to secure the long-term well-being of all its members, including equitable access to available resources, respect for human dignity with due regard to diversity, personal and collective autonomy and responsible participation." 40

The focus on "equitable access" and non-discrimination as a core foundation of social integration is particularly evident in the work of bodies concerned with anti-racism. In the International Convention on the Elimination of Racial Discrimination (CERD) adopted in 1965, Article 2 (1)(e) calls on State Parties to "encourage, where appropriate, integrationist multiracial organizations and movements and other means of eliminating barriers between races" ${ }^{41}$ Here, "integration" carries the connotation of removing segregationist barriers of discrimination, while "integrationist" implies "composed of various cultural backgrounds," as opposed to homogeneous.

The Council of Europe's European Commission against Racism and Intolerance (ECRI) has increasingly touched on issues of integration in its work. ECRI has drawn attention to the links between integration and combating racism and racial discrimination, by pointing out that public debate on integration may stigmatise communities ${ }^{42}$ and that certain integration measures may be in breach of non-discrimination principles. ${ }^{43}$ This can be the case when an "obligation to integrate" is imposed on certain groups or penalties are inflicted for failing to integrate, but also with regard to language policy. ${ }^{44}$

Pentikainen has noted that not only ECRI, but also the Advisory Committee of the Framework Convention for the Protection of National Minorities (ACFC) and the OSCE High Commissioner on National Minorities (HCNM) "have put a lot of emphasis on the importance of the knowledge of the official (state) language for integration in the case of minority groups." 45 Despite the stress on the official language, integration is commonly defined in contrast to assimilation. This is the context in which integration is mentioned in the Council of Europe's Framework Convention for the Protection of National Minorities (FCNM), one of the few international legal instruments to mention "integration" specifically. Article 5, paragraph 2 of the FCNM reads thus: "Without prejudice to measures taken in pursuit of their general integration policy, the Parties shall refrain from policies or practices aimed at assimilation of persons belonging to national minorities against their will and shall protect these persons from any action aimed at such assimilation." Paragraph 46 of the Explanatory Report of the FCNM notes that "Paragraph 2 does not preclude Parties from taking measures in pursuance of their general integration policy."

\footnotetext{
40 Ibid., pg. 23.

${ }^{41}$ http://treaties.un.org/doc/Treaties/1969/03/19690312\%2008-49\%20AM/Ch_IV_2pg.pdf.

42 See, e.g., ECRI's third report on the Netherlands (\$128), available at www.coe.int/ecri.

43 See, e.g., ibid. (\$49-50) and ECRI's third report on Denmark (\$68).

44 See, e.g., ECRI's third report on Latvia (\$120-1).

45 Pentikainen, 'Creating an Integrated Society,' pg. 348.
} 
Despite the useful work of international human rights bodies on various aspects of integration, the concept is not a legal one, and the complex interrelationships it is meant to describe are difficult to capture in treaties and monitoring reports. After reviewing in detail the work of various international organizations, Pentikainen concludes that "there is still an urgent need to clarify and further develop the concept" ${ }^{46}$ Interestingly, a newcomer to the field of human rights and integration, the European Union, has recently rapidly pushed forward work on integration, specifically with reference to immigrants.

\section{The European Union and Immigrant Integration}

Since the 1999 European Council meeting in Tampere, the EU has become increasingly active and influential on issues relating to immigrant integration. Until Tampere, the EU had been primarily concerned with integrating immigrants into the labour markets of EU member states. At Tampere and soon thereafter, the EU began to take a broader approach by stressing the integration of immigrants into society, primarily through participation and non-discrimination.

At Tampere EU leaders agreed that the aim of immigrant integration policy should be to equalize the rights and obligations of third-country nationals with those of the citizens of the EU. The package of anti-discrimination directives adopted in 2000 consolidated this focus on equality and non-discrimination as a core element of immigrant integration, supplemented by the concept of "civic citizenship" put forward by the Commission in November $2000 .{ }^{47}$

In 2004, the Justice and Home Affairs Council adopted the "Common Basic Principles for Immigrant Integration Policy in the European Union." 48 The first principle moves the focus of integration beyond immigrants alone, stressing that "integration is a dynamic two way process of mutual accommodation by all immigrants and residents of Member States." While reiterating the importance of participation in various realms (Principles 3, 5 and 9) and non-discrimination (Principle 6), the Principles also contain some additional important elements.

Principle 8 notes that "the practice of diverse cultures and religions is guaranteed under the Charter of Fundamental Rights and must be safeguarded" and thereby acknowledges the important of cultural maintenance. At the same

46 Ibid., 368.

${ }^{47}$ For a brief overview of the development of EU immigrant integration policy, see the relevant part of the European Commission's home page at http://ec.europa.eu/justice_home/fsj/ immigration/integration/fsj_immigration_integration_en.htm and the links to the respective documents.

48 Ibid. See also Jan Niessen and Mary Ann Kate (2007), From Principles to Practice: The Common Basic Principles on Integration and the Handbook Conclusions. Brussels: MPG, available at http://www.migpolgroupg.com/multiattachments/3769/DocumentName/ Principles_to_Practice_CBP_Handbook3.pdf. 
time, Principle 7 echoes those who stress the importance of intercultural contact, underlining that "frequent interaction between immigrants and Member State citizens is a fundamental mechanism for integration". While recognizing diversity, there is also indication of a common core: "respect for the basic values of the European Union" (Principle 2) and the assertion that "basic knowledge of the host society's language, history and institutions is indispensable to integration" (Principle 4).

If, as noted earlier, the degree of Europeanization of immigration policy is variable, the same must be said for immigrant integration policy. Despite the adoption of the "Common Basic Principles," sharing of best practices, and increased EU funding, states have retained a large degree of sovereignty in this sphere. Nonetheless, Christian Joppke has argued that a convergence of national models of dealing with immigrants is taking place, largely based on the replication of practice in the Netherlands. Joppke has argued that the "emergent gestalt of contemporary European immigrant integration is a peculiar coexistence of civic integration and antidiscrimination policies." 49 The former are obligatory civics courses for immigrants, while the latter refer to policy measures taken following the adoption of the Race directive in 2000.

\section{Points of Consensus and Our Approach}

After reviewing the evolution of conceptions of "social integration" and the varied uses of the term in the academic, human rights and policy literature, a number of points of consensus can be identified. Contemporary discourse portrays integration in contrast to assimilation. In certain contexts, integration may lead to voluntary assimilation, but the European human rights regime prohibits forcible assimilation. Moreover, as was argued earlier, large-scale assimilation, even on a voluntary basis, is highly unlikely given the resilience of sub-national identities, the consolidation of a minority rights regime protecting those identities and the increasingly diverse nature of European societies, which are all becoming societies of immigration.

While acknowledging the reality of cultural diversity, integration does not entail the parallel, separate coexistence of ethnocultural groups, but rather their interaction. While sociologists as far back as Durkheim noted that social linkages, exchange and reciprocity can generate coherence and unity, in a context of cultural diversity, individual and group contacts can also reinforce the maintenance of particularistic identities. While contact between persons belonging to different ethnocultural groups can lead to conflict, Allport and his disciples have demonstrated that, under specified conditions, it can also reduce prejudice. Recent work suggests that "intercultural competence" can also be taught and learned, thereby decreasing the likelihood of conflict and tension. In

49 Joppke, 'Transformation of Immigrant Integration,' pg. 247. 
the context of integration, a core competence area is knowledge of the official or state language, though knowledge of minority languages by members of the majority is also desirable. Knowledge of the national language can not only facilitate contact, communication and cooperation, it can also further participation and equal access to various social goods.

The post-World War II emergence of a global human rights discourse, particularly in the realm of anti-racism and minority rights, focused attention on the rights of ethnic, religious and linguistic minorities, immigrants and indigenous people. Until recently, integration was considered to concern primarily these groups. However, more recent work, particularly at the United Nations, Council of Europe, and European Union, suggests that integration implicates all of society, that it is a "two-way street" of mutual accommodation. There is a broad consensus that integration is closely intertwined with both participation and the promotion of non-discrimination and equality.

Participation is conceived not only as the foundation of democratic polities, but increasingly, as a critical minority right. ${ }^{50}$ While a vibrant democracy requires the participation of all members of society, effective participation by persons belonging to minorities is essential so that majority-dominated democratic institutions take minority needs into consideration. While effective minority participation can lay the groundwork for the protection of minority identities, participation need not lead to particularism. Indeed, it is only through participation that minorities, immigrants and other members of society develop a sense of belonging to a broader national community. ${ }^{51}$ This sense of belonging has traditionally been seen as a core aim of integration.

Participation in and of itself is not a guarantor of social cohesion, as all may participate, but asymmetries in power and access to resources can lead to distorted outcomes in which all participate but only some gain representation. Thus, not participation alone, but participation and representation are needed, as it is only when all members of society, regardless of their sub-national identities, see members belonging to their groups represented in positions of social, economic, cultural and political influence that participation will yield an integrative effect.

In order to minimize the impact of power and resource asymmetries, there is a growing consensus on the importance of non-discrimination in integration.

50 See Advisory Committee on the Framework Convention for the Protection of National Minorities (2008), Commentary on the Effective Participation of Persons Belonging to National Minorities in Cultural, Social and Economic Life and in Public Affairs. Strasbourg: Council of Europe, available at http://www.coe.int/t/dghl/monitoring/ minorities/3_FCNMdocs/PDF_CommentaryParticipation_en.pdf.

51 On this point, see the remarks by Rita Sussmuth, former speaker of the German parliament and expert on immigrant integration in Council of Europe (2006), Achieving social cohesion in a multicultural Europe: Concepts, situation and developments, Trends in social cohesion, No. 18. Strasbourg: Council of Europe, pg. 31. 
Non-discrimination can not only help level the playing field for democratic participation, but it can also eliminate the artificial barriers to beneficial contact and cooperation that are erected when individuals, groups or institutions engage in unjustified differential treatment of persons on grounds such as presumed race, skin colour, national or ethnic origin, language, religious affiliation and other grounds. Here, the focus cannot be solely on equality of opportunity, as glaring differences in social outcomes that are not the result of differential treatment can also undermine social cohesion and the maintenance of a sense of belonging by all members of society.

Thus, in our conception, social integration is a process of unifying society by strengthening participation, intercultural contact, and non-discrimination. However, each of these pillars has an important sub-component. In the case of participation, it is representation; for intercultural contact, it is intercultural competence; for non-discrimination, it is the promotion of equality. The three pillars are linked and all are essential for successful integration. Participation and non-discrimination alone can be implemented without substantial interaction between the majority and various minorities, thereby resulting in separation. At the same time, intercultural contact can also take place in non-democratic systems whose members may have acquired intercultural competence. Unless such contact is accompanied by participation and non-discrimination, it can lead to domination or forcible assimilation.

\section{Measuring Social Integration in Latvia}

In measuring integration in Latvia, the aforementioned tripartite scheme has been used as a framework by the authors of this study. The editors provided authors with a suggested list of indicators (see Appendix) to guide them in analysing the various realms in which integration takes place - in civic and political life, the labour market, the social sphere, the education system, the media and information sectors, and in cultural life. Some of the indicators were adopted wholesale from studies by the Council of Europe, ${ }^{52}$ the European Parliament ${ }^{53}$ and others, but some reflect Latvia's distinct situation.

Indicators reflect not only the situation in society, but public perceptions of that situation. The inclusion of data on perceptions is important, as perception can become reality if it serves to guide the behaviour of individuals or groups in society or policy-makers. Moreover, subjective evaluations of various disparities are important in understanding their social and political significance. Discrimination is widely believed to be a source of social strife and alienation.

${ }^{52}$ See, e.g., Concerted development of social cohesion indicators.

${ }_{53}$ See European Parliament, Directorate General Internal Policies of the Union (2007), Setting Up a System of Benchmarking to Measure the Success of Integration Policies in Europe. Brussels: European Parliament. 
However, as E. K. Francis has shown, "under certain conditions, the differential treatment of ethnics may not only be functional but also legitimate." ${ }^{4} 4$ Thus, data on perceptions should assist in demonstrating whether a disparity is creating tensions that undermine integration or not.

The editor urged the authors to provide their overall assessment of the situation of integration in their respective realm of inquiry and to point to any significant current trends. At the same time, similar to the methodology used in one effort to measure democracy in Latvia, ${ }^{55}$ authors were urged to identify the greatest achievement, the most serious problem and the most urgent task. While social integration is an ongoing process, limitations of space, available data over time and the desire to speak to current debates in Latvia dictated placing a time frame on the analysis. In most cases, authors were asked to focus on the situation since 2001, when Latvia adopted its first integration policy framework. However, occasionally developments are traced over a longer time frame, as some change (e.g., language acquisition) has been gradual and significant over a long period.

This is not the first effort to measure integration or analyse integration policy in Latvia, though it might be the most comprehensive. In order to lay the groundwork for the detailed analysis of integration trends in various realms of social life, a critical analysis of the development of integration policy in Latvia is essential. It is to such an analysis that we now turn.

${ }^{54}$ E. K. Francis (1976), Interethnic Relations. New York: Elsevier, pg. 270.

55 Juris Rozenvalds, ed. (2005), How Democratic Is Latvia: Audit of Democracy. Riga: University of Latvia Press. 


\section{The Soviet Heritage and Integration Policy Development Since the Restoration of Independence

\author{
Juris Rozenvalds
}

\section{The Soviet Heritage Regarding Integration}

Latvia developed historically as an ethnically diverse society, and representatives of around 150 different ethnic groups live in the country. However, according to the 2009 data of the Central Statistical Bureau, the vast majority of inhabitants (93.2\%) belong to the four largest groups - Latvians $(59.3 \%)$, Russians (27.8\%), Belarusians (3.6\%), and Ukrainians (2.5\%). Since persons belonging to the latter three groups generally use the Russian language in daily life, from the standpoint of integration policy one of the most important cleavages is between those whose native language is Latvian (in the 2000 census $58.2 \%$ of the population) and those whose native language is Russian or Russian-speakers (37.5\% of the population).

The ethnic structure of Latvia evolved over centuries and initially was quite homogenous, as the share of Latvians approached $90 \%$ in the 16th and 17 th centuries. Until World War I members of other ethnic groups, primarily members of the ruling elite (e.g., Germans, Russians, and Poles), gradually entered the territory of Latvia. Peasants of a different ethnic origin were not channelled into Latvia en masse, and thus, no areas of ethnic minority compact settlement developed

The involvement of inhabitants of Latvia in the events of World War I, as well as the related mass flight of Latvia's inhabitants to inner Russia had a significant impact on Latvia's demography in the early 20th century. Population losses during the war meant that Latvia's total number of inhabitants reached the level of 1897 only in 1935. Moreover, the number and share of Baltic Germans in Latvia declined by half over the same period.

However, the most far-reaching changes in Latvia's ethnic structure took place during and after World War II. During this period, Latvia lost almost all members of two historical minorities, the Germans and the Jews. About 60,000 Germans were repatriated to Hitler's Reich in 1939-1940, while the Jewish minority was almost completely annihilated in the tragic events of the Holocaust. The merciless repressions of the 1940s, flight and emigration to a number of 
Western countries by refugees, as well as post-war deportations dramatically reduced the number of Latvians in Latvia. In 1959 there were almost 180,000 fewer Latvians in Latvia than in 1935.

Though the number of Latvians in Latvia declined significantly, the total number of inhabitants in Latvia grew on account of migration from other republics in the USSR. In 1959 the total number of inhabitants exceeded the 1935 total by 230,000 . The majority of the increase was accounted for by Eastern Slavic settlers, whose share in the population grew rapidly. The share of Russians grew from $10.6 \%$ in 1935 to $26.6 \%$ in $1959,29.8 \%$ in 1970 , and $34 \%$ in 1989. A similar, but less dramatic increase took place in the Belarusian share $(1.4 \%$ in $1935,2.9 \%$ in $1959,4 \%$ in 1970 , and $4.5 \%$ in 1979 and 1989$)$ and Ukrainian share $(0.09 \%$ in $1935,1.4 \%$ in $1959,2.3 \%$ in $1970,2.7 \%$ in 1979 and $3.5 \%$ in 1989) in the total population of Latvia.

Total population and ethnic breakdown of Latvia's population, 1935-2009 (1000s and \%)

\begin{tabular}{|l|c|c|c|c|c|c|c|}
\hline & $\mathbf{1 9 3 5}$ & $\mathbf{1 9 5 9}$ & $\mathbf{1 9 7 0}$ & $\mathbf{1 9 7 9}$ & $\mathbf{1 9 8 9}$ & $\mathbf{2 0 0 0}$ & $\mathbf{2 0 0 9}$ \\
\hline Total & 1950,4 & 2093,5 & 2364,1 & 2502,8 & 2666,6 & 2375,3 & 2261,3 \\
\hline incl. & & & & & & & \\
\hline Latvians & 75.4 & 62.0 & 56.8 & 53.7 & 52.0 & 57.7 & 59.3 \\
\hline Russians & 10.6 & 26.6 & 29.8 & 32.8 & 34.0 & 29.6 & 27.8 \\
\hline Belarussians & 1.4 & 2.9 & 4.0 & 4.5 & 4.5 & 4.1 & 3.6 \\
\hline Ukrainians & 0.09 & 1.4 & 2.3 & 2.7 & 3.5 & 2.7 & 2.5 \\
\hline Poles & 2.5 & 2.9 & 2.7 & 2.5 & 2.3 & 2.5 & 2.4 \\
\hline Lithuanians & 1.2 & 1.5 & 1.7 & 1.5 & 1.3 & 1.4 & 1.3 \\
\hline Jews & 4.8 & 1.7 & 1.6 & 1.1 & 0.9 & 0.4 & 0.4 \\
\hline Germans & 3.2 & 0.1 & 0.2 & 0.1 & 0.2 & 0.1 & 0.2 \\
\hline
\end{tabular}

Sources: Central Statistical Bureau of Latvia: http://data.csb.gov.lv /DATABASEEN/Iedzsoc/ Annual\%20statistical\%20data/04.\%20Population/04.\%20Population.asp and Central Statistical Bureau of Latvia, Results of the 2000 Population and Housing Census in Latvia: Collection of Statistical Data. Riga: 2002, pg. 121.

In the final decades of Soviet rule, a situation developed in which two numerically similar groups had formed - a Latvian language group and Russianspeakers - which differed in their sources of information, their attitudes towards the situation in Latvia and in their value orientations. In later years, with the transformation of Latvian society and the restoration of independence, when the issue of societal consolidation came to the forefront, these differences became very important in the context of creating an integration policy.

Violent incorporation into the Soviet empire, merciless repressions, the abasement of ethnic sentiments, as well as Soviet unification and levelling in the post-war period created a whole range of stable orientations in the consciousness of the Latvian part of society, and this had a major impact on social processes. In the first place, one must mention the idealization of the pre-war independence era, including the six years of authoritarian rule by Kārlis Ulmanis. 
The Soviet regime's categorical denial of this period created a black-and-white perception of history based on binary opposites.

Among Latvians there was also a widespread view that the leadership of the Latvian Soviet Socialist Republic (LSSR) defended the republic's interests less vigorously than analogues in Estonia and Lithuania and was more eager to follow Moscow's dictates. Thus, many Latvians acquired a black-and-white historical memory of the "real socialist" past, while Latvia's neighbours appeared to have a more nuanced picture which took into account Estonia's development in the 1960s and 1970s or Lithuania's undeniable socio-economic growth in the immediate post-war years. One of the most typical manifestations of these day-to-day habits of the mind in the 1990s was the lingering hope that problems could be resolved through a surge of activity based on simply denying the Soviet legacy and restoring the pre-war social order and its ethnic composition. This hope often displaced debate about the suitability of various solutions based on the past to the situation of 1990s Latvia and contemporary understandings of social and economic policy. In this regard, it is notable that Latvia is the only post-Soviet or post-communist country to have maintained its pre-war constitution and electoral system, with small changes thereto (e.g., a bill of rights and a $5 \%$ threshold)

The truly complex and tragic history of Latvia and the Latvians in the 20th century created the conviction in everyday consciousness of the unique character of Latvia's situation. This, in turn, was linked with the perception that Latvians were a "chosen people", but in a negative way - that they had suffered more than all other nations in the 20th century. This was thought to impose some special obligations on Western countries towards Latvians and Latvia, while Latvians, for their part, had the right, in the name of overcoming the injustices of the past, to act in ways that were not always in accordance with the accepted standards for civilized political behaviour of the Western world.

The lengthy debasement of Latvian national feelings in the Soviet empire, as well as progress in the process of Latvia's Russification which generated serious threats to the existence of the Latvian language created a kind of "catastrophe rationale", which was rather widespread in Latvia's political discourse in the 1990s. The essence of this rationale involved asserting that if a certain issue was not addressed in a certain way, Latvians as a nation would cease to exist. This fear is still alive, notwithstanding its clear inconsistency with the fact that since the days of the "singing revolution" Latvians have clearly dominated in independent Latvia's political life.

Finally, Soviet rule produced a disposition in everyday consciousness which could be termed "a minority complex". In Soviet times, Latvians comprised an insignificant minority in the composition of the enormous empire (about $0.5 \%$ of the Soviet population). In Latvia itself, the local authorities controlled policy areas touching upon Latvian culture, education, as well as local industry and agriculture (where Latvians predominated). By contrast, Moscow controlled 
the flow of culture, education and information for new arrivals, as well as the generally Russian management of so-called all-Union enterprises. As a result, the aforementioned circumstances created a peculiar Soviet era Latvian "privilege" - concentrating only on one's own problems. Issues of language, culture and ethnicity, in the awareness of broad parts of Latvian society, were linked only to Latvians. The popular motto of the Third Awakening - "We want to be masters in our native land" - was linked in everyday consciousness with the readiness to stress Latvian rights, without recognizing the rights and needs of others in society. As noted by Elmārs Vēbers, this also became one of the reasons that in the mid-1990s Latvians were unprepared for the idea of a political or civic nation "and perceived it negatively and in an intensely overwrought fashion". ${ }^{1}$ In later years, Latvian public opinion reacted in a similar way, with misunderstanding and suspicion, towards the ratification of the Framework Convention for the Protection of National Minorities. The aforementioned dispositions played an important role in the process of mass mobilization during the "singing revolution," but after independence sometimes became a hindrance to attaining social stability.

In contrast to Latvian identity, the identity of Latvia's Russian-speakers in the Soviet period was characterized by all the features of a "normal" identity in which socio-economic affiliations override the importance of ethnic origin, language or cultural background. At the basis of this was the primacy of a historically determined identification with the state over ethnicity, as well as the advantages enjoyed in the Soviet Union by Russian-speakers, which often acquired the status of self-understood axioms in everyday consciousness. Vladislavs Volkovs, who has written widely on the identity of Latvia's Russians, calls this characteristic "ethnic nihilism". ${ }^{2}$ Insofar as socio-economic priorities dominated over specifically ethnic ones in the consciousness of Russians during the period of the "singing revolution" and the initial years of independence, these priorities did not conflict with the efforts of Latvians to achieve the restoration of independence as a decisively important precondition for ensuring the defence of their culture and language. This prevented the emergence of ethnic conflict in the early 1990s and created a peculiar "inertia of normality" which largely ensured the peaceful evolution of events in the revolutionary period of 1988-1991 and the first years after independence.

This distinguishes the situation in Latvia from that in former Yugoslavia, where all the major ethnic groups, including the Serbs, saw their existence as threatened, though often on openly mythological and irrational foundations. Thus, a clash of "minorities" was created, which had tragic consequences for

${ }^{1}$ Elmārs Vēbers (2007), 'Vai teiksim ardievas sabiedrības integrācijai?' in Leo Dribins, ed., Pretestība sabiedrības integrācijai: cēloņi un sekas. Riga: LU Filozofijas un socioloğijas institūts, pg. 119.

2 Vladislavs Volkovs (1996), Krievi Latvijā. Riga: LZA Filozofijas un sociolog̣ijas institūts, pg. 67. 
the history of the peoples of Yugoslavia. Over the course of the 1990s, as a consequence of the transformation in Latvia, the identity of Latvia's Russians slowly evolved into that of a minority which has to actively stand up for its language and cultural rights. The potential for ethnic mobilization on the part of Latvia's Russians was illustrated most clearly in the broad protests against education reform in 2003-2004.

With regard to the preconditions for integration policy, one must also mention demographic and socio-economic factors, which, in certain aspects, created a more benevolent environment for the implementation of integration policy in comparison with the other Baltic states. In demographic terms, the peculiarities of settlement patterns of Latvia's inhabitants and the related differences in cultural and economic processes in comparison with Estonia and Lithuania should be mentioned. In contrast to North-eastern Estonia, for example, Latvia historically has not witnessed the emergence of whole regions (certain parishes in the eastern province of Latgale are the exception) in which minorities live compactly and in isolation from Latvians. Minorities in Latvia are rather evenly spread throughout the whole of Latvia's territory, particularly in the cities. Latvia traditionally has had a rather high rate of ethnic inter-marriage: of all Latvian males entering marriage in 2008, for example, $20.0 \%$ married outside their ethnic group, while the same holds true for $19.8 \%$ of Latvian women. ${ }^{3}$ In Estonia, by contrast, only $9-10 \%$ of Estonians enter exogamous marriages. In contrast to Estonia, Latvia has not witnessed the emergence of significant socio-economic differences between ethnic communities, particularly with regard to income levels. Ethnic origin is not strongly correlated with poverty, which affects Latvians and minorities equally (see Mihails Hazans' and Feliciana Rajevska's chapters below).

The ability of political forces to ensure the implementation of policy acceptable to the most significant groups in society would have a crucial impact on subsequent integration policy. For the first time since the tragic events of the summer of 1940, the opportunities for relatively free competition between political forces emerged in Latvia with the epic process of transformation in the Soviet Union accompanying Gorbachev's perestroika and the "singing revolution" that followed.

\section{The Heritage of the Years of the "Singing Revolution" Regarding Integration}

During the years of the "singing revolution" two paths towards independence were actively debated in Latvia's public sphere. The first can be called the "socially realistic" path, which was represented by the Popular Front of

\footnotetext{
${ }^{3}$ For these data and those from other years, see the home page of the Central Statistical Bureau of Latvia at www.csb.gov.lv.
} 
Latvia (PFL), the largest and most influential national democratic organization in Latvia founded on 8 October 1988. In its first programme of 1988, it stressed: "the PFL promotes and consolidates the efforts of all of Latvia's inhabitants, regardless of their social status, language, party, religious or national affiliation, to democratize society and further its moral renewal". ${ }^{4}$ The first generation of leaders of the PFL were well aware of the complicated nature of ethnic relations in Latvia and implemented a moderate and realistic policy which took into consideration post-war demographic changes and stressed the consolidation of all inhabitants of Latvia on the road to sovereignty within a renewed Soviet Union, then, after the appeal of the PFL board on 31 May 1989, towards complete independence from the Soviet Union. The congresses of the PFL in 1988 and 1989 offered a national programme oriented towards unifying all of Latvia's inhabitants, based on the realization that the renewal of independence would be possible only with the active support of members of all of Latvia's ethnic groups. In this regard, the PFL assigned great importance to informing minorities about Latvia's history and current social and political events. To meet this end, the Russian edition of the PFL newspaper "Atmoda" ("Awakening") was published and a team of lecturers was created to conduct outreach work. The PFL adopted a stand on citizenship issues that respected post-war reality - it advocated granting citizenship to all permanent residents who had lived in Latvia at least ten years.

The other, "legalistic" path for attaining independence was represented by the Citizens Committees of the Republic of Latvia and the Citizen's Congress. Following the example of the Citizen's Congress of the Republic of Estonia, the citizen's movement emerged in spring 1989 and elections to the Citizens' Congress took place in April 1990. A detailed analysis of the activities of the Citizen's Congress from 1990 through its closure in 1993 falls beyond the purview of this chapter. The most important point here is that the Citizens' Committee and Congress emphasized legal continuity and the illegal nature of the Soviet occupation, and thus, viewed all persons who settled in Latvia after 17 June 1940 as illegal immigrants who either had to leave Latvia or receive resident permits from authorized representatives of the Latvian state. In October 1990 the newspaper of the Citizens' Committee Pilsonis (Citizen) praised the efforts of Estonian militants in trying to achieve a forced resettlement of post-war settlers: "While the minds of many respected Latvians here and in exile are busy with the issue of how to include the colonists by granting them citizen's rights, our cool-headed and more farsighted northern neighbours are thinking more about how, in as civilized and polite a manner as possible, to get rid of these uninvited guests." ${ }^{5}$ Clearly, in the context of this approach, the very

${ }^{4}$ Latvijas Tautas fronte (1989), Latvijas Tautas fronte. Gads pirmais. Riga: LTF, pg. 208.

5 'Imigrantu piespiedu izsūtīšana - optimālais risinājums,' Pilsonis, No. 7, 16 October 1990, pg. 1. 
idea of integrating post-war "colonists" was unacceptable in principle. From the perspective of the Citizen's Committee, first the rights of the citizens of the Republic of Latvia and their descendents needed to be restored. Then the activists in the citizen's movement hoped for the mass emigration of minorities that would bring Latvia back to pre-war demographic proportions.

However, during the years of the "singing revolution," the realistic platform of the PFL predominated. Pressure from the central structures of the USSR and imperialistic forces within Latvia played an important role. At the beginning of January 1989, as a counterforce to the PFL, the International Workers' Front of Latvia was created, and it subsequently participated in the creation of the USSR United Workers' Front in summer 1989. At the same time, the Communist Party of Latvia (CPL) was initially oriented towards cooperation with the PFL, as evidenced, for example, by the presentation of CPL First Secretary Jānis Vagris at the demonstration "For a Law-Based State" on 7 October 1988, as well by the fact that about $1 / 3$ of the delegates to the first PFL congress were CPL members. However, gradually, as the stance of the PFL radicalized and the influence of conservative forces in the CPL grew, in particular after the split of the CPL, relations became confrontational.

At the time, the Russian-speaking part of society in Latvia was not politically united, though, as Nils Muižnieks has noted, even progressive Russianspeakers had serious misgivings about the policy of the PFL (not to mention more radical nationalist organizations), which had at its core liberal nationalism and an emphasis on the priority of the Latvian nation. ${ }^{6}$ However, according to the assessment of Juris Dreifelds, only $20-30 \%$ of Russian-speakers supported the efforts of the conservative forces to renew the Soviet era status quo. ${ }^{7}$ Sociological surveys demonstrated that in $199039 \%$ of all minority respondents supported Latvian independence. ${ }^{8}$ On 3 March 1991 a referendum on Latvian independence took place as a means to outmanoeuvre the USSR central authorities, who planned to organize a referendum on saving the Union on 17 March. The all-Union referendum was meant to be a negative answer to the issue of "freeing" the Baltic states.

In the Latvian poll all permanent residents over the age of 18 in Latvia could participate and answer the question "Are you for a democratic and independent Republic of Latvia?" The voting list consisted of 1,902,802 inhabitants of Latvia, 1,666,128 participated (87.56\%), and 1,227,562 or $73.68 \%$

${ }^{6}$ Nils Muižnieks (1993), 'Latvia: Origins, Evolution and Triumph,' in Ian Bremmer and Ray Taras (eds.), Nations and Politics in the Soviet Successor States. Cambridge: Cambridge University Press, pg. 196.

7 Juris Dreifelds (1996), Latvia in Transition. Cambridge: Cambridge University Press, pg. 69.

${ }^{8}$ Brigita Zepa (1992), 'Sabiedriskā doma pārējas periodā Latvijā: latviešu un cittautiešu uzskatu dinamika (1989-1992),' Latvijas Zinātņu akadēmijas vēstis. A daḷa, Nr. 10 (543), pg. 22. 
voted in favour while 411,374 or $24.69 \%$ voted against. The Latvian poll has been interpreted in diverse ways. Some authors have seen it as an example of ethnic voting which testified that "among minority voters there was a trend of voting against Latvia's independence or not participating in the ballot." It is hard to agree completely with this interpretation. Undoubtedly, the majority of persons belonging to minorities saw in the events of the "singing revolution" the strong interest of Latvians and generally adopted a neutral stance towards them (which, given the previous experience of Russification, was an achievement on the part of Latvia's democratic forces). However, the share of voting age persons in the entire population who voted for independence $(64.51 \%)$ was significantly (around 12\%) greater than the share of Latvians in the total population (52.05\% in the 1989 census), which suggests that a significant segment of the minority population - at least one fourth - voted for Latvian independence on 3 March 1991. On this indicator, Latvia outdid Lithuania, where the share of those voting for independence was about the same as the Lithuanian share in the total population, and Estonia, where the share of those voting for independence was only a few percentage points higher than the Estonian share in the population.

In line with the spirit of the ideas of the PFL, on 19 March 1991 the Supreme Council adopted a law "On the free development of Latvia's national and ethnic groups and their rights to cultural autonomy". Adoption of the law was significant, as it promoted the activities of minorities and the creation of cultural societies. Later the law would be criticized for lacking an institutional mechanism and for containing certain norms that were impossible to implement. ${ }^{10}$ As Ilga Apine has noted, "the law was later criticized for being declaratory, but it moved things forward at the time." 11

In 1990 and the first eight months of 1991 a situation emerged spontaneously that was quite favourable towards deepening processes of integration and institutionalizing them. One can agree with Elmārs Vēbers that, "the idea of the unity of society has its own pre-history here in Latvia and one does not need to search for an external confirmation for it, as stressed by those politicians who believe that the idea of social unity was imposed on us by foreign countries and international organizations". ${ }^{12}$ At the same time, it should be acknowledged that the beginnings of integration created during the "singing revolution" were not

\footnotetext{
${ }^{9}$ Gatis Puriņš and Uǵis Šulcs (2001), 'Vai 2001. gada Rīgas Domes vēlēšanu rezultāti bija pārsteigums (etniskie balsojumi, atskatoties uz 1991. gada 3. marta aptaujas pieredzi)', available at http://home.lanet.lv/ politics/raksti/3.MARTS/3.MARTS.htm.

${ }^{10}$ Vēbers, 'Vai teiksim ardievas sabiedrības integrācijai?', pg. 117.

${ }^{11}$ Ilga Apine (2008), 'Latvijas etnopolitiskā attīstība neatkarības gados' in Leo Dribins, ed., Sabiedrības integrācijas tendences un prettendences. Latvijas un Igaunijas pieredze. Etnisko attiecību aspekts. Riga: LU akadēmiskais apgāds, pg. 10.

${ }^{12}$ Vēbers, 'Vai teiksim ardievas sabiedrības integrācijai?', pg. 117.
} 
developed further. On the contrary, much of what had been attained was lost in the first years after the restoration of independence.

\section{The First Years of Integration (Non-)Policy in Renewed Latvia, 1991-1997}

In the first years of independence, Latvia did not have a coherent integration policy. It is possible to speak of separate, indirectly connected policies that significantly, but for the most part negatively, influenced spontaneous processes of integration in society. The first that should be mentioned is changes in citizenship policy, which took place not long after the restoration of true independence on 21 August 1991. Though the events of the previous years laid the groundwork for independence, such rapid success came suddenly due to a coincidence of various circumstances that were extremely favourable to the Baltic republics. One can agree with the assessment of Dainis İvāns, the first chairman of the Popular Front, of the events of August 1991: "Of course, everything was decided in Moscow, and thank God for that". ${ }^{13}$ The weakness of our eastern neighbour and the defeat of the pro-imperialistic forces in Latvia, which was most clearly demonstrated by the decisions of the parliament on suspending the activities of the Communist Party and the Interfront on 24 August 1991 and the subsequent ban on 10 September, rapidly decreased the external and internal pressure. This, in turn, became one of the most important factors that furthered the political elite's rapid resort to solutions deriving from the "legalistic" path for attaining independence.

On 15 October 1991 the parliament, in contradiction to the programme of the PFL then in force, adopted a decision to restore citizenship to those inhabitants of Latvia who had it before 17 June 1940 and their descendants. Though the decision renewed citizenship regardless of ethnicity, it created the basis for the division of Latvia's inhabitants into "us" and "them", in which the latter were almost solely post-war non-Latvian settlers. Thus, as Ilga Apine has noted, ethnonationalism became the basis for ethnopolitics. ${ }^{14}$ The 15 October 1991 decision pushed aside those non-Latvians who voted for the PFL in the March 1990 elections to the LSSR Supreme Soviet and for Latvian independence in the referendum of 3 March 1991. Given the generous pre-referendum promises, such a step had a destructive impact - the action of Latvian politicians in the fall of 1991 provided a basis for the conviction that is still widespread among many non-Latvians that they had simply been deceived.

13 Jānis Škapars, ed. (1998), 'Augusta pučs Latvijā. Diskusija: I. Godmanis, D. İvāns, J. Dinēvičs, J. Škapars’, in Latvijas tautas fronte. 1988-1991. Riga: Apgāds Jāṇa sēta, pg. 263.

${ }^{14}$ Apine, 'Latvijas etnopolitiskā attīstība neatkarības gados,' pg. 11. 
If the restoration of citizenship was logical, a problem at the legislative level was the lack of a citizenship law until 1994, which meant that naturalization during this period was not possible. Those inhabitants of Latvia who lost their civic rights with the 15 October decision had to wait for the clarification of their status until 1995, when the law "On the status of those former USSR citizens who are not citizens of Latvia or any other state" was adopted. The distribution of non-citizen passports began only in 1997.

The beginnings of integration policy developed very slowly for a variety of reasons. In the beginning of the 1990s, many members of the Latvian political elite nurtured the conviction that the solution to inter-ethnic relations lay in the return migration of many non-Latvians to their places of origin, first of all, to Russia. Soon after independence, the issue of the withdrawal of Russian troops and the closure of the strategically important Skrunda early warning radar station was high on the Latvian-Russian bilateral agenda, as well as Latvia's domestic policy agenda. The forerunner of the Russian army - the Red army was linked in Latvian eyes to the violent incorporation of Latvia into the Soviet Union. Moreover, the 50,000-80,000 Soviet military pensioners in Latvia (including 22,000 retired officers) had in previous years enjoyed unjustified (in the eyes of the majority) privileges. This created a favourable atmosphere for the emergence of hopes in the mass departure of non-Latvians. Radical nationalist political rhetoric and the activities of certain state institutions kindled these hopes. For example, the Citizenship and Immigration Department refused to include more than 100,000 inhabitants into the population register based on their (often imagined) links to the Soviet army and consistently ignored court rulings on the violation of their rights. The results of this policy were not long in coming - in the early to mid-1990s, close to 200,000 people departed from Latvia, with 52,000 leaving in 1992 alone. As Ilze Brands Kehris has noted, "contradictory political signals (including the discourse of deoccupation and the promotion of repatriation as mandated by law)" played a certain role in creating the public frame of mind in both the 1990s and now. ${ }^{15}$ The Law on Repatriation adopted in 1995, alongside the goals of promoting the return to Latvia of people of Latvian and Liv origin, also set the goal of "promoting the voluntary return of non-Latvians to their ethnic homeland". ${ }^{16}$

There was no room for the creation of a long-term integration policy in such an atmosphere, even more so as citizenship, language and education policy in the early and mid-1990s were all created in line with this spirit. As indicated by Estonian researcher Priit Jarve, one of the additional goals of strict language and citizenship policy in both Estonia and Latvia was to promote the

${ }^{15}$ Ilze Brands-Kehre and Ilvija Pūce (2005), 'Politiskā nācija un pilsonība' in Juris Rozenvalds, ed., Cik demokrātiska ir Latvija? Demokrātijas audits. Riga: LU Akadēmiskais apgāds, pg. 25.

16 See http://www.likumi.lv/doc.php?id=37187. 
departure of Russian-speakers. ${ }^{17}$ Thus, policy towards minorities in the early and mid-1990s embodied the coexistence of overcoming the injustices and inter-ethnic disproportions created by Soviet rule with the abandonment of the preconditions for social consolidation that were created during the years of the "singing revolution."

In the early 1990s, the main topic of political discussion was the citizenship law. Based on the assumption that the Supreme Council which was elected on the basis of another principle had no right to draft restored Latvia's legislation on citizenship issues, real work on preparing a citizenship law began only when the newly elected parliament convened in July 1993. In September 1993 five different draft citizenship laws were submitted in parliament. At first, the draft law was based on the idea of quotas, which envisaged determining the number of new citizens depending on the natural rate of increase among citizens. On 21 June 1994, 66 out of 100 parliamentary deputies voted to adopt a citizenship law with quotas. President Guntis Ulmanis did not promulgate the law and sent it back to parliament for review.

On 22 July 1994, 58 members of parliament supported a citizenship law without quotas, but with a timetable that would allow naturalization to begin first with the youngest applicants for citizenship, denying this right to the most motivated group of middle-aged persons. Subsequent events demonstrated that the 1994 law was not capable of effectively fulfilling its functions - there was a glaring contradiction between the objective necessity of creating the opportunity for post-war settlers to integrate into political life and the legislators' desire to slow the naturalization process to a minimum. After the acquisition of citizenship through naturalization began in 1995, it turned out that the pace was incredibly slow - only $7 \%$ of those who had the right to submit applications from 1995 through 1997 used that right. ${ }^{18}$

Similar trends set the tone in language and education policy at this time. They were marked by efforts to strengthen pressure on the Russian language and ensure the functioning of Latvian as the state language. Latvian was enshrined as the state language as early as 6 October 1988, when the Supreme Soviet of the LSSR adopted amendments to the republic's constitution. On 5 May 1989 the Law on Languages of the LSSR was adopted granting Russian the status of the language of inter-ethnic communication. The Latvian parliament rescinded this norm on 31 March 1992.

17 Priit Jarve (2003), 'Language Battles in the Baltic States: from 1989-2002,' in Farimah Daftary and Francois Grin (eds.), Nation-Building, Ethnicity and Language Politics in Transition Countries. Budapest: LGI, pg. 82.

18 Jekaterina Dorodnova (2003), Challenging Ethnic Democracy. Implementation of the Recommendations of the OSCE High Commissioner on National Minorities to Latvia, 1993-2001. Hamburg: Institute for Peace Research and Security Policy at the University of Hamburg. Working paper 10, pg. 43, available at http:/www.core-hamburg.de/documents/ CORE_Working_Paper_10.pdf. 
In the mid-1990s, a new law on the State Language was drafted which was adopted in 1999. This law placed minority languages on the same level as foreign languages and did not in any way regulate the use of these languages in Latvia. This evoked criticism from both local experts and international organizations, who pointed out that this was in contradiction to the Framework Convention for the Protection of National Minorities, which Latvia signed in 1995 but ratified only 10 years later. This contradiction is still not resolved. Thus, there is a certain basis to the impression of relations between the Latvian language and other languages as a zero-sum game in which the gains of the Latvian language have come at the expense of other languages.

In the realm of education policy, events developed according to a similar scenario. As noted by Ilze Brands Kehris, the Soviet Union bequeathed to Latvia a segregated school system in which schools with Latvian and Russian languages of instruction coexisted. The largest challenge in the realm of minority education, therefore, was not the introduction of minority language training, but acquisition of the state language while permitting minorities to maintain their language, culture and identity. ${ }^{19}$ At the end of the 1980s and the beginning of the 1990s, Polish, Jewish, Ukrainian, Belarusian, Lithuanian and Estonian schools were created, though they attracted less than one percent of all students. In the first half of the 1990s the co-existence of parallel Latvian and Russian language schools continued, though state pressure on Russian language education institutions gradually grew. While guaranteeing the acquisition of education in Latvian, the 1991 Education law envisaged the possibility of education in minority languages as well. Amendments to the Law on Education drafted in 1995 held that "in general education minority schools in which the language of instruction is not Latvian, instruction in at least two subjects in the humanities or the sciences must take place in grades 1 through 9 and three subjects in grades 10 through 12." ${ }^{20}$ Beginning in 2006, all teachers were required to have a Latvian proficiency at the highest level, and teachers in Russian language schools became special magnets for the attention of the State Language centre and its inspectorate. However, education issues were not a topic at the top of the public agenda, especially while there were still widespread hopes that non-Latvians would leave Latvia en masse. When it became clear that the vast majority of non-Latvians would remain in Latvia, when Western pressure destroyed the hope that the naturalization of post-war settlers could be delayed indefinitely, the issue of the Latvian state's relationship with a large part of its inhabitants entered centre stage. Given the important of language

19 Ilze Brands-Kehre and Ilvija Pūce (2005), 'Nationhood and Identity'. In Juris Rozenvalds, ed., How Democratic is Latvia. Audit of Democracy. Riga: University of Latvia Press, pg. 27.

${ }^{20}$ See http://www.likumi.lv/doc.php?id=36364\& from $=$ off. 
in Latvian identity, the issue of the language of instruction in schools rapidly gained importance.

In the mid 1990s Latvia's northern neighbour Estonia rushed ahead of Latvia in elaborating a social integration programme. As a result of cooperation between the Estonian government and the United Nations Development Programme (UNDP), in 1997 the first drafts of a programme were prepared. That same year the first Minister for Population and Ethnic Affairs was appointed. On 2 March 1999 the Estonian government adopted an integration programme entitled "The Integration of non-Estonians into Estonian society." Developments in Estonia had a big impact on debates in Latvia in 1998 and 1999. ${ }^{21}$

The political processes of 1991 to 1997 created several stable dispositions among the Latvian political elite with regard to integration issues that continue to have contemporary significance. For one, the Latvian part of the political elite showed very little interest in integration issues and did not trust minorities. As suggested by elite research in 2003 , only $5 \%$ of Latvian elite representatives thought that minority rights issues were important, while the figure for members of the Russian-speaking elite was $60 \%$. While $90 \%$ of the Russian-speaking elite were convinced of the loyalty of Latvia's Russians towards Latvia, the figure among members of the Latvian political elite was only $20 \% .{ }^{22}$

In the first years after independence a chronic problem in Latvian politics became the inability and lack of desire of the power holders to create and maintain dialogue with the opposition. This pertains to both relations between different Latvian political groupings, as well as to relations between the political elite and the rest of society, but was most fully reflected in relations with minorities. Given the fact that the majority of Latvia's minorities are comprised of post-war settlers, the search for compromise was often perceived by the political elite and a significant segment of Latvian society as the betrayal of national interests. Thus, since the beginning of the 1990s, the notion that only Latvian politicians know what Russians should want has dominated the thinking of the Latvian political elite. From this flows the conviction that Russian-speakers should accept unconditionally the rules of the game being offered to them. ${ }^{23}$ Since the early 1990s, the Latvian political elite has not been united regarding integration issues either. Researchers from the University of Latvia's Institute of Philosophy and Sociology concluded in 2001 that the leading party politicians "express very divergent views on social integration." ${ }^{24}$ Five years later,

${ }^{21}$ n.a. (1998), Nacionālās attiecības un nacionālā politika Latvijā: Domas un vērtējumi Latvijas inteligences apvienības XIX konferencē 1998. gada 4. aprīlì. Riga: LIA, pg. 11.

22 Anton Steen and Brigita Zepa (2003), 'Latvijas elite pārmaiṇu laikā', available on the home page of the Baltic Institute of Social Sciences at http:/www.biss.soc.lv/downloads/ resources/elitesPetij/Elite.pdf.

23 Juris Rozenvalds (2002), 'Monologu kultūras krīze' published on politika.lv on 3 January 2002, available at http://www.politika.lv/temas/sabiedribas_integracija/3852/.

24 Elmārs Vēbers et al., Etnopolitika Latvijā. Riga: ELPA, pg. 47. 
the Baltic Institute of Social Sciences came to a similar conclusion in research entitled Integration Practice and Perspectives. ${ }^{25}$

Since the beginning of the 1990s, a characteristic trait of the Latvian political elite has been its weakness, which is manifested in the inability to adopt balanced strategic decisions in which the interests of state are placed higher than short-term considerations of political gain. As a consequence, many significant political decisions since the restoration of independence, in particular those affecting relations between Latvia's largest communities, attained their final form not as a result of the conscious decisions of Latvian politicians, but rather as the result of external pressure.

All the foregoing hindered the elaboration of a far-sighted and consistent policy. Given the disagreements within the elite and the majority's lack of interest about integration issues, the impetus for formulating integration policy came to Latvia from foreign partners: international organizations and foreign foundations.

\section{Western Influences on Integration Policy}

The main international players in Latvia in the early 1990s were the OSCE Mission to Latvia, the OSCE High Commissioner on National Minorities, the Council of Europe, the United Nations Development Programme (UNDP) office in Latvia, and the Soros Foundation - Latvia. When Latvia approached accession to the European Union and NATO, the stance of these organizations became very significant in raising awareness about integration issues and underlining the necessity of elaborating integration policy.

UNDP, which began its operations in Latvia in 1992, had an essential role in assisting in the development of a Latvian language training programme as well as in setting the groundwork for integration policy. The Law on Language was significantly amended in 1992, envisaging language requirements for many posts in the public and private sectors. This threatened to create tension in society, as many Russian-speakers did not know the language and could be laid off from work. When the Citizenship Law was adopted, insufficient language proficiency prevented many from naturalizing in the early years. In 1994 the Latvian government turned to UNDP and requested the formation of an expert mission to help elaborate a draft Latvian language training programme. This programme was adopted by the government on 1 November 1995. In the first four years, the National Programme for Latvian Language Training worked under the auspices of UNDP, using its wide experience, professional skills, and traditions of administering large programmes. Implementation was so successful that in the second stage after 1998 the programme attracted funding from

25 Brigita Zepa, ed. (2006), Integrācijas prakse un perspektīvas. Riga: BISS, available at http://www.biss.soc.lv/downloads/resources/integracijas_prakse/brosura_LV.pdf. 
the European Union, Sweden, Finland, Norway, Denmark, the Netherlands, and Canada. ${ }^{26}$ In 2001 administrative oversight and responsibility for attaining programmatic goals was taken over by the Latvian Ministry of Education and Science.

Another important UNDP contribution to promoting integration issues and addressing them is linked to the publication of Human Development Reports in Latvia. The first report in 1995 had a chapter on the "Creation of a Multiethnic Society in Latvia," which touched upon integration. The 1997 report, in turn, devoted a special chapter with a detailed analysis of inter-ethnic relations and recommended elaborating a long-term integration programme. ${ }^{27}$

The Soros Foundation - Latvia, for its part, funded most of the research on ethnic relations in the early and mid-1990s, including many projects by the researchers of the Institute of Philosophy and Sociology (Elmārs Vēbers, Leo Dribins, Ilga Apine, Vladislavs Volkovs) and the large research project "On the Way to a Civil Society." It sought to support NGOs working in spheres related to integration, including the creation of the Latvian Centre for Human Rights and Ethnic Studies in 1993, the creation of the Public Policy Centre Providus in 2002, as well as many projects implemented by the Naturalization Board and schools. ${ }^{28}$

However, European organizations had the greatest impact on the beginnings of integration policy, especially the Organization (until 1995, Conference) on Security and Cooperation in Europe (OSCE). Given the wide membership of the organization and its unique experience in promoting inter-state cooperation, the OSCE became a very significant player in Latvia's domestic policy. The importance of the OSCE grew in the context of the desire of Latvia and the other Baltic States to be free of the Russian military presence as soon as possible. At the OSCE Helsinki summit in 1992, Russia agreed to OSCE supervision of the troop withdrawal, demanding in return a more active OSCE engagement in addressing the status of the Russian-speaking population, in particular in Latvia and Estonia.

For this kind of supervision to be implemented, at the end of 1992 the OSCE agreed to create the post of High Commissioner on National Minorities (HCNM) and appointed as first HCNM Max van der Stoel, a diplomat from the Netherlands. Supervision was carried out through regular country visits, correspondence, as well as through the OSCE field mission, which worked in Latvia from the fall of 1993 to the end of 2001. Its mandate stressed addressing citizenship issues and preparing monthly reports to OSCE member states on the situation in Latvia. The HCNM's primary goal was early prevention of conflict

26 Patrice C. MacMahon (2007), Taming Ethnic Hatred: Ethnic Cooperation and Transnational Networks in Eastern Europe. Syracuse: Syracuse University Press, pg. 174.

27 Nils Muižnieks, ed., (1997), Latvia Human Development Report 1997. Riga: UNDP, pg. 65.

28 See MacMahon, Taming Ethnic Hatred, pp. 140-177. 
and timely action to address tensions. In the first half year of his mandate, van der Stoel visited Riga twice and in April 1993 sent Latvian foreign minister Georgs Andrejevs a letter with recommendations to accelerate the adoption of a citizenship law which envisaged moderate demands of applicants for citizenship. Five different parliamentary factions submitted their own draft Laws on Citizenship, ranging from the de facto denial of any naturalization whatsoever to the "zero option" of granting citizenship to everyone. In this context, the proposals put forth by Latvia's Way and the People's Harmony factions containing annual naturalization quotas appeared moderate. In this situation, the HCNM had a broad playing field in which he worked alone as well as in close cooperation with the leadership and experts of the Council of Europe.

Latvia had already in September 1991 submitted an application to join the Council of Europe, which had made adopting an acceptable citizenship law one of the main preconditions for Latvia's membership. The Latvian side actively involved Council of Europe experts in discussions about the draft Law on Citizenship in the preparatory phases. Partially as a result of this involvement, as well as due to the demarches of both the Council of Europe and the European Union, president Guntis Ulmanis returned the initial law to parliament for review. As a consequence, Latvian deputies adopted a more restrictive form of a compromise proposal put forth by the HCNM which envisaged naturalization "windows" setting a timetable for applicants based on their age.

Thus, the Latvian political elite avoided the risk of leading the country into international isolation and Latvia was accepted into the Council of Europe on 10 February 1995. However, the desire of the HCNM and representatives of other international organizations to see in the Law on Citizenship a piece of legislation demonstrating that Latvia fully took into account the interests of minorities remained unfulfilled. Immediately after its creation in 1994, the Naturalization Board came under the watchful eyes of the OSCE Mission and the HCNM, which both urged Latvia over the coming years to take various steps to promote naturalization by liberalizing requirements, organizing language courses, informing non-citizens and adopting an integration policy. ${ }^{29}$

As noted earlier, the pace of naturalization in 1995-1997 was very slow and the idea of the naturalization "windows" turned out to be an unnecessary hindrance, as the stance of Latvia's non-citizens towards the naturalization process, and with it, the political integration process as a whole, turned out to be reserved, at best. This is why the work of the HCNM from 1996 through 1998 was geared towards urging the Latvian authorities to rescind the "windows" system. In 1996 and 1997 clear support for this stand was expressed by the European Union, the Council of Europe, NATO and other international

${ }_{29}$ The work of the OSCE Mission to Latvia has not been well documented. The work of the OSCE HNM is analysed in detail in Dorodnova, Challenging Ethnic Democracy. 
organizations. In 1997 the European Union clearly linked admittance to the European Union with decreasing the number of non-citizens.

The main problem in relations with the OSCE and other international organizations was the stance of the Latvian political elite, which, on the one hand, believed that only cooperation with western countries and rapid integration in western structures could ensure Latvia's long-term independence. On the other hand, there was a gulf between the nationalist convictions of most of the Latvian political elite and western recommendations in the realm of ethnopolitics. This led to a situation in which adhering to western standards was seen as a forced measure, a heavy price Latvia had to pay for the political support of western states. When Fatherland and Freedom representative Guntars Krasts became prime minister in July 1997, it was difficult to hope that the idea of rescinding the naturalization "windows" and the necessity of creating a systematic integration policy would garner political support. This process could only be accelerated through the intensification of external pressure that would make Latvian politicians more responsive to the recommendations of Western partners. This happened in 1997 and 1998.

\section{The 1997-1998 Crisis: The Beginnings of an Integration Policy}

In 1997 and 1998 crisis situations emerged in several of Latvia's external and internal policy realms. In 1997 in Luxembourg European Union leaders adopted a decision to extend invitations for membership negotiations with six candidate countries: the Czech Republic, Estonia, Cyprus, Poland, Slovenia and Hungary. Latvia was not in their number. Though a number of Latvian politicians denied the link between the European Commission's decision and Latvia's social integration problems, the publication on 15 July 1997 of the European Commission's report Agenda 2000 testified to the contrary. The report clearly indicated that "Latvia needs to take measures to accelerate naturalisation procedures to enable Russian-speaking non-citizens to become better integrated into Latvian society. ${ }^{30}$ In 1997 and 1998 international organizations and influential western countries engaged in an unprecedented, coordinated campaign to pressure the Latvian authorities to rescind the naturalization "windows" system. This pressure from the West was suddenly compounded by problems with Latvia's eastern neighbour.

An escalation of tension was caused by extremist activities. On 6 June 1997 an explosion rocked Victory Park in Riga. Two members of the extremist Aizsargi organization were killed in the explosion with which they tried to

30 Agenda 2000 - Commission Opinion on Latvia's Application for Membership of the European Union, pg.19, available at http://www.mfa.gov.lv/data/file/e/kom-kart-zin-1997. pdf. 
destroy the monument to the "Liberators of Soviet Latvia and Riga." Russian media commented widely on this incident, and the Russian Duma adopted a special announcement.

At the beginning of 1998, the crisis in relations with Russia deepened. On 3 March 1998 several hundred pensioners, mostly Russian-speakers, organized an unauthorized demonstration in front of the Riga City Council. When the police used excessive force to clear the demonstrators from a street they were blocking, Russia reacted sharply, and inter-state tensions grew. Russian foreign Minister Evgeny Primakov and Russian presidential press secretary Sergei Yastrezhembsky accused Latvia of serious human rights violations and urged the international community to intervene to regulate the situation in Latvia, particularly with regard to the situation of Russian-speakers. This time it was not merely the usual rhetoric of Russian officials, as western allies were also deeply concerned about the situation. The atmosphere was further exacerbated by the marking of the 55th anniversary of the Latvian Legion, in which state officials and parliamentary deputies participated, as well as by explosions by unknown perpetrators near the Riga synagogue and the Russian embassy.

In this context Latvia's western partners - both influential countries and international organizations - sought to soften the consequences of Russia's reaction, but also to intensify the pressure on the Latvian political elite by urging it to express a clearer position on these events and to finally take real steps towards the consolidation of society. In this situation, the Latvian political elite understood that absent a change in policy, Latvia could lose the political support of western countries. On 31 March 1998 Prime Minister Guntars Krasts created a working group composed of four ministers (Foreign Affairs, Education and Science, Justice, and Culture) under the leadership of deputy prime minister Juris Kaksītis to draft a national programme for the integration of society

In mid-April 1998, at the invitation of Prime Minister Krasts, OSCE HCNM Max van der Stoel visited Riga one more time (his 11th visit). During his visit the Latvian government adopted a decision supporting in principle the elimination of the naturalization "windows". In mid and late 1998 a number of other significant steps linked to integration issues were taken at the legislative level. On 22 June 1998 the parliament adopted amendments to the Law on Citizenship easing naturalization, eliminating the "windows" and permitting non-citizen children born after 1991 to be registered as Latvian citizens.

However, the struggle was not yet over. After the adoption of the amendments to the Law on Citizenship, opponents of the changes halted their promulgation and began to gather signatures for a referendum, which was supported by more than $1 / 10$ of the number of citizens who had been eligible to vote in the previous parliamentary elections. On 3 October 1998 a referendum on the amendments to the Law on Citizenship took place together with the parliamentary elections. The public demonstrated massive interest, as the referendum had the highest participation of any such ballot in Latvian history $-97.14 \%$ of 
those who had participated in the previous parliamentary election voted in the referendum. ${ }^{31}$ Though supporters and opponents of the amendments to the Law on Citizenship were divided roughly equally (44.98\% voted for rescinding the changes, while $52.54 \%$ voted against rescinding the changes), the amendments stood and entered into force.

The response of nationalist political forces to this development became the adoption of a new Education Law on the last day of the parliamentary session on 29 October 1998. Article 9 of the law stated that "in state and local government education establishments education is acquired in the state language," 32 pushing the implementation date for this controversial provision to the seemingly distant date of 1 September 2004. As is known, the implementation of this provision close to six years after its adoption evoked unprecedented protests on the part of Latvia's Russian-speaking population. These protests were directed not so much against the general goal of the education reform - the strengthening of the situation of the Latvian language in society - as against the methods envisioned for achieving this goals and the distinctly paternalistic nature of education policy. On the whole, the education reform led to another result that was unexpected for the nationalists - the strengthening of civic bonds among members of the Russian-speaking population and their transformation from a rather amorphous and politically divided group into a well-organized and increasingly influential political force.

The State Language Agency found that among minority graduates of schools in 2007 and 2008, "Latvian language proficiency is sufficient for study and active participation in social and economic life" 33 and interpreted this as a positive result of the transition to instruction primarily in the state language in state and local government secondary education institutions. However, the influence of the education reform on social integration, particularly on mutual trust between ethnic communities, is ambiguous.

The work of researchers in Latvia also promoted the evolution in public and elite attitudes in the late 1990s and the beginning of work on preparing a social integration programme. An important turning point and the end of the illusion that the task of integration would be obviated by the mass emigration of minorities from Latvia was the research programme "On the Way to a Civil Society" organized by the Naturalization Board with the support of the Soros

${ }^{31}$ The tally is available at the home page of the Central Election Commission at http://web. cvk.lv/pub/public/27532.html.

${ }^{32}$ See http://www.likumi.lv/doc.php?id=50759.

33 See State Language Agency (n.d.), 'Latviešu valodas prasmes un lietojums augstākās izglīî̄bas iestādēs. Izglīīibas reformas rezultāti', pg. 1. Available at http://www.valoda. lv/lv/petijumi/veiktiepetijumi. 
Foundation - Latvia and the National Human Rights Office. ${ }^{34}$ Two very important insights flowed from the research results. First, very few minorities and non-citizens planned to leave Latvia. According to the results of the sociological survey, $90 \%$ of non-citizens and $94 \%$ of all citizens planned on remaining in Latvia. Second, the research revealed significant differences in the attitudes and values of Latvians and minorities, citizens and non-citizens, which threatened to make Latvia into a "binational society." The research prompted the search for ways to overcome the values cleavage. As Elmārs Vēbers notes, "the thesis that citizenship, education and language policy could be implemented ignoring the presence of non-citizens and minorities lost its socio-political relevance." ${ }^{35}$

\section{Preparation of the National Programme for the Integration of Society}

In the second half of the 1990s, the Ministry of Education and Science and other ministries (Welfare, Justice, Interior, Culture) elaborated policy in certain realms linked to social integration. However, work on the basic guidelines for integration policy began only in 1998. An expert group under the leadership of Elmārs Vēbers, a researcher at the Institute of Philosophy and Sociology, prepared a draft framework document on the integration of society in Latvia. On 10 March 1999 the framework document for the national programme was presented to the public for debate. As noted in the webpage of the Naturalization Board, about 25,000 people throughout Latvia participated in about 80 different events related to discussing the document. In the course of the discussion, about 306 articles in the press were devoted to the framework document and the issues surrounding it. ${ }^{36}$ In September 1999 the government accepted the framework document as the basis for drafting a national programme. ${ }^{37}$ In 1999 and 2000 wide debates continued in society about integration in which two different stances collided. The research Integration Practice and Perspectives called these the "national political discourse" and the "oppositional discourse". 38 The "national political discourse" was opposed to the official state integration discourse and to the basic declared approach on minority issues, and in its most radical form, expressed an openly intolerant, even hateful attitude towards Russians in Latvia. The "oppositional discourse," at the same time, criticized both the integration programme and its implementation. ${ }^{39}$ This discourse stressed the

\footnotetext{
34 Baltic Data House (1998), Pētījumu un rīcības programma "Ceļā uz pilsonisku sabiedrību”. Atskaite. 1. un 2. posma rezultāti. Riga: Baltic Data House, available at http://www.biss. soc.lv/downloads/resources/pilsoniskaSabiedriba/pilsoniskaSabiedriba1997.pdf.

35 Vēbers, 'Vai teiksim ardievas sabiedrības integrācijai?', pg. 120.

36 See http://www.np.gov.lv/?id=511.

37 See http://www.np.gov.lv/lv/faili_lv/SI_koncepcija.pdf.

38 Zepa, Integrācijas prakse un perspektīvas, pg. 4.

39 Ibid.
} 
necessity of changing public understanding of the essence of integration and freeing Latvians of the misconception that integration pertains only to minorities. ${ }^{40}$ Minority representatives were also dissatisfied that integration in Latvia was based on existing legislation in the realm of citizenship, but particularly in language and education, which in their opinion invariably changed the officially proclaimed goal of integration into an attempt at assimilation.

Regardless of the very divergent attitudes in society and the attempts of Fatherland and Freedom/LNNK to torpedo the adoption of the integration programme, preparations continued. On 18 July 2000 the government adopted the short version of the programme and assigned the coordination of implementation to the Ministry of Justice, which created a social integration department in November 2000. Finally, the government approved the National programme on "The Integration of Society in Latvia" on 6 February 2001.

\section{Achievements and Weaknesses of the Integration Programme}

An undeniable achievement of the integration programme was the enshrinement of integration as state policy. The programme defines integration as

Mutual understanding between individuals and groups in the context of a common state. The basis for social integration is loyalty to the Latvian state, the awareness that each individual's future and personal welfare is closely tied to the future of the Latvian state, its stability and security. At the basis is a readiness to willingly accept the Latvian language as the state language, respect for the Latvian language and culture, and that of minorities living in Latvia. ${ }^{41}$

The programme envisaged promoting naturalization and civic participation and, for the first time, funding from the state budget for promoting integration. However, even during the preparation phase, a number of the programme's "genetic defects" of both a procedural and substantive nature were evident.

Let us start with the procedural problems. Several other analyses have pointed to the fact that very few members of minorities were involved in the programme's working group. ${ }^{42}$ This is characteristic not only of integration policy development - minority participation in the development, implementation and monitoring of other policy is also low and ineffective. The government has been largely incapable and unwilling to ensure the effective participation

${ }^{40}$ Ibid., pg. 247.

41 'Sabiedrības integrācija Latvijā. Koncepcija.' Riga, 2001, pg. 4.

${ }^{42}$ Open Society Institute EU Accession Monitoring Program (2002), 'Minority Protection in Latvia: An Assessment of the National Programme "The Integration of Society in Latvia,' Monitoring the EU Accession Process: Minority Protection, Vol. 1, An Assessment of Selected Policies in Candidate States. Budapest: OSI, pp. 297-364. 
of persons belonging to minorities in policy development and participation is insufficiently institutionalized. ${ }^{43}$ This is true also of the rather unproductive dialogue between persons belonging to minorities and the president and various ministries.

In 1996, during the presidency of Guntis Ulmanis, a minority advisory council was created as a response to an open letter by minority organizations that there is a lack of government-minority dialogue. The task of the council was to gather information about issues affecting minorities, further dialogue on these issues between minorities and the government, and draft recommendations for addressing problems. Various minority representatives, as well as experts on ethnopolitics were invited. However, the work of the council fell short of initial hopes - there was concern about the risks of politicization (several council members were elected to parliament), as well as a lack of clarity about its functions. During the presidency of Vaira Vỉke-Freiberga, the minority advisory council was never convened, though formally it was never disbanded. On 18 February 2009 President Valdis Zatlers renewed the work of the council under the leadership of former Popular Front chairman and representative of the Latvian Lithuanian community Romualds Ražuks. It is too early to assess the effectiveness of the renewed council.

The conceptual basis of the integration programme also contains certain contradictions and inconsistencies which were determined by the diverging interests of various political forces and their influence on the preparation of the programme. As a result, the document is a political compromise. For the document to be more acceptable, the most controversial issues related to inter-ethnic relations were united in one document with issues pertaining to social inclusion and regional integration, though these were already addressed in other policy documents. A tribute of sorts to the efforts of radical nationalists to prevent the adoption of the programme altogether was mention of the repatriation of minorities in the text of the programme. ${ }^{44}$

The programme's diagnosis regarding Latvia's various cleavages is precise (differences in values and interpretations of history, threat perceptions, mistrust, an unwillingness to link one's future to the state of Latvia), but the programme does not indicate how to address these controversial issues. The basic ideas of the programme are based in the normative tradition, which sees social cohesion as being based on common norms, ideals and values and stresses the importance of institutions of socialization, such as the education system, the army, cultural institutions, etc. Implementation would reflect the tendency to impose a preconceived set of values (primarily understood as ethnic Latvian values),

${ }^{43}$ Nils Muižnieks, ed., (2007), Nacionālo minoritāšu konvencija - diskriminācijas novēršana un identitātes saglabāšana Latvijā. Riga: LU SPPI.

${ }^{44}$ Valsts Programma 'Sabiedrības integrācija Latvijā'. Riga, 2001, pg. 31. See http:// www. politika.lv/temas/sabiedrības_integracija/4106/. 
neglecting the process of negotiation between proponents of divergent values. The programme stresses the priority of the Latvian language and culture, but recognizes the rights of persons belonging to minorities to nurture their own cultures. The fact that integration is a two-way process is mentioned, though subsequently the emphasis is on the tasks of minorities - the need to accept Latvian culture, learn the Latvian language, understand history, be loyal, believe they are needed, etc. In certain cases, the programme sets forth unattainable goals, such as the creation of a unified information space. ${ }^{45}$

Unfortunately, the programme's initial version did not envisage any progress indicators. Subsequent efforts to develop a set of indicators did not result in their introduction into the policy planning process. The programme foresaw a very vaguely defined system of implementation, which created the opportunity to perceive (and portray) as integration policy a very wide range of actions, thereby often masking the government's unwillingness or inability to adopt responsible decisions on politically sensitive issues.

\section{Problems with Integration Policy Implementation and Development}

One of the most visible results of the adoption of the integration programme in 2001 was the creation of state institutions whose main tasks were implementation of integration policy, policy coordination and attracting and administering EU funds. On 5 July 2001 the Parliament adopted the Law on the Society Integration Foundation (SIF). The Foundation was created to further the attainment of the goals set out in the National Programme on "The Integration of Society in Latvia" by ensuring financial support. In 2003, the foundation acquired the right to administer Phare grant programmes, and in 2004, the right to administer EU structural fund grant programmes. ${ }^{46}$

During the parliamentary electoral campaign in 2002, issues pertaining to the institutional set-up for dealing with integration became an important part of the party debate. Latvia's First Party advocated creating a ministry for minorities, while New Era proposed the creation of an integration ministry. After the elections, Latvia's First Party assumed responsibility for the integration portfolio and created a Special Assignments Minister for the Social Integration Affairs endowed with a support structure called a secretariat, not a full-fledged ministry. Over time, its authority came to include "the development and implementation of state policy in the realm of social integration - promotion of the development of civil society, prevention of racial and ethnic discrimination, inter-sectoral issues of preventing discrimination and promoting tolerance in

45 Ibid., pg. 87.

46 On the work of the Society Integration Foundation, see the chapter by Ilona Kunda below. 
society, minority rights, the preservation of Liv culture and traditions, support for the Latvian diaspora, as well as immigrant integration." ${ }^{47}$ The government invited as first minister the then director of the Latvian Centre for Human Rights and Ethnic Studies, political scientist Nils Muižnieks.

A very broad portrayal of integration issues in the integration programme led to a situation in which different ministers (from 2002-2008, five different persons held the job) stressed very different priorities depending on their individual predilections and the political situation at the time. At first, the work of the secretariat focused on minority NGOs and the NGO sector in general, anti-discrimination and the promotion of tolerance. Among the significant initiatives of the secretariat was promoting the ratification of the Council of Europe's Framework Convention for the Protection of National Minorities in 2005 , though the ratification act contained significant reservations and came a full ten years after signature. Two other notable initiatives were promoting the registration of non-citizen children as citizens through a direct mail campaign targeting 15,000 parents and the elaboration of a Roma integration programme and its adoption by the government in October 2006. In subsequent years, the secretariat paid more attention to politically less sensitive issues, such as support for rural NGOs and strengthening ties with the Latvian diaspora, especially those who had left as labour migrants to Ireland and Great Britain. ${ }^{48}$

In the six years of its existence, the secretariat regularly became the focus of controversy. In the early years, this was because its policy often came into conflict with the convictions of the nationalistically inclined segment of the political elite. Another reason derived from the unclear division of labour between the secretariat and the Society Integration Foundation. Tensions in relations between the two bodies surfaced periodically, followed by sharp exchanges of views about the duplication of functions with regard to supporting the NGO sector, the rights of the minister to exercise oversight over the Foundation, and the extent to which the work of the SIF reflected the tasks set for it. ${ }^{49}$ One of the reasons mentioned by the media for these disagreements was a behind-thescenes struggle over control of the flow of funding to support integration. If the minister's initial budget was around 300,000 lats per year $(\sim € 428,000)$, the Society Integration Foundation had a budget of 1.5 million lats ( $€ 2.14$ million) in 2003 and 10 million ( $€ 14.28$ million) in $2008 .{ }^{50}$

47 Cabinet of Ministers regulations No. 764 of 13 November 2007. See http://www.likumi. lv/doc.php?id=166986.

48 David Galbreath and Nils Muižnieks (2009), 'Latvia: managing post-imperial minorities' in Bernd Rechel, ed., Minority Rights in Central and Eastern Europe. London: Routledge, pp. 146-7.

49 Society Integration Foundation governing board meeting minutes No. 57 of 11 December 2007.

50 Dita Arāja (2007), 'Kam tiks SIF naudas lāde?' published on politika.lv, 26 June 2007, available at http://www.politika.lv/index.php?id=14296. 


\section{Quo vadis Integration Policy?}

Official sources portray integration policy in Latvia as a topical realm for society in which Latvia can share its positive experience. For example, the home page of the Ministry of Foreign Affairs offers a generally positive evaluation of accomplishments in the realm of integration: "there are many examples that attest to the successful integration of society in Latvia. Most of these examples are difficult to perceive or quantify, but they can be found in all of society's structure." ${ }^{51}$ At the same time, the views of researchers are much more critical. In a 2007 article "The Tough Nut of Integration in Latvia and Europe," Nils Muižnieks evaluated accomplishments thus:

It should be acknowledged that in the six years since the adoption of the integration programme in 2001, Latvia has not marked significant progress in the direction of attaining the initial basic goals that were set - the rapprochement of the values of inhabitants and the promotion of a sense of belonging to Latvia. A number of recent studies suggest that there are still enormous differences in values and attitudes between Latvians on the one hand, and Russians and most other persons belonging to minorities on the other. With regard to understandings of history and stances towards Latvia's ethnic policy and foreign policy goals, this divide is very deep and is not growing narrower with the change of generations. Survey data over a period of more than ten years suggest that Russian-speakers' sense of belonging to Latvia was and remains very weak. ${ }^{52}$

Over time, the objective necessity for new, more contemporary basic guidelines that reflected changes in the relations among Latvia's ethnic groups became ever more apparent. In 2007 the Integration Secretariat prepared new Social Integration Policy Guidelines 2008-2018. The understanding of integration in this document was cardinally different from that in the 2001 document and largely reflected the Council of Europe's approach to social cohesion. ${ }^{53}$ The new draft document stressed the importance of a democratic, inclusive civil society in social integration, as well as the significance of the ideas of multiculturalism in inter-ethnic relations. The draft document included 17 indicators to evaluate progress in 2012, 2015 and 2018. However, the new guidelines fell victim to changes in the domestic political situation. People's Party Minister of Culture Helēna Demakova categorically objected to the inclusion of ideas

51 See http://www.am.gov.lv/lv/latvia/integracija/integracijas-politikacopy/.

52 Nils Muižnieks (2007), 'Integrācijas “cietais rieksts” Latvijā un Eiropā,' Diena, 25 October 2007, available at http://www.diena.lv/lat/arhivs/kulturas-diena/sabiedribasintegracijas-cietais-rieksts-latvija-un-eiropa.

53 Council of Europe (2004), A New Strategy for Social Cohesion. Strasbourg: Council of Europe, pg. 3, available at http://www.coe.int/t/dg3/socialpolicies/socialcohesiondev/ source/RevisedStrategy_en.pdf. 
of multiculturalism into the draft document, as she considered the "ideology of multiculturalism" to be "in direct contradiction to the idea of a national state." 54 The sharp attacks were effective and further discussion of the draft was halted.

The elaboration of a new policy document was hindered by the doubts that were frequently expressed in the public sphere about the need for a special state structure devoted to integration issues. Such doubts were raised not only by politicians sceptical of the idea of integration in general, but also by the government's social partners, especially after the onset of the global economic crisis. Finally, in 2008, the government adopted a decision to eliminate the secretariat of the Special Assignments Minister for Social Integration Affairs, ostensibly to economize on resources. On 1 January 2009 the Ministry for Children and Families took over integration functions and was renamed the Ministry for Children, Families and Social Integration Affairs. Less than four months later, on 28 April 2009, the government adopted a decision to reorganize this ministry and divide its functions among several other ministries. Most of the integration-related functions fell to the Ministry of Justice, though some, such as anti-discrimination policy, went to the Ministry of Welfare and supporting minority NGOs went to the Ministry of Culture. As a result of the reorganization, most of the former staff of the integration secretariat were fired and state budget funding for fulfilling the various functions was seriously cut, thereby seriously threatening integration policy implementation overall.

Regardless, work on new draft social integration policy guidelines 2010-2016 continued in the summer and autumn of 2009, and in October 2009, the Ministry of Justice was compiling the comments and objections of various ministries to the draft document. If and when the new policy guidelines are adopted by the government, they will replace the 2001 national programme. The introductory conceptual part of the new guidelines marks a significant step forward in comparison with the 2001 programme. They are in line with both the main policy directions of the European Union and with the insights of contemporary social science about the preconditions for integration. The draft document defines integration as a "mutual process of understanding and cooperation between the majority and the minority, in which the minority is an inalienable part of society. ${ }^{55}$ Target groups for social integration policy include ethnic minorities, including Roma, non-citizens, persons subjected to an intolerant attitude and discrimination on the basis of race, skin colour, ethnic affiliation, religious conviction, sexual orientation, as well as immigrants and

54 'Demakova: multikulturālisms Latvijā noliedz okupāciju,' Diena, 26 February 2008, available at http://www.diena.lv/lat/politics/hot/demakova_multikulturaalisms_latvijaa_ noliedz_okupaaciju/a7cdb867f7cac782036c9e68d5d20775?comm_page=1.

${ }^{55}$ Ministry of Justice (2009), 'Sabiedrības integrācijas politikas pamatnostādnes 2010. - 2016. gadam,' (draft document), Riga: Ministry of Justice, pg. 5. 
society as a whole. ${ }^{56}$ The draft document clearly delineates ethnic integration as the precondition for ensuring ethnic harmony from social, regional and diaspora integration. The inclusion of the task of immigrant integration can also be judged as a forward looking, topical approach. Other positive features include the efforts of the authors of the draft to precisely define the responsibilities of the Ministry of Justice in integration policy, as well as to create progress indicators related to integration for concrete policy realms. Unfortunately, given budget austerity, there are no additional resources foreseen for attaining the goals set in the document, which risks turning the new integration policy guidelines into a list of the state's good intentions. A no less important issue is the ability of the Latvian political elite and society as a whole to overcome its long-term divisions over the need for integration policy, its goals and tasks. This will determine whether the provisions of the policy guidelines will remain at the level of declaratory policy, or whether they will serve as the basis for harmonizing relations between the major population groups in society. Given the inevitable inflow of immigrants, asylum-seekers and refugees in the future, integration of new arrivals will also become one of the most important preconditions for sustainable development in Latvia.

${ }^{56}$ Ibid. 


\section{The Society Integration Foundation and 'Ethnic Integration'}

\section{Ilona Kunda ${ }^{1}$}

\section{Introduction}

This is the first attempt to characterize the projects supported by the Society Integration Foundation (SIF) in the realm of ethnic integration. The core question to be addressed is: have the initiatives supported by SIF had a positive impact on overcoming ethnic divisions in society? These divisions are identified and described in the National Programme on "The Integration of Society in Latvia" (hereafter, Integration Programme) adopted in 2001.

The SIF is not the only player in integration policy, but it is significant as an example of a specially created institution with a mandate to implement the Integration Programme. From 2001 through 2006, the SIF administered almost 13 millions lats ( $€ 18.5$ million) in funds. Thus, it is important to understand how effective this model of policy implementation has been: what kinds of results were possible based on the Integration Programme and on implementation envisaging support for initiatives "from below" in the form of project proposals in various subfields of integration.

Nobody has ever sought to measure the impact of the SIF's activities and there is very little academic research about various aspects of its work. ${ }^{2}$ Discussions in 2008 about the division of labour between the SIF and the Integration Secretariat or in 2009 about which institution the SIF should be subordinated to have not been based on any analysis of integration policy outcomes that provide some insight into accomplishments in this realm. This research seeks to analyse the contribution of the SIF to addressing the particularly ethnic aspects of social integration, and not, for example, issues of social inclusion or regional integration. This choice was dictated by the broader research agenda of the Advanced Social and Political Research Institute (ASPRI), as well as by the declared interests of representatives of the SIF themselves.

1 The author would like to thank Aiga Balode, Maksims Kovaļenko, Zane Silabriede and Kristina Morzsevska for research assistance.

${ }^{2}$ Exceptions are OSI/EU Accession Monitoring Program (2002), Monitoring the EU Accession Process: Minority Protection Volume 1. Budapest: OSI, pp. 296-364; and Leo Dribins, ed. (2007), Pretestība sabiedrības integrācijai: cēloņi un sekas. Riga: FSI. 
The SIF was created to promote implementation of the Integration Programme. In asking what the SIF has accomplished in the realm of ethnic integration, one must ask what the Integration Programme proposed to accomplish and whether that was possible. Did the Integration Programme identify and stress the most important cleavages and the preconditions for lessening them, or does it merely offer the implementing agency a catalogue of ideas? In the subsequent implementation process, could decisions and procedures compensate for any deficiencies? In the case of the SIF, an important focus of analysis becomes the policy implementation model itself - support for the initiatives of society, which stresses the capacity of society to spontaneously generate answers and solutions to its problems. The issue here is to ascertain how successfully this model has worked in the context of the limitations of both sides - the SIF and implementers.

Preliminary analysis suggested that the Integration Programme can only serve incompletely as a point of reference in assessing the policy impact (see Juris Rozenvalds' chapter above). Thus, it was necessary to generate a theoretical basis permitting conclusions about the possible impact of SIF-supported projects on lessening cleavages in society. Here, the basis for analysis chosen was contact theory - the hypothesis that certain kinds of inter-group contact can lead to changes in attitudes (see Nils Muižnieks' chapter above). Though this is only one possible approach, it does point to a necessary precondition for change and is suited to Latvia's situation, as it corresponds to ideas contained in the Integration Programme. Taking contact theory as a basis, the author analysed those aspects of the implementation of the Integration Programme that related to promoting the submission of certain kinds of projects and evaluating them (the substantive part of grants competitions and the selection criteria), as well the projects supported.

The time frame for analysis was projects supported from 2002 through 2006, as 2006 was the last year for which project implementation reports were available when the research began in late 2007. Analysis was rendered more difficult because, except for 2002 and 2003, the SIF did not separately identify ethnic integration projects. Thus, the author had to agree with SIF officials on a case-by-case basis on whether a project could be considered an "ethnic integration" project - one that addressed ethnic or linguistic cleavages in society. Overall conclusions about possible policy impact are provisional and suggestive, rather than definitive, as the source of information chosen (implementation reports) has certain weaknesses. The most important limitations were

1) the implementation reports do not include direct questions about contact between the groups involved, so data had to be derived from answers to other questions;

2) implementation reports focus attention only on a limited number of issues and do not usually entail a self-critical assessment of what one has accomplished. However, data were sufficient to identify the most important general trends. 
Further, I sketch in greater detail the theoretical basis for the analysis, characterize the Integration Programme's strong and weak points from the perspective of an implementing agency, and examine how the model of a selforganizing society was implemented in the case of the SIF. In the second part of this chapter, I characterize the projects supported by the SIF in the realm of ethnic integration and offer some general explanations for the peculiarities discovered. In the conclusion, I raise certain issues about further support for ethnic integration in Latvia.

\section{The Integration Programme: A “Road Map” Towards Desired Changes?}

The Integration Programme constitutes the substantive point of reference for all subsequent initiatives and interpretations in this realm of policy - it defines the goals to be attained and the directions for activity. This document has three separate levels and within each of those levels the content is further developed and specified. In the language of policy evaluation, the Integration Programme is a theory of change: it offers an explanation of what needs to be changed and the process through which that is possible.

In analysing the Integration Programme as a document, it is possible to ascertain how much room for setting priorities and interpretation is left to the implementer. It is also important to identify themes that are made sufficiently concrete and those that are left without operationalization. If the policy document includes well-founded ideas, but avoids clearly identifying priorities or mechanisms for achieving the changes desired, there is a great risk that implementation will focus on less important or effective aspects of change. Moreover, avoiding open discussion of certain problems can exacerbate public alienation and cynicism towards the state. My goal was to assess the extent to which the Integration Programme could serve as a map to policy implementation by offering a structured and well-founded model of change with regard to overcoming ethnic divisions and the extent to which it left without concrete elaboration important concepts, topics and activities.

\section{"Road Map" or Catalogue?}

The Integration Programme has three different levels: from

1) abstract concepts and general goals, through

2) directions of activity to

3) a catalogue of examples of concrete projects to be supported.

At the first level, the text of the Integration Programme suggests that the main problem is the ethnic divide, partially also mistrust towards the government, and includes the idea of the creation of common values based on Latvian 
culture and a common citizenship. The idea of integration as a two-way process is stressed many times, as is the idea of cooperation and the necessity for both sides to overcome mutual mistrust and a felling of being threatened.

At the second level there is simultaneously an elaboration of certain topics, but a de-emphasis of the most controversial topics. The topic of ethnic divisions is simply reduced to language, minority culture and education, leaving aside issues of mistrust, ${ }^{3}$ mutual threat perceptions, as well as history and other problematic issues pertaining to belonging and identity.

Overall, it should be noted that the introductory part of the Integration Programme names a whole range of important goals - active partnership between all groups in building the future, two-way relations overcoming divisions relating to history and culture. However, a number of these ideas are not developed any further (e.g., varying interpretations of history, mutual threat perceptions, etc.) and no priorities are identified. Some of the solutions suggested are contradictory as well. For example, agreeing on a national identity is only possible on the basis of ethnic Latvian culture, which in essence means a culture conflict for many members of society.

Thus, the Integration Programme leaves identifying many solutions and resolving a whole range of contradictions in the hands of the implementing agency. On the one hand, a lack of concrete policy stances could open the way for progressive ideas and solutions. On the other hand, relying on the spontaneous proposals of society carries a great risk of reproducing existing relations, strategies and understandings.

An additional drawback is the lack of any progress indicators in the 2001 document. Thus, the point of departure for policy implementation is in many ways progressive, but internally contradictory. In terms of operationalization, the document is a political compromise that creates additional challenges for implementation.

\section{Which Circumstances Can Promote Overcoming Society's Divisions?}

In policy implementation, it is important whether the main policy document clearly names the mechanism through which divisions are to be overcome and whether that mechanism can achieve results. If the main policy document does not do this, it is necessary to search for indications that initiatives from society can spontaneously offer solutions that could be seen as effective.

In the introductory sections of the Integration Programme, there is frequent reference to cooperation between different groups, trust, and overcoming

${ }^{3}$ See the Integration Programme in Latvian, which on page 8 states 'In the psychological sense, integration is the ability to trust,' available at http:/www.politika.lv/temas/ sabiedribas_integracija/4106/. 
insecurity. This emphasis also corresponds to theoretical ideas about changes in attitudes and overcoming ethnic distance. Though overcoming cleavages can be linked to numerous factors, the author chose Gordon Allport's contact hypothesis as a point of departure. ${ }^{4}$ As shown by research conducted in Latvia, a significant and durable trend in Latvian society, particularly among ethnic Latvians, is the prevalence of strategies of separation. ${ }^{5}$ To ascertain the possible impact of the SIF on ethnic integration, I sought signs of contact and a characterization thereof in the project implementation reports: was there contact, was the status of participants equal, was contact sustained, what was the content and who was the initiator of the joint action.

The contact hypothesis is supplemented by John Berry's scheme of acculturation strategies, which distinguishes four possible strategies according to the interaction of four different factors: the desire to maintain one's cultural traditions and readiness to engage in contact with the other group. According to Berry, integration is a balance between both dimensions, and global research shows that the inclusion of new arrivals takes place best according to this scheme. ${ }^{6}$ Berry's thesis explains why it is important to reinforce security about one's culture, but that that needs to be balanced by contact, as only a sufficient sense of security about one's cultural identity can serve as a basis for the willingness and ability to maintain contact with members of other groups. Berry's scheme provides an additional rationale for the necessity of contact, particularly in analysing the many projects supported by the SIF in the realm of maintaining and demonstrating one's cultural heritage.

The quantitative instrument for analysis of project implementation reports was based on the aforementioned ideas of Allport and Berry, specifying the areas in which contact took place, the target groups, the planned (knowledge, skills) and unplanned results. The guidelines for the project competitions and other documents used for project selection were analysed with regard to whether they focused attention on contact taking place in projects.

\section{Policy Implementation as a Continuation of Policy Formulation}

Any idea becomes transformed during the policy process and policy creation continues in the implementation phase. In the case of the projects supported by the SIF, there are several phases of transformation. The first phase is the priorities and areas proposed by the Integration Programme, followed

${ }^{4}$ Gordon W. Allport (1954/1979), The Nature of Prejudice. Cambridge: Perseus Books.

${ }^{5}$ See Inese Šūpule and Brigita Zepa (2006), 'Etniskā apdraudētība kā dzīves kvalitātes aspekts,' in Dzīves kvalitāte Latvijā. Riga: Zinātne.

${ }^{6}$ For a recent statement, see John W. Berry et al, eds. (2006), Immigrant Youth in Cultural Transition. London: Lawrence Erlbaum Assoc. 
by the priorities proposed by the SIF, the content emphasized by the guidelines in the grant competitions and the aspects highlighted in the guidelines for evaluators. Here, we will try to follow the process of transformation and the potential to focus on the most important ideas of ethnic integration in all phases mentioned.

The mission of the SIF defined in the law - "to promote the implementation of the Integration Programme" - meant promoting the implementation of a range of contradictory ideas that represented a political compromise. Several different approaches were possible on the part of the SIF: proactive involvement in interpreting the ideas of the Integration Programme by promoting a public or expert discussion about specifying the most contradictory elements; reliance on the "self-organization of society"- that is the ability of society to proposes solutions "from below"; or some combination of a reactive and proactive approach.

It can be assumed that the choice is largely linked to the fact that any institution has to find a balance among various goals: the maintenance of its existence and the strengthening of its autonomy ${ }^{7}$ on the one hand, and the need to further the substantive goals it was set up to achieve on the other. The SIF is no exception. After characterizing the balance of approaches chosen by the SIF, the possibilities and drawbacks of the chosen model in the contract of integration policy implementations will be explored.

Thus, the analysis begins by examining two sets of issues:

1) the policy implementation model chosen by the SIF (supporting the "self-organization of society"), its links with the SIF's institutional autonomy, and some advantages and drawbacks of this model; and

2) the standard decision-making process in the life cycle of a project competition with a view to identifying phases where it is possible to focus integration practices in a certain way. These are the phases in which it is possible in theory to compensate the deficiencies of the Integration Programme.

\section{The Choice of a Policy Implementation Model and Its Functioning}

On 6 February 2001 the Cabinet of Ministers adopted the National Programme on "The Integration of Society in Latvia" and designated the Ministry of Justice responsible for coordinating implementation. On 5 July 2001, one half

\footnotetext{
7 In the context of this research, autonomy is understood as an institution's possibility to influence its own goals and tasks, taking into account the external environment's changing influence on the concrete sphere. Researchers in organization theory and public administration indicate that each institution has a propensity to seek autonomy, the more so if such an opportunity is enshrined in legislation.
} 
year after adoption of the Integration Programme, the parliament adopted the law on the Society Integration Foundation (SIF), which entered into force on 1 September 2001. The SIF would become a special player in integration policy, as its mission was defined as "promoting implementation of the goals of the National Programme on the Integration of Society in Latvia." On 27 December 2002 a new institution, the secretariat for the Special Assignments Minister for Social Integration Affairs (hereafter, simply Integration Secretariat) was created that took over coordination functions form the Ministry of Justice.

Though implementation of the Integration Programme was meant to be a collective and all-encompassing process, the true configuration of state, local government and NGO actors developed in a more fragmented way, with a specific distribution of resources and opportunities for acquiring funding. The SIF acquired a rather independent status, as it operated on the basis of a separate law and that law envisaged a high degree of autonomy. It stated that the SIF Council, which is organized on the basis of parity, adopts all the main decisions. The SIF is a public foundation and, according to the law, not subordinate to any other institution in the state administration. Its budget is separate from the state budget, and the law foresees that state budget funds are given directly to the SIF, which requests state budget means directly from the Cabinet of Ministers. The law does not name a member of the Cabinet of Ministers who is responsible for carrying out supervisory functions with regard to the SIF. ${ }^{8}$

The highest administrative decision-making body is the SIF Council, which decides on allocation of resources, as well as the main directions of work. The SIF has special committees which prepare the necessary information and draft decisions for the work of the Council, and an executive secretariat led by a director. The secretariat supports the work of the Council, as well as announces all project competitions, informs the public about them, receives project proposals, evaluates them, signs contracts with project implementers, as well as supervises and monitors projects. The SIF secretariat was led by Nils Sakss from its formation until January 2008, while Aija Bauere was appointed director on 9 September 2008. This study pertains to the period from 2002 to 2006.

The tasks of the SIF are linked to the management of resources and their distribution for implementing social integration projects, including tasks throughout the cycle of attracting resources, managing them and communicating with the public. ${ }^{9}$ Legislation governing the operation of the SIF grants it a general authority to attract funding to promote social integration in Latvia, which allows it to seek funding pro-actively or to respond to offers of funding. Decisions on concrete funding are taken by the SIF Council.

${ }^{8}$ Nils Sakss 'Politiskā ķīmija skar Sabiedrības integrācijas fonda likumu,' Latvijas Vēstnesis (Government Herald), 4 October 2007, available at http://www.lv.lv/index.php?menu=do $c \& s u b=$ komentars\&id $=164051$.

9 See the home page of the SIF at http://www.lsif.lv/par-mums. 
When the SIF was created, it had a relatively large freedom for manoeuvre and several different scenarios were possible. From the very beginning, the first director of the SIF took the tactic of creating a system that would lead towards EDIS accreditation, thereby becoming attractive to the European Union and other external donors. ${ }^{10}$ That provided space for a certain autonomy on the part of the SIF, while determining the SIF's neutrality with regard to promoting certain types of integration in a pro-active manner. This is acknowledged by the former director of the SIF secretariat Nils Sakss:

My approach was to create a financial mechanism. If we started with 200,000 lats and now there are 6 million, I doubt if such progress would have been possible if the Foundation had gone into the content. I believe that in Eastern Europe we are the only case in which the Integration Foundation has received such EDIS accreditation. If the SIF had gone a different path, I think that funding would have been much smaller, but then the Foundation would work more as a proactive guide dealing with the content. Another aspect was that rather soon after the creation of the Foundation the Integration Secretariat was created. When the Foundation was being created, nobody said a word that such a ministry should be created. That appeared quickly, suddenly, as a political decision... ${ }^{11}$

This configuration of circumstances influenced the role of the SIF Council, which narrowed its functions in determining the substance of integration, just as the Integration Secretariat began to work. In commenting on the beginning of the SIF's work, Nils Sakss noted that the SIF Council could have played a rather active role on the substance of integration if the Integration Secretariat had not been created. ${ }^{12}$ This does not mean that the SIF Council had no substantive issues on its agenda, but the minutes of Council meetings suggest that this took place rather rarely. ${ }^{13}$

Thus, the SIF embarked on the course of creating a transparent, precisely functioning machine. Attracting funding through various mechanisms meant choosing which initiative "from below" to support. This model was based on supply and was accompanied by standardized working procedures (e.g., criteria for evaluating projects in grants competitions ${ }^{14}$ ), the long-term priorities set by donors (e.g., development of civil society), and also certain restrictions (e.g., recipients could not be informal initiative groups).

${ }^{10}$ Extended Decentralized Implementation System (EDIS)

${ }^{11}$ Author's interview with Nils Sakss, 22 January 2008.

12 Ibid.

${ }_{13}^{13}$ One example was the issue of the further development of the SIF at the end of 2007.

${ }^{14}$ In accordance with information provided by the SIF, evaluation criteria were adopted from the European Commission's Practical Guide to Contract Procedures for EC External Actions (6. Grants). These are Standard recommendations for creating any grants competitions. They are available at http://ec.europa.eu/europeaid/work/procedures/implementation/ practical_guide/index_en.htm. 
As the work of the SIF developed from 2001 to 2008, one concludes that significant growth has taken place - from a staff of five persons in 2001 and 2002 to a staff of 75 in 2008. In terms of staff, the largest departments are those for monitoring structural funds and programmes, as the requirements for implementing projects with European Union and other sources of funding place significant human resource demands on the SIF secretariat. All the departments in the SIF secretariat with the exception of those dealing with accounting, support and internal audit functions are involved in one or another of the SIF project implementing cycles.

To implement the model chosen, the SIF operated according to detailed procedures which are determined by the SIF project management handbooks, which are drafted for each of the financial instruments administered by the SIF. Supervision of the projects supported by the SIF meant the introduction of the principle of double control throughout the period of project administration and the fact that two SIF staff members are responsible for each activity (Project managers from the supervisory department and financial control workers). The capacity of the SIF to implement its functions precisely and transparently is attested by the fact that through 2008 the administrative court received only one application appealing an evaluation decision in the EU Transition facility grant scheme "Promoting the integration of society in Latvia," and in 2008, the court found in favour of the SIF. ${ }^{15}$ Of course, the lack of complaints can also be explained by a desire to avoid lengthy legal proceedings, given the work load of the administrative courts, though all indications suggest that effective SIF work and communication with applicants is an important factor.

\section{A Supply-Driven Model of Supporting Initiatives from Below}

In interviews conducted during the research in 2008, most respondents thought that the funding mechanism for social integration inherent in the SIF (and in the Integration Secretariat) was successful because it permitted members of the public to take the initiative in the realm of social integration, taking a "bottom-up" approach, not imposing an artificial concept. Indeed, those projects that were submitted and supported came from non-governmental organizations (about $40 \%$ ), local governments and institutions linked with them, and nonprofit limited liability companies. Alongside the positive aspects of this model (the opportunity for society to express itself), one must note also the drawbacks of this approach. As Elmārs Vēbers pointed out in 2007, several categories of issues fall outside this framework:

1) those which are broader than one project; and

${ }^{15}$ See the 2008 SIF annual report, available at http://www.lsif.lv/files/Gada-parskats-2008. pdf. 
2) those which do not have an appropriate implementing organization during a call for project proposals. ${ }^{16}$

An analysis of the projects confirms the second point, for example the limited response of applicants to certain kinds of calls (dialogue among social science teachers, information exchange regarding civic education, etc.) may be linked to a low level of organizational development in certain areas. The issue of integration topics that transcend the limits of one project is linked with the role of the local governments in implementing integration policy. Of course, local governments could be applicants in individual projects in all the grants competitions administered by the SIF, but it would be important to strengthen their strategic role and capacity to create and implement long-term, systemic inclusive measures in their communities. The only competition devoted to strengthening the role of local governments in 2003 aimed at promoting the drafting of local integration programmes, which by itself would not create implementation mechanisms. Moreover, research suggests that local governments repeat the mistakes of the national Integration Programme by creating action plans as uncoordinated catalogues of opportunities with a large focus on social issues. ${ }^{17}$ Thus, the issue remains open whether spontaneous organization without capacity building is a sufficiently effective mechanism.

Continuing the line of thought suggested by Vēbers, one can suggest that a supply-driven model leaves topics which a potential group of implementers does not consider possible to offer to the SIF as a state institution considered by some to represent the ethnic Latvian majority. ${ }^{18}$ Is the SIF considered an appropriate dialogue partner by all social groups? As former director of the SIF Nils Sakss noted in an interview, Russian NGOs "of a certain kind" have not offered their projects to the SIF. This leaves unanswered the question - if the "bottom-up" approach ensures representation of only one part of the spectrum, who will maintain dialogue with the rest of the spectrum and who will make these distinctions? This contradiction is illustrated by data about communication with the public - according to the annual report of the SIF for 2008, only $5 \%$ of the publications about the SIF were in Russian-language newspapers, thereby reproducing a lop-sided dialogue. ${ }^{19}$

${ }^{16}$ Elmārs Vēbers (2007), 'Vai teiksim ardievas sabiedrības integrācijai?' In Leo Dribins, ed., Pretestība sabiedrības integrācijai: cēloñi un sekas. Riga: FSI, pg. 125.

${ }^{17}$ Baltic Institute of Social Sciences (2004), Pašvaldību loma sabiedrības integrācijas procesā. Riga: BISS.

18 Alienation from government is a well-documented phenomenon in Latvia.

${ }^{19}$ See the annual report of the SIF at http://www.lsif.lv/files/Gada-parskats-2008.pdf. 


\section{Implementing a Supply-Driven Model: the Contribution of the SIF}

In its public communication the SIF seeks to stress the modest nature of its role and possibilities. For example, in its 2007 annual report, the SIF notes that it is an institution whose work is completely dependent on the desires of donors and their willingness to entrust the SIF with financial resources. However, this does not exclude the possibility of influencing the creation of substantive guidelines. For example, in relation to funds allocated by the state budget, the Integration Secretariat submitted to the SIF social integration priorities, thereby formally ensuring policy coordination in the realm of social integration. Legislation did not envisage a concrete manner in which the SIF had to ensure implementation of these priorities, and until 2008 these priorities suggested by the Integration Secretariat were interpreted as advisory. That does not mean that they were not taken into consideration in the guidelines and statutes of Project competitions, but officials from both the SIF and the Integration Secretariat have noted that there is no legislation in force that states that the two bodies had to cooperate. In 2008 both institutions heatedly discussed duplication of functions with regard to supporting the NGO sector, the issue of supervision and autonomy, the SIF's activities in the public space, ${ }^{20}$ and the conformity of the SIF's activities with the general goals set forth in the Integration Programme. The management of the SIF always maintained its independent view on such issues.

It should be stressed that in other aspects as well the former long-time director of the SIF Nils Sakss was essential in shaping the work of the SIF. It is important to note that his role was in no way purely administrative. For example, until January 2008, in most cases, the initiative to attract new projects and programmes came from Sakss himself, who prepared the relevant reports for the SIF Council. ${ }^{21}$

\section{Statutes and Evaluation Criteria as Means of Focusing Bottom-Up Initiatives}

In investigating how the content of the main policy document was transformed in the implementation process, one must examine the grants competitions organized by the SIF. In this section, we analyse the contribution of the statutes and evaluation criteria for grants competitions in implementing ethnic integration, stressing how they focus the "supply" of project implementers

\footnotetext{
${ }^{20}$ See, e.g., the $57^{\text {th }}$ minutes of the SIF's Council of 11 December 2007, 'Sabiedrības integrācijas fonda padomes sēdes protokols Nr.57,' Internal document of the SIF.

21 This was noted in interviews with several SIF staff on 12 March 2008.
} 
and structure the choice of which solutions are most effective. ${ }^{22}$ While the management of the SIF saw themselves as supporters of initiatives from below, to receive the SIF's support, certain conditions must be met which focus the content of the supply in certain ways by marking out certain fields of activity, desirable types of activities, etc. Such focusing is inevitable, even if the authority of the SIF in administering the concrete financial instrument was limited by the funder's criteria and the participation of the Integration Secretariat in assisting to determine priorities. ${ }^{23}$

The task here is to characterize the result of this focusing, concretely:

1) To what extent does that which is implemented in the SIF grants competitions reflect the themes in the Integration Programme and cover the field?

2) To what extent do SIF grants competitions react to new needs?

3) To what extent does the SIF compensate for weaknesses in the Integration Programme?

4) To what extent do the evaluation criteria help to choose the offer with the greatest chance of having an impact in the realm of ethnic integration?

Hereafter, conclusions are based on an analysis of the documentation of the grants competitions. ${ }^{24}$ At least nominally, practically all the topics in the Integration Programme dealing with ethnic aspects of integration appear in the statutes of SIF grants competitions - citizenship and naturalization, creating integration programmes at the local government level, school exchanges, support for minority cultural NGOs, etc.

\section{An Overview of the Competitions}

The initial period of 2002 and 2003 should be perceived as cautious attempts to gain understanding about which activities might attract the most

${ }^{22}$ In analysing evaluation criteria, the author chose the statutes of competitions funded by the state budget, as well as those funded by the PHARE programme (which were the most significant sources of financial support for ethnic integration projects from 2002 through 2006. To examine the development of the ideas, two competitions from each source of funding were chosen from the initial stage of SIF's work and a later stage. The concrete unit of analysis was the sections on evaluation criteria for the competitions 'Support to NGO activities in the realm of ethnic integration in 2002 and 2004' and the PHARE competitions in 2003 and 2006 for the programme 'Promoting the integration of society in Latvia'.

${ }^{23}$ E.g., the PHARE programme has concrete programme guidelines, the fiche was drafted by the Integration Secretariat, which also submitted implementation reports to the Ministry of Finance. The Integration Secretariat also drafted annual priorities.

${ }^{24}$ Information regarding the content of grants competitions is usually found in the following sections: 'Goals and priorities of the grants competition,' - the general orientation; 'Types of activities' or 'Directions and activities to be supported' - both with specific thematic directions and concrete activity types. 
support from potential project implementers, as the statutes of the competitions using state budget funding are very general: "any measures which promote the mutual understanding and harmony of ethnic groups living in Latvia." Specific activities to be supported are formulated only in the competition "Mass media for the promotion of social integration." In subsequent years, some new ideas were included (e.g., information about the education reform) and the approach was made more specific. However, the PHARE Programme "Promoting the integration of society in Latvia" (from 2004) is most in line with the spirit of the Integration Programme. There one sees measures such as intercultural education for various groups, promotion of inter-ethnic dialogue, promotion of cooperation on best practices in bilingual education, etc. Overall, the statutes of the grants competitions organized by the SIF cover practically all the themes in the Integration Programme which are clearly linked to the ethnic aspects of integration: citizenship and naturalization, drafting integration programmes by local governments, school exchanges, support for minority NGOs, etc.

\section{To What Extent Do SIF Grants Competitions Meet New Needs?}

Several SIF initiatives that specify certain topics outlined in the Integration Programme and react to new challenges should be positively evaluated, including:

- "Informing and Promoting Activity among Residents of Local Parishes" (2002);

- "Support for measures to inform the public in the realm of minority education" supplementing the PHARE competition (2003);

- Social integration activities in areas predominantly inhabited by noncitizens and minorities; employment promotion activities in areas predominantly inhabited by non-citizens and minorities; Latvian language acquisition initiatives in areas predominantly inhabited by non-citizens and minorities (2005).

The mechanism for project identification and support created by the SIF is completely capable in the framework of competitions to react to new needs of the public, to define with sufficient precision types of activities and directions, since this was done on many occasions. One shortcoming is that not all ideas can evoke interest without certain public awareness raising and NGOs are not always the most appropriate implementation agents. On occasion, informal interest groups (which cannot receive support within the context of the PHARE programme) might be more appropriate, and smaller grants competitions, which require less time to prepare and implement, might be more effective. 


\section{Compensating for Drawbacks in the Integration Programme}

Here, we analyse firstly, fields of action in the Integration Programme that were not clearly labelled "ethnic" but which could be used to lessen the ethnic divide, and secondly, important topics in the Integration Programme (two-way communication, active partnership), which were mentioned in the introductory part of the Integration Programme, but were not stressed afterwards. This would require the appropriate instruments in the statutes of the competitions and evaluations, as well as encouraging potential applicants to submit certain types of ideas.

First, let us examine the topics where emphasising the ethnic component could have had significant added value. This opportunity was most evident with regard to civic participation - practical experience in participation and cooperation with regard to common problems is incomparably better that rhetoric in sending people the message that they have a joint responsibility for their lives and future.

In 2002 a competition entitled "Informing and Promoting Activity among Residents of Local Parishes" was announced. Though it did not exclude the possibility of submitting projects with joint activities involving Latvians and minorities, that aspect was not specifically stressed and the SIF did not classify such projects as "ethnic integration."

In subsequent years, the topic of "civic participation" was taken up in the PHARE grants competitions "Promoting the integration of society in Latvia,"25 but the formulations in the 2003 and 2005 competitions speak only about "non-citizen, non-Latvian-speaking inhabitant and ethnic minority" integration in various fields, without mentioning any Latvian participation in these measures. The statute of the 2006 grants competition stressed various forms of dialogue, but in the realm of culture and information exchange, not in civic participation.

With regard to stressing two-way contact with the assistance of Project competitions, the SIF did this starting from 2002. The most precise application of this idea took place in the school exchange competitions beginning in 2002 . The justifications for these competitions refer to the necessity of learning in practice about what unites people: "getting to know each other and cooperation in implementing joint events". Unfortunately, this very concrete idea of common activities was applied mainly to children and youth, though in later years, teachers and vocational school students were also mentioned as a target group.

The potential of linking ethnic integration to civic participation was not exploited, as there were separate competitions on ethnic integration and civic

25 In the 2003 Phare grants programme 'Promoting the integration of society in Latvia,' activity 1.2. 'increasing the public's participation in discussing issues before decision-making';

1.5. 'promoting social integration initiatives at the local and regional levels,' etc. 
participation. However, nothing prevented potential applicants from seeing the integrative potential of making such links and submitting projects of such a nature. A second interesting issue has to do with the "disappearance" of certain topics after the introductory part of the Integration Programme (the two-way nature of integration, overcoming symbolic divisions, active partnership, and cooperation between various social groups). One can understand the avoidance of elaborating on the two-way nature of integration, given the political sensitivity of the issue in 2001. Even today, the idea that overcoming divisions requires steps from both sides is not self-evident to many. The Integration Programme often indicates differences in values and attitudes. Overcoming such differences inevitably implies confronting controversial issues and discussing them.

At the level of implementation, the SIF could have addressed these issues by working them into the statutes of competitions or by creating special competitions to promote contact and cooperation. The issue of promoting dialogue about controversial issues is slightly more problematic. The SIF is a state institution and adherence to political neutrality can be seen as one of the most important preconditions for its work. This complicates addressing extremely politicized issues.

If we examine the extent to which the SIF promoted inter-ethnic contact, we see that, in certain cases, the issue was addressed directly. Other instances in which the statutes of competitions stressed the two-way nature of contact were:

- A 2002 competition for the media set the task of "promoting the awareness of Latvia as a multicultural country" (the same in 2003 and 2004) and most of the desired activities are oriented towards common elements and dialogue;

- "Support for NGO projects in the realm of ethnic integration" (2002) "any measures that promote understanding and harmony among the ethnic groups living in Latvia";

- The 2004 competition "Support for NGO projects" includes "multicultural education" as a priority;

- The PHARE 2003, 2004, 2005 and 2006 competitions each have six to ten priorities/activities, for example, school exchange of experience, intercultural education, media exchange, promotion of ethnic dialogue, etc.

However, the statutes of competitions highlight clearly "two-way contacts" only regarding schools and the media. In other cases the choice is left to the project implementers.

Inter-cultural dialogue is a particular topic of interest. With regard to activities in the realm of culture, the competitions organized by the SIF offer two possibilities. First of all, the goal of the state budget funded grants competition "Support for minority cultural societies and associations" was "creation of a beneficial environment for the implementation of measures to support minority education, culture and languages". As can be seen, this concerns not dialogue, 
but strengthening one side. Secondly, the statutes of the PHARE and the Transitional Facility grants competitions urged "broadening cultural contacts," creating "joint cultural projects," thereby going beyond the orbit of minority societies. Was the public ready to go further than strengthening its own identity and to take the next step - communicate with other groups? This we will see in the characterization of the projects supported.

It can be concluded that overall, but particularly with the 2003 PHARE competition, potential applicants were offered a wide repertoire of possibilities to receive support on a wide range of topics. Next, we turn to an analysis of how evaluation criteria could assist in filtering out projects with the greatest potential of promoting the overcoming of ethnic divisions in society.

\section{The Contribution of Project Evaluation Criteria}

Criteria serve as a filter of supply. On the one hand, criteria structure the selection, on the other, they help applicants understand the characteristics of a project that is likely to be supported so that applicants can shape their own offer. This raises the following questions: what is the current contribution of evaluation criteria to integration policy implementation? What is the quality of the choices that can be made from the existing criteria and to what extent do they facilitate choices about projects which can most further integration?

In seeking to answer these questions, we examined project application evaluation criteria used by the SIF in 2002 through 2006. We set as tasks ascertaining the evolution of quality criteria and evaluating the existing system's strong and weak aspects in terms of providing possibilities for choosing high quality project content. The role of criteria with regard to possible applicants is twofold: on the one hand, criteria send signals about desirable content, on the other, very complex or very simple criteria can widen or limit the range of applicants. The potential project applicant in 2002 received very little information about how his ideas would be evaluated. The statute of the 2002 competition only indicates which realms will be evaluated, but does not explain in any detail the substance of the evaluation. In the 2003 PHARE competition, applicants are already told about the assignment of points for each criterion, and where the relevant information can be found in the grant application. PHARE 2006 explains the general thrust of the criteria (what is being sought for in the evaluation process) and the minimal number of points by subsection.

In compiling the numerical indicators of evaluation criteria from 2002 through 2006, one can see that the requirements became considerably more detailed: from three quality and six administrative suitability parameters in 2002 to 11 quality and 19 administrative suitability parameters in 2006. At the same time, opportunities for dialogue between applicants and the SIF grew, as the applicant could supplement insufficiently explained administrative information. One can conclude that the applicant had to conform to ever more criteria, 
which demonstrated the applicant's desired level of professionalism, but the evaluation process did not automatically exclude applicants with less experience, as in later years one had the opportunity to improve the documentation after submission.

The analysis of the best expert can be limited by criteria which are not oriented towards the identification and evaluation of elements of a successful integration project. The primary difference between a project evaluator and other types of programme or policy evaluators is that the former is forced to pose questions about the future ("will it promote...?"), while the latter deal with the past. In both cases, cause and effect are analysed and, in the case of projects, it is whether the activities proposed have a connection with the results predicted. If the basis of the activities is a faulty assumption about cause and effect, the desired changes cannot take place regardless of ideal organization, enthusiasm and perfect financial management. In accordance with modern evaluation theories, the quality of an intervention is one of the primary areas in which one must seek for answers about the possible attainment of a goal.

Thus, the share in the evaluation attributed to the logic of change should be rather high. For the share to adequately reflect the logic of change, criteria for identifying and evaluating it must focus the attention of the evaluator on the relevant field's most important mechanisms of change. In the case of integration, they have to promote the selection of activities which can reduce the divisions in society.

Analysing project evaluation criteria from 2002 through 2006, it is evident that the share of "quality" (or "content") criteria is large and over time even grew from 75 to 80 out of 100 points. Thus, an evaluation of the quality of the proposed solution technically carried much weight, and this is laudable.

The second issue is whether these criteria focus attention on the most important preconditions for change in the concrete policy area, here, contact between different social groups and the quality of that contact. Other significant aspects linked to contact are the possibility of potential applicants to address and reach the target audience and an understanding of this group's needs. ${ }^{26}$ Thus, the applicant should demonstrate knowledge about the target audience and the ability to engage in contact with it in such a way as to resolve the problem. Another important theme is the duration of the contact. Sufficient duration of the contact does not directly flow from the essence of the change envisaged: to convey information, episodic contact is sufficient, while changing attitudes or inculcating new skills requires longer contact. In the case of integration projects, the time dimension has particular importance which cannot be ignored.

26 "Programs cannot be evaluated in isolation from the problem settings and the people being served.” Posavac E., Carey R. (2003) Program Evaluation Methods and Case Studies. $6^{\text {th }}$ edition, Prentice Hall, pg. 57. 


\section{The Logic of Intervention in SIF Project Evaluation}

The criteria linked with the logic of intervention are directly and indirectly located in all three quality subsections: "Significance," "Methodology," and "Sustainability." ${ }^{27}$ In analysing the statutes of the competitions, one notes the following general characteristics:

- The share of methodology criteria grows (from 15 to 30 points);

- Over time there is a gradual increase in the level of detail in all subsections;

- The weight of the so-called "added value"(5 points) remained unchanged, which is an evaluation of the innovative nature of the solution proposed or the use of a tried and true solution;

- Up to four criteria can be used to define the problem, three to four for the possibility of influencing the problem, which in various ways ask the same question, do not stress different aspects that would allow identifying problems and their solutions more precisely, cause and effect, etc.

- The formulation of questions is often vague: "to what extent will it influence..."

A separate issue to be discussed is the target group and its involvement. The needs of the target group and contacts with it are the basis for the structure of the entire project. If the needs are not defined in a concrete and well-founded manner, if it is not indicated which aspect of the problem the project will address, or if the project does not work with those most affected by the problem identified, the rest of the project's structure may not be useful. Unfortunately, this area is insufficiently elaborated - only one to two criteria pertain to the target group's needs and, in more recent years, involvement. Even in the PHARE 2006 competition, precisely defining the needs of the target group is worth only five points out of 100 ! Theoretically, this provides the possibility of giving a high evaluation to a project which is not based on the clearly identified needs of the target audience.

It is positive that, with time, one finds in the section "Methodology" the criterion "involvement of the target group." The general trend of criteria development over time seems positive (except for the low weight given to good practices and innovation), which is evidently linked with the development of PHARE competition documentation. The weight of quality criteria and the level of detail increase, but in three areas of "quality" they duplicate one another with regard to the definition of the problem, the quality of the solution, and the logic

27 The authors considered indirect criteria to be those which posed apparently general questions 'will the Project make a contribution...', 'can an influence be predicted...', 'will it spur progress towards the goal of the programme?' Answers here also shape the logic of intervention, to wit, the question: how will the applicant address the problem and does it look as if s/he will succeed? 
of implementation. As of 2006, evaluators were given written explanations of the criteria, but they do not ask (any) specific questions about the preconditions for overcoming the ethnic divide, and thus, it is up to the evaluator to decide whether or not to search for them.

In order to evaluate projects more successfully, it is necessary to pose specific, focused questions which reflect good practice in specific types of projects and to identify the most important nodal points (particularly the type of contact, its content and duration), which would permit a more in-depth evaluation of the applicant's understanding of the logic of change. It is possible that general criteria permit overly frequent use of clichéd approaches and support for just about any activity, regardless of the problem, target audience and context.

Overall, one can conclude that the numerical share of quality criteria is high, however, they are quite generic,${ }^{28}$ and they do not focus the evaluator on the essence of the ethnic divide, mechanisms for overcoming it, and the suitability of the contact to the goal set. Thus, experts face a difficult task in evaluating the basis of the entire range of project activities - the applicant's understanding of the desired changes and the possibility of implementing them.

\section{Recommendations for Improving the Criteria}

1. A greater degree of detail for criteria reflecting the logic of intervention, including identifying the division to be influenced and the basis for believing why it is possible; characterize relations with the target audience.

2. Greater attention to these aspects of addressing the problem: is the duration of the target audience's involvement sufficient for attaining the goal? Is the direction of communication in accordance with the goal to be achieved?

3. Increased weight to innovative approaches and use of best practices.

Overall, it is necessary to pose directly the question: "Is there reason to believe that the activities proposed will lessen significant ETHNIC divisions in society?"

In order to draft such supplementary criteria, experts should be commissioned to work with SIF staff to develop a more focused filter for evaluating ethnic integration projects that might have broader applicability beyond Latvia. If such changes were implemented in the evaluation process, the SIF would

28 According to information provided by the SIF, the evaluation criteria were taken from the European Commission's Practical Guide to Contract Procedures for EC External Actions $\left(6^{\text {th }}\right.$ Grant). These are standard suggestions for any kind of grants competition. They are available at http://ec.europa.eu/europeaid/work/procedures/implementation/practical_guide/ index_en.htm. 
have the possibility of gathering essential information about the policy field and to adjust its activities accordingly over time.

\section{SIF Supported Ethnic Integration Projects, 2002-2006}

In this section, we characterize the quality of the outcome of the entire process analysed above. The analysis is limited by reliance on project implementation reports which described those aspects of the project requested by the SIF. Often, these reports provided the information we sought in only an indirect way. Though we conducted a quantitative analysis, the conclusions point only to general trends, as in many cases, information was insufficient to draw definitive conclusions. However, the lack of information is also significant, as it demonstrated which aspects the SIF was interested in. ${ }^{29}$

First, let us characterize the substantive direction of the projects and the target audiences, then turn to the issue of contact, which is very important in ethnic integration projects. Moreover, we will comment on the share of projects with contact in the context of strategies of separation so typical in Latvian society. Ethnic integration projects supported by the SIF from 2002 through 2006 reflect the potential diversity of the field. Measures were implemented in various sub-fields of ethnic integration, starting with the promotion of naturalization $(\sim 10 \%)$ and ending with the promotion of employment $(\sim 2 \%)$. As could be expected, a large share of the projects dealt with nurturing the cultural heritage $(\sim 30 \%)$ or promoting language acquisition ( $\sim 40 \%)$. Less popular areas of action were public policy in a certain realm (except education reform) $-5 \%$. Less than $10 \%$ of the projects dealt with ethnic integration of socially marginal groups.

There is diversity in the kinds of knowledge and training provided through projects: organization management, labour law, the constitution, local tourism, journalism, conflict resolution, civic participation, democratic development. The kinds of skills inculcated through projects were varied as well, though reference to these was rarer in the project final reports. Skills areas are both general, such as fostering a debate, drafting projects, computer skills, but also specific - creating costumes, preparing a play, creating a newspaper, flower arrangement, leading a tour, etc. This all testifies to the potential breadth and diversity of contact and communication. It is another question whether and how this potential was used.

A separate question must be asked about sensitive content - about questions shaping symbolic integration, which in Latvia's case are particularly

29 For example, the implementation reports from 2002 through 2006 did not foresee indicating the subfield of integration addressed by the Project, the field in which participants are gaining knowledge of skills, the manner of reaching the target audience, the involvement of the target group, the duration or manner of the contact, etc. 
important. The Integration Programme states that "an evaluation of historical circumstances" is "a precondition for integration," so that "the young generation's historical consciousness in particular does not become a barrier to the integration process." As research consistently demonstrates, the primary cleavages in Latvian society are differences in the sense of belonging among different groups, their attitude towards history, culture and identity questions (see Aivars Tabuns' chapter below). Thus, it was important to ascertain to what extent projects touched upon the symbolic dimension of values and attitudes towards controversial topics, while implementing a dialogue based on respect.

Out of more than 200 projects analysed, in fewer than twenty cases were measures oriented towards discussion of politically or psychologically sensitive topics (a sense of belonging, interethnic relations). This can be characterized as an avoidance of the symbolic dimension, a policy of silence. Unfortunately, this avoidance only deepens the divisions for which this policy was created and brings us back to the issue of whether the public is capable of spontaneously compensating for drawbacks in policy. Another uncomfortable topic is two-way contact and the contribution of Latvians to integration. If this topic was touched upon, it was not evident in the final reports for projects.

\section{Kinds of Participants and Activities}

The issue of the target audience is important, as the Integration Programme notes, "integration processes should not be promoted as mass measures to integrate social communities. They have to be individualized and concrete in relation to each person and situation." The project implementation reports show a wide range of target audiences from 17 individuals to half a million. Broad awareness raising campaigns were rather common: in about $1 / 3$ of all cases, all of society was the target audience for information (most often in the form of printed materials). About $1 / 4$ of all measures involved informing a concrete target group.

Other methods to achieve one's goals were the following: $1 / 4$ for creating an environment for the use of language (mainly through language courses), $1 / 3$ through education, $1 / 5$ through creating and demonstrating traditional cultural values. The most common types of activity are seminars, launches, occasional concerts, exhibits, excursions, the technical equipping of an organization. Only rarely was a web page created, a film shown or a competition organized.

Returning to the issue raised earlier about project target audiences, it seems that it would be beneficial if projects widely involved youth. Indeed, youth were a target group in one quarter to one third of all ethnic integration projects supported by the $\mathrm{SIF}^{30}$ In later years, reporting forms require indicating the age

${ }^{30}$ In earlier years there was no requirement to clearly indicate the age of the target group, so conclusions are tentative. 
of the target audience and it is possible to acquire a more precise figure of the share held by youth. It is important that, with changing funding priorities and funders, youth remain a priority in the SIF's work.

The path for reaching the target audience is an issue where we were unable to acquire a sufficiently clear picture and thus, can only comment on general trends. The reporting forms do not require indicating how a project organizes the target audience's opportunity to come into contact with the project, and this shows the importance of this aspect from the funder's point of view. About 1/5 of the projects contain indications that the beginning of the project is announced in the media. This is true particularly of language courses, in which a public announcement is a requirement for receiving a grant. In half the cases it could be concluded that the announcement is aimed at an open target group and theoretically, anyone can apply. In practice, the question remains whether the target group utilizes the channel chosen by the implementer of the project and whether the implementer can address his audience in a convincing manner. Providing information does not necessarily mean that information is received.

In about $1 / 5$ of the cases, one can conclude that the beginning of a project is announced to a concrete target audience (e.g., disadvantaged women who had already received advice from a lawyer or a social worker in the organization). However, here too, it is not possible to state with certainty that such a manner of addressing the target group is effective and that those who can receive the greatest benefit from the project are reached.

\section{What Kind of Contact Took Place in the Projects?}

Taking into consideration that certain kinds of contact are the main precondition for a change in the perception and attitudes of various groups, the contribution of the SIF in the realm of ethnic integration should be sought in the existence and character of such contact. Ours was the first attempt to gather information about inter-group contact and communication from between the lines of project final reports in SIF funded projects, and on some issues, our research team did not find a consensus. ${ }^{31}$ Thus, we discuss the existence of contact only as a general trend and further work on the methodology of analysing contact is necessary. To recall our earlier considerations, we sought two different signs of person-to-person contact: its two-way character (equal status among contact participants) and a series of contacts or encounters.

Moreover, another important aspect was whether the initiative came from the group itself or "from above," as initiative from the group itself could be seen as more closely linked with people's true interests and motivation for common

31 All final reports were coded by two researchers (pairs of researchers were created randomly out of a total of five researchers) and the consensus level among coders varied. We mention only those cases in which there was a high degree of consensus - around $80 \%$. 
action. In other words, such an initiative might be more sustainable. At the same time, if target groups are involved "from above," such contact may not be completely equal and its sustainability might be limited, as the participants themselves did not create the agenda.

In analysing project implementation reports, the research team was rather united on whether there was face-to-face inter-group contact: this was the case in about $30 \%$ of all cases. Of these cases, about $2 / 3$ were series of events, not episodic contact, so about $\mathbf{2 0 \%}$ of the projects had face-to-face contact which took place more than once.

Since one of the preconditions for a change in attitudes is the equal status of the contact participants, we sought signs of such equality in the activities that took place (schoolchildren working together, people from the local community, etc.), instead of an event in which a person of higher social status repeatedly provides information to those of a lower status (lecturer and auditorium). For the analysis, we used the question "What was the nature of inter-ethnic contact: one way (one group dominates), two-way (with the relative dominance of one group) or mutual (egalitarian)." An example of mutual, egalitarian contact would be a student exchange, in which both sides learn about one another.

Which cases do we consider to be successful and which are less suited to attaining the goals of the Integration Programme ${ }^{32}$

- Ethnically diverse youth groups with participants from various regional schools are created; in the course of the project, the youth learn to accept others, analyse their action, and cooperate with others.

- A similar number of children from Russian and Latvian folklore groups prepare a new folklore programme, get acquainted with minority, Latvian and Latgallian culture.

- Creative workshops, non-traditional sports and art activities for youth from various ethnic and social groups.

- Bilingual seminars in all the schools of a parish about topics that are of interest to youth.

Events such as these have mostly involved youth. Projects with adults as the target audience involve face-to-face contacts more infrequently. One could reason that adult contact takes place naturally in the workplace. However, a significant number of projects were supported in which the contact potential was not utilized, in other words, the impact on integration was less than optimal.

There were cases in which two-way contact was not essential, as the measure responded to an acute lack of information (without which further integration was not possible) or envisaged the possibility of expressing one's view to the state administration. Successful examples include: a preparatory programme

32 Project details have been changed, these are composite portraits that unite variations on a theme. 
for naturalization, a hotline about the education reform, a seminar for minority families about "Changes in the education system and my child." 33 Moreover, it should be acknowledged that it is altogether laudable that some minority cultural projects are oriented towards the first step (strengthening oneself), as insecurity about one's own identity hinders contact. ${ }^{34}$

Taking into consideration these "particular cases," it is possible to estimate that face-to-face contact in projects supported from 2002 through 2006 could be justifiably absent in $25 \%$ of all cases. However, together with the approximately $20 \%$ of all projects including contact, that raises the question of the contribution of the remaining half of all supported projects towards easing the ethnic divide.

At the same time, it is necessary to note that such a result reflects a broad trend in Latvian society. Both Latvians and minorities feel threatened and compete with each other, which strengthens the desire for separation. As researchers at the Baltic Institute of Social Sciences have noted, such strategies of separation are characteristic for $48 \%$ of ethnic Latvians and $17 \%$ of persons belonging to minorities. ${ }^{35}$ It can be assumed that the project ideas that were supported partially reproduce the attitudes and communications strategies that are prevalent in society, though this issue with regard to those who submit projects and their ability to offer social innovations requires further research.

An analysis of the projects casts doubt on the myth of the self-organizing society, as in most cases projects reached their target audiences "from above." In the case of school projects, this is not surprising, as only legal entities can submit projects. However, "adult" projects were also usually submitted by institutions that deal with the target audience as part of their day-to-day duties (e.g., a local government) or the character of the measure top-down (a lecturer creates a course and offers it to an audience). ${ }^{36}$ The authors considered active involvement of the target audience to have taken place if it was involved in creating the content of the measure, implementing it and evaluating it - however, implementation reports mention this aspect only rarely. It is possible that other project documentation indicates ways in which the target audience was involved, but this is not considered vital information in the project implementation reports from 2002 through 2006.

33 About $15 \%$ of projects were devoted to naturalization and the education reform.

34 Since support for minority cultural organizations has been long-term and systematic, such projects could be about $1 / 3$ of all cultural-heritage related projects

35 Šūpule and Zepa (2006), 'Etniskā apdraudētība kā dzīves kvalitātes aspekts,' Dzīves kvalitāte Latvijā. Riga: Zinātne, pg. 362.

36 To make this question more concrete, we tried to ascertain the level of involvement of the target audience in each type of measure, but the implementation reports often did not have sufficient information to draw definitive conclusions. Evidently, this aspect was not considered to be that important. 


\section{The Special Case of Cultural Contacts}

The practice of co-existence of various ethnic cultures in the context of one national state requires a separate analysis in SIF supported projects. As noted earlier, the Integration Programme leaves this controversial issue in the hands of the implementers. ${ }^{37}$ In accordance with the approach of John Berry, which has also been applied to Latvia, cultural contact takes place when the group is sufficiently secure about the possibility of preserving its heritage culture and this is a necessary precondition for readiness to communicate with another group. At the same time, security derives from one's ability to live in accordance with one's culture and recognition of it in the public sphere. ${ }^{38}$

Latvia's situation is interesting in that both the minority and the majority feel threatened. ${ }^{39}$ Thus, creating security has to take place from all sides at once, which is indeed a great challenge. The sense of threat logically leads to the priority of self-assertion, not dialogue. For example, research led by Elmārs Vēbers entitled Ethnopolitics in Latvia characterizes cultural societies as being small organizations with an aging membership (45-60 years) whose events reach a small audience ("members of the society, their families and friends"), pointing out that "a regular system of cooperation between Latvian and minority culture has not been created." Pēteris Laķis once called this the "tradition of parallel monologues." 40 This raises the question as to the type of interaction that should be promote in Latvia, where the majority feels threatened and the minority feels unrecognized. There is no clear answer to this question, but it is possible to see what kinds of cultural interaction were proposed by society and gained support from the SIF.

About $1 / 3$ of all SIF supported projects were in the realm of the cultural heritage and language, including organizing cultural events, preservation of the heritage in various ways, public education, etc. The types of activity included seminars, presentations, concerts, exhibits, excursions, and in certain cases, competitions and the creation of several web pages about the ethnic culture of different groups. If such activities were aimed at youth and included intercultural interaction, the contribution of these projects to integration would be considerable. However, the basis for optimism is rather weak, as much research suggests that minority cultural societies have not been very successful at attracting youth. From the project implementation reports, one concludes that often the

37 The Integration Programme suggests unifying on the basis of the Latvian language and culture, which requires minorities, who have their own ethnic culture, to live in a situation of cultural conflict. This has been studied by a number of sociologists in Latvia (e.g., Zepa, Korolsova, Rungule), who have pointed to the difficulties of youth in the process of identity formation.

38 John Berry, presentation in Riga at the conference, 'Intercultural Relations in Culturally Diverse Societies: Revisiting the Multiculturalists’ Approach,' 7 October 2008.

39 See, e.g, Brigita Zepa, ed. (2006), Integration practice and perspectives. Riga: BISS.

40 Elmārs Vēbers, ed. (2000), Integrācija un etnopolitika. Riga: LU FSI, pg. 390. 
activities were self-contained and that demonstrating one's culture takes place with regard to that part of the public which is already involved or informed. In many cases, these projects represent self-assertion, not dialogue. This cultural activity is usually limited to traditional culture, especially festivals. Contemporary cultural activities might have a greater potential to become forces for dialogue and creative transformation. ${ }^{41}$ Unfortunately, SIF supported projects from 2002 through 2006 do not touch upon contemporary culture. This is an unused resource which could be addressed through a proactive approach.

A significant integration instrument is the Latvian language. SIF support for language has been primarily in the traditional field of language courses. Some projects tried to develop informal, creative approaches aiming to create an environment for use of the language, particularly in Latgale's schools, where youth were given the opportunity to use the Latvian language in practice through various joint activities (interest clubs, etc.). Such measures definitely hold the potential of being effective and should be continued.

The Integration Programme rather unambiguously points in the direction of cultural dialogue. In practice, both parties to a dialogue have to first acquire a sense of security, otherwise there is a risk of merely self-assertion and strengthening one's own territory. In most projects that were proposed and received support, the latter appears to have taken place, continuing the tradition of "parallel monologues." Culture too often is interpreted only as traditional culture.

From the analysis of cultural projects, it must be concluded that the emphasis on the ability of society to organize by itself and offer effective, topical solutions does not always work. Without a proactive approach to raise awareness about new approaches, potential implementers reproduce earlier used models. Very few projects touch upon issues related to history or identity. The possible reasons may be that potential applicants are not ready to address more complex issues or they did not view the SIF as an appropriate partner.

In addition to planned results and benefits, projects sometimes yielded broader social benefits, which should be assessed positively. These benefits can be seen in three areas:

1) the range of partner institution and the broadening of social networks,

2) the creation of new initiatives (new forms of self-organization etc.), and

3) a greater understanding about certain topics (e.g., one local government's report suggests that for the first time, it gained insight into issues affecting non-citizens in the community).

${ }^{41}$ Nils Muižnieks, ed. (2007), Nacionālo minoritāšu konvencija - diskriminācijas novēršana un identitātes saglabāšana Latvijā. Riga: SPPI, pg. 52. 


\section{Summary and Conclusions}

The SIF was created in 2001 to further the implementation of the Integration Programme. Thus, in assessing the contribution of the SIF to ethnic integration, the starting point is the quality of the goals and achievement mechanisms contained in that policy document. As the analysis here and elsewhere in this book attest, the Integration Programme is a rather thankless document as a guideline for action. Though the Integration Programme stresses important goals for Latvia (two-way integration and cooperation among all groups, overcoming mistrust, agreeing on a common understanding of history, etc.), it has serious drawbacks. The goals are not prioritized and certain issues related to overcoming the ethnic divide are not elaborated upon beyond the introduction. The origins of this divide, its depth and the means for overcoming it are specific to Latvia and are left by the Integration Programme to the policy implementation phase for clarification.

The management of the SIF chose to develop the institution as an administrator of financial mechanisms by creating the appropriate supervisory, control and audit systems and getting EDIS accreditation, which permitted the decentralized administration of significant EU programme funding. In choosing to administer these funds through open and closed grants competitions, the SIF was successful in achieving a certain level of institutional autonomy. At the same time, this meant that primary model for implementing ethnic integration policy (as far as the SIF was concerned) became support for initiatives "from below" in the form of projects. Thus, the driver of policy was the "supply" from society.

The SIF adhered broadly to the content of the Integration Programme and nominally covered all the topics therein, and since 2002 organized grants competitions with funding from the state budget, as well as the European Union. In accordance with the results of the competitions, the best projects offered by applicants were supported. This mechanism was considered successful by both the SIF and the Integration Secretariat, whose leadership both stressed that this allowed the public to offer its vision of integration.

The model of supporting projects has both plusses (the aforementioned possibility to support bottom-up initiatives) and drawbacks - it does not cover the whole range of topics, those producing the supply of projects have their own limitations linked to institutional stability and competence, and certain thematic areas may lack appropriate potential implementers altogether. The most controversial ethnic integration topics were reflected in projects only episodically e.g., issues of history are practically not addressed, nor are the role or task of Latvians in the integration process. This may be partially due to the image of the SIF as a "conservative" state institution - certain Russian-speaking NGOs have not opted to participate in grants competitions.

A distinct issue is the quality of the initiatives from below. Preliminary analysis suggests that the project supported often reflected a "top-down approach." 
The manner in which the target audience is involved in creating the content of the projects should be examined far more critically. The projects supported until now lead one to question whether the perception of the "self-organizing society" is a myth or to use this concept in a more restrained manner. The model of supporting initiatives "from below" could benefit from several improvements - the promotion of certain themes in a proactive manner and a re-evaluation of the potential of implementers to promote innovation. There were cases in which topical issues were addressed in a pro-active manner - promoting the civic activity of parish inhabitants, focusing employment and language training activities in places where non-citizens and minorities live, and others.

The options available to implementers through competitions organized by the SIF have been quite broad and have become more detailed over the years. The process of evaluating the "supply" of projects was organized in accordance with standard European Commission guidelines and gave a high share of points to quality without focusing on specific factors promoting ethnic integration, identification of the needs of the target groups or innovative activities.

In analysing the potential impact of projects supported by the SIF on ethnic integration, the theoretical basis used here was Allport's inter-group contact theory. This is topical in Latvia's situation, as strategies of separation are widespread in Latvian society, particularly among ethnic Latvians. In compiling the results of the project analysis, I conclude that approximately $20 \%$ of the projects supported from 2002 through 2006 included the contact which had the potential of leading to changes in attitudes. In another portion of the projects, such contact was not essential (naturalization, informing about the education reform), though considering these projects, in more than $50 \%$ of all cases there was no face-to-face contact.

Thus, the overall conclusion about the contribution of the projects supported by the SIF to ethnic integration in 2002-2006 is the following: though the projects supported include a range of successful models, particularly the projects aimed at youth and activities promoting the participation of parents in the process of changing the education system, in about half of the projects the lack of face-to-face contact reduces the potential for a positive impact.

The working procedures and system of the SIF operate professionally and, over time, a significant capacity in attracting and administering funding was developed. A more focused selection of projects (searching for signs of contact and self-organization) and elements of a proactive strategy could lead to better results in future work.

Given recent institutional changes and new integration challenges, it is an appropriate time to spark a public debate about the SIF. It appears as if the SIF is moving away from the issue of social integration and moving into new thematic areas because there are new financial opportunities. There is a need to define which ethnic integration issues are still topical and which institution will push the policy agenda forward. 
In implementing bottom-up projects, it is necessary to consider the following:

- The symbolic aspects of integration (history, culture, national identity) will not disappear and some state institution should address them. If the SIF is not the optimal partner for addressing these issues, which institution is?

- Projects revolving around civic participation should include and stress the dimension of inter-ethnic cooperation.

- Youth should continue to be a priority target group, particularly in activities related to civic participation and dialogue.

- If the content of ethnic integration is determined by the "supply" proposed by potential implementers, it is necessary to ensure the presence of inter-group contact, sufficient duration of the contact, and the initiative of the target group.

Though ethnic integration still appears to many to be abstract and artificial, processes of group segregation and mistrust persist. Moreover, when the economy recovers, new immigrants will soon be knocking on our doors, forcing us to re-evaluate once again the creation of divisions and the way to lessen them. 


\section{Part II}

Integration in Various Life Realms 


\section{Citizenship, Participation and Representation}

Ilze Brands Kehris

\section{Introduction}

Inclusion through the full, equal and effective participation of all members of society in social, economic, cultural and political life is a core aspect of integration. To reach equality of participation, the unequal status and power of majority and minority groups have to be programmed into the equation, and special attention has to be paid to the participation of minorities and migrants in political decision-making processes. The right to effective participation is one of the core rights of national minorities, as the codification of this principle into Article 15 of the Council of Europe Framework Convention for the Protection of National Minorities indicates. The rationale for treating participation as a key aspect of integration goes beyond minority rights and has a solid basis in the democratic citizenship literature. ${ }^{1}$

The arguments against an exclusive focus on electoral participation and resulting majority rule are well known, and participatory democracy as the model has also been confirmed outside the academic literature as a general EU policy approach. Broad participation not only provides legitimacy to the polity and the decisions taken, but the inclusion of diverse views in policy deliberations also improves governance and outcomes. The imperatives of deliberative democracy point to the importance of including such pluralism in the public debates preceding the election of representatives and decision-makers, but also in the "horizontal deliberations" within elected bodies - hence the need for meaningful representation of minorities within structures that otherwise would be dominated by the majority. Such representation can contribute to the substantive representation of the interests of these diverse groups, which is the necessary corollary to effective participation. In a further distinction of representation the deliberative function has also been distinguished from the "aggregative function" - the situation when the interests of the groups represented are not only deliberated in the general forum of decision-making, but are taken into account where the decision has direct bearing on those interests.

1 Will Kymlicka, Wayne Norman (2000), Citizenship in Diverse Societies. Oxford: Oxford University Press. 
It is generally accepted that integration is a two-way process, whereby newcomers/minorities and those already settled/majority mutually adjust existing frameworks and institutions. In the political arena such a process can only take place through participation of minorities in the deliberative and decisionmaking processes, where they can make claims that can be accommodated in a mutually negotiated process. The stress on minority rights to participate is an implicit acknowledgment that structures and procedures - indeed power - will favour the majority. Minority rights are thus necessary for genuine democratic participation. At the same time, the participation of all and a pluralism of perspectives is in the interest of all, since this increases the chance for better outcomes and represents good governance.

The inclusion into citizenship and political participation of minority groups is not an option, but a necessity for the integration of society, as inclusion works against marginalization, fragmentation through isolation and "racialization" of social relations. Full and active participation in the larger society, while retaining a minority identity if desired, enhances a sense of belonging to a common overarching citizenship identity. ${ }^{2}$ Christian Joppke argues that we are witnessing the decline of particularistic citizenship identities connected to nations, and a "lightened" citizenship based on universalist content is emerging. If this is the case, inclusion poses no problems as the entity is more open to diversity, but the potential threat to a common sense of belonging and cohesion can be addressed by going beyond the procedural liberal democratic citizenship to a thicker, value-based version of liberalism as identity, which can replace national and particularistic belonging to the state. ${ }^{3}$ Even for those who argue that the national dimension of identity remains, the uniform acceptance of the principle of non-discrimination also entails an acceptance of diverse personal identities within a common overarching identity.

If the basic object of overarching belonging is the state, then it is critical to analyse citizenship, including not only citizenship as a legal status signifying membership in a polity. All three generally accepted dimensions of citizenship must be analysed: political and legal status, the legal rights and duties and "the individual practices, dispositions and identities attributed to, or expected from those who hold the status." "Political integration includes not only access to political status, rights, opportunities and representation on an equal basis, but also the activities and participation of people themselves, with an acceptance of the laws, institutional framework and political values in place. ${ }^{5}$

${ }^{2}$ Ibid.

${ }^{3}$ Christian Joppke (2008), 'Immigration and the identity of citizenship: the paradox of universalism,' Citizenship Studies, Vol. 12, No. 6, December, pp. 533-546.

${ }^{4}$ Rainer B Bauböck (ed.), (2006), Migration and Citizenship. Legal Status, Rights and Political Participation. Amsterdam: Amsterdam University Press, pg. 16.

${ }^{5}$ Ibid., pp. 11-12. 
Political integration involves several dimensions, including political participation, mobilization and representation. The mere existence of rights cannot suffice when evaluating political integration of minority and migrant populations. It is necessary to examine the implementation of these rights and participation in various dimensions, including voting, standing for election, taking part in the work of elected bodies, making political claims and discussing these through public debate, and involvement in civil society organizations and protest actions. Integration involves the provision of rights, the removal of obstacles and barriers to the exercise of these rights to provide real opportunities for participation, including the pro-active encouragement/activization "from above" and mobilization "from below" of political engagement by minority populations. Since "effective citizenship depends on structural opportunities for participation and a widespread disposition to use them," promoting participation by minorities is logical. ${ }^{6}$ Promoting political participation thus involves providing not only rights and opportunities for participation, but also incentives for political participation. ${ }^{7}$

Although the integration literature and policies in Europe generally target migrants, the question of whom integration addresses and whose participation should be enhanced is not as clear as it may seem, quite apart from the general neglect in practice and policies of majority adaptation implied in the principle of two-way integration. Does integration address third country nationals who are permanent residents only (since EU citizens arguably no longer qualify for "external" status)? Or should integration concepts and policies address all who are present beyond short visits on the territory of the state, i.e. including temporary residents? What about refugees and vulnerable asylum seekers? What about irregular migrants? Although a legal perspective focusing on the rights that come with a certain legal status, be it citizenship or residency, automatically excludes irregular migrants, these persons clearly have a presence in society and most also contribute by working (even if not by paying taxes). The focus on expelling all who do not have legal status may create the illusion that they are already "on the way out", but most estimates indicate that there are stable or growing numbers of irregular migrants in all EU member states. If we do not reasonably expect voting rights to be provided to irregulars, then a case can credibly be made that there is room for authorities' consultation with this group of vulnerable persons, since the state remains responsible for a minimum level of respect for rights and provision of services (emergency health, education of children) of all on its territory. Nevertheless, this chapter will follow the generally accepted practice of focusing on minorities and (regular) migrants for integration purposes. In Latvia, this means not only the relatively

${ }^{6}$ Alexander T. Aleinikoff and Douglas Klusmeyer (2002), Citizenship Policies for an Age of Migration. Washington, D.C.: Carnegie Endowment for International Peace, pg. 42.

7 Ibid., pg. 54. 
few third country nationals, but primarily the former Soviet citizens who are non-citizens, as well as for some purposes the national minorities, including those with naturalized citizenship status.

Exclusion from citizenship and therefore from full participation represents a democracy deficit. The citizenship and integration literature, largely relating to migration, increasingly has focused on the inclusion of the second generation of migrants (i.e. born on the territory of the receiving state, but of parents who were immigrants) as a "litmus test" for the openness of the integration regime. ${ }^{8}$ At the same time, the denial of reasonable political rights to non-citizens (e.g. voting rights at the local level) goes against the goal of closing the rights gap between permanent residents and citizens declared by the European Union since the 1999 Tampere Council. In contrast to the view not infrequently heard in Latvia that there is a choice between facilitating access to citizenship through naturalization or increasing the rights of non-nationals, the premise here is that both aspects are necessary elements for the promotion of effective political participation. Encouraging full membership in the polity by naturalization should not affect the willingness to promote other forms of political participation of those who cannot or choose not to naturalize. The view that providing too many rights to non-citizens will make them more passive in acquiring citizenship is not born out by empirical studies, which tend to show that political engagement in its various forms (civil society, local level participation) provides "training" opportunities and works to encourage further participation. ${ }^{9}$

Integration indicators clearly have to go beyond the legislative framework to include measurements of practice. At the same time, defining indicators beyond rates of naturalization, proportionality of representation in elected bodies and the like is enormously challenging, since the quality of the inclusion and participation should also be measured, and this will inescapably include subjective elements and qualitative methodologies. The lack of comparability of any potential indicators, since not only their content but their very definition is context-dependent, does not take away from the usefulness of a framework of indicators to structure an assessment of the political integration of society.

\section{Citizenship}

Considering the large number of persons in Latvia who have the specific status of non-citizen, it is understandable that the focus concerning access to citizenship has over the years been almost exclusively on this group. For the purposes of integration - especially in the long-term, when new immigrants

8 Ibid.

9 Rinus Penninx, Karen Kraal, Marco Martiniello, Steven Vertovec (eds.) (2004), Citizenship in European Cities. Immigrants, Local Politics and Integration Policies. Aldershot: Ashgate; and Aleinikoff and Klusmeyer (2002), Citizenship Policies in an Age of Migration. 
will arrive - and also for a fuller understanding of the approach to citizenship overall, it is necessary to broaden the vision to include access to citizenship for all long-term residents in Latvia. Although access to citizenship is guaranteed through descent, a measurement of integration will have to include also access for other members of society, including the openness of the state and society to newcomers and the possibility for newcomers to become full members of society.

The Citizenship Law adopted in 1994, as amended in 1995, 1997, and 1998, determines who can register as citizens and who can access citizenship through naturalization or registration or special procedures, and also defines the main procedures for naturalization. The Law on the Status of Those Former USSR Citizens Who Do Not Have the Citizenship of Latvia or That of Any Other State was adopted in 1995, and determines the special status of "noncitizen" for those former Soviet citizens who were registered as living on the territory of Latvia on 1 July 1992, or if their last place of registered domicile before that date was on the territory of Latvia and their children - provided that they have no other citizenship (Soviet military personnel who retired after 28 January 1992 excepted).

The status and rights of residency of persons other than citizens and noncitizens, who have the right to permanent residency in Latvia, are determined by the Immigration Law, which sets the basis for access to the territory of Latvia, as well as to residency and permanent residency. ${ }^{10}$

Access to residency for third country nationals requires proof of subsistence means and health insurance, and a work permit for employment if the residency is temporary. EU citizens and their family members, also European Economic Area and Swiss citizens, are governed by other, EU-compliant regulatory legislation, but for residency beyond 90 days they also require proof of sufficient financial means and health insurance. Access to permanent residency requires a five-year period of continuous legal residency, sufficient income and health insurance, as well as proof of knowledge of the state language at level A2.

The status of EU permanent resident also requires this level of Latvian language proficiency. Since the EU Council Directive 2003/109/EC on long-term resident third country nationals was applied also to Latvia's non-citizens, the regulations adopted at the national level on procedures to acquire EU permanent resident status also apply to Latvian non-citizens, just like third country nationals, despite the fact that the former are permanent residents of Latvia. The language requirement, although permitted under EU regulation as additional "integration conditions," has made this status less interesting to Latvian

10 The status of asylum seekers, refugees and persons with alternative status or under subsidiary protection is set in the Asylum Law, and the status of stateless persons is set in the Law on Stateless Persons, but these persons' residence rights are still determined through the Immigration Law. 
non-citizens, as by passing similar language tests and a history test, they can become EU citizens by acquiring Latvian citizenship.

Access to territory and residency are rights with various levels of restrictions for different groups. Thus, even if access to citizenship is provided based on a five year permanent residency period, the road to permanent residency is not necessarily readily accessible, especially for third country nationals. Although the number of persons in Latvia who do not have permanent residency is not very large, over time an increasing number of such persons, who may face difficulties in accessing this residency status, would potentially be a negative integration indicator.

Since the basic guiding principle for the development of Latvia's approach to citizenship has been legal continuity, there has been a strong stress on ius sanguinis in citizenship legislation. Thus, descendents of citizens of Latvia on 17 June 1940, who have registered as such, are citizens. There is privileged access to citizenship based on ethnicity, as Latvians and Livs whose permanent place of residence is Latvia, who do not have citizenship of another state or have an expatriation permit from a state of previous citizenship are to be considered holders of Latvian citizenship according to the law. The predominance of ius sanguinis remains evident, even if the 1998 amendments entitling children born on territory of Latvia after 21 August 1991 to citizenship of Latvia through registration added a certain element of ius soli. Nevertheless, birth on the territory of Latvia has to be accompanied by other elements - living on the territory of Latvia and parents who are either non-citizens or stateless.

A ius soli element is also found in the entitlement to citizenship of persons with permanent residence who have completed a full educational course in general education schools in which the language of instruction is Latvian, if the parents of such a person do not hold the citizenship of another state. A similar entitlement exists for foundlings and orphans living in Latvian orphanages or boarding schools. In the broadest sense, the mere possibility of naturalization based on a five-year period of permanent residency, including newcomers, is an element of ius soli. Although the mix of ius sanguinis and ius soli elements is more the rule than the exception in today's Europe, the access to Latvian citizenship based not on descent, but on residence is in principle an indicator of a certain openness to inclusion, thus a positive criterion for integration. The link to schooling in Latvian schools is a particularly interesting element, and also less common, with connotations of integration.

The non-citizen, in Latvian terminology, is thus not any third country national, but a former Soviet citizen with a right to reside permanently in Latvia. Non-citizens have a number of rights set in Latvian laws, and their position is considered closer to that of citizen than to that of other foreign nationals or stateless persons, as shown by the consular protection of the state extended to non-citizens and the right to return to Latvia, and as reiterated on several occasions by the Constitutional Court of Latvia. Non-citizen status generally gives 
the holder access to the naturalization procedure and he or she can become a citizen upon the fulfilment of the material and procedural requirements for naturalization.

The Citizenship Law includes a list of exclusion criteria for access to citizenship through naturalization. This list includes those with a criminal record in Latvia or in another country at the moment the Citizenship Law entered into force, those who acted against the independence of Latvia, the democratic parliamentary structure of the state or against the existing state power in Latvia with unconstitutional methods, if this is confirmed by a court decision, or those in the service of a foreign army or security services (or police) - prerequisites which can be found also in several other European countries' laws. There is in addition a rather extensive list of former activities relating to the specific historical circumstances in Latvia precluding the right to citizenship. These factors include having expressed fascist, chauvinistic, national socialist, communist or other totalitarian ideas or having incited to racial hatred of discord, if this has been established through a court decision; being an official of a foreign state power, administration or law enforcement institution. The largest groups excluded permanently from naturalization are probably those persons who have chosen to live in Latvia right after the demobilization from the USSR army and who did not have permanent residency in Latvia before entering the service of this army. Likewise, persons who have served in the KGB or the security services of a foreign state, if this fact has been established through the order foreseen by law, are not eligible for citizenship. Finally, persons who after 13 January 1991 have acted against the Republic of Latvia by participating in various specified pro-Soviet organizations are also barred from naturalization.

As the lengthy list illustrates, care has been taken by the legislator to ensure that persons connected to the Soviet military, to Soviet security services as well as persons remaining within pro-Soviet civilian structures related to the Communist Party, are excluded from citizenship - although their permanent residency is not called into question. Although estimates of the number of persons affected vary, the probable range is several tens of thousands of persons, some 1-3 percent of the population. These persons' right to a citizenship - a human right, albeit a lesser known one - is not respected in practice. Moreover, the exclusion of these persons from eligibility in principle, although part of the state's right to set its own citizenship requirements, is presumably based on national security considerations and was arguably legitimate and proportional upon the reestablishment of independence. Like the lustration laws preventing similar groups from political participation, the passage of time should ease security concerns, and the effectiveness of this measure as well as its proportionality should be questioned. Additional elements to take into consideration are the unequal treatment of these persons, based on their place of origin, compared with those Latvian citizens by descent that have served and been active in the same Soviet structures, but are not limited in their access to Latvian citizenship. 
As an indicator for integration, the exclusion of groups of persons who reside permanently on the territory of the state from access to citizenship is undoubtedly a negative phenomenon.

After having resided on Latvian territory for a five year period while holding a permanent residence status, a person is eligible for naturalization as a citizen through the general naturalization procedures. The Citizenship Law prohibits dual citizenship for persons naturalizing. At the same time, the same article goes on to state that in case a person is considered also a citizen of a foreign state by laws of that state, then in the legal relation with the Latvian state the person shall be considered solely a Latvian citizen - thus allowing for the possibility that a person may in fact hold dual citizenship.

The analysis of citizenship legislation shows that although Latvia has a relatively liberal citizenship regime, there are other aspects which make this legislation more restrictive. The permanent exclusion of certain groups, as well as restrictions on access to territory and residency for third country nationals, are examples of such factors. The requirement to pass tests and language requirements at a higher level than several other EU member states are also illustrations, while the continued predominance of ius sanguinis elements also point to a possible lack of openness towards full inclusion of newcomers, although naturalization is provided for under specific circumstances. The lack of clarity on dual citizenship adds uncertainty, which will ultimately be determined by case law interpretation or by amendments to citizenship legislation.

\section{Naturalization and Registration of Citizenship}

On 1 July 2009, out of 2.3 million inhabitants, 351,435 persons were noncitizens, representing $15.6 \%$ of the population. Although this is a significant decrease from the early 1990 s, when a third of the population were former Soviet citizens who were not descendents of Latvian citizens, it should be noted that the largest decrease has come from emigration in the first years after independence of persons with weak links to Latvia, and natural decline through death (the non-citizen part of the population includes a higher share of elderly persons).

Altogether, over 130,000 applications for naturalization have been made since 1995, when the process started, and there were in December 2009 132,870 naturalized citizens of Latvia (including 13,806 children who were naturalized along with their parents), indicating a high rate of positive decisions. Application rates for naturalization have gone through two peaks - one in the period following the liberalization of legislation at the end of the 1990s, and one around the time of Latvia's accession to the EU. The highest number of applications received came in 2004 with over 21,000 submissions. However, the decline in naturalization applications since then has been dramatic, with a low point in 2008 , when only 2,600 applications were made, which has only marginally increased in 2009 to 
3,470 . With this rate of naturalization, the problem of a large share of non-citizens among the population will remain for some time.

\section{Table 1. Naturalization Applications}

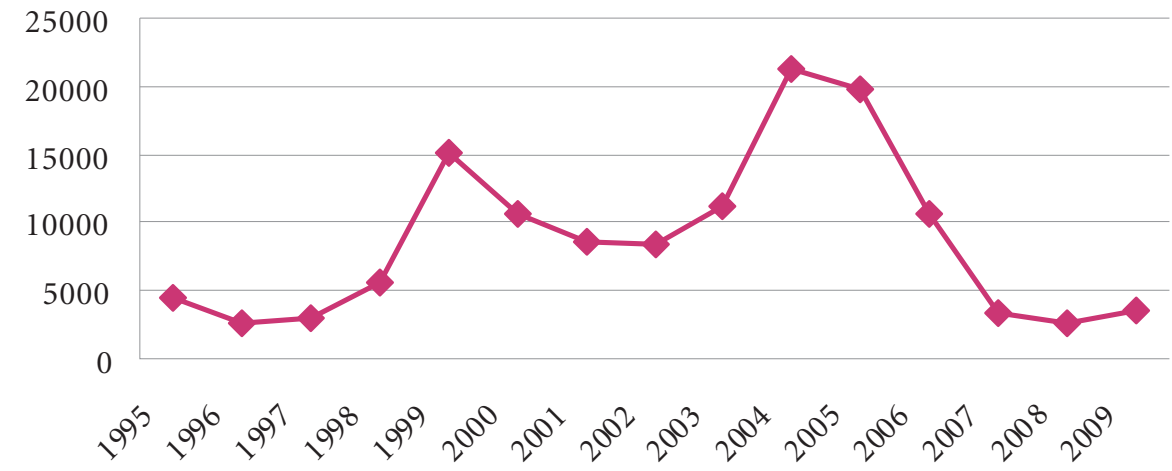

Source: Naturalization Board data.

Table 2. Naturalization Applications by Gender 1996-2009

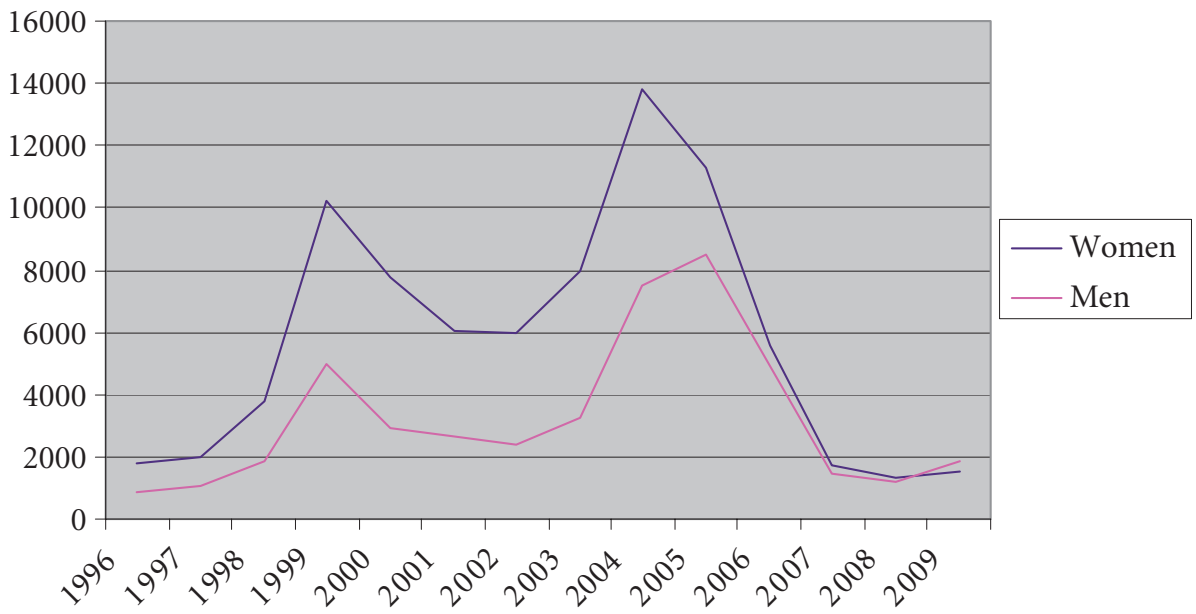

Source: Naturalization Board data.

Interestingly, there have been substantial variations in the gender balance in applications and naturalizations over the years. The cumulative figures since naturalization started in 1996 until the end of 2009 show that $63 \%$ of all naturalization applicants have been women. However, if in the first decade or so, the ratio of women to men was relatively stable at two thirds to one third, then since the mid-2000s there have been more or less similar number of applicants from the two sexes, while in 2009 , for the first time, there were more men applying for naturalization than women.

Although these changing trends require detailed investigation, there is no a priori indication that women face greater obstacles in accessing naturalization. 
As could be expected, the biggest share of naturalized citizens are of Russian ethnicity, who have submitted $68 \%$ of all naturalization applications in the 14 years since naturalization started, which corresponds to their share among the non-citizens of Latvia (on 1 July 2009 66\% of non-citizens were Russian). ${ }^{11}$ The next largest ethnic group to naturalize is the Belarusians, with over $10 \%$ of all naturalization applications (with a share among non-citizens of $13 \%$ ), followed closely by Ukrainians ( $9 \%$ of all applications, $9.5 \%$ among the non-citizens).

There do not appear to be any great differences in access to citizenship according to ethnicity when the largest applicant groups are compared. The application and fulfilment of criteria by third country nationals is at present difficult to ascertain, in view of the fact that this group is still very small. It could be, in the future, that more attention needs to be paid to potential difficulties in fulfilling some of the criteria for certain groups. It is not inconceivable, for instance, that lacking the exposure to the Latvian language that most non-citizen applicants have had for many years, and with increasing linguistic distance between Latvian and the language of origin of the applicant, the language exams and expected proficiency level would be harder to attain.

Even if the rate among those who are qualified to apply is low, the rate of naturalization among those who apply for naturalization is high, indicating very few rejections of those who go through the process. Nevertheless, in the last few years a trend for an increased failure rate at exams has become evident. Thus, for history exams the failure rate of below one percent in 2000 has over time increased to over ten percent, and in the last two years even to $18 \%$. The failure rates for language exams were always relatively higher, starting in the same period at about $10 \%$, but increasing to $20 \%$ in since 2006 , and reaching an all-time high of $39 \%$ in 2009 . These dramatic changes over the last decade, and in particular over the last five years, require urgent investigation and analysis.

Although an applicant who fails the exam can retry, a tightening of legislation in 2006 increased the time period needed before a second test. For language exams this period is now 6 months, while for the history and constitutional knowledge exam it is 3 months. In addition, an applicant can retake the exam a maximum of three times, but if all three are failed, a new naturalization application has to be submitted and the entire procedure started anew after a delay.

The level of required language proficiency corresponds to the Common European Reference Framework for Languages rating B1, basic knowledge. This level is relatively common among those countries in the EU that do require language proficiency, although some have lower requirements (level A2 is

${ }^{11}$ It should be noted that approximately $60 \%$ of Russians living in Latvia are citizens of Latvia - more than 367,000 ethnic Russians are citizens of Latvia - while there are 232,000 Russian non-citizens and approximately 30,000 Russian citizens with residency in Latvia as of 1 July 2009. 
required by Austria, A1 by France, A2 by the Netherlands and Portugal, a mix of A2 and B1 for Spain and Luxembourg), while only one country - Denmark has higher requirements (B2). ${ }^{12}$

Although there was concern over the low rates of naturalization following the brief upsurge after the 1998 referendum and one of the possible obstacles to naturalization was identified as fees that were high compared to average income and pensions, fees were gradually reduced, and provisions for the waiving of fees were established. Over the years, a significant share of the naturalization applicants has paid a lowered fee or no fee at all. In 2009, for the first time, the number of persons paying the full fee was fewer than half. It seems, then, that the cost of naturalization is not deterring persons, and there are no indications that any exclusion takes place directly based on socio-economic conditions.

Following a referendum in 1998, the Citizenship Law was amended to make it possible for children born to either non-citizen or stateless parents after 21 August 1991 to be recognized as citizens upon registration. These children are thus born as non-citizens (or stateless), and are not automatically made citizens, but their parents can submit applications for their recognition as citizens of Latvia until the year they turn 15. After that age, the youth can themselves apply to be registered as a citizen, but at that point has to show proof of Latvian language proficiency. Since this process was started at the end of the 1990s, slightly over 8,000 children have been recognized as citizens. However, this is a long-standing contentious issue, as the number of non-citizen children in Latvia still remains stable, at about 13,000, since new non-citizen births outweigh the low number of registrations, numbering below 500 annually.

Certain categories of persons can be recognized as citizens through registration. All in all, the number of registered citizens through this procedure was by 31 December 2009 9,364. Of those, almost 65\% were in the age group 15-30 years of age, which would seem to indicate that the largest group is not those who can claim citizenship through descent or ethnicity (Latvians and Livs), but persons who have completed their full course of education in Latvianlanguage schools. The number of such persons is below 500 per year.

There are also some persons who have become citizens of Latvia in recognition of particular meritorious contributions to the state of Latvia, for which the procedure is adoption of a specific law by parliament for the individual in question. This way of acquiring Latvian citizenship does not require the renunciation of any previous citizenship, and therefore de facto allows for dual citizenship, and also is possible even for some of the persons who are denied access to the ordinary naturalization procedures (former army personnel). Although the list of persons who have become citizens through this procedure is

12 Presentation by Sara Wallace Goodman based on data from European Union Democracy Observatory (EUDO) Citizenship Project at the $2^{\text {nd }}$ plenary conference 'Comparing Citizenship Policies in Europe' in Edinburgh, 21-22 January 2010. 
quite diverse, ranging from athletes to bankers and entrepreneurs, their number does not exceed a few hundred, with the majority acquiring citizenship in the late 1990s. Although the procedure allows for openness on an individual basis for a broad range of persons, the risk of arbitrariness and lack of transparency seems particularly high.

\section{Access to Political Participation}

Citizenship remains the key political participation criterion, as the right to vote and stand as a candidate for elections in national elections is reserved to citizens only, and in local elections to citizens of the EU. Non-citizens and other residents do not have the right to participate in elections, but they can be members of political parties and other civil society organizations, as well as participate in public political events and protest actions, even if they do not have the right to be the organizers thereof.

Participation in elections remains at the centre of political participation in Latvia, and the relevant laws include citizenship criteria for all types of elections. Thus the Law on Saeima Elections states that citizens of Latvia who have attained 18 years of age are eligible to vote, while citizens aged at least 21 are eligible to stand as candidates, although some categories of persons are barred from this right (based on past membership of USSR or Latvian SSR or foreign security services, membership of the Soviet communist parties and related organizations after 13 January 1991, etc.). The same applies to referenda.

The Law on European Parliament Elections extends the right to vote in line with EU requirements to all EU citizens, who should be aged 18 or above who are included in the voters' register (based on residence) in Latvia, while EU citizens above age 21 included in the voters' register can stand as candidates. The lustration norms of the national parliament elections - i.e. the prohibition to participate as candidates based on security service or communist party membership - are not applied in the European Parliament elections.

The more intensely discussed question on election participation concerns voting rights for permanent residents at the local level. Although approximately half of the $27 \mathrm{EU}$ member states provide some form of local election rights for third country nationals (active or passive), including Latvia's Baltic neighbours Estonia and Lithuania, key large countries such as France, Germany, the UK, Poland, Italy do not. The case for providing such rights to non-citizens has been made in various Council of Europe, OSCE and even EU fora, but despite the introduction of local voting rights for EU citizens from other member states introduced with the Maastricht treaty, the adoption of a legal requirement to provide such rights is not likely to be supported at EU level through a con- 
sensus. ${ }^{13}$ The arguments for legitimacy of democracy, minority participation as well as good governance still stand, however, and Latvia's authorities are regularly exposed to international recommendations to this effect. The issue also regularly recurs in public debate, due to the specific circumstances in Latvia with the significant number of permanent residents who have been residing in Latvia for decades or longer, but who have not become citizens.

Participation eligibility in local elections is determined in the Election Law on City Councils and District Councils. In addition to citizens of Latvia, EU citizens are eligible to vote if they are included in the Residents' register (all voters have to have attained 18 years of age and must be included in the Voters' register in order to vote). In order to stand as candidate for the elections, a person has to have been resident in the territorial unit for at least the preceding 10 months, to have been either employed or self-employed in that territory for at least the preceding 4 months or has to own real estate. The age limit to stand as candidate in local elections is 18 , which thus is lower than the age a person must have reached in order to stand as candidate in either national or EP elections. The lustration norms are in effect also for candidates in local elections. Latvian non-citizens and third country nationals do not have any right to participate in elections. This limitation stands out particularly in the case of local elections, in which, following EU requirements, EU citizens with only minimal links to the territorial unit in question do have rights both to vote and stand as candidates, while persons without EU citizenship, including non-citizens who have long-standing ties to Latvia, and in many cases who are born on the territory, do not have these rights.

EU citizenship, specifically through the post-Maastricht local election rights of EU citizens, has created a challenge to the long-standing majority consensus on national citizenship as a criterion for formal political participation rights, including at the municipal level. Although this is the case in all those EU member states which do not provide third country nationals permanent residents with participation rights in local elections, the issue is particularly salient in Latvia. This is both because the share of non-citizens among the population remains large, and also because this group has been resident in Latvia for a minimum of two decades, but a large share was born in Latvia. Even though most noncitizens have access to citizenship through naturalization, the exclusion of such a large number of tax-payers from participating by voting for representatives at the local level, where decisions which directly affect them are made, is even more difficult to accept in view of newcomers from other EU member states having such rights. Over time, especially if the number of EU citizens increases and they become more visible, this contrasting situation will become untenable

13 Jo Shaw (2007), The Transformation of Citizenship in the European Union. Electoral Rights and the Restructuring of Political Space. Cambridge: Cambridge University Press. 
and should logically work in the direction of providing the right to participate in elections at local level for all permanent residents.

Another issue, specific to Latvia, is the question of exclusionary criteria for candidates in elections included in the lustration clauses. These are increasingly anachronistic after almost two decades of renewed independence, but effectively bar some high-visibility minority representatives (as well as members of the majority with similar backgrounds) from participation as elected politicians on the territory of Latvia. ${ }^{14}$

\section{Conceptual Framing of Rights to Political Participation}

Citizenship is closely linked to the renewal of independence, the 1922 Constitution, and the citizenry, based on citizens from before the war and their descendents. The choice of this basis for independence in 1991, together with the dramatically changed composition of the population during the Soviet period, explains why citizenship was seen as such a key denominator of belonging right from the beginning. However, over 700,000 former Soviet citizens found themselves on Latvian territory after the break-up of the Soviet Union. In the initial years after independence, policy approaches fluctuated between proposals to include all who were for independence to the little disguised hope that Soviet-era settlers would leave. Gradually, after significant international pressure, the political elite accepted the need to provide for access to inclusion as full citizens to those whose permanent residency was in Latvia. Until the end of the 1990s, however, non-citizens' access to naturalization was limited through quotas (or naturalization "windows" which introduced gradual access based on age and date of arrival in Latvia), which were lifted after a referendum in 1998. The referendum also extended further the ius solis elements of citizenship by recognizing that all children born in Latvia to non-citizen parents after 1991 have the right to be registered as citizens.

Social and economic rights of non-citizens were recognized early on, although some discriminatory provisions were only gradually removed from

14 This is the case for the MEP from Latvia Tatyana Zhdanok, who had in the early postindependence period been a member of parliament in Latvia, but was after that struck off election candidates' list for the Riga City Council for having been a member of the Communist Party after the cut-off date of 13 January 1991, a case which was unsuccessfully contested in the European Court of Human Rights. Nevertheless, both the Constitutional Court of Latvia as well as the ECtHR stressed the necessarily temporary dimension of such restrictions. 
legislation, and some even remain today. ${ }^{15}$ Generally speaking, however, the socio-economic rights of non-citizens, as well as their genuine and lasting links to the state, have been recognized on separate occasions by the legislator, the judiciary and the executive authorities, and non-citizens rights are closer to those of citizens than are those of resident foreigners, especially third country nationals.

Nevertheless, this recognition never included a vision of political rights for non-citizens - especially not the right to vote or stand as a candidate for elections, which is almost unanimously seen by the majority and the establishment as legitimately limited to nationals. The road to full political participation, it is argued officially, is naturalization, and this, it is claimed, is open to all on relatively lenient terms, compared to the rest of Europe. At the same time, the number of minority representatives who are citizens is significant, and since they belong to the same ethnic minorities as the non-citizens, many "minority political claims" are made and heard, including on the rights of non-citizens, through established political parties and elected politicians at both national and local level.

In the period before accession to the EU the international community played a significant role in pressuring and alerting the majority decision-makers to the general expectation of effective participation as a prerequisite for democracy. However, the debates led to a rather polarized response. If the need to take some measures to facilitate inclusion into citizenship of non-citizens was accepted by decision-makers, the lesson was learned that questions of citizenship are the exclusive competence of a sovereign state. The choice of focusing the discourse on legally based arguments led to the recognition that there are no legally binding international standards that can force provision of citizenship or the right to participation in local elections by non-citizens and that several of the largest countries in Europe do not provide such rights to their permanent residents who are not citizens. This line of argument has become the standard response of Latvian authorities whenever international observers comment on the political rights of non-citizens in Latvia. The comfort of this legal clarity has not created any hope that international dialogue - now that NATO and EU membership has been achieved - will have any impact on the will to extend political participation rights.

There are signs that there may be some evolution in public opinion and that even if support for non-citizen voting rights at the local level has not reached a majority, the population at large is not so clearly opposed to such rights. In

15 The most recently contested difference was the right to pensions for time periods worked on Soviet territory outside of Latvia, which was previously not included in calculation of pensions for non-citizens, while it was for citizens. The European Court of Human Rights found such a differentiated approach discriminatory, and the government in 2009 proposed legislation that would exclude these periods for all; another contested right is the right to own land in the border areas. 
2008 , for instance, $47 \%$ of respondents in a representative survey of residents supported the provision of local election participation rights for non-citizens, while $39 \%$ opposed this and $14 \%$ found it difficult to answer. ${ }^{16}$ A study from 2009 found that among citizens of Latvia, $27 \%$ were very or moderately positive to the provision of voting rights at the local level to non-citizens, with an additional $24 \%$ stating they were neutral in this question. $43 \%$ of the respondents were very negative or moderately negative $(19 \%)$ toward this proposition, and $8 \%$ stated it was difficult to answer. Of those that were positive, the most frequent reason given was simply "they live here", but for those with a negative view, the most common reason was "they should naturalize" and the second one was that "they are not loyal towards Latvia, they don't respect Latvia", but this response category was almost equal to the one asserting that voting rights should on principle be reserved for citizens only. ${ }^{17}$

The conceptual framing of political participation within the context of citizens and non-citizens has arguably had a side-effect of creating obstacles to participation by third country nationals, especially in the political field. The framework for providing participation rights - and even more so, the promotion of political mobilization - is not likely to be forthcoming until the issues revolving around Latvian non-citizen participation - especially in local elections - are addressed. Thus, the image of a liberal citizenship regime will remain tempered by restrictions to participation of non-citizens, as well as the slow rates of naturalization of those who are eligible.

\section{Legal Framework for Political Parties and Civil Society Organizations}

The Law on Political Parties determines that only citizens of Latvia who have reached the age of 18 can be founders of a party, and there should be no fewer than 200 founders. Membership, however, is more open: citizens and EU citizens residing in Latvia who are at least 18 years old can be members of a party - and interestingly, in view of the prohibition to participate in elections - so can Latvia's non-citizens (but not third country nationals). There is a requirement that at least half of members of a party have to be citizens of Latvia. Nevertheless, political participation through active work within parties is more accessible than participation in elections, even if restricted for third country residents of Latvia. The law on political parties does not include any restrictions on creating ethnic parties or regional parties.

${ }^{16}$ AC Konsultācijas (2008), Kvantitatīvs un kvalitatīvs pētījums par sabiedrības integrācijas un pilsonības aktuālajiem aspekti. Riga: AC Konsultācijas.

17 Viktors Makarovs and Aleksejs Dimitrovs (2009), 'Latvijas nepilsoņi un balsstiesības: kompromisi un risinājumi,' published on politika.lv on 14 September 2009, available at http://www.politika.lv/temas/sabiedribas_integracija/17591/ 
According to the Law on Associations and Foundations, there are no citizenship requirements for founders and members of non-governmental organizations and associations, but leaders of such organizations must be residents of Latvia, who are at least 18 years old (members can be younger). Civic participation through NGOs - including the right to establish such organizations - is thus open to all, although there is a requirement to register organizations in the NGO register, and their activities are regulated by law and the organization can be closed if violations of the law are found in a court. A specific Law on Religious Organizations determines the legal order for establishing these, which includes the requirement that at least 20 Latvian citizens aged 18 or above must be among the founders, but any resident of Latvia can be a member of such an organization.

Membership in trade unions is also not restricted to citizens, as residents of Latvia who work or study are entitled to freely establish trade unions, according to the law On Trade Unions. A trade union is officially registered if no fewer than 50 persons, or one fourth of the number of employees of an enterprise or institution, have joined it.

Freedom of assembly is guaranteed to every person in the Constitution, but although the Law on Meetings, Marches and Pickets also reiterates this right, the law specifies that the organizer, the leader, leader assistant and guardian of order of such an event may not be a person who is not either a citizen or noncitizen of Latvia or a person with a permanent residency permit.

The legal framework thus establishes a system of gradually extended rights for political participation. Although there are citizenship criteria for participation in elections which exclude both third country nationals and Latvian non-citizens, participation in political parties is broadened to the non-citizen category (albeit not as founders), while participation in NGOs and trade unions as a member is open to all residents. Participating in protest actions can clearly not be prohibited on the basis of citizenship or residence, but the organization of such events is only allowed for permanent residents, Latvian non-citizens and citizens.

\section{Minority Representation and Participation Through Elections}

Only a handful of post-1991 migrants are represented in elected bodies in Latvia, ${ }^{18}$ but traditional ethnic minorities are noticeably present, both at the national and local level. The proportionality of this representation compared to the share in the population depends on whether the entire population or only citizens are used as the base line, as among citizens $28 \%$ belong to minorities,

${ }^{18}$ In the most recent municipal elections (in June 2009) 2 Danish citizens, 2 Lithuanian citizens, 1 German citizen and 1 Swedish citizen competed successfully as resident EU citizens for seats on local councils. 
while approximately $40 \%$ of the population belong to minority groups. If the citizenship criterion is taken at face value and recognized as a legitimate criterion for participation in elections, then representation is much closer to proportional, at least at the national level. ${ }^{19}$

The present parliament, the $9^{\text {th }}$ Saeima, was elected in 2006. Of the 100 members of parliament, ${ }^{20} 78$ have identified for statistical purposes as ethnically Latvian, which is somewhat higher than the $72 \%$ share amongst the population (there are no official statistics on the ethnic origin of those eligible to vote). Of the rest, 15 self-identified as Russian, 1 each as Jewish, Karelian and German (as a traditional national minority), and 4 chose not to answer the question on ethnicity.

In terms of the gender dimension, 19 of the 100 MPs are women. However, for the two parties that are generally considered to be the minority platform parties, and which are assumed to attract minority voters - the more radical opposition party For Human Rights in United Latvia (FHRUL) (5 MPs) and the more moderate party coalition Concord Centre (18 MPs) - all the deputies are men. The question of gender mainstreaming among minority politicians thus seems particularly relevant, and was addressed in interviews with nine minority politicians in late $2008 .^{21}$

Most of the interviewees had little to say on the topic, but seemed to generally think that there were equal opportunities, and at times tried to come up with examples of women from their parties. FHRUL does not have a woman in parliament, but its representatives insist that this is compensated by having an active woman member of the European Parliament. A FHRUL member also expressed the view that this is a natural process, that women are probably busier with household matters, but that no 'artificial' measures are in place to promote a change. On the other hand, a Concord Centre representative clearly stated that there are not yet equal opportunities for women, even if progress continues to be made. He also added that the party leadership itself has seen evidence of the problems with a "conservative society" in this regard, where

${ }^{19}$ Ilze Brande Kehre and Ilvija Pūce (2005), 'Political Nation and Citizenship,' in Juris Rozenvalds, ed., How Democratic is Latvia. Audit of Democracy. Riga: University of Latvia Press.

20 'Statistika par deputātiem,' available at http://www.cvk.lv/cgi-bin/wdbcgiw/base/saeima9. GalRez.statko. Interestingly, the statistics on ethnicity no longer appear on the Saeima home page, as in previous parliaments, but they are available at the home page of the Central Election Commission.

${ }^{21}$ Semi-structured interviews on political participation were conducted with 9 active minority politicians (members of parliament and members of the Riga City Council) within the framework of the project 'A European Approach to Multicultural Citizenship. Legal, Political and Educational Challenges' (EMILIE), materials for 9 participating partners' countries available at http://emilie.eliamep.gr. 
women on the candidate lists frequently get struck out. ${ }^{22} \mathrm{He}$ also stated that the party is aware of the challenge of women's under-representation within their ranks and is working towards promoting gender balance through some kind of system of preferences. Another FHRUL member of parliament, in contrast to his party colleagues, clearly stated that there is no equal opportunity for women in Latvia, that society as a whole is conservative and looks with suspicion on the participation by women in political life, but that the Russian minority community is even more so. He also stated that there are regular struggles within the party on the issue, and that something like quotas would have to be set up, so that at least a third of the candidates on lists are women - even if eventually it is up to the voters to decide, and they can strike them out. The view that voters would try to eliminate the women on a list was expressed by several interviewees.

The presence of minority representatives who work actively to make claims for minority rights in Parliament is visible, and the various representatives from the two main minority associated parties FHRUL and Concord Centre have in their different political forms had clear agenda-setting powers, which are evident as engendering discussions and tabling proposals for legislation that aim at providing increased rights to non-citizens. Other minority-related proposals are also made, ranging from the regularly recurring proposal to designate Russian Orthodox Christmas and Easter as official holidays, or various language-related proposals. These proposals almost never have a long life, as they are introduced and briefly debated, but either voted down in plenary or sent off and "buried" in committees.

At the same time, there are various "counter-measures" - initiatives taken by nationalistically oriented parties, primarily Fatherland and Freedom/ Latvian National Independence Movement (with 5 MPs presently in parliament), to restrict existing minority rights, particularly in relation to use of language other than Latvian, as well as on issues relating to citizenship acquisition. Thus, in the first 5 months of 2008, there were four proposals relating to ethnic minority issues which in essence meant the reduction of rights, while there were six proposals to expand these rights. ${ }^{23}$ Results from a parliamentary debate monitoring study show that a large number of strategies are used by a small number of active nationalist counter-claimants to exclude and delegitimize not only the claims made by the minority politicians on behalf of ethnic minority groups or non-citizens, for instance, but the very "messenger politicians" themselves. ${ }^{24}$

22 The Latvian voting system allows for the additions of + and - for any candidate on a list, which are eventually added up and can play a significant role in changing the positions among candidates on a list, and thus actually determine who is elected from the list, even if the vote goes to the list as such.

23 Marija Golubeva et al. (2008), 'Izaicinājums pilsoniskajai līdzdalībai.' Riga: Providus, pg. 12, available at http://www.providus.lv/public/27122.html.

24 Ibid., pp. 17-18. 
The minority party FHRUL for its part, uses explicit discursive "legitimizing strategies" for groups such as non-citizens. The result, however, is that there is an ongoing parallel monologue in parliamentary debates, which is almost ritualistically sustained by the same few representatives of these dramatically opposing sides. The proposals of both sides are generally voted down relatively early in the process, but the main problem is the lack of involvement of the moderate majority in the debates. The majority tactic appears to be oriented at killing off the proposals by silence and votes against or, even more disturbing, abstentions.

Riga is by far the most populous city, with 713,000 residents out of the 2.3 million of the entire country. The concentration of resources in the capital means that competing for the leadership of the city has always been at the top of the political agenda. Given its ethnic composition, the capital is also interesting for the purpose of analysing political participation: Latvians represent $40 \%$ of the population, Russians approximately the same, while the remaining $20 \%$ are mainly other "old" minorities (most of whom, although they belong to different ethnicities, are "Russian-speakers"), although a small percentage of new migrants and foreigners are also included.

The Riga City Council is composed of 60 deputies, and the last elections were held in June 2009, on the same day as the elections to the European Parliament. Participation in these elections at $58.9 \%$ was above the average for municipal elections throughout the country, which was $53.75 \%$. Out of 17 parties participating with candidate lists, only four were elected this time, so the two largest could form a convincing majority, instead of the frequently unstable coalitions with several different constellations of previous Riga City Councils. Interestingly, the largest party by far became the Concord Centre, perceived as a minority-oriented party, which received over $34 \%$ of the vote, and a corresponding 26 seats. As a result, for the first time ever, Riga elected a mayor belonging to the Russian minority.

Although there is no publicly available source for city council deputies' ethnic belonging after the 2009 elections, it is possible to identify deputies as belonging to ethnic majority or minority based not on their names, which is an unreliable proxy for ethnicity in Latvia, ${ }^{25}$ but on the recognition of individual politicians in a relatively small society, as well as their language use and proficiency. With all appropriate caveats, one can estimate that 30 deputies are persons belonging to minorities, while 28-30 are Latvians (with possibly two

${ }^{25}$ Although Russian (and some other Slavic groups) and Latvian origin family names can be easily identified, the high rate of intermarriage and resulting mixed ethnic backgrounds, which has been taking place for decades and even centuries, means that the name does not necessarily reflect the self-identified ethnic identity of its bearer. 
claiming Liv ${ }^{26}$ background). This is a significant increase in the representation of minorities in the city council, since in the previous council 40 of the deputies self-identified as Latvians and two as Livs. ${ }^{27}$

Lest one interpret political integration processes overly optimistically, it is important to note that the parties themselves have a strong tendency to have either exclusively majority or minority deputies. All 26 of the Concord Centre deputies are minority representatives, despite this party's claim to be multi-ethnic and include also Latvians (they do to a limited extent on the parliamentary level). Two other parties, with 14 (Civic Association) and 8 (New Era) deputies respectively, have an all-Latvian elected candidate list. It is only Latvia's First Party/Latvia's Way which can aspire to the claim of being ethnically mixed, since out of the 12 elected deputies, 4 are minority representatives. In general, though, the party lists indicate a rather segregated political scene. Nevertheless, the success rate of the Concord Centre in these elections, which could not credibly have been achieved on minority votes alone, indicates that this party was able to attract also Latvian voters.

\section{Perceptions of Minority Politicians on Participation}

All the minority politicians interviewed stated that participation of minorities is insufficient or ineffective, and some stated that there is no possibility to actually influence any of the decisions finally taken. As the main obstacles to effective participation of minorities some of the interviewees mentioned the large number and very existence of non-citizens. Some also stressed insufficient knowledge of the Latvian language of some active politicians, which limits their ability to participate in political debates in elected bodies, adding also insufficient knowledge of legal matters. Some stated that language proficiency requirements directly limit participation by minorities. One person also stressed that the minorities themselves are insufficiently active, while another stated that there is a lot of energy and minority activism, which means that there is an effect, but not thanks to the political system, but rather despite it. This person also insisted that there had been a lot of influence on the actual situation of minorities over the years, but that this is perhaps not always noticeable. One interviewee expressed frustration or resignation regarding the situation of being in constant opposition and not being able to influence any decisions at all, including decisions that are primarily of concern to minorities themselves. One MP saw as the main obstacle the quality of Latvian politicians, whom he described as "closed", suspicious and Russophobic, and the quality of minority

${ }^{26}$ Livs (also called Livonians) are a constitutionally recognized indigenous people in Latvia, who belong to the Finno-Ugric group, although in the last census of 2001 there were reportedly only 177 Livs left in Latvia, after long processes of assimilation.

${ }^{27}$ See www.cvk.lv/cgi-bin/wdbcgiw/cvk/pv2005.pv2005_rezult_plus.stat?nr=0100 
politicians and civil society actors, whom he criticized for not cooperating and coordinating sufficiently.

Several of the interviewees acknowledged that if one looks at the proportion of minorities who are citizens, representation is more or less proportional at the national level. However, one interviewee proceeded to add more complexity by bringing attention to differences at the local level, pointing out that in Daugavpils, the second largest city in Latvia and one where Latvians are in a minority position with around $17 \%$ of the population, Latvians are overrepresented in the local elected council. He also stressed that there is an ongoing process of political mobilization of Russian-speakers, although he also pointed out that participation in elections is generally lower among non-Latvians than Latvians. Another interviewee expressed the view that the representation of numerically small minorities in the elected bodies is good, but the Russian minority is underrepresented, and its role inadequately reflects its share of the population. One politician also pointed to the key blocking role that the minority MPs can have on decisions in parliament, preventing the passage of decisions that would be detrimental to minority interests.

Several MPs suggested that there were no positive examples of minority political efficacy, while one MP mentioned two minority-related claims in the Constitutional Court - where opposition members of parliament themselves submitted an application challenging quotas of state language requirements in private media and discrimination in the provision of subsidies to minority language private schools. This confirmed the perception of the rather unusual role for the Constitutional Court, which has at times become an arena for political struggles that should have taken place in parliament. While the parliamentary majority ignored or overrode minority views, the court hearings provided a real platform for dialogue between the two opposing political sides. One more optimistic interviewee, however, expressed the view that the State Language Law had been a success for minority politicians, and the existence of media in the Russian language, in his view, is only the result of minority politicians' struggle in the 1990s. Also, the minority school reform was adapted, according to this interviewee. An interesting view was provided by one FHRUL MP, who claimed that the influence on questions of finance and general social affairs is good, but completely absent on issues of language and citizenship or other issues specifically of concern to minorities. In general, minority views on positive examples were quite contradictory: the general assessment was that there were very few such examples, but there was also a tendency to claim credit for any and all positive minority-rights related decisions. The one example mentioned by almost all interviewees, but with different assessments of the success of the large-scale mobilization, was the minority education reform completed in 2004. This was mentioned as both a success (only thanks to the activities of minority politicians and protesters was the reform "softened") and a failure (the reform was not stopped). One interviewee stated that this reflects what is 
common for minority politicians - only partial successes with both a positive and a negative side.

Interviewees stated that there were "many" negative examples where they had no influence on decisions relating to matters of direct concern to them. Several cited the minority education reform with all the protests that did not stop the process. Others added also the numerous times proposals to enshrine Orthodox Christmas and Easter as official holidays had been blocked. The question of use of language other than the state language with administrative and local authorities was mentioned as a key issue that needs a solution at the legislative level, but where progress is difficult to achieve by minority representatives.

\section{Voter Participation}

There are no official ethnically disaggregated data on participation in elections, but there are some survey data on intent to participate and reported participation, as well as attitudes towards elections. In the most recent survey, conducted in January $2009,{ }^{28}$ on citizens' intent to participate in the municipal elections or the European Parliament elections (which were both held on 6 June), $41 \%$ claimed that they would certainly participate and $26 \%$ that they would most likely participate, while $8 \%$ said they would certainly not participate and $11 \%$ stated that they most likely would not participate (with $14 \%$ stating "difficult to say"). ${ }^{29}$ Although this survey did not include ethnicity as a demographic dimension, which would allow specific analysis according to ethnic group participation, it did include (primary) language of the interviewee, divided simply into Latvian and Other (but clearly the last category would mostly be Russian), which can serve as a proxy for ethnicity. If the two positive answer categories are combined together, there is no great difference between these groups: $69 \%$ of Latvian-speakers foresaw that they could or most likely would participate, while $65 \%$ of Russian-speakers did the same. Likewise, the negative attitudes of $18 \%$ of Latvian-speakers are comparable to the $20 \%$ of similarly-minded Russian-speakers. However, the clear intent not to participate was more pronounced among Russian-speakers (11\% vs. 6\% for Latvianspeakers), while there was also a slightly larger share from this group who had a clear intent to participate (43\%), compared to the Latvian-speakers $(41 \%)$.

There are other forms of political participation where the level of involvement of majority representatives and minorities differs significantly. In the 2008 survey among permanent residents (thus, not only citizens) on whether

${ }^{28}$ SKDS (2009), Vèlētāju attieksmju pētījums 2009. Riga: SKDS.

${ }^{29}$ The actual participation rate was almost $54 \%$ in both elections, but the reported intent generally has been overoptimistic in all such surveys over the years, so this discrepancy was not exceptional. 
they had signed the petition in March-April 2008 calling for amendments to the Constitution that would permit the voters to require the dismissal of the parliament through a referendum, over $42 \%$ Latvians reported having signed the petition, while only $17.4 \%$ non-Latvians reported the same. ${ }^{30}$ This petition came at a time of rising discontent with politics and politicians, and reflected what for Latvia was an unusual level of mobilization to protest the perceived cynicism and alienation of politicians from "the people". These figures seem to indicate that the growing mobilization was more intense among Latvians than non-Latvians. Similar differences were also reported in a survey later in 2008 with regard to a question of participation in signing petitions for a referendum some $40 \%$ of Latvians said they had done so, while the corresponding number for Russians was $13 \% .^{31}$

At the same time, shortly thereafter, in January 2009, at a political rally in the old town of Riga of a newly formed party (but with MPs at the helm who were not new to politics) which tried to capitalize on anti-government sentiment, the audience was reportedly ethnically mixed. After the rally the crowds did not disperse peacefully, but groups of participants engaged in acts of vandalism against private and state property and other aggressive behaviour, which took hours for the police to contain. This level of violence at a protest event had not been experienced earlier in Latvia. However, the presence at these events of persons from different ethnic backgrounds, reported also by journalists, was also a novelty in Latvia, where most protests and demonstrations have been largely mono-ethnic.

A survey from August 2004 on factors that influenced participation in the European Parliament elections shows rather significant discrepancies between Latvians and other ethnic groups. Among citizens, 65\% of Latvians reported having participated, while the reported participation rate for non-Latvians was lower by 10 percentage points $-55 \%$. The same survey also indicates that the level of exposure to Central Election Commission information on the upcoming elections had been significantly higher among Latvians (72\% reported having seen TV clips either once or repeatedly) than other ethnic groups (some 55\% reported having seen these). The question of the linguistically divided media spheres needs to be taken into account here, but an incident that took place in connection with the 2005 municipal elections illustrates a deliberate blockage of the provision of information in Russian. In January that year, the nationalist party Fatherland and Freedom/Latvian National Independence Movement (TB/ LNNK) challenged the Central Election Committee's right to air the information clips in Russian on the upcoming elections that it had produced for TV on the grounds that these would violate the state language law, which foresees that information from state institutions can only be provided in Latvian. The clips

${ }^{30}$ SKDS (2008), Pētījums par iedzìvotāju līdzdalību parakstu vākšanāa 2008. Riga: SKDS.
${ }_{31}$ Ibid. 
were withdrawn a couple of days after the complaint. ${ }^{32}$ Although this factor had seemingly improved in the last elections, when official clips were aired also in Russian-language media, the continued sensitivity to language issues and the embrace of a controlling, punitive approach to language policy means that access to information on elections in minority languages clearly needs attention in both research analysis and practical work by the authorities.

\section{Consultative Bodies and Civil Society Organizations}

The first minority consultative council was created in the 1990s under the first President of Latvia after the renewal of independence, President Ulmanis. Although an innovative development at the time, it suffered from various shortcomings, never turned into an effective mechanism, and was discontinued. However, a variety of consultative mechanisms have been established in Latvia since. Counting at both national and local level, more than 100 such mechanisms have at one point been established. The target audience of these is sometimes national minorities, sometimes non-citizens (at the local level), and they can be either concerned with a broad range of issues, or specific themes, such as those attached to line ministries (e.g. Ministry of Education). However, in most cases there have been questions regarding the effective functioning and specific tasks and competences of these councils, including the transparency of appointment procedures, the regularity of working meetings, and the impact on decision-making. Minority representatives with experience in these councils have generally expressed scepticism with regard to their functioning, although some have also been critical of the minorities' capacity to participate effectively in such work. ${ }^{33}$

Recently, a council for national minorities has been re-established under President Zatlers, but it is unclear what functions and competences such a council can have, considering the President's own limited constitutional role. The composition of the council, with the appointment of a Lithuanian origin former MP of a ruling party at its head, has not lent credibility to it in the eyes of some of the main minority groups. Other initiatives are taking place at the municipal level, where the active self-organization of certain minority groups in Liepaja during 2009 seems to have been initiated in parallel to measures taken at the city council level.

There have been no serious assessments of the functioning and shortcomings of the consultative councils, although the interviews with minority politicians indicate that there is a general sense of their usefulness in theory, but

${ }^{32}$ Latvian Centre for Human Rights (2005), Human Rights in Latvia in 2004. Riga: LCHR.

${ }^{33}$ Sigita Zankovska-Odiña (2008), 'Nacionālo minoritāšu līdzdalība - vai un cik efektīga?' Riga: LCHR. 
uselessness in practice until now. Several of the nine interviewees expressed their support in principle for such mechanisms. Some also stressed that there are ways to make such structures effective - depending on the authorities' wish to engage in real dialogue - but then stating that such structures in Latvia today clearly do not meet this standard. However, one person replied "categorically no," proceeding to explain that such mechanisms can work in countries such as Finland, Belgium and elsewhere, but not in Latvia, since here they are formed for entirely different purposes. A second MP also considered that these mechanisms "never work anywhere", explaining that he himself had participated in some, and that they had been useless. One politician argued that the consultative councils are important in themselves as a sign that there has to be a dialogue with the minorities. Another politician stressed that the consultative councils have been established "for show" only. The views were overall quite similar, and confirm that a thorough assessment of the existing councils needs to be done to identify shortcomings and possible remedies.

Finally, the rate of participation in civil society organizations is still not high in general in Latvia, and much of the participation concerns membership in religious organizations or trade unions, followed by sports and cultural organizations. ${ }^{34}$ In general, a larger number of persons is involved in organizations with "hobby-type" interests rather than public interest ones. Almost two-thirds of Latvian residents have not been involved in any kind of civil society organization, but the rate of participation is higher among ethnic Latvians (40\%) than non-Latvians (30\%). Reported membership in an NGO is higher among Latvians (5.3\%) than among Russians $(3.3 \%)$, although in this category the "Other" groups score a little higher than the majority (5.7\%). ${ }^{35}$ Differences in participation rates in trade union activities also appear in survey results from 2008. While $12.5 \%$ of Latvian respondents claimed to have participated in trade unions, only $8.1 \%$ of Russians stated the same. ${ }^{36}$ This is important, as trade union membership and participation is open to all, regardless of citizenship, so there are obviously some unknown obstacles at work in this case.

Another reported ethnic difference is in the rate of participation in public debate events, where $14 \%$ of Latvian respondents claimed to have participated, while the figure for Russian was only 7\%. In view of the lack of participation rights at local elections for non-citizens, it is significant that far fewer noncitizens $(7 \%)$ compared to citizens $(12 \%)$ report participating in debates. This seems to be indicative of the lack of engagement and inclusion of non-citizens even on matters of concern to them in their everyday lives. There are no formal obstacles to such participation, but there clearly is a need for mobilizing involvement in public life for this group of residents. In this context the

\footnotetext{
${ }^{34}$ SKDS (2007), Attieksme pret pilsonisko sabiedrību. Riga: SKDS.

${ }^{35}$ SKDS (2008), Latvijas iedzìvotāju aptauja. Riga: SKDS.

${ }^{36}$ Ibid.
} 
superficiality of the official position that non-citizens can and should naturalize and thus acquire all participation rights and become good citizens becomes even more obvious. While no efforts are made to mobilize this potentially marginalized group - which consists of ethnic minority members - their inclusion in effective participation remains unlikely.

\section{Non-Traditional Participation: Protests}

Participation in various public protest events - demonstrations, marches, pickets and the like - has gradually developed over the years, although only very few large-scale events have taken place, as most involve short actions by crowds ranging from a handful to a few hundred protesters. An exception to this was the first large demonstrations since independence, which took place in connection to the minority education reform and the transition to an increased share of Latvian instruction in Russian-language schools. The largest of these took place on the day of Latvia's accession to the EU, 1 May 2004. While the demonstration at the place of the Soviet-era Victory monument in Riga gathered some 20,000 participants - in a city of a little over 700,000 inhabitants - a grand celebration of the accession was taking place just across the river Daugava in the Old Town of Riga, where representatives of Latvia's government, parliament and the president were delivering speeches to the Latvian people, completely ignoring the alternative event, which gathered minority representatives. ${ }^{37}$ Although such a stark contrast of the different participants in different events was probably never repeated since, the tendency that minority protestors were politically mobilized by "minority-related concerns" or by active minority politicians, while "mainstream" protests tended to gather Latvian participants, has been evident over the years. Against this background, the 13 January 2009 violent protest action in Riga, mentioned above, is indeed a break with the trend.

The activity around the education reform, which was implemented for secondary schools in September 2004, meant that public protest events were organized on a regular basis, albeit on a varying scale. A record kept by an MP and activist on education reform indicates that from April 2003 until November 2005198 actions in support of education in one's native language were organized by the "Shtab" (Headquarters for the defence of Russian-language schools), of which 110 were held outdoors. 35 of these had more than 1,000 par-

${ }^{37}$ Latvian Centre for Human Rights (2005), Human Rights in Latvia in 2004. 
ticipants. ${ }^{38}$ The authorities and indeed society at large was only slowly getting used to this kind of action, however, and most of the initial reactions by both executive and legislative authorities were centred around finding legal ways to restrict the development of more public protest. In contrast to the mobilization of Russian-speaking minority groups, ethnic majority groups had not yet mobilized much for this kind of public expression of opinions. ${ }^{39}$ However, as protest actions - small-scale and peaceful - have become a regular part of the urban scene, increasing numbers of Latvians also took to this form of political participation. As a result, the participation rate in demonstrations, which in the mid-2000s was reportedly very high precisely among minority representatives, and especially youth, ${ }^{40}$ increased also for all groups in society. This is corroborated by evidence in a 2008 survey, where some $12 \%$ of Latvians report having participated in public protest meetings, pickets, demonstrations, while the corresponding figure for Russians is $11 \%$, and for other ethnic groups $9 \%{ }^{41}$

In terms of belief in the potential for change through protest actions, it is interesting to consider the attitude of minority politicians, who were quite actively engaged in the protest actions in the mid-2000s. Among minority politicians interviewed, several persons commented that protest actions may have a role depending on the circumstances, but not always. One person recalled the role of the large-scale protest actions as "softening" the education reform, but another interviewee expressed the view that protest actions can be effective only if they mobilize large numbers of persons. One interviewee stressed the importance of protest actions precisely because other forms of participation are not effective, believing that such actions would become less important when minorities reach a more equal status in politics and use traditional methods of participation better. Two interviewees cautioned that protest events can at times also have a counterproductive effect, as they can evoke counter-mobilization, generate fear or dislike from other social groups, and prompt anti-minority decisions. One politician foresaw that protest actions will be more and more marginal, while other participation forms will grow in importance. Nevertheless, another long-

38 Vladimir Buzaev (n.d.), 'Khronika aktsii v zashchitu obrazovanii na rodnom yazyke, provedennikh no initsiative organizatsii i lits, vkhodyashchikh v Shtab zashchity russkikh shkol' [Chronicle of actions in support of education in one's native language, held at the initiative of organizations and persons that participated in the Headquarters for the support of Russian schools], available at the FHRUL home page http://www.zapchel.lv/?lang=ru $\&$ mode=party\&submode=history\&page_id=2107.

39 Kristīne Gaugere and Ivars Austers (2005), Nevalstiskās organizācijas Latvijāa: sabiedrības zināšanas, attieksme un iesaistī̌sanās. Riga: Soros Foundation-Latvia, pp. 30-31.

40 Baltic Institute of Social Sciences (2004), Integration of Minority Youth in the Society of Latvia in the Context of the Education Reform. Riga: BISS, pp. 68-69. In that report, 51\% of surveyed secondary school students from minority schools reported having participated in protest events, while an additional large proportion claimed they had wanted to, but had not due to various practical obstacles.

41 SKDS (2008), 'Latvijas iedzīvotāju aptauja'. 
term member of parliament stated that protest actions are absolutely necessary "in order to put pressure on the government." There was thus less consensus on the role of protest actions amongst the politicians interviewed, even among members of the same party.

\section{Conclusions}

Citizenship remains a core indicator of integration for Latvia, and the high number of non-citizens who are permanent residents is an obstacle to high ratings for integration of society. In order to get a fuller picture of the state of affairs with regard to political integration, the challenges at the starting point in 1991 should be recognized, and the trends of naturalization over time need to be closely monitored and analysed. Although citizenship continues to be based primarily on the continuity of the republic from before the occupation and thus ius sanguinis principles, elements of ius soli have opened up access to citizenship.

The citizenship regime of Latvia is overall in line with other EU member states, although certain specific aspects, like the permanent exclusion of certain groups from naturalization, make it more restrictive. The low rates of naturalization from among those eligible to naturalize is cause for concern and a negative indicator for integration, regardless of whether the cause lies with insufficient outreach by the authorities or insufficient motivation by the potential citizens, or both. 2009 saw increasing rates of non-citizens who chose to take on Russian citizenship while remaining resident in Latvia (see the Conclusion by Nils Muižnieks). Though the overall figures are still quite low, they were for the first time on a par with the number of non-citizens who became Latvian citizens by naturalization. This was most likely due to economic hardship and the hope of benefiting from additional Russian social security entitlements. Nevertheless, the lack of a clear sense of belonging to the state - in contrast to a stronger sense of belonging at the local level - should be a signal for policy-makers to intensify efforts to attract residents to citizenship.

Political participation in elections is limited to citizens, but there are other forms of political participation open to all residents. The picture of political integration is mixed: minority representatives actively and visibly participate in political life and elected bodies, but there are differences in political mobilization among the ethnic groups. Political parties mostly tend to be if not mono-ethnic, then at least oriented towards either the majority or minority ethnic voters, and party's candidates for office also tend to belong to the corresponding ethnic group. While political interaction is high between the groups, integration still remains low in almost all parties.

Voters' participation does not differ significantly among citizens of the different ethnic and linguistic groups, but other forms of involvement in political and civic activities are less uniform. Passivity and the tendency to ethnic self- 
segregation in organizations and public activities are the most significant risks to integration through political participation.

Political participation among those minority representatives who are citizens is more proportional than if the entire population is taken into account, and the parliamentary representation is numerically important, with almost a fifth of the MPs declaring themselves to belong to a minority, and with the two parties generally seen as representing minorities holding 23 seats out of 100 . In addition, the claims made relating to minority rights and interests by these MPs are regularly put on the agenda and debated. However, the adoption of proposals gives a less rosy picture, as almost all minority-related proposals for legislative amendments are voted down. The minority MPs themselves, however, also stress their ability to block any proposals to restrict minority rights. Recent changes in the Riga City Council have provided more proportional representation than ever before in this important elected body, with at least 30 out of 60 deputies belonging to minorities, as well as an elected mayor of Russian origin.

Finally, the large number of former Soviet citizens who are not citizens of Latvia and the large share of the ethnic minority population has entailed an almost exclusive focus on these groups when analysing integration in Latvia. However, the specific sensitivities around citizenship, political participation and language have, for the time being, entailed a closure or even blindness to the need to address integration more broadly for various target groups. Thus, the access to the territory and access to residency for third country nationals who are not in the category of Latvian non-citizens are important factors for measuring the integration potential in Latvia.

\section{Greatest Achievement}

The greatest achievement concerning integration in the area of citizenship, representation and political participation is the consistently strong representation in elected bodies of minority platform parties and minority groups, despite the problem of a high share of non-citizens who cannot vote. In a key development, in 2009 , an ethnically Russian politician representing a minority platform party became mayor of Riga, thus breaking the post-1991 pattern of political presence only as permanent opposition by minority platform parties, but excluded from participation as a member of a ruling coalition. This actual sharing in political power by minority group representatives who portray themselves as such is a visible symbol of political integration, and the fact that they were elected by an ethnically mixed group of voters is a hopeful sign that the electorate may be less ethnically divided than the political elite. 


\section{Most Serious Problem}

The key problem remains inadequate possibilities for political participation because of lack of voting rights at municipal level for non-citizens, including for 350,000 Latvian non-citizens, and lack of effective consultative mechanisms at local and national level, including specifically also for minority groups and non-nationals. In addition, political parties are generally not ethnically integrated, which contributes to blocking development on these issues.

\section{Most Urgent Task}

The key task is to formulate pro-active policies of inclusion into political life of all permanent residents, including by actively mobilizing political engagement of all members of society. This includes working towards voting rights for non-citizens at local level, elaborating effective and meaningful consultative mechanisms at national and local level, encouraging increased ethnic diversity within political parties and strengthening civil society engagement by all members of society, including specifically by those belonging to minority groups. 


\section{Ethnic Minorities in the Latvian Labour Market, 1997-2009: Outcomes, Integration Drivers and Barriers}

\section{Mihails Hazans}

\section{Introduction}

During the first years after independence, the labour market situation was unfavourable for many representatives of ethnic minorities and, thus, for nonLatvians as a group. There were three main reasons for this. First, during the Soviet era non-Latvians were to a much larger extent than Latvians concentrated in the sectors which suffered the strongest contraction in the transition process manufacturing, as well as research related to the military-industrial complex. Second, in most cases the Latvian language skills of persons belonging to minorities were not sufficient for competing in the labour market on equal terms with Latvians. In 1996, less than two fifths of the population with a non-Latvian mother tongue considered their Latvian language skills as good or fair. ${ }^{1}$ Third, many non-Latvians did not have Latvian citizenship, which restricted their labour market possibilities. In 1995, the proportion of Latvian citizens among the minority population only slightly exceeded one third. ${ }^{2}$

As a result, in the late 1990s, according to labour force survey (LFS) data, labour force participation and employment rates among the minority population were lower than among Latvians, while minority unemployment rates were significantly higher. This was the case both on average and after accounting for other relevant factors. For instance, if two economically active persons from the same region, of the same age and gender, and with the same education level were compared, a non-Latvian individual had a significantly higher unemployment risk than his/her Latvian counterpart. ${ }^{3}$ Moreover, substantial differences were found between employed Latvians and non-Latvians in terms of

${ }^{1}$ B. Zepa, O. Žabko and L. Vaivode (2008), Language. March - April 2008. Riga: Baltic Institute of Social Sciences, Figure 5.1.

${ }^{2}$ Nils Muižnieks, ed., (2006), Latvian-Russian Relations: Domestic and International Dimensions. Rìga: University of Latvia Press, pg. 17.

3 Mihails Hazans (2005), 'Unemployment and the Earnings Structure in Latvia.' World Bank Policy Research Working Paper No. 3504. Washington DC: World Bank, pg. 42 and pp. 89-90. Available at SSRN: http://ssrn.com/abstract=659103 
distribution among occupations and industries. ${ }^{4}$ This is not an unusual situation: Zimmermann et al. note that "most of the existing research on ethnic minorities in Europe agrees on the existence of labour market disadvantages for ethnic minorities. Ethnic minorities typically have significantly higher unemployment rates, lower labour income, and they are less likely to find and keep their jobs than the majority population." 5 There are a number of recent studies related to the labour market situation of minorities in the Baltic countries. ${ }^{6}$

As Latvia has an unusually large (more than 40\%) minority population with a substantial geographical dispersion that is mostly locally born but lives primarily in a different language environment, comparisons with the labour market situation of minorities in other countries are difficult. In Estonia, the Russian-speaking population is also large but less dispersed geographically and more separated socially than in Latvia. In Ukraine, the state language is much

${ }^{4}$ Ibid., pp. 36-9.

${ }^{5}$ K. F. Zimmermann, M. Kahanec, A. Constant, D.J. DeVoretz, L. Gataullina and A. Zaiceva (2008), Study on the Social and Labour Market Integration of Ethnic Minorities, IZA Research Report 16, Bonn: IZA, pg. 11.

${ }^{6}$ See S. Aptekar, (2009) 'Contexts of exit in the migration of Russian speakers from the Baltic countries to Ireland', Ethnicities, 9, 507-526; Mihails Hazans (2007a), 'Looking for the workforce: The elderly, discouraged workers, minorities and students in the Baltic labour markets,' Empirica 34 (4), pp. 319-349; Mihails Hazans, (2007b), 'Coping with growth and emigration: Latvian labour market before and after EU accession', available at SSRN: http://ssrn.com/abstract=971198; Mihails Hazans (2007c), 'Latvian labour market before and after EU accession,' Beyond Transition Newsletter, 18 (1), pp. 10 -11; Mihails Hazans (2007d), 'Social and labour market integration of ethnic minorities in Latvia.' Background study for Zimmermann et al. (2008), Bonn: IZA (unpublished manuscript); Mihails Hazans (2010), 'Labour market integration of ethnic minorities in Latvia,' in Martin Kahanec and Klaus F. Zimmermann (eds.), Ethnic minorities in European labour markets: Challenges and solutions. Cheltenham, UK and Northampton, MA, US: Edward Elgar (forthcoming); Mihails Hazans, J. Dmitrijeva and I. Trapeznikova (2007), 'Determinants of unemployment duration in Latvia,' Research report to the Ministry of Welfare prepared for the project "Causes and duration of unemployment and social exclusion" of the National Programme of Labour Market Studies. Available at http:// www.lm.gov.lv/upload/darba_tirgus/darba_tirgus/petijumi/12_pet_en.pdf; Mihails Hazans, I. Trapeznikova, and O. Rastrigina (2008), 'Ethnic and parental effects on schooling outcomes before and during the transition: evidence from the Baltic countries', Journal of Population Economics, 21 (3), pp. 719-749; M. Kahanec and A. Zaiceva (2009), 'Labour Market Outcomes of Immigrants and Non-Citizens in the EU: An East-West Comparison,' International Journal of Manpower, 30 (1/2), pp. 97-115; K.-O. Leping and O. Toomet (2008), 'Emerging ethnic wage gap: Estonia during political and economic transition,' Journal of Comparative Economics 36(4), pp. 599-619; M. van der Leij, M. Rolfe and O. Toomet (2009), 'On the Relationship between Unexplained Wage Gap and Social Network Connections for Ethnical Groups,' paper presented at EALE 2009, available at http://www.eale.nl/Conference2009/Programme/PapersE/add101802_SegFnXKTo7. pdf; B. Zepa, I. Tomsone, I. Šūpule, L. Krastina (2006), 'Labour market integration of minority youth' (in Latvian), Riga: Baltic Institute of Social Sciences, available at http:// www.biss.soc.lv/downloads/resources/SIF\%202005-2006/Makets_jauniesi.pdf; and Zepa et al., (2008), Language. March - April 2008. 
closer to Russian. Therefore, the few international comparisons provided in this paper should be interpreted with care.

Due to the very large share of ethnic minorities in Latvia's population, their labour market integration is of utmost importance from both a social and economic perspective. This chapter provides an account of the dynamics of the main integration indicators during the period between 1997 and 2009. Special attention is paid to developments during the period of rapid economic growth in 2002-2007, and the outcomes at the end of this period, as well as to the changes caused by the economic crisis of 2008-2009.

This chapter examines four broad aspects of labour market integration. First, we compare the basic labour market outcomes (such as employment and earnings) of the minority and majority populations, ${ }^{7}$ applying a set of standard internationally comparable indicators. The single most informative measure of labour market inclusion of any social group is the employment rate. It, in turn, is determined by the labour force participation rate and the unemployment rate. Low participation signals exclusion, segregation or discouragement. High unemployment or low earnings among members of a group indicate the presence of labour market barriers (internal or external, including possible discrimination).

After calculating the ethnic gaps in employment and earnings, we can determine to what extent these gaps can be explained by inter-ethnic differences in human capital, demographic and geographic characteristics. We show that in Latvia, the main labour market barriers faced by minorities are related to Latvian language skills.

Next, we measure the degree of labour market segregation of minorities by looking at inter-ethnic differences in the distribution of the employed population between occupations and economic activities; language skills play a prominent role also in this respect. Furthermore, we look at the use of the Latvian and Russian language by workers who are not native speakers, thus measuring the intensity of inter-ethnic contacts at the workplace. Finally, we look at the perception of state language proficiency requirements by minority and majority workers, as well as evidence of discrimination of some "visible" minorities, including Roma.

${ }^{7}$ Due to space limitations, other outcomes of interest, such as prevalence of self-employment, participation in on-the-job training among employed and in publicly provided training among the unemployed, duration of unemployment, etc. remain outside the scope of this chapter. 


\section{Factors Facilitating Labour Market Integration of Minorities in 1997-2007}

The most important measure of the extent to which a certain group of the population is integrated into the labour market is the employment rate, i.e. the proportion of the employed among the (working age) population. From the employment perspective, the decade between 1997 and 2007 was marked by impressive progress in the field of labour market integration of ethnic minorities. In the age group 15 to 74 years, the employment gap between Latvians and non-Latvians, which was as big as 8.5 percentage points in 1997, steadily narrowed and disappeared completely by 2007 (see Table A1). Within the "standard" working age (15 to 64 years) the minority employment rate in 2007 was even one point higher than among Latvians.

Chances to be employed depend strongly on an individual's human capital, as well as on the situation in the local labour market. For instance, other things being equal, the probability to be employed is higher for a person with tertiary (university) education than for a person with secondary or primary education; likewise, a person living in Riga region is more likely to be employed that an otherwise similar person in Latgale. ${ }^{8}$ Therefore, when comparing Latvian and minority employment levels and trends, the composition of these two groups in terms of education, age, region and degree of urbanization has to be taken into account.

As shown in Figure 1 (upper panel), the composition of the Latvian and minority population aged 15-74 in terms of educational attainment was rather similar both in 2002 and in 2007. In 2007, however, the minority population featured slightly lower proportions of both low-educated and highly-educated individuals than ethnic Latvians. The proportion of secondary general school graduates among the minority population in 2007 had gone up by 4.5 points compared to 2002. More substantial differences between the two ethnic groups in terms of educational attainment are found in the population aged 25 to 44 years (i.e., the age group most active in the labour market) (see Figure 1, lower panel). During the five year period, the gap between Latvians and minorities in terms of proportion of persons with higher education has increased from 2.5 to 5.4 points. On the other hand, the proportion of low-skilled has increased more among minorities than among ethnic Latvians. These changes cannot be characterized as favourable for the employment of the minority population.

Figure 2 (upper panel) compares the composition of the Latvian and minority population in terms of region and degree of urbanisation at the place of residence. In this respect, the differences between the ethnic groups are very substantial, but one cannot say that these differences favour one of the groups

\footnotetext{
${ }^{8}$ Hazans (2007b), 'Coping with growth and emigration: Latvian labour market before and
} after EU accession,' Table 1.3. 
from the employment perspective (here, we consider all kinds of employment, not just paid employment). More importantly, there are almost no changes between 2002 and 2007. Figure 2, lower panel demonstrates that during this period the age composition of the two ethnic groups has not changed in a way which would affect employment rates.

Population aged 15-74

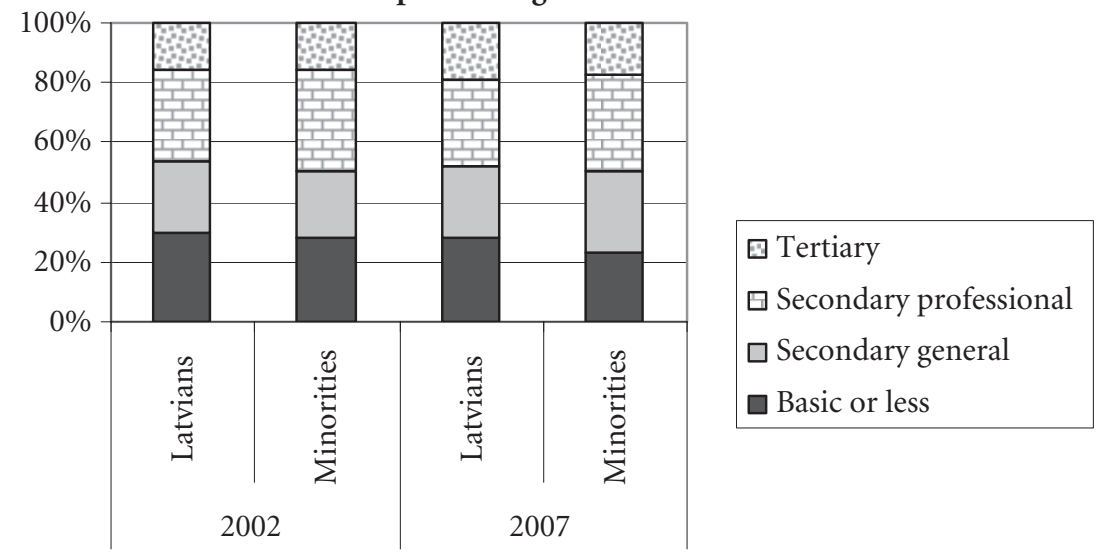

Population aged 25-44

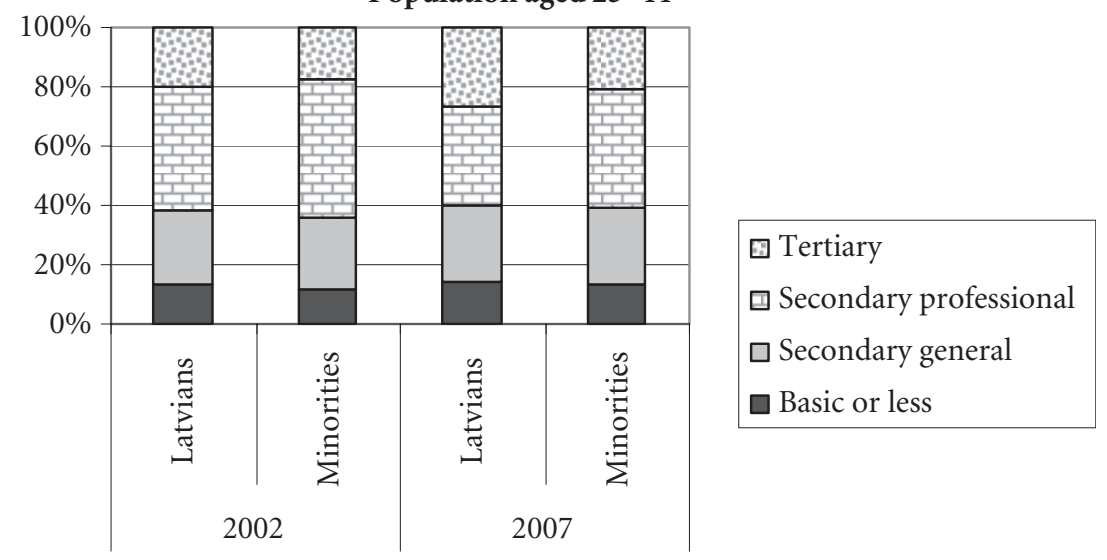

Figure 1. Latvian and minority population by educational attainment in 2002 and 2007

Source: Calculations using LFS data.

To sum up, there is no reason to link the disappearance of the ethnic employment gap with changes in the composition of the Latvian and minority population in terms of educational attainment, regional dispersion, or degree of urbanisation (the same is true also for the period between 1997 and 2002). What, then, were the factors which facilitated the labour market integration of minorities? 


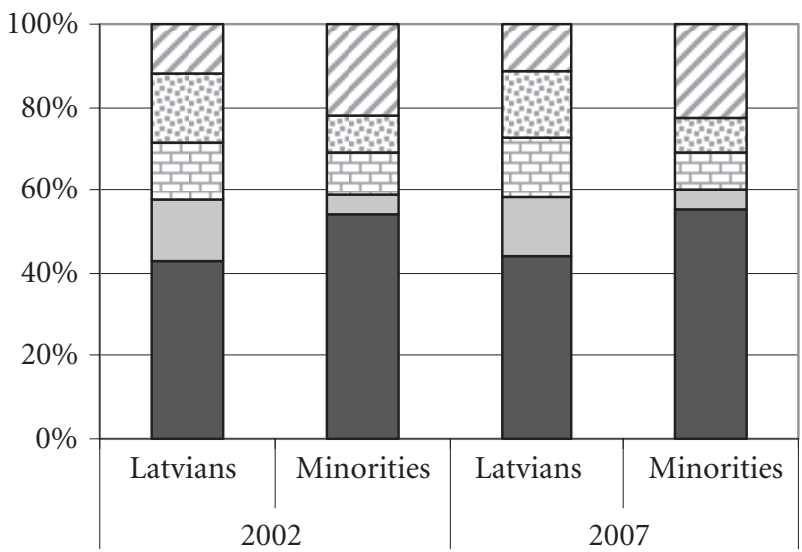

\section{$\square$ Latgale}

曰 $\mathrm{G}$ Kurzeme

$\boxminus$ Zemgale

$\square$ Vidzeme

$\square$ Riga and Pieriga

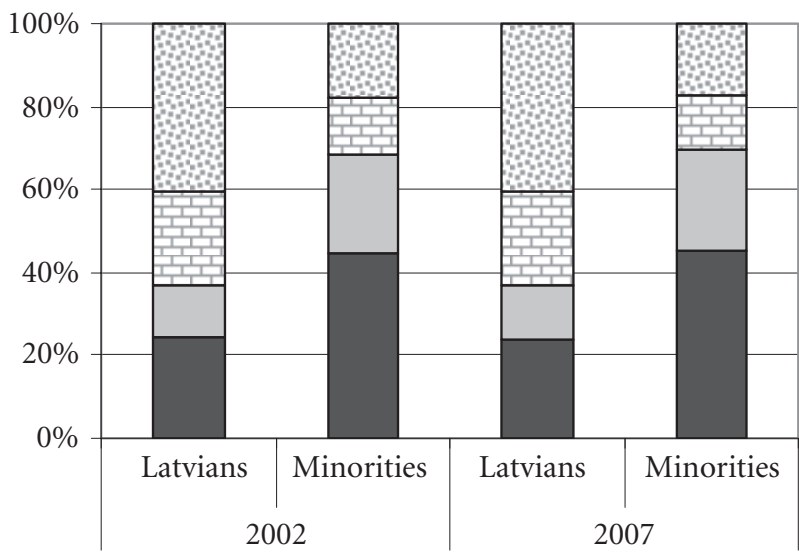

๑ Rural areas 口 Small cities $\square$ Big cities

$\square$ Riga

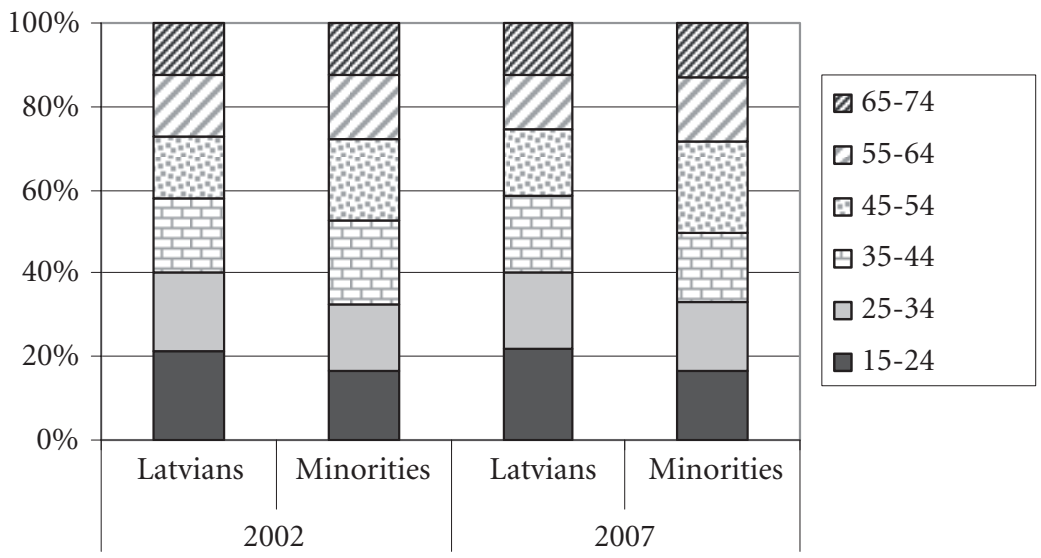

Figure 2. Latvian and minority population aged $15-74$ by region, degree of urbanization, and age group in 2002 and 2007

Source: Calculations using LFS data. 
First, as seen in Figure 3, the Latvian language skills of the minority population have been gradually improving. Second, the proportion of non-citizens among minorities has fallen from $65 \%$ in 1995 to $45 \%$ in the middle of $2008 .{ }^{9}$ Thus, the mismatch between the minority labour supply and market demand has become substantially smaller.

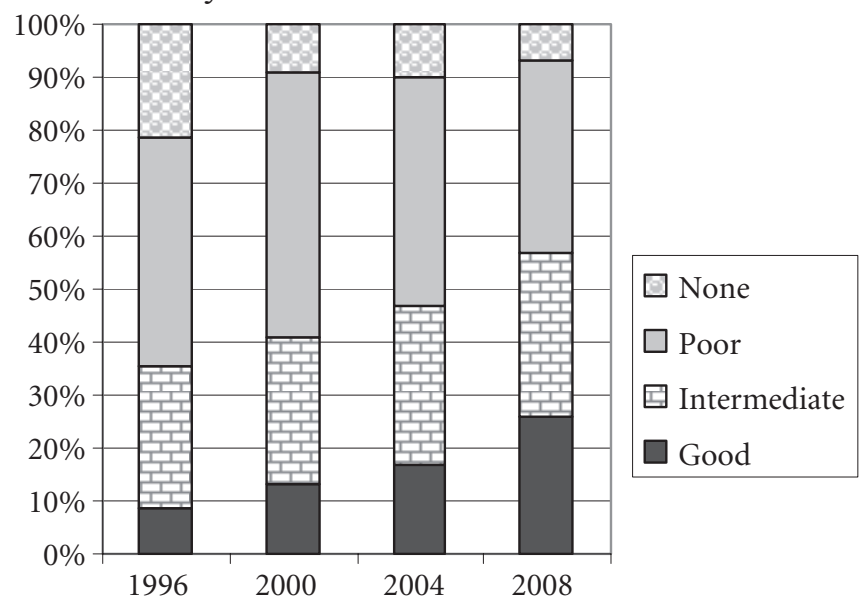

Figure 3. Self-assessed Latvian language skills among population aged 15-74 whose mother tongue is not Latvian (1996-2008)

Notes: Surveys conducted in June 1996, March-April 2000, November-December 2004, and March-April 2008, Zepa et al. (2008), Language. Figure 5.1.

Third, rapid growth of the Latvian economy in 2002-2007 combined with the outflow of the Latvian labour force after European Union accession in $2004^{10}$ resulted in a steadily increasing number of job vacancies, especially in construction, manufacturing, retail trade and private services. The combination of growing demand and falling supply of labour had two important consequences for the labour market. On the one hand, real wages went up, leading to an increase in labour force participation rates. This effect was more pronounced among groups which earlier featured a relatively low level of labour force participation. Given that both the unemployment and inactivity levels among the minority population were initially higher than among ethnic Latvians, minorities were over-represented among new hires (see Tables A1-A2 for details).

On the other hand, employers' de facto requirements towards new workers have become lower along all dimensions, including state language skills. This also facilitated minority employment, especially taking into account that

9 Data of the Latvian Population Register.

${ }^{10}$ See Mihails Hazans, and Kaia Philips (2010), 'The Post-Enlargement Migration Experience in the Baltic Labor Markets,' in Martin Kahanec and Klaus F. Zimmermann (eds.), EU Labor Markets After Post-Enlargement Migration. Berlin-Heidelberg, Germany, London, UK and New York, US: Springer, pp. 255-304 for details. 
in the service sector good Russian language skills were considered an asset. Loosening hiring standards in terms of Latvian language proficiency of course led to a temporary worsening of the average quality of the Latvian language in the service sector, which led to a new round of inter-ethnic tensions both in public discourse and in everyday life. It is important to understand, however, that in the medium-term more liberal hiring standards resulted in improved Latvian language skills of the minority population and an increased number of non-Latvians actively using the Latvian language on a daily basis. Figure 3 provides evidence that the Latvian language skills of the minority population were improving much more quickly between December 2004 and March 2008 than in the previous four years. This cannot be attributed to the education reform, because a similar result is found also within the age groups 35-49 and 50-74 years. ${ }^{11}$

De facto liberalization gave a chance to work in a Latvian-languageintensive environment to many non-Latvians who previously had no or very few contacts with Latvians. Thanks to an increasing number of inter-ethnic contacts at the workplace, both Russian-speakers and Latvian-speakers could improve their knowledge of the "other" language, while the dominant role of the Latvian language has not been threatened. Data on language use at the workplace (Figure 4) supports this argument. Between 2004 and 2008, among both native Latvian-speakers and native Russian-speakers, the proportion of workers who speak Latvian more than Russian showed the largest increase at the expense of those who use only the native language. This suggests that relatively liberal access to jobs for minorities can facilitate not only their labour market integration but also cultural (including language) and social integration. Language-based labour market restrictions, by contrast, are unlikely to lead to successful integration of a large minority. Such restrictions create a "lock-in" effect: often, the necessary degree of fluency in Latvian is difficult to achieve just by learning in class, but in the workplace, a person with some knowledge of the language will almost surely reach the required level within one year or less; the problem is, how to get to the workplace.

The above discussion helps to explain the polarization of public opinion on how strict the legal requirements for state language proficiency should be for employees (and how these requirements should be enforced). One part of society puts more value on the economic benefits from higher employment rates among the minority population and the social benefits from integration via the workplace, as well as from a growing number of active users of the Latvian language, while the other part perceives as a serious immediate problem and a strategic threat a temporary decline in the average quality of the Latvian language in the service sector, which is inevitable in such circumstances. Naturally, the former advocates a more liberal approach in language policy in

${ }^{11}$ Zepa et al. (2008), Language, Figure 5.2. 
the labour market, while the latter advocates stricter requirements and tougher enforcement. We present survey evidence on public support for both views below. However, it is worth noting at this point that for native Latvian speakers in the latter group the perceived disadvantage and threat is more personal than the perceived benefit by those in the first group; hence, the second group is much more vocal.

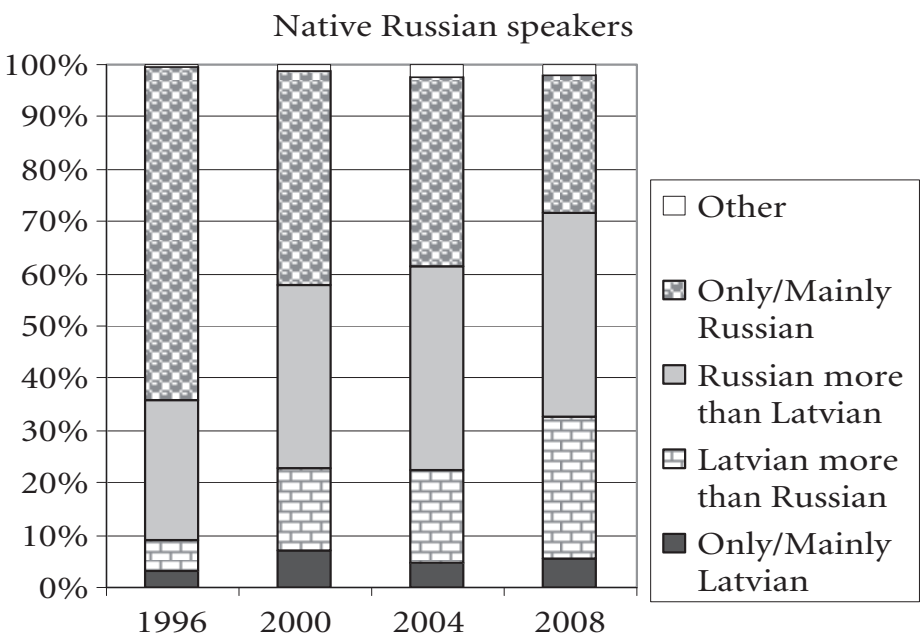

Native Latvian speakers

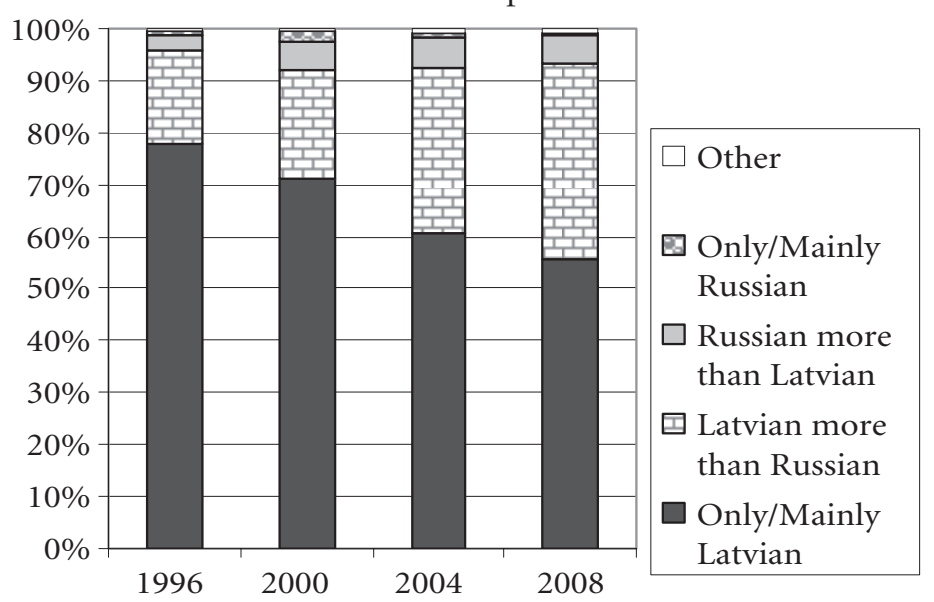

Figure 4. Language use at the workplace, by workers' mother tongue (1996-2008)

Notes: Only employed persons included. Non-response (less than $1 \%$ ) excluded. Source: Calculation with data from Zepa et al. (2008), Language.

Finally, uneven regional development has also contributed to improving the labour market situation of the minority population. The increase in employment rates between 2002 and 2007 tended to be larger in regions where the share of 
the minority population is higher (Figure 5, upper panel). In particular, the largest (more than 10 points) increase in the employment rate is found in Latgale, where non-Latvians account for over $60 \%$ of the population, while in Vidzeme, where just one out of ten inhabitants is non-Latvian, the employment rate increased by less than 2 points. Likewise, in Riga and other big cities, where $55-60 \%$ of the population are of non-Latvian ethnicity, employment growth was much stronger than elsewhere (Figure 5, lower panel).

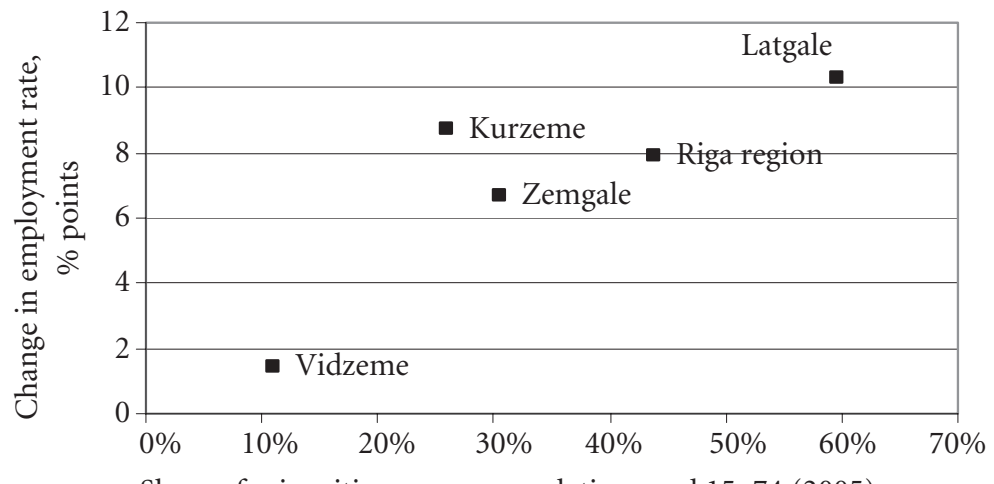

Share of minorities among population aged 15-74 (2005)

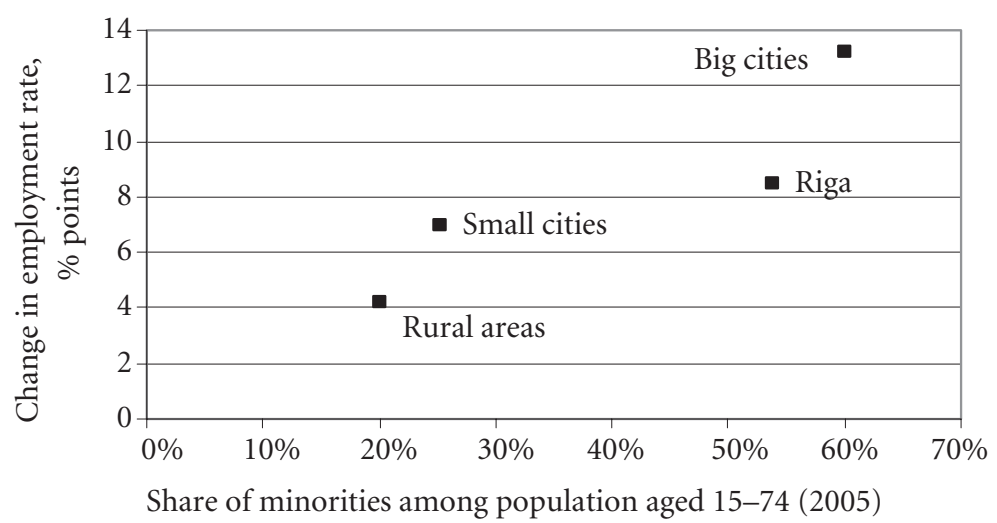

Figure 5. Share of minority population and increase in employment rates (2007 vs. 2002) by region and degree of urbanization

Notes: Employment rates in the Figure refer to population aged 15-74, but results do not change qualitatively when rates for population aged 15-64 are used.

Source: Calculations with LFS data.

\section{The Dynamics of Employment Rates by Ethnicity}

This section analyses the dynamics of employment rates among ethnic Latvians and non-Latvians in different demographic groups. Figure 6 illustrates the evolution of employment rates among Latvians and non-Latvians by gender. A steady reduction of the ethnic gap in employment was observed for 
both genders in 1997-2007. By the end of this period, the employment rate of minority men exceeds that of ethnic Latvian men by almost two points. Among women the ethnic gap was wider during the whole period and remained positive (at 1.5 points) in 2007. This is of course related to the fact that females concentrate in language-intensive service sector occupations. However, among the working-age (15 to 64 years) population, the ethnic employment gap disappeared by 2007 for females as well (Table A.1).

As Latvia entered a recession in the middle of 2008, the trend in the ethnic employment gap has been reversed. In the first three quarters of 2009 there was an almost two-point gap in favour of Latvian men and an almost five-point gap in favour of Latvian women (Figure 6). Moreover, in the third quarter of 2009, both male and female minority employment rates were by about 6 points lower than employment rates of ethnic Latvians.

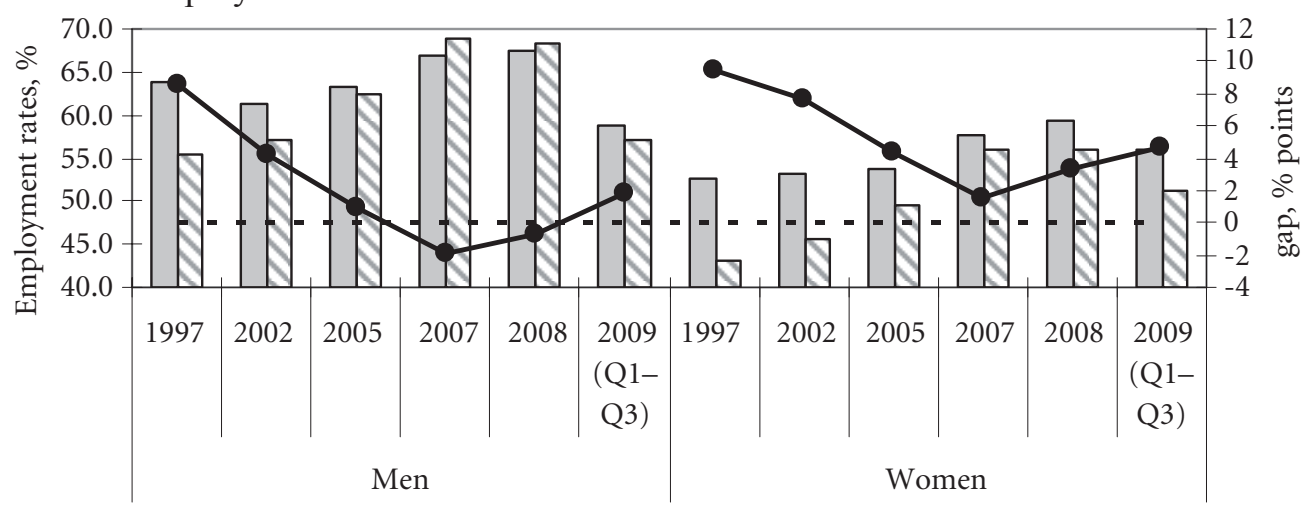

$\square$ Latvians $\square$ Non-Latvians $\longrightarrow$ Gap (right axis) - - - Equality line

Figure 6. Employment rates by ethnicity and gender, 1997-2009. Population aged 15-74

Source: Calculation based on LFS data (reproduced by permission from Hazans (2010), 'Labour market integration of ethnic minorities in Latvia.')

By comparison, in Estonia, developments during the 2000s were broadly similar; among males, the widest gap (4 points) was observed in 2003, while among females it reached 8 points in 2006; the overall gap remained at 2 points in 2007-2008 for the 15-74 years old, but has been closed by 2007 among the working age (15-64 years) population. ${ }^{12}$

${ }^{12}$ See Statistics Estonia (2009), 'Labour status of population aged $15-74$ by ethnic nationality, sex and age,' available at http://pub.stat.ee/pxweb.2001/I_Databas/Social_Life/09Labour_ market/08General_data_of_labour_market/02Annual_statistics/02Annual_statistics.asp. 


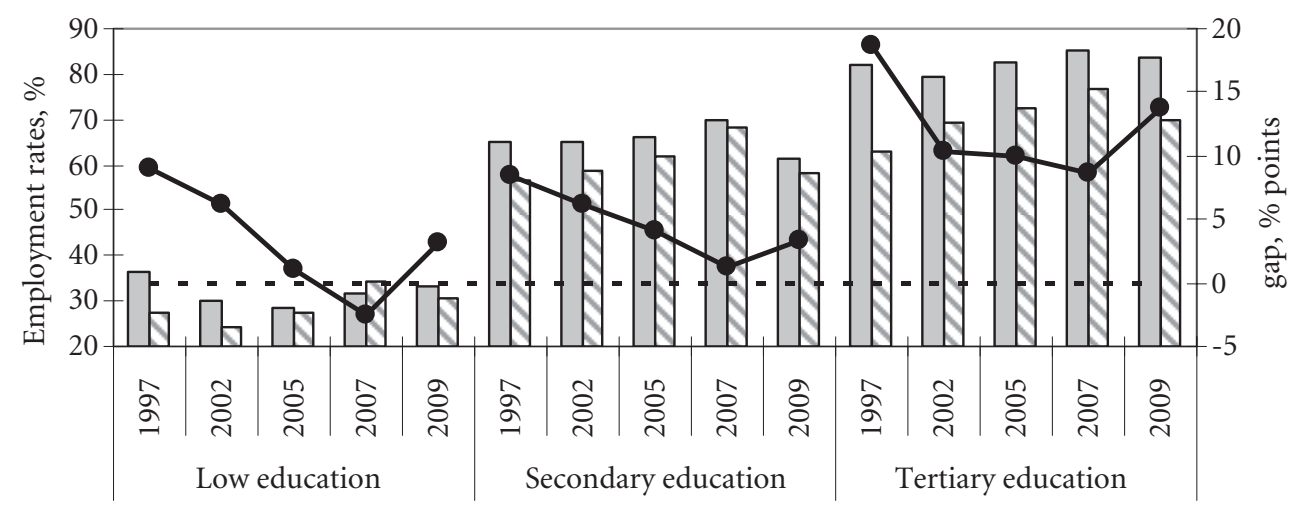

Latvians 0 Non-Latvians Gap (right axsis)

- - - Equality line

Figure 7. Employment rates by ethnicity and educational attainment, 1997-2009. Population aged 18-74

Notes: Year 2009 data refer to the first three quarters.

Source: Calculation based on LFS data

Figure 7 presents the evolution of employment rates among ethnic Latvians and non-Latvians by educational attainment. ${ }^{13}$ In the late 1990 s, a significant ethnic gap in employment is found at every level of education: almost 19 points among tertiary educated persons, and 9 to 10 points among persons with secondary or below secondary education. Between 1997 and 2007, the employment level of the high- and medium-skilled population was growing in both ethnic groups, but growth was faster among minorities. By 2007, the ethnic gap in employment rates among secondary educated Latvians and non-Latvians was reduced to just 1.2 points, but during the crisis of 2008-2009 it increased again, exceeding five points in the third quarter of 2009; the three-quarter average in 2009 was 3.4 points. Likewise, among the low-skilled, the ethnic employment gap was about one point in 2007 but three points in the first three quarters of 2009 , reaching eight points in 2009/Q3. For persons with tertiary education, the ethnic gap in employment, which was as wide as 19 points in 1997, was fluctuating around 10 points during 2002-2008, but increased to almost 14 points in the first three quarters of 2009.

Figure 8 compares the dynamics of labour market integration of minorities across age groups and types of settlement (more details found in Table A.1). During 2002-2007, the employment gap between Latvians and minorities

13 Teenagers aged 15 to 17 years (almost all of them with education below secondary) are excluded because in this age group interpreting employment is not straightforward. In 1997 , the employment rate in this category was $10 \%$ among Latvians and $4 \%$ among nonLatvians. Between 2002 and 2007, just 3 to 5\% of teenagers aged 15-17 were employed in both ethnic groups, while in 2009/Q1 this rate was less than $1 \%$. 
narrowed sharply in all age groups except the elderly (65-74 years), and in all types of settlement except big cities outside Riga, while in the two cases mentioned above as exceptions there was a modest reduction.

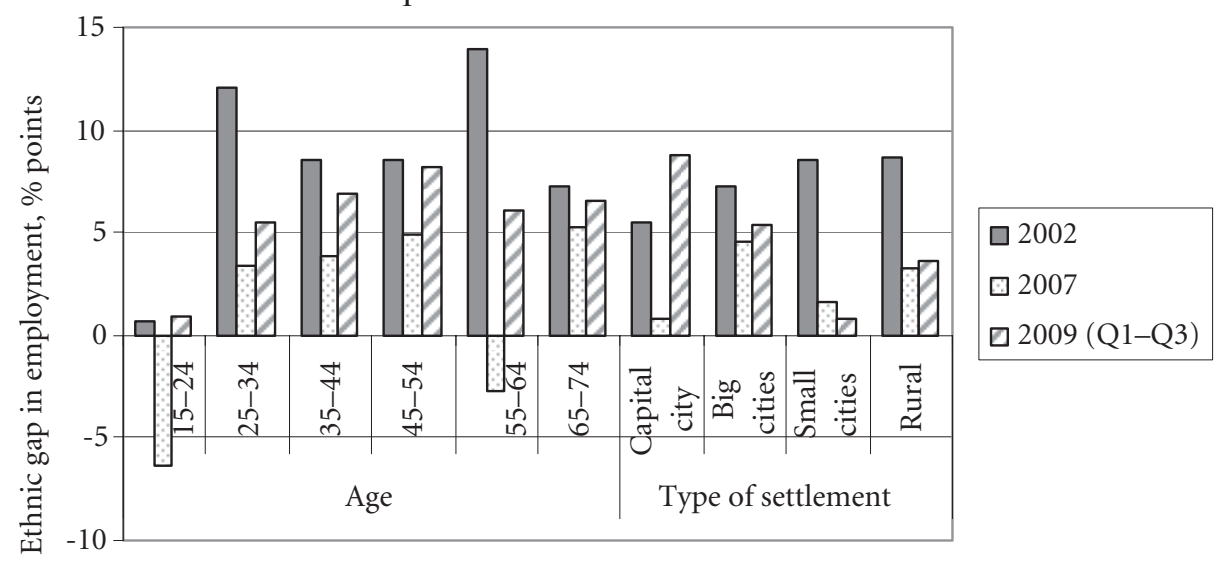

Figure 8. Ethnic gap in employment by age group and type of settlement (2002, 2007, and 2009/Q1)

Source: Calculation based on LFS data

In 2007, the last year of the growth period, a substantial (about 4 points on average) ethnic employment gap is found in the prime-age group (25-54 years), among the elderly (65-74 years), in big cities outside Riga, and in the countryside; the employment rate of minority youth and persons aged 55 to 64 was higher than that of their Latvian counterparts. Further inspection of Figure 8 identifies three groups of the minority population which suffered disproportionately from the employment shock during the first year of the economic crisis: youth, those older than 54, and residents of the capital city. As a result, in the first three quarters of 2009 the ethnic employment gap was positive in all age groups and in settlements of all types; in Riga and other big cities (home to $70 \%$ of the minority population) this gap was, respectively, nine and five points wide.

The existence of labour market integration barriers is manifested by differences in labour market outcomes which cannot be explained by differences in demographic and human capital characteristics of the minority and majority population. This approach, known as gap decomposition, was proposed by Blinder ${ }^{14}$ and Oaxaca ${ }^{15}$ and is widely used by labour economists when studying gender or ethnic discrimination and, more generally, differences in labour market outcomes between demographic groups. There is a considerable body

${ }^{14}$ A. S. Blinder (1973), 'Wage Discrimination: Reduced Form and Structural Estimates,' The Journal of Human Resources, 8, pp. 436-455.

15 R. Oaxaca (1973), 'Male-Female Wage Differentials in Urban Labor Markets,' International Economic Review, 14, pp. 693-709. 
of recent research related to ethnicity or immigrant status. ${ }^{16}$ In the context of this paper, the explained ethnic employment gap is the part of the total difference in employment rates between Latvians and minorities which is due to differences in distribution of the two groups by human capital, demographic, and geographic characteristics. The remaining part (the unexplained ethnic employment gap) can be then attributed to differences in language skills, citizenship status, other inter-ethnic differences, and possible discrimination. The explained and unexplained ethnic earnings (pay, wage) gaps are defined in a similar way, although in this case the control variables might include also some job characteristics.

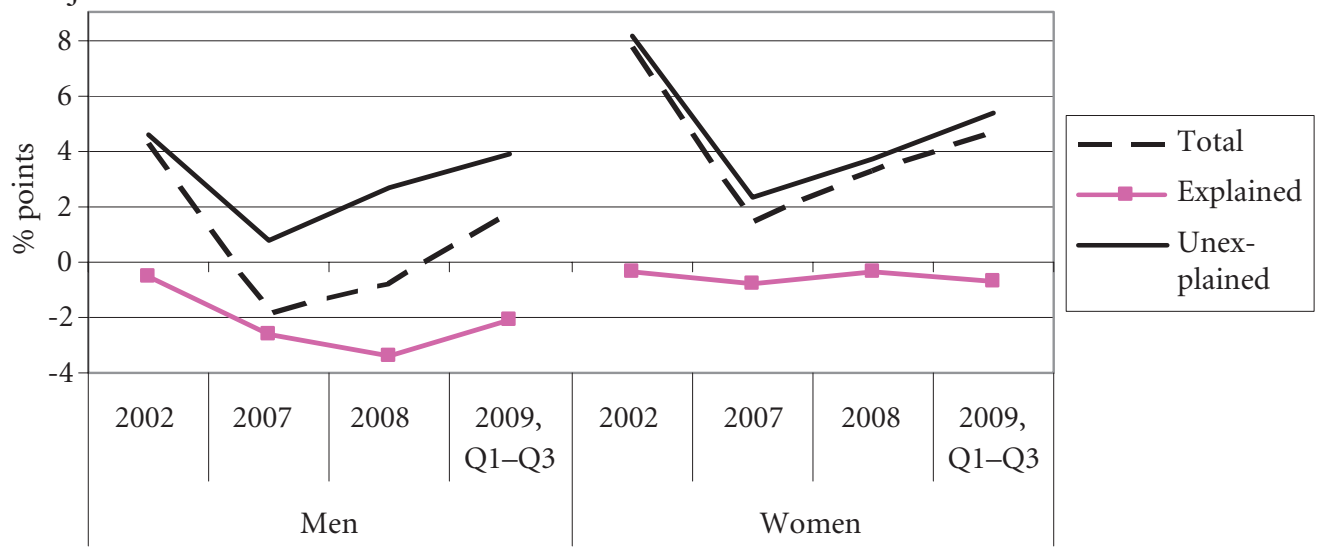

Figure 9. Explained and unexplained ethnic employment gap, 2002-2009

Notes: The explained gap is the part of the total difference in employment rates which is due to differences in distribution of the two groups by human capital, demographic, and geographic characteristics. Control variables include: age group, education (7 categories), family status, region, degree of urbanisation, and quarter. The remaining part (the unexplained gap) can be then attributed to differences in language skills, citizenship status, other inter-ethnic differences, and possible discrimination. The unexplained gap is statistically significant at the $1 \%$ level in all years for females and in 2002, 2008, 2009 for males. Source: Calculation based on LFS data

The decomposition of the ethnic employment gap into explained and unexplained parts is presented (separately for males and females) in Figure 9 for

${ }^{16}$ See A. Constant, M. Kahanec and K.F. Zimmermann (2006), 'The Russian-Ukrainian Earnings Divide,' IZA Discussion Paper No. 2330; Mihails Hazans (2005), 'Unemployment and the Earnings Structure in Latvia,' World Bank Policy Research Working Paper No. 3504. Washington DC: World Bank. Available at SSRN: http://ssrn.com/abstract=659103; Hazans (2007b), 'Coping with growth and emigration'; Mihails Hazans (2008), 'Post-enlargement return migrants' earnings premium: Evidence from Latvia', available at SSRN: http://ssrn. com/abstract=1269728; Hazans et al. (2007), 'Determinants of unemployment duration in Latvia'; Hazans et al., (2008), 'Ethnic and parental effects on schooling outcomes before and during the transition"; Leping and Toomet (2008), 'Emerging ethnic wage gap'; and Kahanec and Zaiceva (2009), 'Labour Market Outcomes of Immigrants and Non-Citizens in the EU.' 
the years 2002, 2007, 2008, and 2009. The explained gap is negative for both genders in 2002, as well as in 2007-2009. This means that if employment prospects would depend only on gender, age, educational attainment, region and type of settlement, then employment rates would be somewhat higher among minorities than among ethnic Latvians. Hence the unexplained ethnic employment gap exceeds the observed (total) gap. In 2002, the unexplained gap was 4.6 percentage points among females and 8.1 points among males. In five years, these ethnic effects have declined to 0.7 points for males and 2.4 points for females. ${ }^{17}$ It is fair to say that in 2007 the ethnic (including language) effect on employment was negligible among males and rather small among females. This does not exclude of course effects of substantial size within some categories (for instance, females with poor Latvian language skills).

Overall the conclusion from Figure 9 is that the unexplained gap in employment rates between Latvians and non-Latvians has narrowed down substantially between 2002 and 2007, but significantly increased again with the beginning of the economic crisis, reaching four points among males and exceeding five points among females.

\section{Labour Force Participation, Job Security and Unemployment}

Inspection of labour force participation rates (see Table A.2) reveals that since 2004, minority males are more active in the labour market than Latvian males. The female activity gap in favour of ethnic Latvians was as high as 5 points in 2002, disappeared by 2004 and stayed near zero until 2007, but increased to 2 points in 2008 (Figure 10). The largest reduction of the ethnic gap in participation occurred among the low skilled, as well as in the age groups 55-64 and 25-34. Minority youth features activity rates above those of Latvians throughout the period. More detailed inspection (see Table A.3) finds that starting from 2007 this is the case among both students and non-students. On the other hand, among persons with tertiary education, as well as among those aged 65 to 74 and among residents of big cities (except Riga), the gap declined just a little between 2002 and 2007, but bounced back in 2008.

During the initial stage of the crisis, minority workers faced a higher risk of losing their job. Table 1 presents annual labour market flows from employment by gender and ethnicity. For example, between 2007 and 2008, outflow to unemployment was 1.8 times higher among minority males than among their Latvian counterparts, while for females this ratio was 1.6. Higher vulnerability to the crisis among minority workers is to some extent due to their

17 The explained gaps have declined as well. This happened because the increase in labour demand was more pronounced in groups where minorities are over-represented (see Figure 5, for example). 
concentration in manufacturing and construction (see below), the hardest hit sectors. However, econometric analysis shows that outflow from employment was significantly higher among non-Latvians also after controlling for sector, occupation and region.

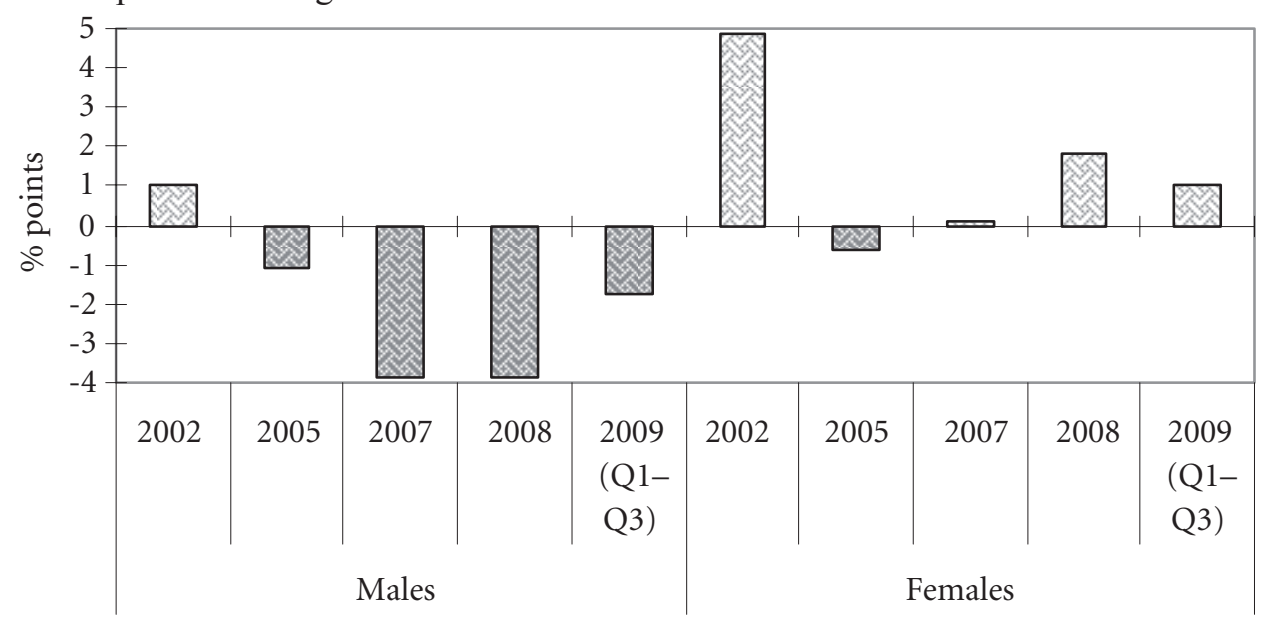

Figure 10. Gap between ethnic Latvians and minorities in labour force participation by gender, 2002-2009

Source: Calculation based on LFS data.

Table 1. Labour market status of persons employed one year ago, by gender and ethnicity (2008 and 2009), \%

\begin{tabular}{|c|c|c|c|c|c|c|c|c|}
\hline & \multicolumn{4}{|c|}{ Males } & \multicolumn{4}{c|}{ Females } \\
\cline { 2 - 10 } & \multicolumn{2}{|c|}{2008} & \multicolumn{2}{|c|}{$2009(\mathrm{Q} 1-\mathrm{Q} 3)$} & \multicolumn{2}{c|}{2008} & \multicolumn{2}{c|}{2009 (Q1-Q3) } \\
\cline { 2 - 9 } & Latvians & Minorities & Latvians & Minorities & Latvians & Minorities & Latvians & Minorities \\
\hline Employed & 93.7 & 90.3 & 84.2 & 79.6 & 93.1 & 90.5 & 88.6 & 85.1 \\
\hline Unemployed & 3.6 & 6.5 & 10.9 & 14.4 & 2.9 & 4.6 & 5.7 & 9.1 \\
\hline $\begin{array}{c}\text { Economically } \\
\text { inactive }\end{array}$ & 2.7 & 3.2 & 4.9 & 6.0 & 4.0 & 4.9 & 5.7 & 5.8 \\
\hline Total & 100 & 100 & 100 & 100 & 100 & 100 & 100 & 100 \\
\hline
\end{tabular}

Source: Calculation based on LFS data

Over the years, unemployment rates have been consistently higher among minorities than among ethnic Latvians. However, minority unemployment rates have been falling faster up until 2005 for males and up until 2007 for females (Figure 11). In 2007 (at the end of the growth period), both male and female unemployment rates were about 1.5 times higher among minorities. The recession-related increase in unemployment between 2007 and 2009/Q3 appears to be larger among Latvian males compared to their minority counterparts, but it was the other way around among females. Hence, the ethnic ratio of unemployment rates reached a historic low of 1.25 for males but was as high as 1.58 for females. 


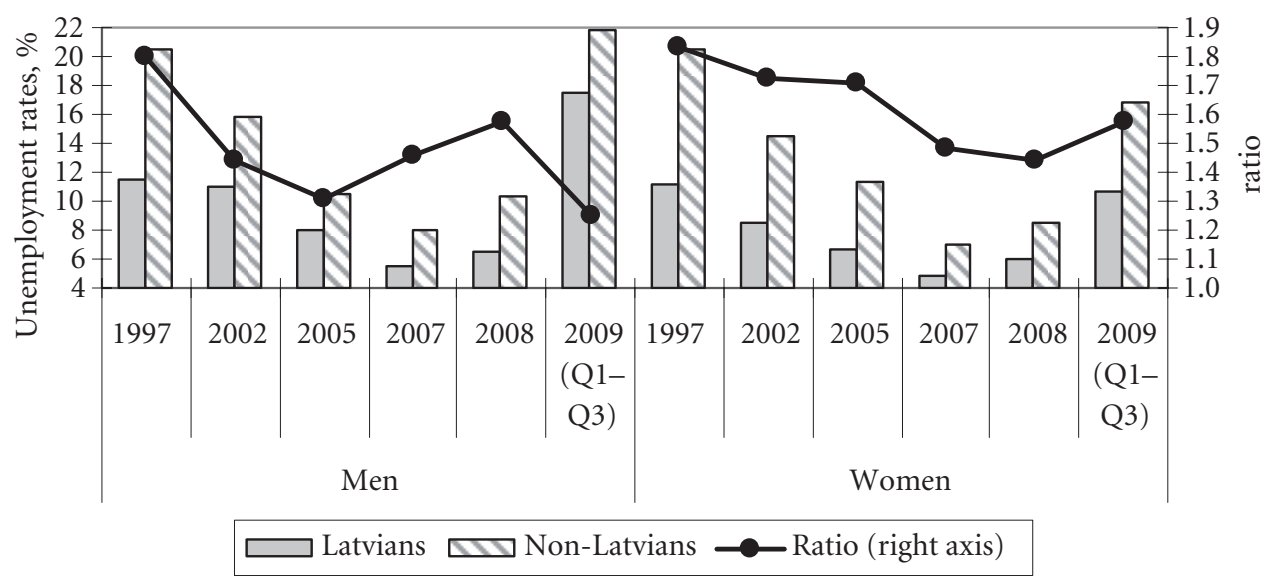

Figure 11. Unemployment rates by ethnicity and gender, 1997-2009

Source: Calculation based on LFS data (reproduced by permission from Hazans (2010), 'Labour market integration of ethnic minorities in Latvia.'

In Estonia, the unemployment rate among minorities in 2007-2008 was about two times higher than among ethnic Estonians, while in 2004-2006 this ratio stood at about 2.4. ${ }^{18}$

Table 2. Registered unemployed by ethnicity and Latvian language skills before and during the crisis

\begin{tabular}{|c|c|c|c|c|c|c|c|}
\hline & \multicolumn{3}{|c|}{ All } & \multicolumn{2}{c|}{ Males } & \multicolumn{2}{c|}{ Females } \\
\cline { 2 - 8 } & Jan'08 & Sep'08 & Sep'09 & Sep'08 & Sep'09 & Sep'08 & Sep'09 \\
\hline Ethnicity & & & & & & & \\
\hline Latvian & 54.2 & 52.5 & 53.9 & 54.1 & 55.0 & 51.4 & 52.8 \\
\hline Other & & 43.1 & 40.2 & 41.4 & 39.1 & 44.3 & 41.2 \\
\hline Not stated & & 4.4 & 5.9 & 4.4 & 5.9 & 4.4 & 6.0 \\
\hline Total & 100 & 100 & 100 & 100 & 100 & 100 & 100 \\
\hline Latvian language skills & & & & & & & \\
\hline $\begin{array}{c}\text { Completed education in } \\
\text { Latvian }\end{array}$ & & 52.6 & 54.5 & 54.1 & 55.2 & 51.5 & 53.9 \\
\hline Highest degree certificate & & 6.1 & 6.2 & 4.1 & 4.2 & 7.5 & 8.1 \\
\hline Medium degree certif. & & 15.9 & 15.5 & 11.0 & 11.9 & 19.4 & 19.0 \\
\hline Lower degree certificate & 12.0 & 12.4 & 11.5 & 13.9 & 13.0 & 11.3 & 10.1 \\
\hline No certificate & 12.6 & 13.1 & 12.2 & 16.8 & 15.7 & 10.5 & 8.9 \\
\hline Total & 100 & 100 & 100 & 100 & 100 & 100 & 100 \\
\hline
\end{tabular}

Source: Elaboration on State Employment Agency data.

The proportion of minorities among the registered unemployed was about $46 \%$ in the beginning of 2008 , increased to $47.5 \%$ by the end of $2008 / \mathrm{Q} 3$,

${ }^{18}$ Statistics Estonia (2009), 'Labour status of population aged $15-74$ by ethnic nationality, sex and age.' 
but returned to the pre-crisis level a year later (see Table 2). Given that the proportion of minorities in the labour force was just $40.4 \%$ according to the 2008 LFS, this confirms that minorities face somewhat higher unemployment risk than ethnic Latvians and that the initial stage of the crisis was particularly unfavourable for minorities.

\section{Earnings}

According to LFS data, in 2002-2009 minority workers earned on average 8 to 9 percent less than ethnic Latvians (Table 3). The size of this gap remained quite stable, although it decreased somewhat by the end of the growth period in 2007 and increased during the crisis years 2008-2009. The most substantial ethnic pay gap (21 percent on average) is found among public sector female workers. More detailed analysis ${ }^{19}$ shows that among males, the ethnic earnings gap is virtually absent in the lower part and in the middle of the distribution of earnings. Among private sector female workers, the gap is present only in the lower end of the distribution, while among public sector female workers, it is most pronounced in the middle.

Table 3. Evolution of the ethnic gap in earnings, 2002-2009

\begin{tabular}{|c|c|c|c|c|c|c|c|c|c|}
\hline & & & & & & \multicolumn{2}{|c|}{ Males } & \multicolumn{2}{|c|}{ Females } \\
\hline \multicolumn{4}{|c|}{ Full-time workers a } & \multicolumn{2}{|c|}{ All workers } & $\begin{array}{l}\text { Private } \\
\text { sector }\end{array}$ & $\begin{array}{l}\text { Public } \\
\text { sector }\end{array}$ & $\begin{array}{c}\text { Private } \\
\text { sector }\end{array}$ & $\begin{array}{l}\text { Public } \\
\text { sector }\end{array}$ \\
\hline 2002 & 2007 & 2008 & $\begin{array}{c}2009 \\
\text { Q1-Q3 }\end{array}$ & 2002 & $\begin{array}{c}2009 \\
\text { Q1-Q3 }\end{array}$ & 2007 & 2007 & 2007 & 2007 \\
\hline \multicolumn{10}{|c|}{ Ratio of mean earnings (minority vs. Latvians, \% ) } \\
\hline 91.4 & 92.4 & 90.7 & 90.6 & 91.7 & 92.4 & 98.4 & 90.4 & 92.6 & 79.2 \\
\hline
\end{tabular}

Mean unexplained ethnic pay gap between Latvian and otherwise similar minority workers ( $\%$ of mean Latvians' earnings)

\begin{tabular}{|c|c|c|c|c|c|c|c|c|c|}
\hline $11.3 * * *$ & $5.8 * * *$ & $7.2 * * *$ & $8.1 * * *$ & $11.1 * * *$ & $7.4 * * *$ & 0.1 & 1.8 & -1.2 & $8.9 * * *$ \\
\hline $7.8 * * *$ & $4.1 * * *$ & $5.5 * * *$ & $5.9 * * *$ & $7.7 * * *$ & $5.2 * *$ & -4.7 & 0.2 & -0.4 & $4.8 * *$ \\
\hline
\end{tabular}

Notes:

a Full-time status as reported by workers, but those working less than 35 hours per week excluded.

${ }^{\mathrm{b}}$ Controls include gender, educational attainment (7 categories), being a student or pupil, age and its square, marital/cohabiting status, degree of urbanisation at residence (4 categories), type of contract, job tenure, usual weekly hours worked, ownership sector, sector of economic activity (12 categories), job location (5 regions and capital city), reference month.

c Additional controls: occupations (27 two-digit ISCO groups) and plant size (5 categories). Earnings functions not corrected for selectivity. $* * *, * *$ - estimates significant at $1 \%$ (respectively, 5\%) level.

Source: Calculation based on LFS data.

${ }^{19}$ See Hazans (2010), 'Labour market integration of ethnic minorities in Latvia.' 
The average ethnic pay gap unexplained by human capital and demographic characteristics of the workers, as well as by the type of contract, job tenure, usual weekly hours worked, ownership sector, sector of economic activity and location of the enterprise, has declined from 11 points in 2002 to 6 points in 2007 but increased to 8 points in 2009. Like the raw gap, it is most pronounced among public sector female workers: 9 points, 5 of which remain even within narrow occupation-firm size cells. The unexplained gap is virtually absent in the private sector and among public sector male workers.

International comparisons suggest that the ethnic pay gap in Latvia is modest. Leping and Toomet ${ }^{20}$ find that in Estonia, the ratio of earnings of minority and Estonian males fluctuated around 90\% in 2002-2004 but increased to $95 \%$ in 2005 , while the unexplained ethnic pay gap fluctuated around $20 \%$ in 2000-2004 but became two times smaller in 2005. Leping and Toomet and Leij et al. ${ }^{21}$ argue that barriers to the labour market and segregated social networks are the main factors behind the unexplained ethnic wage gap in Estonia.

In the United States in 2000, Hispanic workers of both genders earned on average about $20 \%$ less than white workers, but when education level is controlled for, the gap is just $7 \%$, and when occupation is also controlled, there is no gap. ${ }^{22}$ However, the wage gap between Hispanics and whites has a tendency to increase; the median earnings of Hispanics were $74 \%$ of whites in 2006 and $72.6 \%$ in $2007 .^{23}$

An interesting situation can be found in Ukraine, where during the late 1990s and early 2000s Russian-speakers of both genders enjoyed quite substantial earnings premia over Ukrainian speakers; ${ }^{24}$ these premia were larger and showed an increasing trend longer for males than for females, but have been declining since 2003 and 2000, respectively.

\section{Occupational and Sectoral Segregation}

Table A.4 compares the occupational distribution of ethnic Latvian employees with the distribution of their minority counterparts in 2002 and in 2007. It appears that these distributions are fairly stable over time. The proportion of highly skilled non-manual workers has increased slightly in both ethnic groups (more among Latvians) at the expense of low-skilled non-manual and unskilled

${ }^{20}$ Leping and Toomet (2008), 'Emerging ethnic wage gap.'

${ }^{21}$ Leij et al. (2009), 'On the Relationship between Unexplained Wage Gap and Social Network Connections.'

22 Debora Reed and Jennifer Cheng (2003), Racial and Ethnic Wage Gaps in the California Labour Market. San Francisco, CA: The Public Policy Institute of California; summary available at http://www.ppic.org/content/pubs/rb/RB_503DRRB.pdf.

23 The Opportunity Agenda (2009), 'Equality - State of Opportunity, 2009,' available at http://opportunityagenda.org/stateofopportunity/indicators/equality/.

${ }^{24}$ Constant et al. (2006), 'The Russian-Ukrainian Earnings Divide.' 
manual workers. The overall degree of occupational segregation is measured by the dissimilarity index $D I .{ }^{25}$ In the given context, DI shows the minimal proportion (in percent) of non-Latvians who would have to change occupations in order to make their occupational distribution identical to that of Latvians. This measure suggests a modest vertical segregation between ethnic groups: when the four "super-groups" (highly skilled non-manual, low-skilled non-manual, skilled manual, and elementary occupations) are considered, $D I_{4}=12.0$ in 2007 (almost two points up compared to 2002), while for the nine major groups of occupations $D I_{9}=13.1$ ( 0.6 points up). This is a significantly lower level of segregation than in Estonia $\left(D I_{4}=15.9\right.$ and $D I_{9}=18.4$ in $\left.2007^{26}\right)$. Vertical segregation in Latvia is more pronounced among women $\left(D I_{4}=13.6\right)$ than among men $\left(D I_{4}=10.7\right)$.

Latvians are in higher proportions in highly skilled non-manual occupations, while non-Latvians - in skilled manual and elementary occupations. In 2007, 24.7 percent of Latvian employees were senior officials, managers or professionals, while among non-Latvians this proportion was 15.2 percent. It is worth noting, however, that the proportion of persons with a tertiary education is also higher among ethnic Latvian employees than among their minority counterparts: 27 vs. 21 percent (this gap is less than 4 points though among employees younger than 35 years). Hence promotion of tertiary education among ethnic minorities can be considered a way of improving both their living conditions in a long-term perspective and the productive potential of the Latvian labour force in general.

The distribution of ethnic Latvian and minority employees among sectors of economic activity in 2002 and 2007 is also presented in Table A.4. The distribution of the two ethnic groups among sectors is much less similar than their occupational distribution: the index of dissimilarity calculated for the four "large" sectors (agriculture, industry and construction, market services and non-market services) in 2007 was 16.4 (one point below the 2002 level), while it was just 12.0 in the case of the four "large" groups of occupations. Interestingly, the opposite situation is found in Estonia, where $D I_{4}=9.4$ for the four above mentioned economic sectors.

In 2007, nearly one third of Latvians and about one out of four non-Latvians worked in non-market services; almost 7 percent of Latvians and just half of this proportion among minorities were employed in agriculture (recall that only hired employees are considered here). On the other hand, more than a third of minority workers are found in industry, as opposed to one out of four Latvians. 37 percent of Latvian employees were employed by state or local governments,

${ }^{25}$ See O. T. Duncan and B. Duncan (1955), 'A Methodological Analysis of Segregation Indexes,' American Sociological Review, 20, pp. 210-217.

${ }^{26}$ Own calculation based on data from Statistics Estonia (2009), 'Labour status of population aged $15-74$ by ethnic nationality, sex and age.' 
NGOs, or publicly owned (by at least $50 \%$ ) enterprises, while for minority employees this proportion was just 24 percent. Proportion of minorities among employees in public administration is below $20 \%$, or less than a half of their share in population.

\section{Latvian Language Skills and Labour Market Outcomes}

Table 4 finds that both occupational and sectoral segregation of minority workers is to a large extent explained by Latvian language skills. According to self-reported classification in a survey conducted between November 2005 and January 2006, 62 percent of employees aged 18 to 64 are native Latvian speakers, 20 percent have good knowledge of Latvian language, 12 percent medium level knowledge, and 6 percent - poor knowledge. Among employees with good Latvian language skills just 6 percent would have to change occupation to make their occupational distribution identical to that of native Latvian speakers, while for workers with medium and poor Latvian language skills this proportion is, respectively, 24 and 49 percent (these figures refer to distribution between highly skilled non-manual, low-skilled non-manual, skilled manual, and elementary occupations, but the results are almost identical when 9 major ISCO groups are considered). A similar picture emerges as far as sectoral segregation is concerned: just 9 percent of minority employees with good Latvian language skills would need to change the sector of employment in order to have both groups distributed among agriculture, industry, market services, and non-market services in the same proportions. For workers with medium and poor Latvian language skills the dissimilarity index is 15 and 22 percent, respectively.

Average earnings of minority workers are positively related to their Latvian language skills. In 2005, those with good knowledge of the Latvian language earned, on average, 2 percent more than native Latvian speakers, while those with medium and poor Latvian language skills earned, respectively, 9 and 12 percent less than native speakers (Table 4). However, there is no unexplained pay gap for workers with poor Latvian language skills (plausibly, they are occupied in jobs where this factor is not considered important), while employees with good and medium Latvian language skills earn on average 4 and 6 percent less than native Latvian speakers with similar personal and job characteristics (Table 4). 
Table 4. Occupational and sectoral segregation and earnings of minority workers by self-reported Latvian language skills level, Full-time employees aged 18-64, 2005

\begin{tabular}{|c|c|c|c|c|c|c|}
\hline \multirow{2}{*}{$\begin{array}{l}\text { Knowledge } \\
\text { of Latvian } \\
\text { language }\end{array}$} & \multirow{2}{*}{$\begin{array}{l}\text { Share of } \\
\text { workers }\end{array}$} & \multicolumn{2}{|c|}{$\begin{array}{l}\text { Dissimilarity index a of segregation } \\
\text { from native Latvian speakers }\end{array}$} & \multirow{2}{*}{$\begin{array}{l}\text { Ratio of mean } \\
\text { earnings } \\
\text { to those of } \\
\text { native Latvian } \\
\text { speakers }\end{array}$} & \multirow{2}{*}{\multicolumn{2}{|c|}{$\begin{array}{l}\text { Unexplained } \\
\text { earnings gap } \\
\text { between the given } \\
\text { category and native } \\
\text { Latvian speakers }\end{array}$}} \\
\hline & & $\begin{array}{l}\text { By four super- } \\
\text { groups of } \\
\text { occupations }\end{array}$ & $\begin{array}{c}\text { By four main } \\
\text { sectors of economic } \\
\text { activities }\end{array}$ & & & \\
\hline Native & 62.5 & - & - & - & $\mathrm{b}$ & c \\
\hline Good & 19.9 & 5.9 & 9.1 & 102.1 & $4.0 * *$ & $3.7 * *$ \\
\hline Medium & 12.2 & 24.2 & 15.4 & 90.9 & $5.7 * * *$ & $6.4 * * *$ \\
\hline Poor & 5.4 & 49.0 & 22.3 & 88.2 & 1.9 & 0.9 \\
\hline
\end{tabular}

Note: a The dissimilarity index $D I$ (known also as Duncan index) is a number between 0 and $100 \%$, with 0 indicating equal distribution of ethnic (or other) groups among occupations (or sectors), and $100 \%$ indicating complete segregation. In the given context, DI shows the minimal proportion of workers with good, medium and poor Latvian language skills which would have to change occupation (or sector of economic activity) in order to make their distribution among occupations (sectors) identical to that of native Latvian speakers. ${ }^{\text {b }}$ Without occupation and plant size controls. ${ }^{c}$ With occupation and plant size controls. ***, ** - estimates significant at 1\% (respectively, $5 \%$ ) level. Source: Calculation with survey data, $\mathrm{N}=4040$; see Hazans (2007b), 'Coping with growth and emigration,' Tables 1.11, 1.13 and 2.7 .

Based on another survey from 2006 with information on respondents' selfassessed language skills relative to those necessary for the given job, minority female workers whose job does not require language skills except for their mother tongue earn $8 \%$ less than their otherwise similar counterparts who need other languages at work (a similar result holds for ethnic Latvians of both genders, while among minority males this effect is absent). Moreover, minority females earn 19\% less (other things being equal) when their Latvian language skills are insufficient for their job. ${ }^{27}$

We now turn to state language proficiency as the key factor behind the barriers. Table 5 finds that the registered unemployed feature a much lower incidence of good Latvian language skills and a much higher incidence of poor skills than employed wage earners. Moreover, even when state language skills are present among the registered unemployed, they are frequently not certified. Almost a quarter of minority unemployed registered in 2005-2006 did not have any legal proof of their state language skills (Table 5, column 3). The last three columns of Table 5 report the distribution of all (rather than just minority) registered unemployed by state language skills in 2005-2006 (the growth period), as well as before and during the crisis (September 2008 and September 2009). Despite some fluctuations, the distribution is quite stable; in particular, 12 to $13 \%$ of all unemployed lack certified state language proficiency

${ }^{27}$ See Hazans (2008), 'Post-enlargement return migrants' earnings premium,' Section 3 and Table 4. 
at any level. Other research ${ }^{28}$ finds that for this group the probability of exit from registered unemployment to employment is substantially lower than for other registered unemployed; moreover, this category is also much more likely to leave unemployment while not having found a job. Furthermore, the likelihood of completing professional training programmes at the State Employment Agency is positively related to certified state language skills. ${ }^{29}$

Table 5. Latvian language skills among employees and registered unemployed

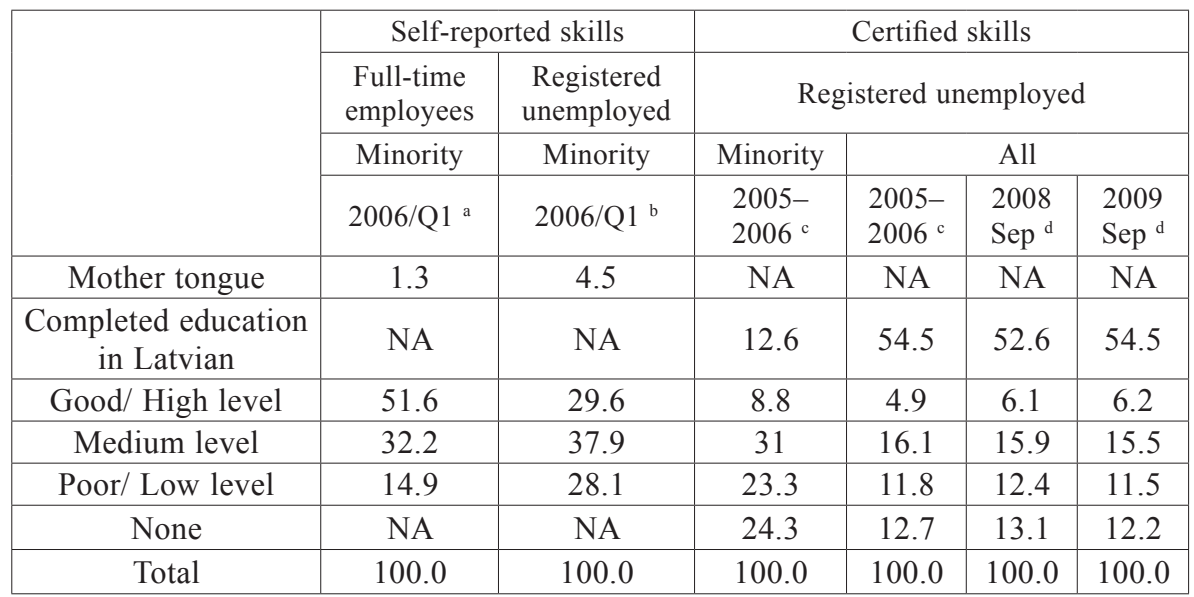

Sources: ${ }^{a}$ Calculation with data of wage earners survey for the National programme of labour market studies. ${ }^{b}$ Calculation with data of survey of registered unemployed, see http://www. nva.1v/docs/1_45135dc4cb20b9.91339932.pdf ${ }^{\mathrm{c}}$ Calculation with administrative data. ${ }^{\mathrm{d}}$ State Employment Agency.

Figure 12 compares self-reported and certified state language skills of the minority population aged 18-64 across five social groups: students, employed, unemployed (not necessarily registered), retired, and other inactive. Again, unemployed and inactive (except for students) have weaker Latvian language skills than the employed. Moreover, 50 to $60 \%$ in all groups (even more among the retired) do not have any certificate.

${ }^{28}$ Hazans et al. (2007), 'Determinants of unemployment duration in Latvia.'

29 Ibid. It is worth noting that handling the language issue in the framework of active labour market policies has been improving. Up until 2007, registered unemployed were offered Latvian language courses, but these courses did not directly lead to receiving or upgrading a certificate of the state language proficiency. This was corrected following a recommendation given by the authors. Furthermore, while the State Employment Agency offers professional training courses only with instruction in Latvian, since 2009 it has introduced training vouchers which are free from this restriction. 
Minorities aged 18-64 by self-reported Latvian language skills

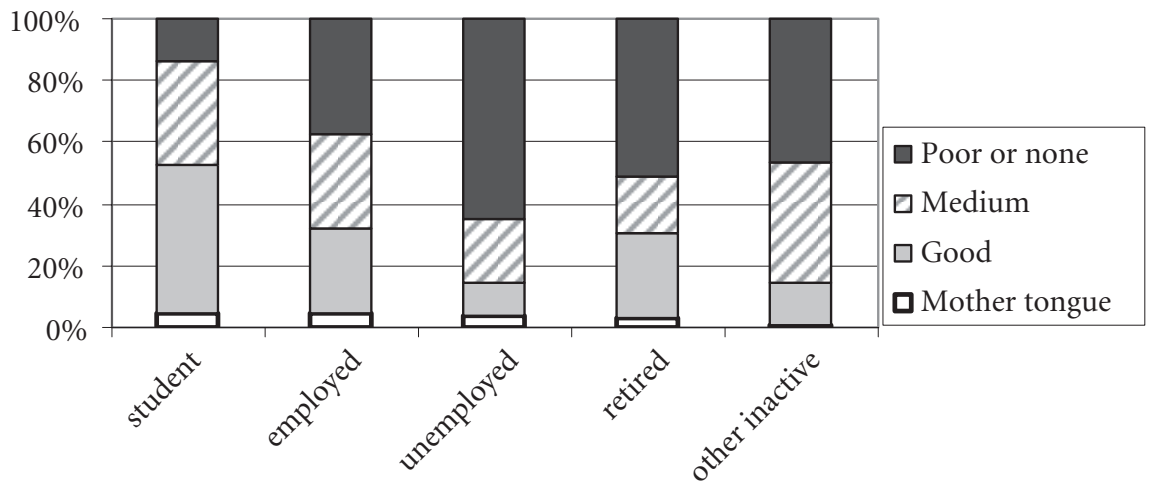

Minorities aged 18-64 by certified Latvian language skills

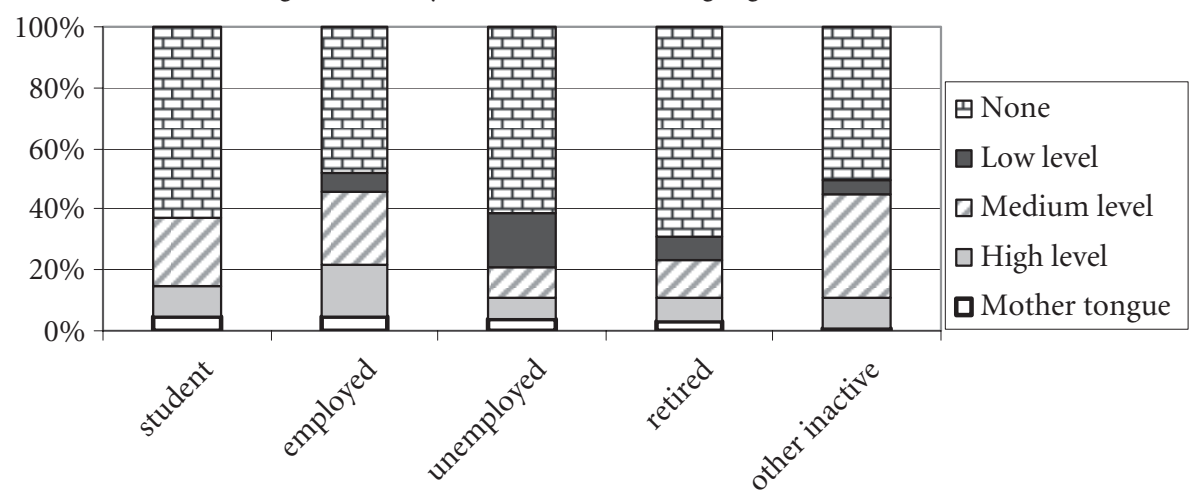

Figure 12. Minority population aged $18-64$ by labour market status and state language skills, 2007/Q3-2008/Q1.

Upper panel: Self-reported Latvian language skills

Lower panel: Certified Latvian language skills

Source: Calculation with data from Zepa et al. (2008), Language.

Finally, Figure 13 shows how labour market outcomes of the population are related to state language skills. The minority population with good Latvian language skills is not much different from native Latvian speakers (although it features a slightly lower proportion of students at the expense of retirees; this is due to the difference in the age structure, see Figure 2). The minority population with medium or poor Latvian language skills features a higher proportion of working-age inactive persons; what is more, among those with poor Latvian language skills there is also a higher proportion of unemployed. 


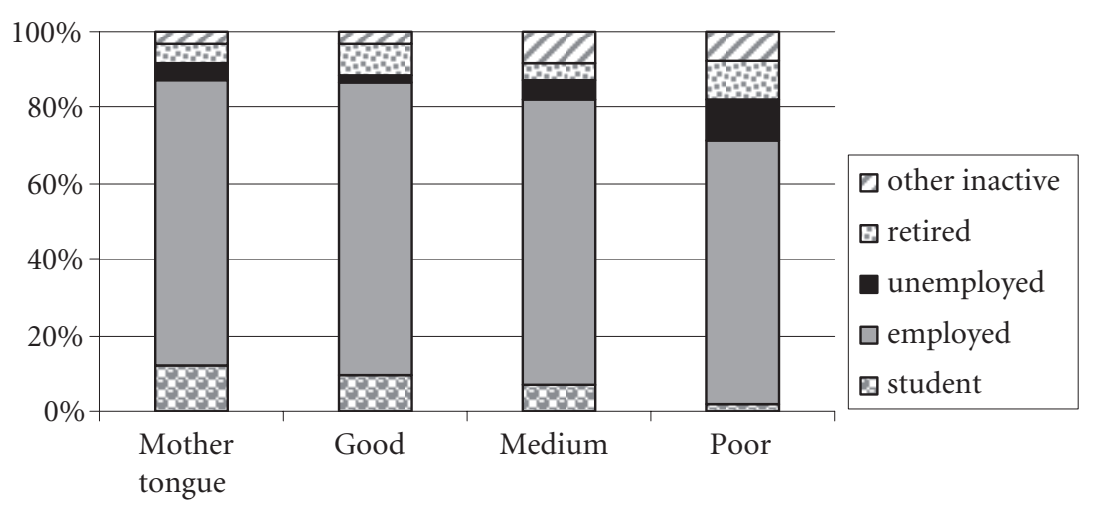

Latvian language skills

Figure 13. Population aged 18-64 by self-reported state language skills and labour market status, 2007/Q3-2008/Q1

Source: Calculation with data from Zepa et al. (2008), Language.

\section{State Language Proficiency Requirements}

According to the State Language Law, the following categories of employed persons are subject to state language proficiency requirements: (i) Employees of state and municipal institutions, courts and agencies belonging to the judicial system, state and municipal enterprises, as well as companies in which the state or a municipality holds the largest share of the capital; (ii) Employees of private institutions, organizations, enterprises, as well as self-employed persons, whose activities relate to legitimate public interests (public safety, health, morals, health care, protection of consumer rights and labour rights, workplace safety and public administrative supervision) or who perform certain public functions. The requirements for specific occupations are formulated in terms of one of the six levels: lower and upper basic (1A, 1B); lower and upper intermediate (2A, 2B); lower and upper advanced (3A, 3B). Each employer is responsible for preparing (within 3 month after registration) a list of required state language proficiency levels for all jobs in the firm/organization. The requirements cannot be lower than those in the government regulations; employees whose jobs are not listed in the regulations but who work directly with customers should provide to the clients the necessary information on goods and services in the state language.

The first version of the regulations was issued in 2000, but the list of occupations was extended several times in 2001-2008. In a survey held in 2006/Q4-2007/Q1, employees were asked to compare their Latvian language skills, as well as language proficiency requirements imposed by employers (or by the law when relevant) with the level which is in fact necessary to perform their professional duties. Overall, 19\% of the employees were not subject to 
any state language requirements, $71 \%$ consider the requirements consistent with professional duties, $1 \%$ see them as insufficient, while almost $9 \%$ think the requirements are "substantially higher" than really necessary. Interestingly, such an assessment is more frequently given by Latvians $(10.4 \%)$ than by nonLatvians $(6.4 \%)$; this is true also within each of the major groups of occupations (except for professionals, whose judgement is, on average, the same for both ethnic groups), as well as for employees of central government institutions and for private sector employees (Figure 14, upper panel).

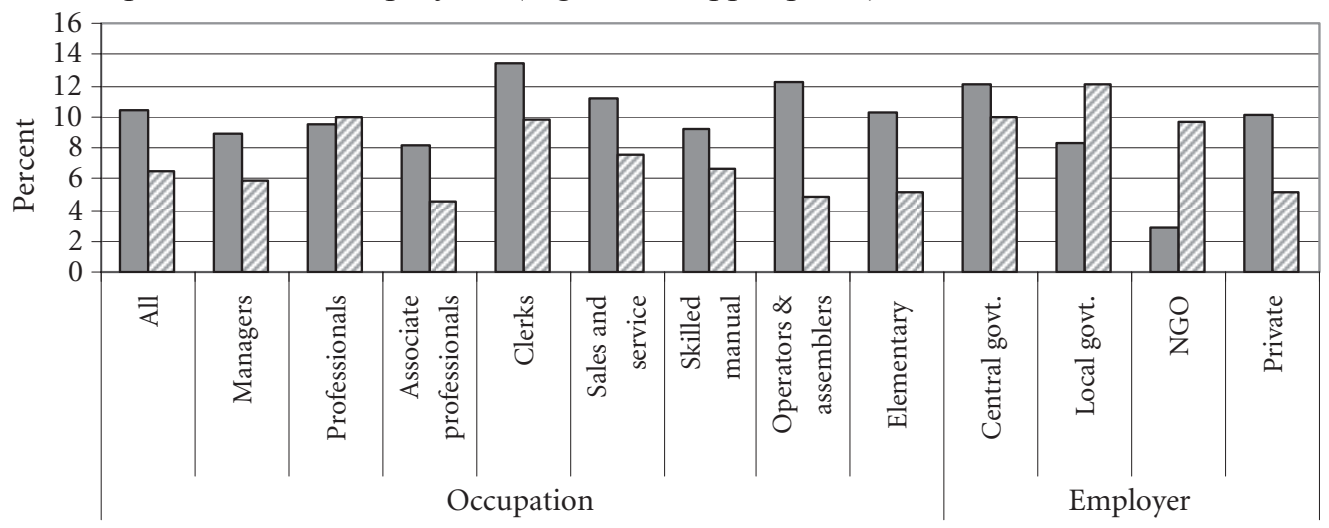

Latvians $\square$ Non-Latvians

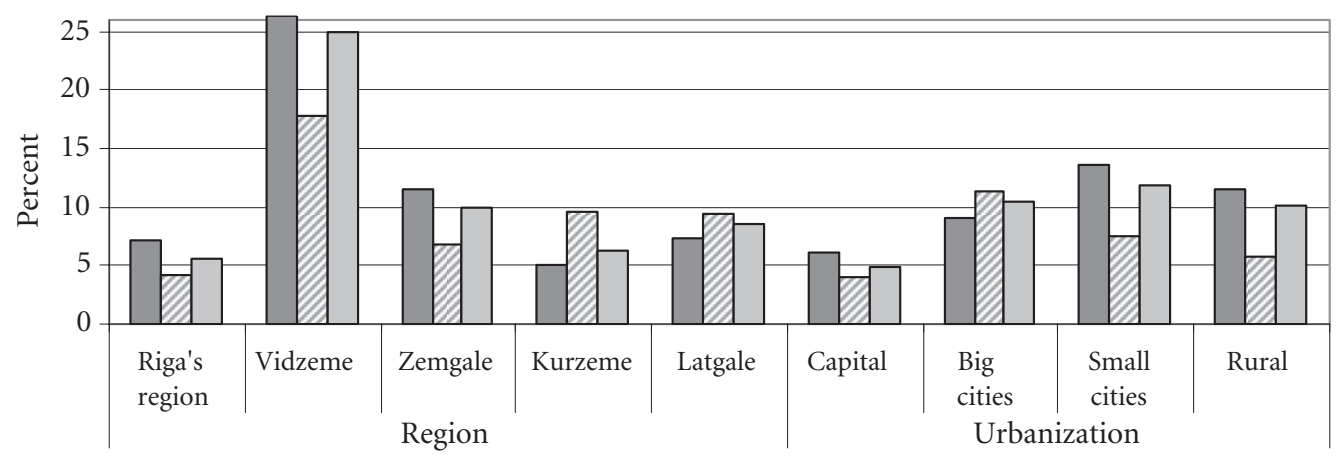

Latvians $\square$ Non-Latvians $\square$ Total

Figure 14. Employees who think that state language requirements imposed by employers for the position they occupy are substantially higher than necessary for performing professional duties. Upper panel: by ethnicity, occupation, and sector. Lower panel: by ethnicity, region, and urbanization

Source: Calculation with data of survey of wage earners, N =10177, Latvian University of Agriculture (2007), Datasets of the surveys of employees and employers conducted in 2006-2007 for the project "Specific problems of Latvia's and its regions' labour market" commissioned by the Ministry of Welfare for the National Programme of Labour Market Studies. 
For non-Latvian employees, the highest proportion (12\%) of those who thinks that language requirements for hiring were too strict is found in local government institutions, followed by central government institutions and NGOs, as well as among professionals and clerks in general (10\%). At a more detailed level, the highest rates of perception of the state language requirements as too strict were found among stationary plant and related operators $(20 \%)$, customer service clerks, general managers, and office clerks (12 to $13 \%$ ), teaching professionals (11\%), life science and health associate professionals, business and social science professionals, personal and protective services workers, food processing, timber, textile, and related craft workers, models, salespersons and demonstrators, and sales and services elementary occupations (9 to 10\%).

The perceived strictness of state language requirements varies substantially by region and urbanization level (Figure 14, lower panel): 18\% of minority workers see them as too strict in predominantly Latvian Vidzeme region, while in Riga region this rate is less than 5\%; in big cities except Riga the disapproval rate among minority workers is $11 \%$, while it is just $5 \%$ elsewhere.

These results suggest that on the eve of 2007, the state language proficiency requirements were largely consistent with the real needs implied by professional duties, although some liberalization could be useful in regulations for selected occupations, as well as in application of the requirements outside Riga, especially in Vidzeme region. Moreover, as the results of Section 3 suggest, the labour market itself provided incentives to acquire adequate Latvian language skills.

However, the second version of the government regulations (approved in July 2009), while based on the same general approach mentioned above, substantially extended the list of the occupations affected, especially in the private sector, and in some cases raised the required proficiency levels. For some occupations the requirements in the public sector are now higher than in the private sector. One of the factors which contributed to hardening of the regulations was the temporary worsening of the quality of the Latvian language in the service sector in 2006-2007, when a labour shortage forced employers to lower de facto requirements towards new workers. However, in a survey conducted in $2008,{ }^{30}$ only $18 \%$ of native Latvian speakers supported using legal regulation of usage of languages or applying restrictions to those who do not have a command of Latvian as the way to promote a Latvian language environment for non-Latvians.

Workers who do not have a certificate of the required level are given until Sept 2010 (basic level), March 2011 (intermediate level) or Sept 2011 (advanced level). It is already clear, however, that these deadlines are not realistic. Experts interviewed in October 2009 assumed that the new regulations will not result in mass layoffs as they probably won't be enforced too strictly and the

${ }^{30}$ Zepa et al. (2008), Language. 
deadlines will be moved. However, these regulations will have a strong signalling effect. In particular, they are likely to increase emigration rates and reduce return migration among minorities.

\section{Is There Evidence of Ethnic Discrimination in Hiring?}

Table 6 summarizes evidence on potential ethnic discrimination in hiring from representative large-scale surveys of employees and employers held in 2006 in the framework of the National Programme of Labour Market Studies. In the employees' survey, about $5 \%$ of Latvian respondents and $2 \%$ of minority respondents reported that in the enterprise in which they work, applicants of Russian or other Slavic origin would have small chances to be hired, while only about $1 \%$ of respondents thought that applicants of Latvian ethnicity would face such a problem. Representatives of visually distinct minorities face more barriers: in the same survey, $25 \%$ of Latvian respondents and $30 \%$ of minority respondents reported that Roma applicants are unlikely to be hired; 9 to $10 \%$ of Latvians and 6 to $7 \%$ of non-Latvians think that chances are small for Jews and other minorities. Results of the employers' survey (which are of course likely to underestimate the incidence of discriminatory practices) are largely similar: for instance, $3.5 \%$ of enterprises where the working language is Latvian would not hire an applicant of Russian or other Slavic origin $8 \%$ would not hire a Jewish applicant, $27 \%$ would not hire a Roma applicant, and 7\% would not hire other minorities. For Roma, the rejection rate is $27 \%$ also in enterprises where the working language is only or mainly Russian, while it is $17 \%$ in enterprises where Latvian is the main, but not the only working language.

Table 6. Evidence of ethnic discrimination in hiring, 2006

\begin{tabular}{|c|c|c|c|c|c|c|c|c|}
\hline \multirow{3}{*}{$\begin{array}{l}\text { Ethnicity of a } \\
\text { potential job } \\
\text { applicant }\end{array}$} & \multicolumn{3}{|c|}{$\begin{array}{l}\text { Employees' survey: low chances } \\
\text { to be hired by the respondent's } \\
\text { enterprise (\% of all answers) }\end{array}$} & \multicolumn{5}{|c|}{$\begin{array}{l}\text { Employers' survey: no chances to be hired by } \\
\text { the respondent's enterprise ( } \% \text { of all answers) }\end{array}$} \\
\hline & \multicolumn{3}{|c|}{ Respondent's ethnicity } & \multicolumn{5}{|c|}{ Languages used in the enterprise } \\
\hline & Latvian & $\begin{array}{l}\text { non- } \\
\text { Latvian }\end{array}$ & Total & $\begin{array}{l}\text { Only } \\
\text { Latvian }\end{array}$ & $\begin{array}{l}\text { Mainly } \\
\text { Latvian }\end{array}$ & $\begin{array}{l}\text { Mainly } \\
\text { Russian }\end{array}$ & $\begin{array}{l}\text { Only } \\
\text { Russian }\end{array}$ & Total \\
\hline Latvian & 0.9 & 1.2 & 1.0 & 0.5 & 0.2 & 0.3 & 0.4 & 0.3 \\
\hline $\begin{array}{l}\text { Russian and } \\
\text { other Slavic }\end{array}$ & 4.7 & 2.2 & 3.6 & 3.5 & 1.1 & 0.2 & 0.0 & 1.7 \\
\hline Jewish & 9.9 & 6.3 & 8.3 & 7.9 & 2.9 & 1.5 & 0.4 & 4.0 \\
\hline Roma & 24.6 & 29.9 & 27.0 & 27.2 & 17.0 & 26.6 & 27.5 & 22.2 \\
\hline Other minorities & 9.5 & 6.8 & 8.3 & 6.9 & 3.4 & 2.4 & 4.5 & 4.3 \\
\hline $\mathrm{N}$ & 6397 & 3780 & 10177 & 1815 & 2805 & 1172 & 245 & 6066 \\
\hline
\end{tabular}

Source: own calculation with data of Latvian University of Agriculture (2007).

To sum up, although hiring discrimination against workers of Russian or other Slavic ethnicity seems to exist, there is no evidence that it reaches levels at which it would influence the employment rate among these minorities. This is 
consistent with interview-based evidence that Russian-speaking emigrants from Latvia and Lithuania to Ireland, unlike their counterparts from Estonia, migrate to escape low wages and irregular employment, rather than because of their experiences as minorities. ${ }^{31}$ Nevertheless, mono-ethnic or almost mono-ethnic enterprises might emerge in Latvia due to extensive use of social networking in recruiting. ${ }^{32}$ On the other hand, the incidence of hiring discrimination against visual minorities is not negligible and, in the case of the Roma, it is substantial. The latter finding is consistent with evidence from other countries of Central and Eastern Europe. ${ }^{33}$

\section{Conclusion}

Despite flawed policymaking, impressive progress was achieved between 1997 and 2008 in the field of labour market integration of Latvia's large minority population. This was possible thanks to a period of strong economic growth accompanied by a massive outflow of the labour force after EU enlargement. Yet, the unemployment risk was higher among minorities, other things being equal, and the ethnic gap in employment rates remained substantial among the population with a higher education. As Latvia entered a recession in the second half of 2008, some gains in the relative position of minorities in terms of employment rates and earnings were lost; in the third quarter of 2009 the ethnic gap in employment has reached six percentage points.

Analysis suggests that economic interests drive integration, and ethnically mixed companies contribute to integration via inter-ethnic communication at the workplace. Both occupational and sectoral segregation of minority workers is to a large extent explained by lack of Latvian language skills, which is thus the main integration barrier. However, the labour market provides incentives to acquire adequate Latvian (as well as Russian) language skills. Relatively liberal access to jobs for minorities can facilitate not only their labour market integration but also cultural, language and social integration. Language-based labour market restrictions, by contrast, create a "lock-in" effect. Furthermore, any shift towards a more hard-line language policy is likely to increase permanent labour emigration among the minority population thus aggravating Latvia's demographic problems.

31 Aptekar (2009), 'Contexts of exit...'

${ }^{32}$ Hazans (2010), 'Labour market integration of ethnic minorities in Latvia.'

${ }^{33}$ See, e.g., Zimmermann et al. (2008), Study on the Social and Labour Market Integration of Ethnic Minorities. 


\section{Greatest Achievement}

The greatest achievement in labour market integration was the elimination of the ethnic employment gap by 2007. Unfortunately, this achievement has not survived the crisis: the gap has bounced back reaching almost six points in $2009 / \mathrm{Q} 3$.

\section{Most Serious Problem}

The most serious problem is that minorities face a significantly higher unemployment risk, especially among the population with a higher education.

\section{Most Urgent Task}

The most urgent task is to achieve a more adequate representation of the minority population in the public administration - currently it is below $20 \%$, or less than a half of the minority share in the population. 


\section{Appendix}

Table A.1. Employment rates by ethnicity and demographic group, 2002-2008.

Population aged 15-74

\begin{tabular}{|c|c|c|c|c|c|c|c|c|c|c|c|c|}
\hline & \multicolumn{4}{|c|}{ Latvians (\%) } & \multicolumn{4}{|c|}{ Non-Latvians (\%) } & \multicolumn{4}{|c|}{ Gap (\% points) } \\
\hline & 2002 & 2004 & 2007 & 2008 & 2002 & 2004 & 2007 & 2008 & 2002 & 2004 & 2007 & 2008 \\
\hline \multicolumn{13}{|l|}{ Education: } \\
\hline $\begin{array}{l}\text { Less than } \\
\text { secondary }\end{array}$ & 30.3 & 27.5 & 31.9 & 30.5 & 24.1 & 24.8 & 34.4 & 34.4 & 6.2 & 2.7 & -2.5 & -3.9 \\
\hline $\begin{array}{c}\text { Upper } \\
\text { secondary }\end{array}$ & 65.1 & 65.1 & 69.6 & 70.0 & 58.9 & 62.6 & 68.4 & 67.4 & 6.2 & 2.5 & 1.2 & 2.6 \\
\hline Tertiary & 79.5 & 81.6 & 85.1 & 86.7 & 69.2 & 73.1 & 76.5 & 75.1 & 10.3 & 8.5 & 8.6 & 11.6 \\
\hline \multicolumn{13}{|l|}{ Gender: } \\
\hline Men & 61.3 & 62.2 & 67.1 & 67.4 & 57.1 & 60.3 & 68.9 & 68.2 & 4.2 & 1.9 & -1.9 & -0.8 \\
\hline Women & 53.3 & 52.6 & 57.6 & 59.3 & 45.6 & 49.5 & 56.1 & 56.1 & 7.7 & 3.1 & 1.5 & 3.3 \\
\hline \multicolumn{13}{|l|}{ Age: } \\
\hline $15-24$ & 31.2 & 30.0 & 36.4 & 35.8 & 30.5 & 31.6 & 42.8 & 40.9 & 0.7 & -1.6 & -6.4 & -5.1 \\
\hline $25-34$ & 80.0 & 77.5 & 81.5 & 81.4 & 68.0 & 72.8 & 78.1 & 78.8 & 12.1 & 4.7 & 3.4 & 2.6 \\
\hline $35-44$ & 80.4 & 83.9 & 85.6 & 88.2 & 71.8 & 75.8 & 81.8 & 80.8 & 8.5 & 8.1 & 3.8 & 7.4 \\
\hline $45-54$ & 81.1 & 79.4 & 84.7 & 84.9 & 72.5 & 73.9 & 79.8 & 78.4 & 8.6 & 5.5 & 4.9 & 6.5 \\
\hline $55-64$ & 48.1 & 48.8 & 56.5 & 60.8 & 34.1 & 46.8 & 59.1 & 57.8 & 13.9 & 2.0 & -2.7 & 3.0 \\
\hline $65-74$ & 14.8 & 15.7 & 21.0 & 23.2 & 7.6 & 9.1 & 15.8 & 17.9 & 7.2 & 6.6 & 5.2 & 5.4 \\
\hline $15-64$ & 63.0 & 62.8 & 67.9 & 68.8 & 57.0 & 61.3 & 69.0 & 68.5 & 6.0 & 1.5 & -1.1 & 0.3 \\
\hline \multicolumn{13}{|c|}{ Type of settlement } \\
\hline Capital city & 61.4 & 63.3 & 67.1 & 68.5 & 55.9 & 59.5 & 66.4 & 64.9 & 5.5 & 3.9 & 0.8 & 3.5 \\
\hline Big cities ${ }^{a}$ & 53.0 & 54.8 & 64.4 & 66.5 & 45.7 & 49.3 & 59.9 & 59.2 & 7.3 & 5.5 & 4.5 & 7.2 \\
\hline Small cities & 56.3 & 55.6 & 61.1 & 62.2 & 47.7 & 54.0 & 59.5 & 60.0 & 8.6 & 1.5 & 1.6 & 2.2 \\
\hline Rural & 56.1 & 54.7 & 58.9 & 59.9 & 47.4 & 50.4 & 55.7 & 57.7 & 8.7 & 4.3 & 3.3 & 2.2 \\
\hline Total $^{\mathrm{a}}$ & 57.1 & 57.1 & 62.1 & 63.2 & 50.8 & 54.5 & 62.0 & 61.7 & 6.3 & 2.7 & 0.1 & 1.5 \\
\hline
\end{tabular}

Notes: a Daugavpils, Jūrmala, Jelgava, Liepāja, Rēzekne, Ventspils.

Source: Calculations with LFS data. 
Table A.2. Labour force participation rates by ethnicity and demographic group, 2002-2008. Population aged 15-74

\begin{tabular}{|c|c|c|c|c|c|c|c|c|c|c|c|c|}
\hline & \multicolumn{4}{|c|}{ Latvians (\%) } & \multicolumn{4}{|c|}{ Non-Latvians (\%) } & \multicolumn{4}{|c|}{ Gap (\% points) } \\
\hline & 2002 & 2004 & 2007 & 2008 & 002 & 2004 & 2007 & 2008 & 2002 & 2004 & 2007 & 2008 \\
\hline \multicolumn{13}{|l|}{ Education: } \\
\hline $\begin{array}{l}\text { Less than } \\
\text { secondary }\end{array}$ & 6.3 & 32.7 & 35.6 & 35.3 & 31.5 & 30.6 & 38.3 & 40.4 & 4.8 & 2.1 & -2.7 & -5.2 \\
\hline $\begin{array}{c}\text { Upper } \\
\text { secondary }\end{array}$ & 2.0 & 71.2 & 73.0 & 74.7 & 69.9 & 73.3 & 74.0 & 74.3 & 2.1 & -2.1 & -1.0 & 0.3 \\
\hline Tertiary & 83.3 & 83.9 & 87.6 & 89.0 & 74.3 & 78.5 & 80.9 & 80.4 & 8.9 & 5.4 & 6.7 & 8.6 \\
\hline \multicolumn{13}{|l|}{ Gender: } \\
\hline Men & 8.8 & 68.3 & 70.9 & 72.1 & 67.8 & 69.4 & 74.8 & 76.0 & 1.0 & -1.1 & -3.9 & -3.9 \\
\hline Womer & 8.2 & 57.0 & 60.5 & 63.1 & 53.3 & 57.6 & 60.4 & 61.3 & 4.9 & -0.6 & 0.1 & 1.8 \\
\hline \multicolumn{13}{|l|}{ Age: } \\
\hline $15-24$ & 8.1 & 35.9 & 40.4 & 41.0 & 40.6 & 40.1 & 49.1 & 47.5 & -2.4 & -4.2 & -8.7 & -6.5 \\
\hline $25-34$ & 87.8 & 84.8 & 85.8 & 87.6 & 79.6 & 84.6 & 84.7 & 86.2 & 8.2 & 0.2 & 1.1 & 1.4 \\
\hline $35-44$ & 88.9 & 89.9 & 89.6 & 93.0 & 84.9 & 85.9 & 87.8 & 90.0 & 4.0 & 4.0 & 1.8 & 3.0 \\
\hline $45-54$ & 8.4 & 85.6 & 88.9 & 88.8 & 81.9 & 85.7 & 85.5 & 86.9 & 6.5 & -0.1 & 3.4 & 1.9 \\
\hline $55-64$ & 51.4 & 52.2 & 58.5 & 63.8 & 40.1 & 52.5 & 62.6 & 62.9 & 11.3 & -0.4 & -4.1 & 0.9 \\
\hline $65-74$ & 15.6 & 16.0 & 21.1 & 23.4 & 8.8 & 10.1 & 16.6 & 17.9 & 6.7 & 5.9 & 4.5 & 5.5 \\
\hline $15-64$ & & & & & & & & & & & & \\
\hline \multicolumn{13}{|c|}{ Type of settlement } \\
\hline Capital city & 67.5 & 68.8 & 69.9 & 72.5 & 64.1 & 68.0 & 71.5 & 71.7 & 3.4 & 0.8 & -1.6 & 0.8 \\
\hline Big cities ${ }^{\text {a }}$ & 62.3 & 62.2 & 68.5 & 71.1 & 57.5 & 59.3 & 64.4 & 65.1 & 4.8 & 2.8 & 4.2 & 6.0 \\
\hline Small cities & 62.9 & 60.7 & 64.6 & 66.8 & 58.0 & 62.4 & 64.9 & 67.3 & 5.0 & -1.7 & -0.3 & -0.6 \\
\hline Rural & 61.1 & 59.2 & 62.2 & 63.8 & 54.0 & 56.8 & 60.7 & 63.4 & 7.0 & 2.4 & 1.4 & 0.4 \\
\hline Total $^{\mathrm{a}}$ & 63.2 & 62.3 & 65.4 & 67.4 & 59.9 & 63.0 & 67.0 & 68.1 & 3.3 & -0.7 & -1.6 & -0.8 \\
\hline
\end{tabular}

Notes: a Daugavpils, Jūrmala, Jelgava, Liepāja, Rēzekne, Ventspils.

Source: Calculations with LFS data. 
Table A.3. Population aged 15-24 by participation in education and in the labour force, 2002-2008

\begin{tabular}{|l|c|c|c|c|c|c|c|c|}
\hline & \multicolumn{4}{|c|}{ Latvians } & \multicolumn{4}{c|}{ Non-Latvians } \\
\hline \multicolumn{1}{|c|}{ Status } & $\mathbf{2 0 0 2}$ & $\mathbf{2 0 0 5}$ & $\mathbf{2 0 0 7}$ & $\mathbf{2 0 0 8}$ & $\mathbf{2 0 0 2}$ & $\mathbf{2 0 0 5}$ & $\mathbf{2 0 0 7}$ & $\mathbf{2 0 0 8}$ \\
\hline Student, economically active & 13.6 & 13.5 & 12.4 & 12.8 & 9.4 & 11.0 & 17.4 & 15.6 \\
\hline Student, economically inactive & 52.6 & 54.3 & 51.7 & 51.7 & 48.4 & 54.9 & 40.3 & 43.5 \\
\hline Non-student, economically active & 24.6 & 24.8 & 28.0 & 28.2 & 31.2 & 24.5 & 31.7 & 31.9 \\
\hline Non-student, economically inactive & 9.3 & 7.5 & 8.0 & 7.3 & 11.0 & 9.6 & 10.6 & 9.1 \\
\hline Students, total & 66.2 & 67.8 & 64.1 & 64.5 & 57.8 & 65.9 & 57.7 & 59.0 \\
\hline of which: & & & & & & & & \\
\hline Tertiary level students & 22.6 & 23.1 & 20.3 & 21.5 & 19.0 & 24.3 & 25.1 & 27.1 \\
\hline Upper secondary level students & 31.6 & 32.5 & 30.8 & 30.1 & 27.8 & 33.1 & 26.2 & 24.7 \\
\hline Primary level students & 11.3 & 12.2 & 13.0 & 12.9 & 10.9 & 8.5 & 6.4 & 7.2 \\
\hline Completed education level & & & & & & & & \\
\hline Tertiary & 5.3 & 6.0 & 6.1 & 6.6 & 4.6 & 4.6 & 7.1 & 6.6 \\
\hline $\begin{array}{l}\text { Secondary professional or upper } \\
\text { secondary vocational }\end{array}$ & & & & & & & & \\
\hline Secondary general & 13.6 & 12.0 & 11.2 & 10.4 & 15.6 & 12.3 & 12.5 & 12.2 \\
\hline Less than secondary & 28.6 & 26.7 & 27.2 & 27.9 & 27.5 & 32.3 & 35.3 & 37.6 \\
\hline Number obs. & 52.5 & 55.3 & 55.5 & 55.1 & 52.3 & 50.8 & 45.1 & 43.6 \\
\hline
\end{tabular}

Notes: "Students" are all respondents who have defined their activity status during the four weeks before the survey, where studies may refer to general or vocational school, college, or university. Labour market status is defined with respect to the survey week.

Source: Calculation with LFS data. 
Table A.4. Occupation and sector of economic activity in the main job by ethnicity, 2002 and 2007. Employees aged 15-74, \%

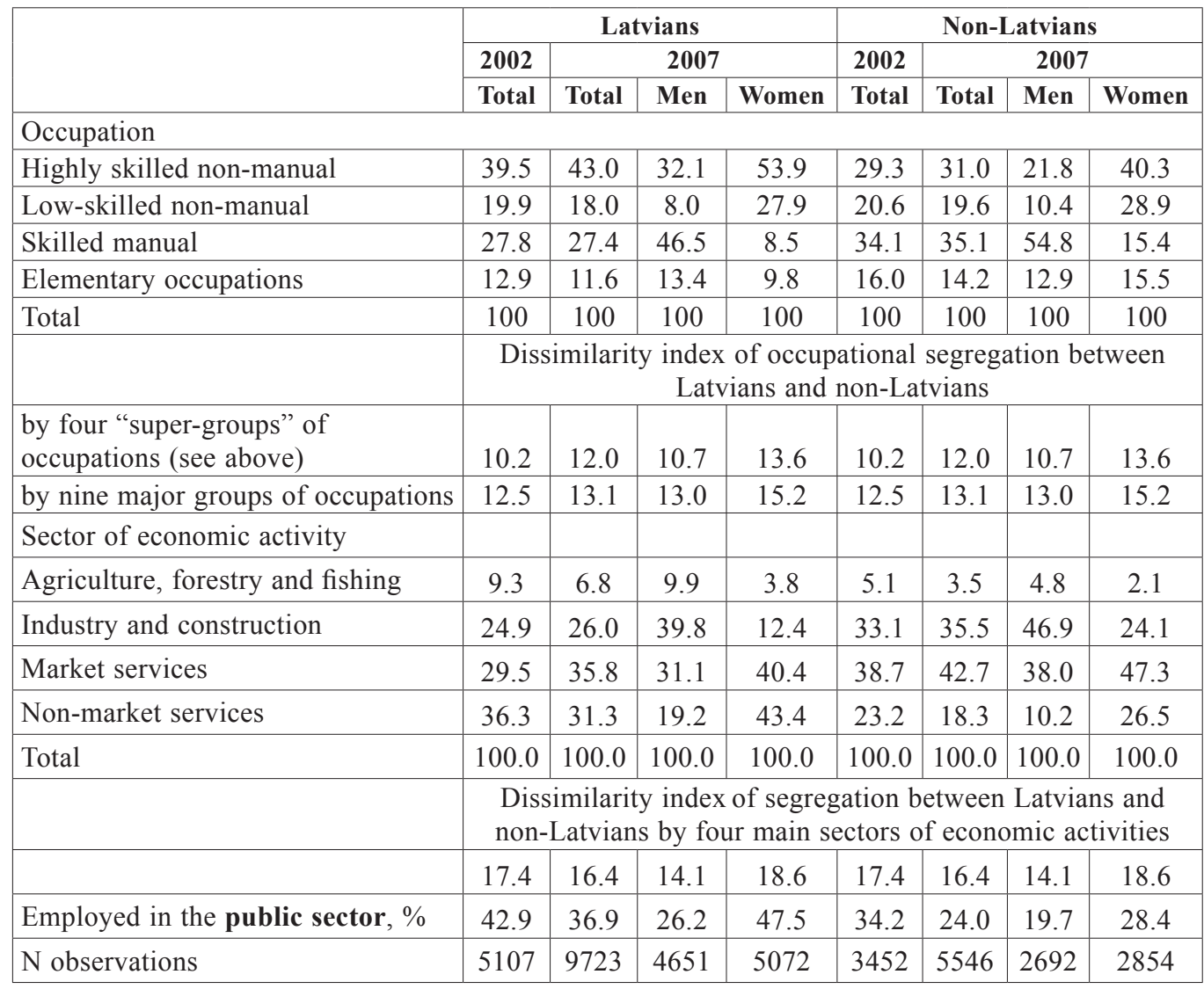

Notes. ${ }^{a}$ Dissimilarity index DI (known also as the Duncan index, see Duncan and Duncan, 1955 ) is a number between 0 and $100 \%$, with 0 indicating equal distribution of ethnic (or other) groups among occupations, and $100 \%$ indicating complete segregation. In the given context, $D I$ shows the minimal proportion of non-Latvians which would have to change occupations in order to make their occupational distribution identical to that of Latvians'.

Source: Calculation with LFS data. Reproduced by permission from Hazans (2010). 


\section{Social Policy and Integration Feliciana Rajevska}

\section{Introduction}

Social policy is related to concepts such as social inclusion and social cohesion. Social cohesion is the ability of a society to ensure welfare for all of its members, minimizing major differences and avoiding polarization. That is the definition that was provided in the social cohesion strategy approved by the Council of Europe's Committee of Ministers on 31 March 2004.

Social cohesion is a complex phenomenon which can be analysed from three perspectives:

- As an ideal or goal formulated in various programmes and government declarations;

- As a process involving the activities of all relevant stakeholders, including the allocation of resources, the establishment of institutions and the training of personnel;

- As an acquisition, by which we mean the true effects of all of these activities on the ability to minimize substantial differences in society.

In this chapter, the author will take all three of these aspects into account, but the primary focus will be on the end results of policy and the effects on people's lives. Integration in the social sphere is a very wide field, and it cannot be covered in a single chapter. For that reason, the author has chosen to focus on such issues as combating poverty and social exclusion, the functioning of the social security and health care systems, national housing policy, and the integration of ex-prisoners. This choice is based on a stable trend of polarization in Latvian society.

For several years now, there have been increasing worries about the availability of health care services. The proportion of inexpensive housing is negligible in comparison to the situation in other EU member states, and that makes it more difficult for people to find a home. A certain point of reference in this study is the Latvia Human Development Report 2002/2003: Human Security. Table 1 focuses on a series of questions about areas in which respondents feel threatened, with answers given on a scale of 1 to 4 , with " 1 " meaning that the respondent did not feel threatened at all, and " 4 " meaning that the person felt seriously endangered. 
Table 1. Perception of General Threat, September 2002

\begin{tabular}{|l|c|}
\hline \multicolumn{1}{|c|}{ What do you fear? } & Avg. response \\
\hline If I get sick, I won't be able to afford treatment & $3.28(1)$ \\
\hline $\begin{array}{l}\text { If I get sick, the medical services which I receive will not be of a } \\
\text { sufficient level of quality }\end{array}$ & $3.27(2)$ \\
\hline I will get seriously ill & $3.26(3)$ \\
\hline When I get old, my pension will be insufficient for survival & $3.08(4)$ \\
\hline I will have no money & $3.08(4)$ \\
\hline I will suffer an accident & $3.08(4)$ \\
\hline I will not be able to pay rent and for utility services & $3.03(5)$ \\
\hline
\end{tabular}

Source: Māra Sīmane, ed. (2003), Latvia Human Development Report 2002/2003: Human Security. Riga: UNDP, pp. 30-31.

A survey commissioned by the Latvian Ombudsman's Office and conducted by the SKDS public opinion research agency in November 2008 found similar answers $-74 \%$ to $83 \%$ of respondents said that the listed threats are important to them. When asked about the importance of the rights of prisoners and those who have been released from prison, only $23 \%$ and $24 \%$ of respondents respectively said that they are important, while $33 \%$ and $26 \%$, respectively, said that they are not. ${ }^{1}$ It is taking time for people in Latvia to understand that these people are a part of our society, and if they do not become integrated, no one can feel secure.

The functions of social policy include ensuring normal processes of regeneration in a society, stabilizing it, and guaranteeing social protection for those who need it due to various reasons. Processes of social stratification must be regulated so as to ensure that the gap between the richest and poorest people in society is moderate and does not promote any increase in tensions. There must be investments in people via education, health care, and the availability of elementary housing. Social policies must benefit all strata in society, without exception. There are, however, also groups for which assistance from the state or a local government may become decisive at a particular stage or area of life.

\section{Poverty Reduction}

The first serious consideration of the issue of poverty took place with the adoption by the Cabinet of Ministers on 29 August 2000 of a policy document called the "Poverty Prevention Strategy." In this document, poverty was defined as a situation faced by an individual or a specific segment of society when, because of an insufficiency of material and social resources, they have limited opportunities to cover their basic needs (food, housing, clothes and, in certain cases, care). These people have difficulty in taking part in public life. In

\footnotetext{
${ }^{1}$ See http://www.tiesibsargs.lv/lat/petijumi_un_viedokli/petijumi/?doc=444.
} 
preparing for Latvia's accession to the European Union, the Cabinet of Ministers approved a memorandum on social inclusion which the Minister of Welfare signed on 18 December 2003, in Brussels. Since then, several programmes have been established to combat social exclusion and poverty - one for 2004-2006, another for 2006-2008, and yet another for 2008-2013. In 2003, the government introduced a guaranteed minimal income, and in 2005 it set up a system of support payments for families with newborns.

Several ministries and agencies, as well as local governments and the nongovernmental sector have been involved in these programmes. On 3 March 2009, the Cabinet of Ministers approved new regulations on how a family or individual is to be declared as poor, and these stated that a family which is made up of a married couple, people who have joint everyday expenditures and who all live in the same home are seen as poor if their income per family member during the preceding three months has not exceeded $50 \%$ of the minimum monthly wage as of the first day of the relevant year (90 lats or $€ 128$ in 2009). In accordance with amendments passed by the parliament on 29 October 2009 to the Law on Social Service and Social Assistance, people with debts are eligible for social assistance support. The amendments forbid trying to collect debt through the social assistance granted to the person. At a special meeting of the Cabinet of Ministers on 15 September 2009, Welfare Minister Uldis Augulis said that in accordance with this definition, the number of poor people had increased rapidly - from 120,000 in 2008 to 144,000 in 2009, with the expectation that the number would grow even further to 200,000 in 2010.

Poverty levels in Latvia are measured in accordance with EUROSTAT methodology. The threshold for poverty risk is $60 \%$ of available median income, calculated on the basis of the equivalent consumer. ${ }^{2}$ In the EU 25, on average, $16 \%$ of people are in the risk group for poverty, and this indicator is stable. In Latvia, however, the number of people in the group has increased $-19 \%$ in 2005 , as much as $23 \%$ in $2006,21 \%$ in 2007 , and $26 \%$ in 2008 .

The breadth and depth of poverty have always been the focus of research. In 1998, the United Nations Development Programme and the World Bank organized a project aimed at developing policy recommendations for a national anti-poverty strategy in Latvia. This led to a series of publications in which different aspects of poverty were analysed. ${ }^{3}$ Given the ethnic structure of Latvia, it is important to note the conclusion of Aadne Aasland, who demonstrated that:

2 This calculation is based on a modified equivalency scale from the OECD - 1.0, 0.5 and 0.3 , where the first adult is compared to 1.0 , each subsequent household member aged 14 or older is 0.5 , and each child under the age of 14 is 0.3 .

3 See A. Aasland (2000), Ethnicity and Poverty in Latvia. Riga, UNDP; F. Gasmane (2000), Who in Latvia is Poor, and Where are They? Riga: UNDP; F. Gasmane and K. de Neuburg, K. (2000), How to Live on Negligible Resources in Latvia. Riga: UNDP; I. Trapenciere, R. Rungule, M. Pranka, T. Lāce and N. Dudwich (2000), The Views of Poor People: A Social Evaluation of Poverty in Latvia. Riga: UNDP. 
"Ethnic belonging is not of decisive importance in characterizing and analysing poverty in Latvia. When all other conditions are the same, ethnic Latvians have slightly better material lives than ethnic Russians and representatives of other ethnic groups do, but the differences are not sufficient to be of statistical significance." At the same time, however, he also pointed to several areas in which there are substantial differences - employment and the availability of social aid. In the labour market, "the level of participation is fairly similar, but the unemployment level is higher among ethnic Russians and people of other ethnic groups than is the case among ethnic Latvians. (..) Although people from all ethnic groups in Latvia use social assistance services at the same level of frequency, ethnic Latvians receive the assistance which they have sought more often, and they tend to be better informed about the type of aid which they deserve"4 (see also Mihail Hazans' chapter above). Ten years on, there are still fairly substantial differences between Latvians and Russians when it comes to how much they know about their rights and the mechanisms to protect them. When asked whether they had heard anything about the Ombudsman's office, $39.3 \%$ of Latvians, but only $20.5 \%$ of Russians and $28.6 \%$ of others said "yes."

In May 2005 (i.e., one year after Latvia's accession to the EU), a survey was conducted under the auspices of a joint Norwegian, Estonian and Latvian project, "Poverty, Social Aid and Social Inclusion (2003-2006)," to learn the views of local residents about the causes of poverty and gaps in income. A majority of respondents pointed to injustice in society as the main cause of poverty, after which they cited laziness, a lack of will and a simple lack of success. ${ }^{5}$

The Latvian Statistical Board conducts monitoring to evaluate the dynamics of poverty in different types of households (Figure 1). Data from 2005-2007 show that the benefits of the so-called "years of plenty" were not received at all by certain groups of households.

${ }^{4}$ Aasland, Ibid., pp. 47-49.

${ }^{5}$ F. Rajevska, ed. (2006), Sociālā atstumtība un sociālā iekļaušana: situācijas izvērtējums Latvijā. Riga: University of Latvia, pp. 86-87. 


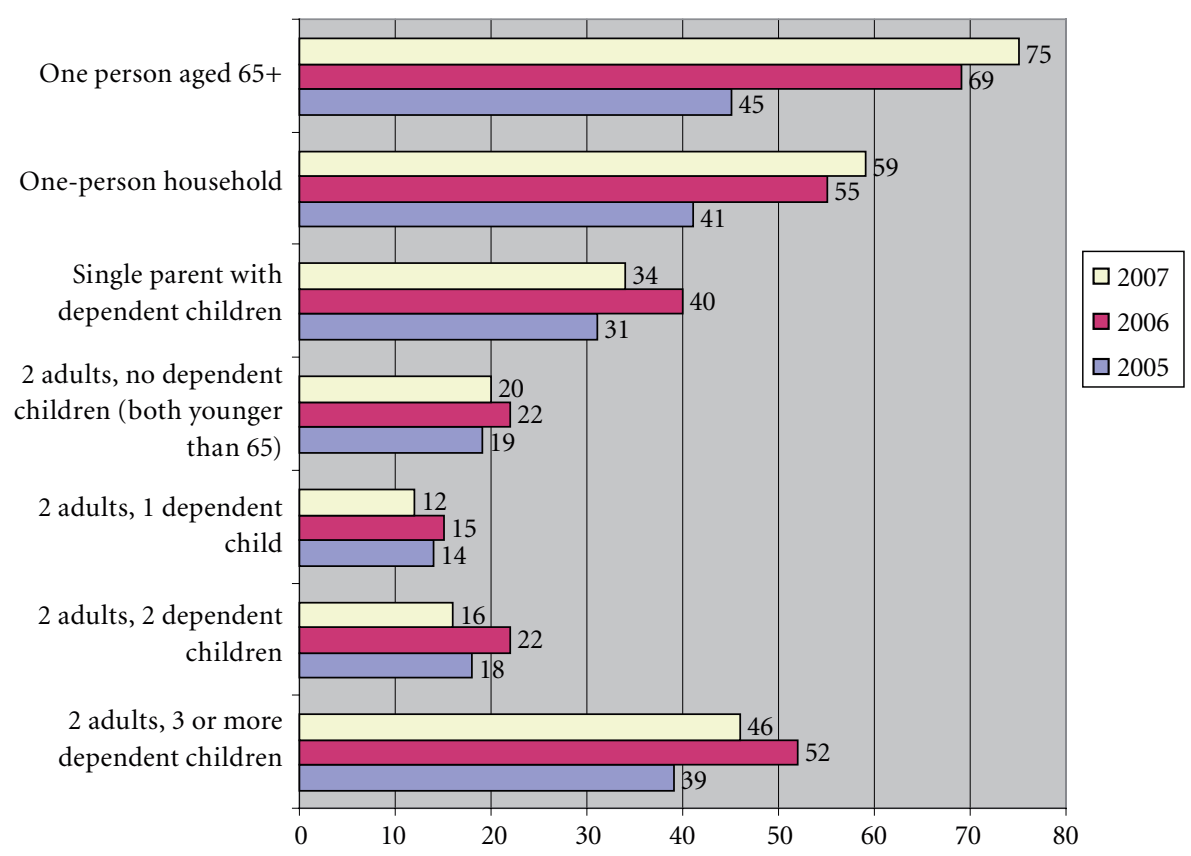

Figure 1. The poverty risk index for households of various demographic kinds, 2005-2007 (\%)

Here we see that the poverty risk index is radically higher for people who live alone and are 65 or older $-75 \%$ of them face the risk of poverty. The steps taken by the government in 2008 in advance of a referendum on substantially increasing pensions were absolutely necessary to narrow the rapidly growing gap between average wages and average pensions. The generous benefit for families with a child up to the age of one explains the fact that comparatively few households with children are in the poverty risk zone.

Being poor means more than just a shortage of money or a standard of living that is lower than average in society. Being poor also often means limited social networks, which means less of an opportunity to receive emotional support. There are poor people in all EU member states, but the level of social disintegration is quite varied across the EU. The relationship between poverty and social disintegration is based on the overall standard of living in the relevant country. Latvia is one of those countries in which the proportion of poor people is above the EU average and is continuing to increase.

The culture of public support for the poor is based not only on a country's social policies and local governments, but also on families, churches, etc. In surveys, people have said that support from family members is among the most important factors in a crisis situation. In the autumn of 2008, as part of a project looking at human development in Latvia, people were asked whether, in a crisis situation, they would rely on themselves or seek help from others. 
Those who chose the latter option were given a list of possible sources of assistance that was fairly broad and was analogous to a survey that was run in 2003 - relatives, friends, colleagues, state and local government institutions, non-governmental organizations, and international organizations. In 2003 the majority of respondents said that they would rely on their own abilities, and only then seek the help of relatives and friends. The fact that once Latvia joined the EU, there was a fairly substantial wave of emigration from Latvia showed that people were relying on themselves. Those who are accustomed to doing so are far more mobile than others. Quite a few of these people have left Latvia, and their proportion in society has declined. It is only logical, therefore, that in the 2008 survey, a majority of people said that they would seek help from their relatives. Relying on one's own abilities was only in second place, followed by seeking help from friends.

Table 2. From whom people would seek help in 2003 and 2008 ( 1 = strongly rely upon, $7=$ do not rely upon $)$

\begin{tabular}{|l|c|c|}
\hline Rely upon & $\mathbf{2 0 0 3}$ & $\mathbf{2 0 0 8}$ \\
\hline Myself & 1.88 & 2.21 \\
\hline Relatives & 2.24 & 2.09 \\
\hline Friends & 2.90 & 2.80 \\
\hline Colleagues & 4.52 & 4.37 \\
\hline State, local government institutions & 4.73 & 4.75 \\
\hline Non-governmental organizations & 5.26 & 5.34 \\
\hline International organizations & 6.38 & 6.24 \\
\hline
\end{tabular}

Source: Latvia Human Development Report 2003, 2008 SKDS survey

Reliance on assistance from the family is also promoted by the institutional mechanism of social aid, because evaluations of one's material situation are based not just on oneself (as is the case in Scandinavia), but on the whole family. A focus on the family, of course, promises a secure source of support, but sometimes this hinders the development of a more diverse network of assistance, and it goes hand-in-hand with distrust in others. This means limiting contacts outside of the family.

Social relations are considered to be a very valuable individual and social resource. Families, friends and organized networks provide emotional support and serve as a source for various gestures of attention, useful information, and financial assistance. This helps to satisfy an individual's need for social inclusion and a sense of belonging. Social disintegration, for its part, creates worries and depression, and it lowers overall welfare and quality of health. Participation in networks is an important form of social capital. In times of need, it can be activated, and under certain circumstances, it can be transformed into economic capital. Involvement shapes trust, creates a foundation for expectations, and is a cornerstone for creating the norms of public life. The welfare states of Scandinavia have universal social insurance systems which involve a pluralism of social contacts and a diversity of social networks. This makes 
it more possible for people to receive support when they need it, and it also strengthens social capital. Social relationships are particularly important under extraordinary circumstances, and they can produce security which eases the negative consequences of material uncertainty.

Petra Boehnke of the Berlin Social Science Research Centre has proposed two alternative hypotheses on links between poverty and social integration the compensation hypothesis and the accumulation hypothesis. The first says that if the state does not ensure adequate social support and cannot guarantee a survival minimum, then compensation for the social security deficit is based on the strategy of personal adaptation, with an increasing number of adults who focus on social networks. In Central and Eastern Europe, this is facilitated by cultural and religious traditions which speak to family solidarity and consolidation, as well as by social security systems which only cover minimal needs. The accumulation hypothesis, for its part, considers social disintegration to be a companion of poverty. ${ }^{6}$ This latter thesis was first formulated by the French sociologist Pierre Bourdieu, who argued that participation in social networks requires so-called exploitation expenditures. If a principle of solidarity that is not based on direct mutual exchanges exists in a family, then most social contacts outside of the family are based on the logic of exchange and mutually useful support. Once poverty sets in, the individual does not have the resources for exchanges. Unfavourable circumstances such as poverty are often associated with shame and stigmatization. Former acquaintances avoid contacts with the person, and the person refrains from them, as well. This means a breakup of existing relationships, with the social contacts of poor people centred on the family. Social contacts outside of the family are cut off.

The massive crisis of 2009 has forced many people to make do, but it has also reemphasized the responsibility of the state for socially weaker groups in society. The illusion of welfare which existed during the so-called "years of plenty" (2005-2008) involved easy availability of loans and a boom in lending. This strengthened the spirit of individualism. Interesting evidence of this is seen in differences in answers given by survey respondents in May 2005 and October 2008 as to whether the existing income gap in society was acceptable and who is to blame for poverty - individuals or society. In 2008, there were considerably fewer people than in 2005 who believe that the income gap in society must be much smaller, which meant more people who argued that poverty is largely the result of an individual's lack of will. The interpretation here might be that broader opportunities emerged once Latvia joined the European Union. That also strengthened the idea that success and higher income are largely dependent on the individual's ambition, dedication, and readiness to improve himself, work relentlessly, and undertake responsibility and risk. Let us add that even

6 P. Boehnke (2008), 'Are the Poor Socially Integrated? The Link Between Poverty and Social Support in Different Welfare Regimes,' Journal of European Social Policy, Vol. 18(2). 
back then many respondents felt that society was responsible for the fact that there are poor people in Latvia. The survey in the autumn of 2008 coincided with the nationalization of Parex Bank and the onset of the crisis in Latvia. Crises create great harm, but they also have certain advantages - they promote social consolidation in the interests of survival, encouraging people to identify and seek out common interests. The New Deal of US President Franklin Delano Roosevelt, after all, was the product of the Great Depression, and it led to a far greater involvement by the state in the process of income redistribution. In the UK, for its part, the country's universal welfare system emerged from the frugality and dangers of World War II which the people of Britain all experienced together. We can assume that, by the summer of 2009, there would again be a change in views as to whether society or individuals are to blame for poverty - there would be fewer people who would be prepared to blame the individual for circumstances that are beyond one's control.

\section{Integration of Pensioners}

Pensioners, and particularly those who live alone, have traditionally been seen as a social risk group. Latvia's national strategy for social protection and inclusion 2008-2010 includes the goal of improving the availability of resources and services to pensioners who are subject to the risk of poverty, and particularly those who live alone. ${ }^{7}$ Pensioners in Latvia were given some extra money for work they did up until 31 December 1995. The additional contribution was negligible at first - just 19 santims $(\sim € 0.27)$. Later it was raised to 30 santims (€0.42), but only for those whose old age pension was no higher than LVL 105 $(\sim € 150)$ in 2006, LVL $135(\sim € 193)$ in 2007, and LVL $225(\sim € 321)$ in 2008. As of 1 June 2008, those who wanted to receive the additional payment had to have worked for at least 30 years (or 25 years in the case of those who retired early because they worked under harmful or particularly difficult circumstances). The average additional sum in June 2008 was LVL $13.88(\sim € 20)$. Because of the upcoming referendum in 2008 , the sum was raised to 70 santims $(\sim € 1)$ per year and given to all pensioners irrespective of the size of their basic pension. Accordingly, the additional sum, on average, amounted to LVL 24.40 ( €35) in 2009. That has been a real boon for pensioners who were not affected by pension cuts during the period of crisis. All pensioners faced a $10 \%$ cut as of 1 July 2009, which meant a decline in the average pension in Latvia from LVL $173(\sim € 247)$ in June to LVL $145(\sim € 207)$ in July. The percentage of those who receive small pensions (up to LVL 135 or $\sim 193$ ) rose by $10 \%$. These changes were anulled by a Constitutional Court decision.

Latvia does not have the kinds of widow pensions which exist in many EU member states, but since the beginning of 2007, the surviving spouse of

\footnotetext{
${ }^{7}$ Report on the National Strategy for Social Protection and Inclusion 2008-2010.
} 
a deceased pensioner receives a one-time support payment at the death of his or her spouse equal to two times the individual's pension. This subsidy also applies to those widows and widowers who were themselves pensioners at the time when the spouse died. In 2007, Parliament increased the untaxed minimum of pensions from LVL $110(\sim € 157)$ to LVL 165 ( €236). In 2008, it extended to 31 December 2011, the ability of people to retire early (at the age of 60 , or two years earlier than normal), provided that they had worked for at least 30 years. Such people receive $80 \%$ of a full pension. During the crisis, however, this was cut to $50 \%$ of the basic sum as of 1 July 2009, the aim being to discourage early retirement and to save money in the social budget.

Despite this drastic cut in the pension for those who retire early, the number of such people nevertheless increased by 2,000 between June and July 2008. The number of working pensioners, however, shrank from 60,800 in June to just 35,000 in July, thus partly compensating for increasing unemployment among people in Latvia who are of working age.

Insured people who have retired at the specified age or later cannot have an old age pension that is lower than the national social insurance allowance a sum that has not been changed since 2005 despite significant inflation and wage increases. Depending on how long the person has worked, a coefficient of $1.1,1.3,1.5$ and 1.7 is applied to the pension, but the basic sum of LVL 45 ( $€ 64)$ remains negligible. This means that the government is saving money at the expense of those people who are least secure in financial terms while, at the same time, paying certain civil servants wages that exceed the sum by 100 times or more.

Differences between citizens and non-citizens in Latvia do not relate only to political rights. They also affect the social status of individuals. The 1995 law on pensions says that years spent working outside of Latvia prior to 1991 are to be counted only for citizens when it comes to calculating their pension. Non-citizens, in turn, get a pension only for the years that they spent working in Latvia, unless there is an agreement with the other country. This discriminatory norm applies to more than 15,000 non-citizens in Latvia. One of them, Natālija Andrejeva, filed a claim with the European Court of Human Rights on this matter. After graduating from the Rīga Polytechnic Institute, she worked for a chemicals factory in the Latvian town of Olaine from 1973 until 1990, but received her wages by mail from Kyiv and Moscow, because as an environmental protection specialist, she was subordinate to bosses in those cities. When Andrejeva retired, those years were not counted in the calculation of her pension. Latvia's courts ruled that her pension had been calculated correctly. She filed her suit with the ECHR in 2000, and the court agreed to hear the case in 2006. In 2007, the case was submitted to the Grand Chamber of the ECT, and after a court hearing in 2008, it ruled in February 2009 that Latvia's system was discriminatory against pensioners who are not citizens of Latvia. The court ordered the government to pay Andrejeva $€ 6,500$ in compensation. Latvia and 
Russia ratified an agreement on partnership in the area of social security in October 2008, meanwhile, and it states that Latvia does recognise the years that people once worked in Russia and vice versa. ${ }^{8}$ Because of the ECHR ruling, Parliament is reviewing the law on pensions. It has been suggested that in order to ensure the principle of equality in this process, citizens, too, should not have pensions which are based on years worked outside of Latvia until 1991.

During a global economic crisis, the sustainability of every country's social security system and the trust of individuals in that system have been tested. A survey conducted in late 2008 found that people do not have much trust in the social security system when a risk occurs.

Table 3. Reliance on the social security system in case of a risk

\begin{tabular}{|l|c|c|}
\hline & $\begin{array}{c}\text { Unweighted } \\
\text { number }\end{array}$ & $\begin{array}{c}\text { \% of } \\
\text { total }\end{array}$ \\
\hline $\begin{array}{l}\text { I believe that I will receive more or less sufficient funding to } \\
\text { ensure my standard of living }\end{array}$ & 50 & 5 \\
\hline I'll make do & 171 & 17.2 \\
\hline It won't satisfy my needs & 552 & 54.8 \\
\hline I don't know & 227 & 23.1 \\
\hline Total & 1,000 & 100 \\
\hline
\end{tabular}

Source: SKDS survey, November 2008

As we can see in Table 3, most people are concerned about the Latvian social security system and uncertain about what will happen to them if a risk situation arises. Only 5\% of people say that they would maintain their standard of living via social assistance if they were to lose their primary source of income. More than one-half $(54.8 \%)$, in turn, say that the social security system is inadequate for their needs. It is hard to understand why fully $23.1 \%$ of people could not answer the question, but it does suggest that people simply don't have much information about the system. This causes greater concerns among people, and it does nothing to suggest that policies in this area are based on a sense of responsibility. All in all, people think that politicians and bureaucrats do not ensure observation of the public interest (an average rating of 3.64), and $43.7 \%$ of survey respondents think that politicians and bureaucrats ensure this interest poorly or not at all.

\section{Access to Health Care as a Factor Integrating Society}

A European Commission White Paper states that health is the central need in people's lives, and that at the level of the European Union and the world, EU member states must support people's health with effective policies and

\footnotetext{
8 A. Dimitrovs (2009), 'Tiesības uz izsvītrotajiem gadiem,' in www.politika.lv, 24 February 2009.
} 
programmes. ${ }^{9}$ The Lisbon Treaty of 2007 also emphasizes the responsibilities of member states when it comes to developing health care systems. ${ }^{10}$ Latvia has a memorandum on social inclusion (2003) which defines the main tasks aimed at improving health care - informing socially excluded people about their rights, state-guaranteed health care services and ways of receiving these; strengthening the system of primary health care by reducing the number of patients registered with each general practitioner and increasing the number of such practitioners; improving the level of information among patients and their co-operation with general practitioners, particularly in economically less developed regions; supplementing the list of medications and medical products compensated by the state with new diagnoses and the relevant products in accordance with available financing, thus increasing the number of people with serious disorders who are guaranteed regular access to necessary medication; developing the system of emergency care services; establishing a unified information and communications system; and improving the provision of emergency care to people in Latvia's rural areas. ${ }^{11}$

Latvia's public health strategy care states that the country's health care system is based on the principle of social solidarity. All of the residents of the Republic of Latvia have the right to receive health care services that are covered by mandatory health insurance, and they must pay taxes proportional to their income. Section 111 of the Latvian Constitution states that "the state protects people's health and guarantees a minimum amount of medical assistance to everyone."

During the reform phase, one goal in terms of health care policies was an increase in the availability of relevant services. Statistics show, however, that accessibility has actually diminished. A 2003 study found that one-third of respondents $(33.4 \%)$ had to do without health care services for various reasons. Among them, $10.6 \%$ did not have access to more than one service. Reasons include a lack of money or health insurance (23.1\%), a lack of time $(9.4 \%)$, long queues $(3.7 \%)$, and an excessive distance to the necessary health care institutions $(3.4 \%) .{ }^{12}$ As is the case in other areas, there are significant differences among Latvia's regions when it comes to the accessibility of health care services. Inaccessibility in Riga is lowest (23.5\%), because Latvia's largest health care institutions are concentrated in the capital city. In Kurzeme, inaccessibility is higher than the national average $-36.4 \%$ in 2003 . In southern Latgale, the

${ }^{9}$ Commission of the European Communities White Paper Together for Health: A Strategic Approach for the EU, 2008-2013, Available at http://ec.europa.eu/health/ph_overview/ Documents/strategy_wp_en.pdf.

${ }^{10}$ Ibid.

${ }^{11}$ See the Joint memorandum on Social Inclusion of Latvia, available at http://www.likumi. lv/doc.php?id=90818.

12 V. Boroņenko (2003), Veselības aprūpes pakalpojumu pieejamība Rīgāa. Riga, pp. $43-45$. 
percentage was $35 \% .^{13}$ Data from 2005 do not show any improvements. All in all, $35 \%$ of Latvia's residents said in 2005 that they lacked money to visit a doctor. The plurality $(50 \%)$ of these respondents was 60 years old or older. ${ }^{14}$

In formal terms, health care services are available to everyone in Latvia. Before a patient can receive government financed services, however, he or she must pay a patient fee. There are a few risk groups which are exempted from this fee so as to expand the availability of services - children up to the age of 18 , poor people, the politically repressed, people who suffered health problems as a result of the Chernobyl nuclear disaster, people with mental disorders, and those who are under the care of social care centres and local government senior citizens' homes. People also do not have to pay the fee for emergency medical services if their life has been threatened. When it comes to more complicated medical procedures at the secondary and tertiary level of health care, the state pays for them only if the patient has been sent to a specialist by a general practitioner. The provision of free medications in Latvia is based on universal principles of justice. Medications are provided for people with specific diagnoses and irrespective of their social status. The per capita financing for compensated medications in 2007 was EUR 38. ${ }^{15}$

Latvia has one of the smallest health care budgets in the EU, both in terms of a percentage of GDP and in terms of absolute numbers. These figures show clearly that since the restoration of independence, the health of Latvia's residents has never been a priority for the government. It has always been left up to local residents and their general practitioners. It is no surprise that even during the "years of plenty," per capita state financing in Latvia was just $70 \%$ of the financing provided in Lithuania, 54\% of the spending in Estonia, and 30\% of expenditures in the Czech Republic.

Table 4. Health care financing from the Latvian national budget, \% of GDP

\begin{tabular}{|l|l|l|l|l|l|l|l|l|l|l|l|l|}
\hline & $\mathbf{1 9 9 7}$ & $\mathbf{1 9 9 8}$ & $\mathbf{1 9 9 9}$ & $\mathbf{2 0 0 0}$ & $\mathbf{2 0 0 1}$ & $\mathbf{2 0 0 2}$ & $\mathbf{2 0 0 3}$ & $\mathbf{2 0 0 4}$ & $\mathbf{2 0 0 5}$ & $\mathbf{2 0 0 6}$ & $\mathbf{2 0 0 7}$ & $\mathbf{2 0 0 8}$ \\
\hline \% of GDP & 3.46 & 3.58 & 3.46 & 3.08 & 3.03 & 3.10 & 3.20 & 3.23 & 3.43 & 3.63 & 3.51 & 3.50 \\
\hline
\end{tabular}

Source: Ministry of Health. See http://www.vm.gov.lv/index.php?id=246\&top=129.

Table 5. The per capita health care budget in 2006 (in euros)

\begin{tabular}{|c|c|c|c|c|c|c|}
\hline & Latvia & Lithuania & Poland & Estonia & Czech Rep. & Finland \\
\hline Euros & 194.8 & 279.2 & 289.2 & 362.2 & 645.4 & $1,845.9$ \\
\hline
\end{tabular}

Source: EUROSTAT.

13 Ibid., pp. 46-48.

14 Aija Zobena, ed. (2005), Latvia: Human Development Report, 2004/2005: Human Capability in the Regions. Riga: University of Latvia Press, available at http:/www.szf.lu.lv/files/ petnieciba/publikacijas/Demokratijas_atskaite_9.pdf.

15 Ministry of Welfare (2008), Report on Latvia's national strategy for social protection and social inclusion, 2008-2001. Riga, pp. 57-59. 
The mortality rate in Latvia is among the highest in all EU member states. Of particular concern is the fact that the number of deaths among people of working age has increased dramatically. In 2000, there were 218 deaths per 1,000 residents, but by 2006 that number increased to $223 .{ }^{16}$ Latvia's infant mortality rate has declined from 11 per 1,000 in 2001 to 7.6 in 2006, but this is an unstable trend. In 2007, the infant mortality rate increased to the highest level among all countries in the Baltic Sea region - 8.7 per $1,000 .{ }^{17}$ The improved economic situation was clearly reflected in the fact that the number of suicides declined from 30.8 per 100,000 residents in 2000 to 17.8 in $2007 .{ }^{18}$ The long-lasting economic crisis, however, has substantially increased this indicator, particularly among men. The average life expectancy in Latvia rose from 70.4 years in 2002 to 70.9 years in $2006,{ }^{19}$ but it remains the lowest in the Baltic Sea region. There is also still a considerable gap between the life expectancy of men and that of women - 10.9 years in favour of women. ${ }^{20}$

\section{Table 6. Deaths per $\mathbf{1 , 0 0 0}$ residents in the Baltic States}

\begin{tabular}{|c|c|c|c|c|c|c|c|c|c|}
\hline & $\mathbf{2 0 0 0}$ & $\mathbf{2 0 0 1}$ & $\mathbf{2 0 0 2}$ & $\mathbf{2 0 0 3}$ & $\mathbf{2 0 0 4}$ & $\mathbf{2 0 0 5}$ & $\mathbf{2 0 0 6}$ & $\mathbf{2 0 0 7}$ & $\mathbf{2 0 0 8}$ \\
\hline EU 27 & 9.98 & 9.89 & 9.97 & 10.12 & 9.65 & 9.84 & 9.61 & 9.67 & 9.69 \\
\hline Estonia & 13.44 & 13.57 & 13.51 & 13.41 & 13.11 & 12.86 & 12.89 & 12.98 & 12.76 \\
\hline Latvia & $\mathbf{1 3 . 5 7}$ & $\mathbf{1 4 . 0 1}$ & $\mathbf{1 3 . 9 0}$ & $\mathbf{1 3 . 9 5}$ & $\mathbf{1 3 . 8 5}$ & $\mathbf{1 4 . 2 5}$ & $\mathbf{1 4 . 4 7}$ & $\mathbf{1 4 . 5 2}$ & $\mathbf{1 3 . 9 5}$ \\
\hline Lithuania & 11.21 & 11.61 & 11.84 & 11.87 & 12.03 & 12.83 & 13.20 & 13.52 & 13.15 \\
\hline
\end{tabular}

Source: EUROSTAT.

The birth rate in Latvia remains comparatively low, although it has been increasing -8.53 births per 1,000 residents in 2000, 9.03 in 2003, 9.73 in 2006, 10.23 in 2007, and 10.77 in $2008 .^{21}$

The incidence of HIV/AIDS in Latvia has quadrupled from 958 cases in 2000 to 3,981 in $2007 .{ }^{22}$ In absolute numbers, the number of HIV/AIDS deaths has increased dramatically, too, from 24 deaths in 2000 to 273 in $2007 .{ }^{23}$ This is true despite the fact that the death rate exceeds the EU average only by 0.1 deaths per 100,000 residents (1.3 in Latvia, 1.2 in the EU 27 in 2006). Here, however, we again see a tendency of an increase -1.8 in Latvia in $2007 .{ }^{24}$

More evidence of the negative situation with public health in Latvia is provided by the number of people who are receiving treatment for alcoholism - a

\footnotetext{
16 See http://www.who.int/shosis/data/Search.jsp.

17 Eurostat. See http://epp.eurostat.ec.europa.eu.

18 Ibid.

19 Ibid.

20 Ibid.

21 Ibid.

22 Central Statistical Board of Latvia. See http://data/csb.gov/lv/Dialog/Saveshow.asp.

23 Ibid.

24 Eurostat, op. cit.
} 
rise from 986 in 2000 to 1,308 in 2007 per 100,000 residents. ${ }^{25}$ In absolute numbers, that is 30,084 people, or $1.3 \%$ of all of Latvia's residents.

Registered drug addictions in Latvia rose from 94 per 100,000 people in 2000 to 126 in 2006 in Latvia. ${ }^{26}$ The number of smokers in Latvia (people aged 16 and up) has declined a bit in percentage terms - from $33 \%$ of the population in 2000 to $30.4 \%$ in $2006 .{ }^{27}$ Over the last several years, the percentage of young people (aged 13 to 15 ) who smoke has increased in Latvia - from $34.2 \%$ in 2002 to $37.6 \%$ in 2007. This is a higher percentage than is the case in Estonia, Lithuania, Poland and Slovakia. ${ }^{28}$

Table 7. Tobacco smokers (aged 16 and over), \% of residents ${ }^{29}$

\begin{tabular}{|c|c|c|c|c|}
\hline & $\mathbf{2 0 0 0}$ & $\mathbf{2 0 0 2}$ & $\mathbf{2 0 0 4}$ & $\mathbf{2 0 0 6}$ \\
\hline Estonia & 29.4 & 28.9 & 28 & 29.9 \\
\hline Latvia & $\mathbf{3 3}$ & $\mathbf{3 3 . 2}$ & $\mathbf{3 0 . 1}$ & $\mathbf{3 0 . 4}$ \\
\hline Lithuania & 32 & 28.25 & 27 & 24.5 \\
\hline EU & 29.27 & 28.38 & 27.49 & 26.96 \\
\hline
\end{tabular}

The number of hospital beds in Latvia declined slightly from 773.4 per 100,000 residents in 2002 to 755.4 in 2007, but the number remained far greater than the EU average (from 628.6 to 590.4 beds per 100,000 residents). ${ }^{30}$ The number of practicing physicians in Latvia has not changed substantially in recent years - from 286.3 per 100,000 residents in 2000 to 286.1 in $2007 . .^{31}$

Table 8 . The number of practicing physicians per $\mathbf{1 0 0 , 0 0 0}$ residents in the Baltic states

\begin{tabular}{|c|c|c|c|c|c|c|}
\hline & $\mathbf{2 0 0 0}$ & $\mathbf{2 0 0 2}$ & $\mathbf{2 0 0 4}$ & $\mathbf{2 0 0 5}$ & $\mathbf{2 0 0 6}$ & $\mathbf{2 0 0 7}$ \\
\hline Estonia & 309.7 & 314.7 & 321.7 & 320.2 & 328.9 & -- \\
\hline Latvia & $\mathbf{2 8 6 . 3}$ & $\mathbf{2 7 4 . 7}$ & $\mathbf{2 8 4 . 7}$ & $\mathbf{2 9 1 . 9}$ & $\mathbf{2 9 1 . 5}$ & $\mathbf{2 8 6 . 1}$ \\
\hline Lithuania & 364.0 & 364.2 & 355.6 & 363.2 & 364.8 & -- \\
\hline
\end{tabular}

The development of primary health care is based on general practitioners and a teamwork model involving the physician and a nurse or assistant. ${ }^{32}$ Primary health care consists of primary health care practitioners, most of whom are general practitioners. They are independent physicians, self-employed physicians, or representatives of the private sector. ${ }^{33}$ The difference between "self-

${ }^{25}$ Central Statistical Board of Latvia, op. cit.

26 Ibid.

27 European Health for All Database (HFA-DB), WHO/Europe. See http://data.euro.who. int/hfadb.

${ }_{28}$ See http://www.who.int/whosis/data/Search.jsp.

29 Ibid.

30 Eurostat, op. cit.

31 Ibid.

32 E. Tragakes, O. Avdeeva, M. Schäfer, eds. (2008), Health Systems in Transition, Latvia: Health System Review. European Observatory on Health Systems and Policies, pg. 171.

33 Ibid. 
employed" and "private" relates to the individual's tax status. A self-employed practitioner pays the individual income tax on the basis of his or her earnings, and the facilities and equipment are paid for or rented by the practitioner. Private general practitioners, for their part, have share companies that are taxed as such. Physicians who offer primary health care services must, irrespective of the type of institution where they do their work, conclude a contract with the State Agency on Mandatory Health Insurance. ${ }^{34}$

General practitioners provide primary health care for children, adults and the elderly (when there are acute or chronic problems). This includes outpatient surgery, rehabilitation, care during pregnancy, prenatal care and emergency aid. They prescribe medicines, conduct diagnostic tests, and promote disease prevention and health improvement efforts. ${ }^{35}$ The role of primary health care nurses and assistants includes:

- Ensuring primary health care for eight hours a day, five days a week;

- Assisting general practitioners in treatment and preventive efforts related to all groups of patients;

- Ensuring first aid;

- Ensuring simple diagnostic tests (taking of blood samples, for instance);

- Ensuring health promotion activities. ${ }^{36}$

24/7 services are not guaranteed by general practitioners. In emergency situations, patients can receive assistance from emergency medical personnel or at the emergency room of a hospital. ${ }^{37}$

Social and health care are poorly integrated in Latvia, as are primary, secondary and tertiary health care. There is a shortage of doctors and nurses at the level of primary health care. This relates to a lack of personnel in health care which is the result of demographic circumstances. Reforms have been gradual and experimental in many cases. There have been a number of changes which have gradually led us to the current system. ${ }^{38}$

Closing down inpatient services at 13 small hospitals in 2009 and increasing the patient fee in large hospitals from 5 to 12 lats per 24-hour period means that people are increasingly treating themselves at home, thus becoming chronic patients whose treatment would cost a lot more than would otherwise be the case. The local government representatives and hospital directors met with representatives of the Health Ministry and the State Agency for Mandatory Health Insurance twice in 2009 to argue that the new rules were not in line with public needs and interests. Pressure from the public in 2009 was significant, and

\footnotetext{
34 Ibid., pg. 172.

35 Ibid., pg. 176.

36 Ibid.

37 Ibid.

38 Ibid, pg. 229.
} 
medical institutions ran the risk of losing patients and being reduced to offering only emergency care if the procedure for funding was not changed. Cabinet regulations governing the organization and funding for health care were amended six times in 2009. As of 2010 the fee for a day in a hospital was reduced from LVL 12 to LVL 9.50 and access to health care for low income residents was expanded. As of 30 January 2010 residents whose income per family member over the previous three months did not exceed LVL 130 were exempted from patient's co-payments. At the same time, residents whose incomes did not exceed LVL 150 per month had only to pay $50 \%$ of the co-payment, with a single payment for a surgical procedure not exceeding LVL 15.

The equal availability of services is related to so-called horizontal equality. In the area of health care, this is interpreted as equal access in relation to equal needs. The level of accessibility of any service depends on several factors, including availability of services when they are needed (as opposed to having to wait in long queues which delay the availability of the service), the ranking of services that are defined by law, easier access for people with special needs, geographic barriers, patient fees which affect the availability of health care services for people with low levels of income, and the overall situation with poverty, which affected the ability to pay patient fees. ${ }^{39}$

The equal availability of services is one of the key issues for Latvia's health care system. The good news is that access to health care services is universal, and the services which, by law, are financed by the government are fairly allencompassing. The complications which have occurred in Latvia in terms of the accessibility of health care services have had to do with the scanty budget which is available for health care overall.

Geographic distances also reduce access to health care services. For rural residents in particular, a simple doctor's visit is costly, because specialists are mostly centred in larger cities such as district centres or the capital city. A substantial share of health care financing in Latvia is based on out-of-pocket expenses.

Long-term treatment can create the threat of poverty for a patient, and so the state has set a ceiling on patient fees after which no more fees have to be paid. The total fee for each period of inpatient care cannot exceed a total of LVL 250 ( €356), and the total fee paid for outpatient and inpatient services during the course of one year may not exceed LVL 400 ( €569).$^{40}$ Elderly people are helped very much by the fact that the system of compensation for medications and medical equipment offers compensation equal to $100 \%, 90 \%$, $75 \%$ and $50 \%$ of the total cost for people with certain diagnoses. In 2005 , the government began to pay compensation for medications in accordance with

\footnotetext{
${ }^{39}$ Cabinet of Ministers Regulations of 19 December 2006 No. 1046 on the Procedure for Organizing and Funding Health Care.

${ }^{40}$ Ibid.
} 
the principle of the reference price, which means that the state will pay for the cheapest among medications with the same effects. The compensation percentage rate allows the government to pay compensation to a larger number of patients, but the fact is that Latvia offers less in the way of compensation for medications than do the other two Baltic States. ${ }^{41}$

Latvia's health care system is focused on making sure that a segment of the resources that are devoted to inpatient care is diverted to primary health care in the system of general practitioners, transforming small rural hospitals into daytime inpatient facilities or long-term care centres. ${ }^{42}$

Improvements in people's health are perhaps one of the most complicated issues, because health depends on so many factors - the provision of health care services, income levels, lifestyles and the surrounding environment. ${ }^{43}$

There is much evidence in Latvia to show that people with lower levels of income also have lower levels of health care service use because of financial barriers. The fact is, however, that it is specifically people with lower income who need more health care than others. That is particularly true among pensioners who have comparatively low income and need health care services far more often than others. The same applies to unemployed people, as well as children from families with low levels of income.

\section{The Integrative Potential of Housing Policy}

Housing policy is very important to everyone because it addresses a basic human need. Housing policies in different countries are based on various models with different forms of property ownership - social, public, private and co-operative. In nearly all West European countries, social housing is an inalienable part of overall policy.

The main actors in housing policy are the state, local governments, and the market. The goal of housing policy is to create conditions in which everyone can choose an appropriate home. The Czech author Martin Lux has written that public housing policies are linked to the assumption that state and local government must ensure the redistribution of housing expenditures in a way which guarantees that people from various groups in society have homes. The state must understand its social responsibility, redistributing spending so that a social fund for housing can be created and the state can intervene in the housing market via laws and regulations, the priority being a liberalization of the housing market. ${ }^{44}$ Lux adds that the role of local governments has been increasing

${ }^{41}$ Ministry of Welfare, Report on Latvia's National Strategy..., op. cit., pg. 41. See http:// www.lm.gov.lv/text/549.

42 Tragakes, E., Avdeeva, O. and M. Schäfer. Health Systems..., op. cit., pg. 234.

${ }^{43}$ Ibid., pg. 238.

${ }^{44}$ Lux Martin (2003), Housing Policy: An End or a New Beginning? Budapest: Open Society Institute, pg. 11. 
consistently in the European Union member states when it comes to housing policies. Decentralization in this area has become particularly popular, and there has been both absolute and relative decentralization. In the former case, the whole process is turned over to local governments, which strengthens their influence in this area (local governments approve regulations, set rental ceilings and engage in regional planning). In the latter case, the local government has a limiting role vis-à-vis free market relations in the housing sector. ${ }^{45}$ In EU member states, the duty for local governments is to protect people in those groups in society who cannot afford a home in the free market.

In East European countries, the availability of social housing for the poor remains low because of a lack of financial resources and of shortcomings in the law. The area of operations for local governments is limited, and there are few opportunities to pursue housing policies in an active way.

Housing policy in post-independence Latvia was launched in 1991, when laws were adopted on denationalization of real estate - a process which continued for the subsequent decade and more. The law on rents was adopted in 1993 and amended eight times afterward. It regulates rental conditions irrespective of who owns the real estate, legal relations between renters and owners, their duties and demands, and procedures for concluding, amending and ending rental agreements. ${ }^{46}$ The law defines the types of flats that are considered to be appropriate for people to live in. This refers to lighting and the availability of heat so that the home can be suitable for long-term accommodations and various household objects. Such housing must also correspond to construction and hygienic requirements that have been defined by the Cabinet of Ministers. ${ }^{47}$

Table 9. Apartment privatization in Latvia's regions, major towns and districts, end of year. The percentage of privatized flats among all flats open for privatization

\begin{tabular}{|c|c|c|c|c|c|c|c|c|c|c|}
\hline $\mathbf{1 9 9 6}$ & $\mathbf{1 9 9 7}$ & $\mathbf{1 9 9 8}$ & $\mathbf{1 9 9 9}$ & $\mathbf{2 0 0 0}$ & $\mathbf{2 0 0 1}$ & $\mathbf{2 0 0 2}$ & $\mathbf{2 0 0 3}$ & $\mathbf{2 0 0 4}$ & $\mathbf{2 0 0 5}$ & $\mathbf{2 0 0 6}$ \\
\hline 3 & 10 & 21 & 48 & 63 & 72 & 76 & 79 & 81 & 83 & 85 \\
\hline
\end{tabular}

Source: Central Statistical Board

Article 36.2 of the housing law includes norms which do not allow owners of flats to evict families with children, pensioners, and disabled people from their homes because of debts related to rent and utility payments unless different housing is provided for them.

Until 2007, the main agency in terms of social housing policy was the Ministry for Regional Development and Local Government, but since the beginning of that year, the system has been turned over to the Ministry of Economics, which is charged with social housing policy and its implementation.

45 Ibid., pp. 23-26.

46 See 'Likums par dzīvojamo telpu īri,' available at http://www.likumi.lv/doc/php?id56863

47 Ibid. 
Local governments design and implement social housing policies in their own territories.

Table 10. Constructed flats in Latvia

\begin{tabular}{|c|c|c|c|c|}
\hline & Total & \% of previous year & Paid for by residents & \% paid for by residents \\
\hline 1990 & 13,325 & - & 1,200 & $9 \%$ \\
\hline 1991 & 7,210 & $54.1 \%$ & 856 & $11.8 \%$ \\
\hline 1992 & 4,876 & $67.6 \%$ & 890 & $18.2 \%$ \\
\hline 1993 & 3,753 & $76.9 \%$ & 928 & $24.7 \%$ \\
\hline 1994 & 3,369 & $89.8 \%$ & 798 & $23.7 \%$ \\
\hline 1995 & 1,176 & $52.7 \%$ & 1,068 & $60.1 \%$ \\
\hline 1996 & 1,483 & $83.5 \%$ & 1,331 & $89.7 \%$ \\
\hline 1997 & 1,480 & $99.8 \%$ & 1,332 & $90.0 \%$ \\
\hline 1998 & 1,351 & $91.3 \%$ & 1,251 & $92.6 \%$ \\
\hline 1999 & 1,063 & $78.7 \%$ & 1,048 & $98.6 \%$ \\
\hline 2000 & 899 & $84.6 \%$ & 836 & $93 \%$ \\
\hline 2001 & 800 & $88.9 \%$ & 784 & $98 \%$ \\
\hline 2002 & 794 & $99.2 \%$ & 726 & $91.4 \%$ \\
\hline 2003 & 830 & $104.5 \%$ & 828 & $99.8 \%$ \\
\hline 2004 & 2,821 & $340 \%$ & 1,137 & $40.3 \%$ \\
\hline 2005 & 3,807 & $134.9 \%$ & 1,371 & $36 \%$ \\
\hline 2006 & 5,865 & $154 \%$ & 1,762 & $30 \%$ \\
\hline 2007 & 9,319 & $158.9 \%$ & 2,032 & $21.8 \%$ \\
\hline 2008 & 8,084 & $86.7 \%$ & 1,988 & $24.6 \%$ \\
\hline
\end{tabular}

Source: Central Statistical Board, author's calculations

In 2008, there was intensive work on a draft policy document on social housing, but the government never adopted it. It is important, however, to identify three principles relative to housing policy, as mentioned in the draft project - the principles of participation, assistance and integration. The participation principle states that each person tries to provide his or her own home, chooses a place of residence in accordance with available income, and tries to increase that level of income and, thus, level of welfare. The assistance principle applies if someone cannot afford a home and is poor. The local government helps by renting a social home until the crisis situation has been resolved. The draft document argued that this is a situation which can be resolved quite quickly, because rental agreements can be signed only for six months before being concluded anew. If a local government cannot help people by renting out social homes, then the state offers subsidies for this process. The integration principle, for its part, means that the development of social homes does not create segregation between larger and smaller populated areas. Housing is seen in a complex way, with thought given to where there are jobs, a social infrastructure and other services.

Article 35 of the law on social services and social assistance states that housing support, guaranteed minimal income support and other forms of support 
are paid by local governments from their basic budget. ${ }^{48}$ The scope of the subsidy and the way that it is paid out are determined in regulations which are compulsory for local governments. The law on the way in which assistance for housing purposes is arranged defines various ways in which local governments can help. They can rent out properties which they own, they can rent out social homes, they can provide people with temporary homes, they can help people to exchange one rented flat for another, they can offer subsidies for rental and related costs, they can offer a one-time subsidy for renovations of housing, they can pay for the renovation of housing, or they can help people to purchase or build a home. ${ }^{49}$

The law on local government assistance in housing issues describes those persons and situations in which immediate help is needed. The law also defines those people who receive assistance first and foremost. Existing law says that assistance must be given only to those people who face a completely hopeless situation. The aid is not available to most people - families with children, pensioners, young families, etc. These are people whose income is above the survival minimum, but is not enough to save up money, improve housing conditions or to purchase or rent housing on the basis of market prices. ${ }^{50}$

Latvia's memorandum on social inclusion states that low levels of income and the comparatively high cost of rent and utility services are the main problems related to housing. ${ }^{51}$ These problems have not changed at all over the last five years. There are new problems as well - the inability of some people to repay mortgage loans which they have taken out. The situation is made all the more difficult by the fact that since the restoration of Latvia's independence, the state and its local governments did not participate or only minimally participated in the construction of new residential buildings. Until 2002, the share of homes and apartments built on the basis of local government financing remained very negligible, and between 1996 and 2003, local governments built hardly any homes at all. A positive boom in housing construction began in 2004, when the percentage of homes built at the expense of their potential residents declined from $99 \%$ in 2003 to $57 \%$ in 2004 and $42 \%$ in 2008 . We have to note, however, that the proportion of small and cheap flats in all of this was quite small. Most of the construction was focused on the emerging middle class in Latvia.

${ }^{48}$ See 'Sociālo pakalpojumu un sociālās palīdzības likums,' available at http://www.likumi. lv/doc/php?id=68488.

${ }^{49}$ See 'Par pal̄̄dzību dzīvokḷa jautājuma risināšanā,' available at http://www.likumi.lv/doc. php?id=56812.

${ }^{50}$ F. Rajevska and A. Vanags (2005), 'Ekonomiskās un sociālās tiesības.' In Juris Rozenvalds, ed., Cik demokrātiska ir Latvija? Demokrātijas audits. Riga: University of Latvia, pg. 69.

${ }^{51}$ See 'Latvijas kopējais sociālās iekḷaušanas memorands,' available at http://www.likumi. lv/doc.php?id=90818. 
One reason for the low percentage of state and local government-owned flats is the denationalization of real estate and the privatization of what were once state and local-government owned buildings. This fundamentally changes the structure of Latvia's housing system.

Table 11. New residential buildings ( $1000 \mathbf{~ m}^{2}$ of floor space)

\begin{tabular}{|c|c|c|c|c|c|c|c|c|c|c|}
\hline & $\mathbf{1 9 9 9}$ & $\mathbf{2 0 0 0}$ & $\mathbf{2 0 0 1}$ & $\mathbf{2 0 0 2}$ & $\mathbf{2 0 0 3}$ & $\mathbf{2 0 0 4}$ & $\mathbf{2 0 0 5}$ & $\mathbf{2 0 0 6}$ & $\mathbf{2 0 0 7}$ & $\mathbf{2 0 0 8}$ \\
\hline Total & 200.5 & 191.1 & 188.5 & 187.6 & 194.2 & 452.3 & 552.2 & 812.6 & $1,188.4$ & $1,153.2$ \\
\hline $\begin{array}{c}\text { Paid for by } \\
\text { residents }\end{array}$ & 199.6 & 181.0 & 187.1 & 177.0 & 193.9 & 257.0 & 324.7 & 388.9 & 474.1 & 479.0 \\
\hline $\begin{array}{c}\text { \% paid for } \\
\text { by residents }\end{array}$ & 99.6 & 94.7 & 99.3 & 94.4 & 99.8 & 56.8 & 58.8 & 47.9 & 39.9 & 41.5 \\
\hline
\end{tabular}

Source: Central Statistical Board

The proportion of the housing market controlled by the private sector increased from $76 \%$ in late 2000 to $87 \%$ at the end of 2007.52 That helps to explain why there were 16,767 requests for local government flats during the first half of 2005, while local governments only had 1,726 flats that were available..$^{53}$ In other words, demand for local government flats exceeded supply by a factor of nearly ten.

An EU report on housing statistics in 2005 stated that Latvia was in one of the lowest places in terms of housing construction, the issue being the number of constructed homes per 1,000 residents. According to 2005 data, Latvia built 2.8 homes per 1,000 residents. ${ }^{54}$ At the top of the list among EU member states were Ireland (19), Spain (12.6), Cyprus (8.6), France (6) and Finland (5.8). ${ }^{55}$

The number of social homes in Latvia has increased in recent years. On the one hand, this shows that people have been focusing on the problem, but on the other hand it also shows that there is a certain share of the population which cannot survive on the basis of its own level of income. The number of social homes increased from 56 in 2001 to 74 in 2003 . We must also remember the large number of people who are in the queue for better housing conditions 10,449 in 2003.

There have been various proposed solutions. The law on local government assistance in housing issues was amended early in 2005, and in addition to existing rights, the amended law also stated that local government housing must be given first and foremost to renters from denationalized buildings. Local governments were given the right to help such people to purchase or build new homes, covering their mortgage expenditures fully or in part. The state can

\footnotetext{
52 See http://www.csb.lv/csp/events/csp/events/?mode=arh\&period=06.2008\&cc_ cat $=472$ \&id $=5667$.

53 Ministry of Economics statistics about local government help in housing issues. See http:// www.em.gov.lv/em/2nd/?cat=15897.

54 Ibid., pg. 11.

55 Ibid.
} 
help this risk group by issuing guarantees for the purchase or rental of a home (Article $27 .{ }^{1}$ of the law). These amendments allow local government councils to approve binding rules in this process and to offer one-time housing support for those renters in denationalized buildings who have been evicted from their flat (Article $26 .{ }^{1}$ of the law). The national government helps by providing $50 \%$ of the financing which local governments have available for the subsidy.

New Cabinet of Ministers regulations on the way in which local governments are provided with targeted subsidies related to housing issues were adopted on 5 April 2005. The regulations say that a subsidy is available for $30 \%$ of the value of denationalized housing that is purchased from its owner, but no more than LVL 5,000 per individual case. Sadly, the norm was actually effective only between 2006 and 2008, after which the country's economic crisis brought it to an end.

At the conclusion of this section of the paper, it is worth adding that minorities and immigrants in Latvia have not traditionally lived in any compact territories. They have not been segregated, and ghettoes have not emerged. This, however, is a matter which requires further research.

\section{The Integration of Prisoners ${ }^{56}$}

There are thousands of incarcerated people in Latvia, but the numbers have declined in recent years - from 8,815 at the beginning of 2000 to 6,873 at the beginning of 2009. However, the number of people convicted of crimes each year has been around 5,000. ${ }^{57}$ In comparison to other European countries, the proportion of incarcerated persons remains high. ${ }^{58}$ The proportion of recidivists in the system - i.e., people who have been incarcerated more than once - remains at a level of more than $50 \%$, with a tendency to increase. ${ }^{59}$

56 This part of the chapter was authored by Dace Demme, a 2008 graduate from the master's degree programme on governance and communications at the Vidzeme University of Applied Science.

57 The annual report of Latvia's Prisons Board in 2008.

${ }^{58} \mathrm{See}$ http://www.kcl.ac.uk.

59 Annual reports from the Prisons Board in 2003, 2004, 2005, 2006, 2007 and 2008. 


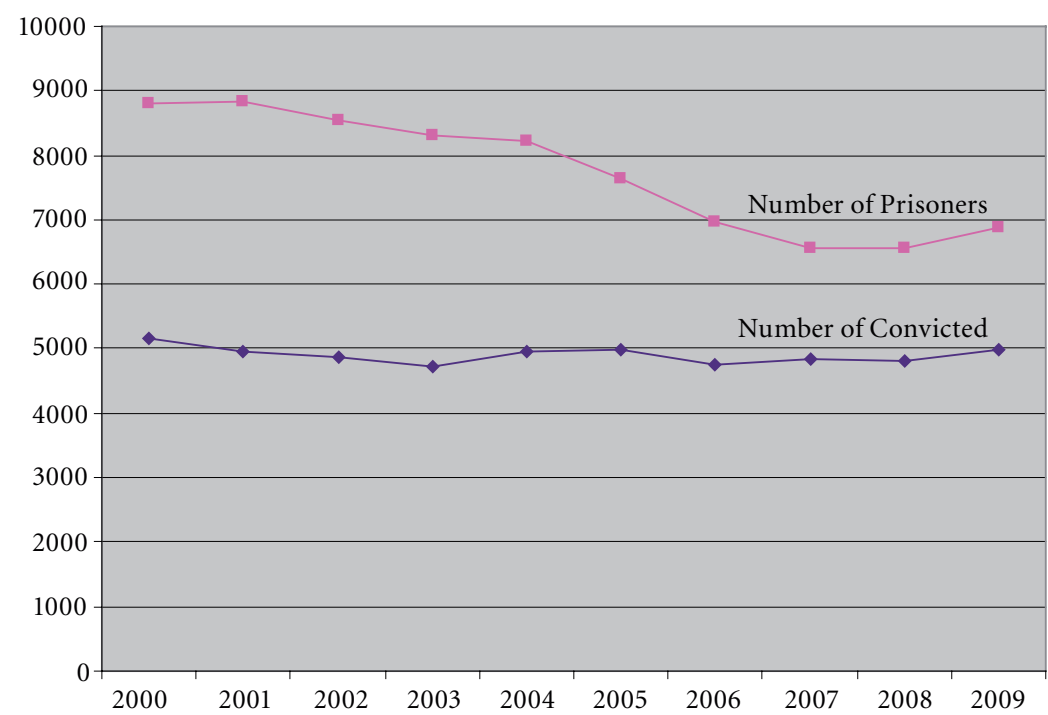

Figure 2. Number of convicted and the number of prisoners, 1998-2009

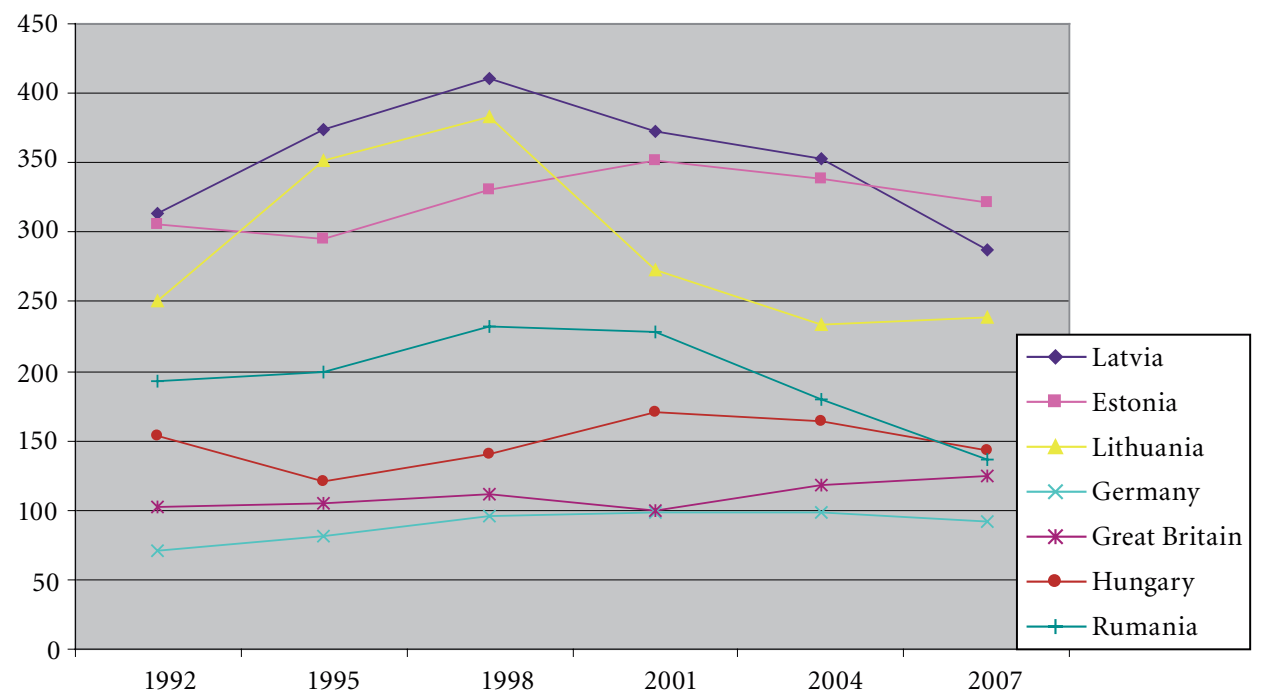

Figure 3. The number of incarcerated people per 100,000 residents 


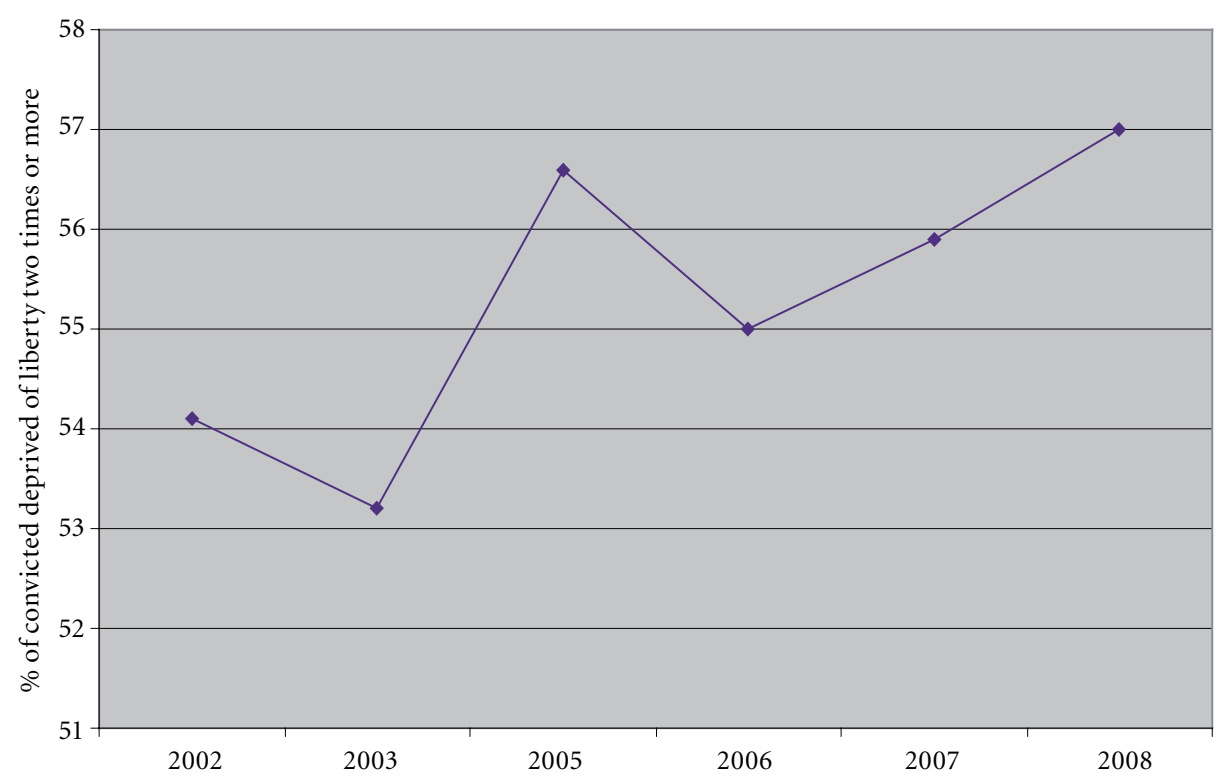

Figure 4. The proportion of recidivists in the system of incarceration

\section{Structural and Regulatory Aspects of the Integration of Prisoners}

In order to integrate ex-prisoners into society, it is necessary to work with them while in prison to so that they do not commit new crimes after serving their sentence. ${ }^{60}$ This resocialization includes education, social rehabilitation and employment.

After the restoration of independence, Latvia had 15 prisons, but since the end of 2008, there have been 12 - four were merged, and one was shut down. After Latvia's accession to the European Union in 2004, the government began to think about ways of improving prisons and ensuring that prisoners had access to different activities.

The European Prison Rules have been binding on Latvia since 11 January 2006. The document states that employees of prisons must be more than just guards, but must also facilitate the reintegration of prisoners into society once they have completed their sentences, offering them care and assistance programmes. Prison administrators should promote the activities of those institutions which offer care and reintegration services to prisoners, both in places of incarceration and elsewhere.

${ }^{60}$ Cabinet of Ministers Regulations No. 7, 9 January 2009, 'On a conceptual document on the re-socialisation of incarcerated persons,' Latvijas Véstnesis, No. 6(3992), 13 January 2009. 
There is reason to doubt whether personnel at Latvia's prisons can satisfy these rules. People need a university degree in education to work at educational institutions, including kindergartens, but, according to Interior Ministry regulations, all that is needed for those who work in the prison system alongside prisoners every day is a high school education and Latvian language skills. Makuševs has argued that "the effort to train and educate specialists with diplomas from kindergarten and high school proved to be unsuccessful. People went down the path of criminality, but we naively hope that a prison guard without any special training will be superior and be able to deal with someone who is a criminal or recidivist in terms of educating, retraining and socially adjusting that person." 61

Early in 2009, the Cabinet of Ministers finally approved a framework document on the resocialization of prison convicts which the Justice Ministry had taken a long time to develop. This marked a significant step toward the reintegration of ex-convicts. The document calls for evaluating the risks and needs of convicts, planning and implementing measures related to their resocialization. This should help prevent money from being invested in projects which have no positive effect on a convict's criminality. ${ }^{62}$ It has to be added, however, that under austerity, there is not enough money for the resocialization of convicts. ${ }^{63}$ This means that there will not be sufficient state funding for the implementation of the aforementioned policy document.

\section{Employment for Prisoners}

Most prisoners who have been convicted spend two or more years in prison. If they do not have any work to do, they forget their working skills and lose their sense of purpose. The aim of providing employment for prisoners is resocialization to allow them to live a law-abiding life after they are set free. The ability to earn some income is a secondary motivation for prisoners to become involved in employment in prison. ${ }^{64}$ The number of convicts with work has increased in recent years. ${ }^{65}$

${ }^{61}$ A. Makuševs, 'Roku dzelžu vietā - profesionālisms un autoritāte,' Diena, 11 April 2008.

${ }^{62}$ M. Luste, 'Notiesāto personu resocializācija - solis pareizajā virzienā,' Latvijas Vēstnesis, 29 January 2009, available at http://www.lv.lv/?menu=doc\&id=187017.

${ }^{63}$ 'Bezdarbs sāk valdīt arī aiz cietumu mūriem,' Diena, 9 January 2009.

${ }^{64}$ H. Purviña, 'Notiesāto personu darbs: panaceja vai utopija?' Jurista Vārds, 12 May 2008.

${ }_{65}$ Annual reports from the Prisons Board in 2003, 2004, 2005, 2006, 2007 and 2008. 


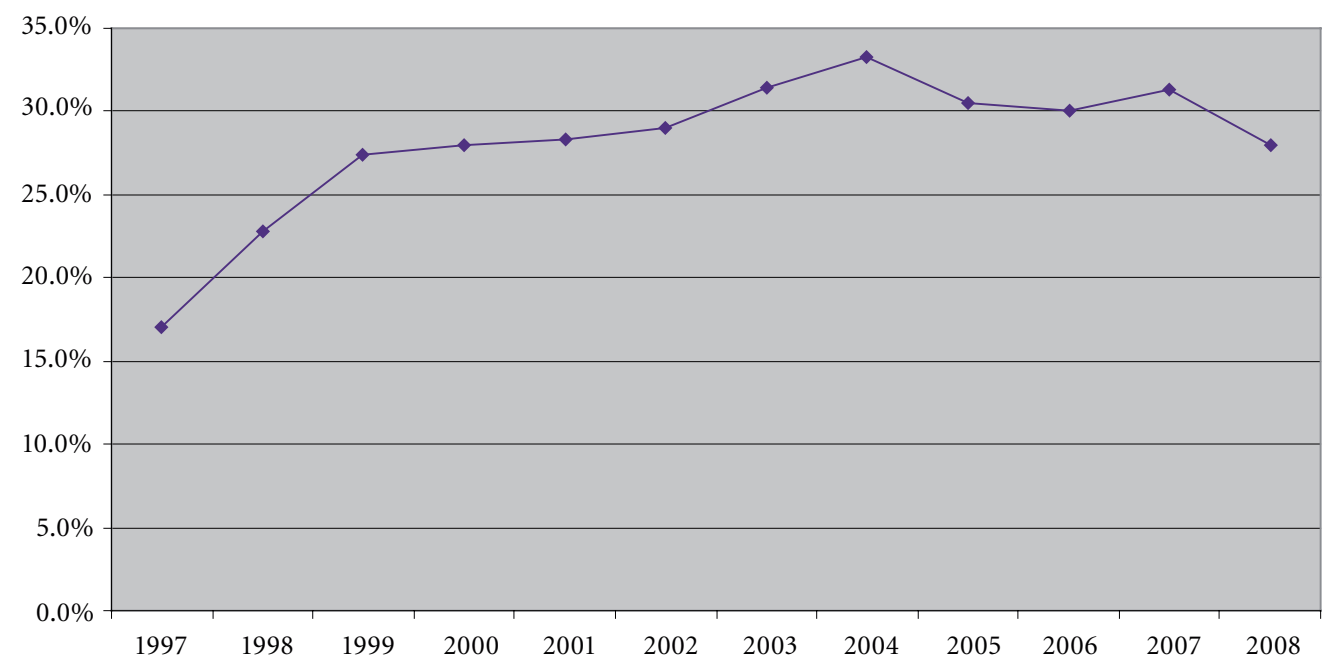

Figure 5. Share of convicts capable of working who are employed in prison

The proportion of prisoners involved in employment was highest between 2003 and 2007, perhaps because during this period many people from Latvia moved to Western Europe in search of work. As a result, employers in Latvia lacked personnel and turned to the use of prisoners as a solution to this problem.

The policy document on the employment of incarcerated people was presented to a meeting of ministerial state secretaries by the Justice Ministry on 29 November 2007. It was the first document of its type, saying that convicts earning a wage are a special category of employed people governed by special legislation. Wage issues, according to the document, had to be addressed on the basis of the same principles which exist for the population at large. ${ }^{66}$

While visiting Latvia in 2006, British expert Ursula Smart said that the main issue in Europe in the $21^{\text {st }}$ century was not finding just any old job for prisoners. Instead, she said, the focus must be on the professional skills of prisoners so as to enhance their ability to find a job after they are released from prison. Such work can be a source of income, but it is safe to say that most prisons operate at a loss when it comes to output capacity. ${ }^{67}$

The employment of a prisoner cannot be directly compared to the employment of someone who is not incarcerated. We all work to improve our capacities and to expand our experience so that we can ensure career growth and higher wages. In the case of prisoners, employment programmes have specific purposes - allowing prisoners to spend their time in a useful way, helping them to

${ }^{66}$ See http://www.mk.gov/lv/doc/2005/TMkonc_081107.doc.

67 Recommendations from a seminar, 'Employment Models in Prisons,' by the Latvian Human Rights Centre, Riga, 20 April 2006. 
maintain their working skills, and only then doing what is possible to develop their skills and experience so that they can find work after being released. Wages are a comparatively minor issue in this case, because wages paid to prisoners tend to be fairly negligible, and besides, prisoners are not allowed to have cash in places of incarceration, so they cannot spend what they earn.

Employment for prisoners is not possible without employers, but employers who want to employ incarcerated people must organize work at the prison, and they must count on the specifics of the labour force there. This implies certain inconveniences and risks.

Latvia's law on the corporate income tax was approved in February 1995 and took effect on April 1 of that same year. Article 19.1 of the law says that companies which employ prisoners do not have to pay the corporate income tax, which was the first step taken by the government to encourage employers to give work to prisoners. One year later, in July 1996, the law was amended to provide for only a $20 \%$ tax reduction for companies employing prisoners. ${ }^{68}$ This reduced support for this process. In October 2005, the law was amended again to exclude the tax discount altogether. ${ }^{69}$

\section{The National Probation Service}

Latvia's National Probation Service (NPS) was established by the Justice Ministry in 2003, before Latvia's accession to the European Union. This was an enormous step toward the reintegration of prisoners into society. The job for the agency is to implement national policies related to the criminal punishment of forced labour, as well as socializing sentences related to compulsory community work. The agency also supervises those who are on probation and helps them to adjust their behaviour. ${ }^{70}$ Between 2003 and 2007, the NPS expanded from six territorial units to 28 , with another 10 affiliates in various parts of the country.

The functions of the NPS have also expanded. There are eight tasks for the agency, and the ones which have to do with the integration of prisoners and exprisoners the most are the design of probation programmes, the implementation of licensed programmes involving prisoners and former prisoners, supervision of people who have received suspended sentences or have received early release from prison, and provision of post-penitentiary assistance to people who are preparing for release or have already been released. ${ }^{71}$

${ }^{68}$ See Latvijas Véstnesis, No. 108(593), 21 June 1996.

${ }^{69}$ See Latvijas Véstnesis, No. 179(3337), 9 November 2005.

${ }^{70}$ The Law on the National Probation Service, 18 December 2003, amended 26 October 2006.

${ }^{71}$ Ibid. 
There are some 10,000 people in Latvia at this time who are involved in the integration of current and former prisoners. ${ }^{72}$ This includes the family members of convicts, as well as prison personnel. The number might be much lower if changes were made to the punitive system. Currently, law enforcement institutions seek prison terms for defendants more often than is really necessary. Living and social conditions in prisons are fairly terrible -20 to 50 prisoners in a single cell, and negligible opportunities for education, rehabilitation and employment. This means that a young petty thief who spends two years in prison will probably become a robber, and not an obedient citizen of the state. It is also true that fewer prisoners would mean a lesser need for resources for their reintegration into society.

\section{Conclusions}

Politicians in Latvia do not have much of an understanding of the fact that a well-developed social policy is a fairly important component in economic growth, because social and economic policies are interrelated and interdependent. The dominant assumption in government is that economic growth and a larger numbers of jobs are in and of themselves enough to guarantee social inclusion.

In policy documents, social integration goals are formulated and the institutional framework for social integration policies has basically been established, but the political process has not ensured an adequate reaction to public needs, and it does not deal with the increasing polarisation which is evident in society.

There are some positive trends: poverty in families with children has diminished to a certain extent. The fact that in summer 2009, the government did not reduce the untaxed minimum for dependent children and has been fairly cautious in dealing with child care subsidies indicates that those who are in power believe that there would be massive public protests if generous family support policies were trimmed in any crude way. However, it does appear that a number of cuts will be made in the 2010 budget. Ever since Latvia's accession to the European Union, there has been positive movement toward a higher untaxed minimum in Latvia - from LVL 21 in 2004 to fully LVL 90 in the first half of 2009. The main beneficiaries of this were people with low wages. They were the biggest losers, however, when the untaxed minimum was slashed dramatically on 1 July 2009 - from LVL 90 to just LVL 35, with each person having to contribute an additional LVL 12.65 a month to the national budget.

The biggest mistake in pension policies was a freeze on the social security allowance payment at a level of LVL 45 during a period of major inflation and wage increases (2006-2008). This seriously worsened the situation of

72 The annual report of the National Probation Service, 2008, pg. 14. 
pensioners against the background of employed people, and it initiated the 2008 national referendum on raising pensions. In the pre-referendum situation, increased pensions were devalued by the 2009 crisis, and pensioners turned out to be the largest group in society from which the government took away $10 \%$ of earned income, which was returned to them in April 2010 by Constitutional Court decision.

In terms of housing policy, the state pursued a policy of non-intervention for a long time, relying on the invisible hand of the free market, as well as on local government housing subsidies. A positive trend emerged along with accession to the EU, but efforts that have been made are not in line with the scale of the problem. The country lacks cheap housing, and the proportion of social homes is the lowest in the EU.

Decisions in the area of health care policy were postponed again and again. The sector has largely been privatized, and during a situation in which the purchasing power of local residents is low, that will mean a massive worsening in the health situation of many people, as well as chaos in the system itself.

The burden on social aid services has increased to a disproportionate degree. There have been improvements in the system in terms of personnel numbers and personnel training, but the abilities of local governments to help people are uneven, and many local governments spend most of the available money during the first half of the year. The national government's decision to cover some of the necessary funding is a partial solution, but a solution nonetheless.

The government's decision in 2008 to limit unemployment benefits to four to six months, depending on the amount of time that the unemployed person had worked before becoming jobless, was a mistake. The result was that many people of working age have found themselves without any income at all. On 1 July 2009, Parliament declared that all unemployed people would receive unemployment support for nine months. There has been a system since September 1 in which the government pays monthly stipends of LVL 100 to people who do public works. Investments in human capital, however, remain very low.

Latvia's penitentiary system is doing poorly with the resocialization of convicts, and the proportion of recidivists remains very high indeed.

\section{Greatest Achievements}

Latvia has entered the European Union's overall social inclusion policy context, which requires conducting measurements of exclusion and poverty, as well as taking steps to address these challenges. The social security system has seen improvements in staffing and staff training. The government's commitment to cover half of the funding to ensure the guaranteed minimal income is a partial solution for local governments with low revenues. Creation of the State Probation Service in 2003 under the auspices of the Ministry of Justice was an important step on the road to the integration of ex-prisoners. 


\section{Most Serious Problems}

The state lacks cheap housing and there is very little social housing. There is a lack of understanding among policy-makers that a developed social policy is an important element of economic growth and that social and economic policy are interdependent. The size of the state social security benefit has not increased since 2005 despite high inflation and wage increases and, at LVL 45, is inadequate and social inequality is growing. The commercialization of health care and the closure of hospitals have decreased accessibility, but Latvia devotes one of the lowest shares of GDP towards health care in the EU. The rate of incarceration remains high, the rate of recidivism is greater than $50 \%$ and growing, and the prison system has not proved successful at resocializing inmates.

\section{Most Urgent Tasks}

Among the most important tasks are the regular revision and increase in the guaranteed minimum income to a level permitting survival, integration of social care and health care, and the creation of cheap housing. As a result of a February 2009 European Court of Human Rights ruling, Latvia must amend pension legislation to equalize the rights of citizens and non-citizens to pensions for time worked until 1991 outside of Latvian territory. A more intense use of alternatives to custodial sanctions should be introduced. 


\section{Education for Social Integration}

\section{Brigita Zepa}

\section{Introduction}

In the context of social integration, the education system can be examined from two different perspectives: on the one hand, to what extent does the education system include or exclude individuals acquiring education; on the other hand, how successful is the education system in inculcating in people the knowledge and skills they need for professional and social life, thereby ensuring the integration of the individual in society. These two issues are closely linked, insofar as an individual's exclusion from the acquisition of education today is a primary cause increasing the risk of social exclusion later in life, denying him or her access to public goods of various kinds.

This chapter investigates two broad issues. The first is linked with strategies within the education system for promoting the development among young people of the knowledge and skills necessary in a democratic society. In the context of social integration, this is recognition of diversity in society, tolerance of others, critical thinking which allows perception of the complexity of social reality and the ability to act in it effectively. The second issue is how the education system ensures the inclusive function towards those being taught, what is the education system's strategy with regard to such "educational mistakes" as low academic attainment and early school leavers.

This chapter will investigate how the education system implements the following tasks of integrating through education:

1) ensuring equal rights to education, promoting inclusive education, reducing the risk of social exclusion;

2) promoting skills for active democratic participation and social responsibility, furthering recognition of diversity among the younger generation;

3) nurturing competence for intercultural contact and cooperation.

In the early 1970s the task of the education system was focused on academic results while remaining agnostic with regard to social aspects. Contemporary European policy sets the education system another important goal as well reducing social inequality and promoting the inclusion and integration into society of various social groups. In the context of this research, this suggests 
the necessity of discovering which educational practices increase social exclusion and which practices further social inclusion. ${ }^{1}$

\section{The Debate on Creating a Unified Education System}

Since the late 1990s when social integration policy was initiated in Latvia, its task was defined as creating a single community society on the basis of acquisition of the Latvian language. A logical continuation of this policy was bilingual education policy drafted in the late 1990s, which set as one of its goals the creation of a unified education system. Currently, this theme cannot be found in education policy documents. At the same time, it is well understood that a school system divided along linguistic lines promotes the reproduction of sociolinguistic communities, which inevitably leads to the construction of one's own positive identity and its juxtaposition with the negative identity of the "other" and serves to maintain a certain level of tension between these communities.

The following education policy steps can be considered as strategies that may help create a unified education system:

1) introduction of bilingual education in minority schools;

2) dual stream schools.

The creation of a unified education system is also furthered by the strategy of the parents of children belonging to national minorities to send their children to Latvian schools.

Among the many education researchers in Latvia, only Maria Golubeva has turned her attention to the issue of creating a unified education system. In her research Integrating Diversity in the General Education System, she used Amir and Sharan's analytical model, which suggests overcoming school segregation by evaluating a number of structural variables (the legal basis, the stances of society, the cultural context) and implementation (school attitudes, links with goals set by politicians). ${ }^{2}$ Golubeva indicates that researching the existing education system in such a way, one can determine which aspects hold more risks and in which circumstances concrete programmes for promoting the creation of a unified education system are necessary, etc.

In their research Minority Children in Latvian Language Schools, Ina Druviete and Marija Gavrilina provide answers to the question "What hinders

${ }^{1}$ European Committee for Social Cohesion (CDCS) (2004), Revised Strategy for Social Cohesion. Strasbourg: Council of Europe.

${ }^{2}$ Marija Golubeva (2008), Dažādības integrācija valsts vispārējās izglìtības sistēmāa. Riga: Providus, pg. 31, available at http://www.providus.1v/public/26462.html. 
the integration of Latvian and Russian schools $?^{3}$ They demonstrate a series of problems one encounters in ethnically and linguistically diverse classes:

1) misunderstandings based on different mentalities;

2) the lack of methodological training;

3) the lack of special textbooks and other teaching materials;

4) difficulties in communicating with parents. ${ }^{4}$

By the same token, Maria Golubeva reviewed this research and detected an effort to highlight differences in the mentality of Latvian and minority children as an even greater problem than the lack of well-trained teachers. ${ }^{5}$ Golubeva begins a debate with Druviete and Gavrilina about their stance "that a minority pupil in a Latvian language school will only partially acquire the so-called ethnic element in education or will not acquire it at all." ${ }^{16}$ Golubeva suggests that an insistent demand that the obligation of each pupil is to "be aware of and feel belonging to an ethnic group" is in contradiction to one of the goals formulated by James Banks for citizen's education in a multicultural society: education should not only provide pupils with the opportunity to freely assert their cultural (or racial, ethnic) identity, but also must ensure pupils the freedom to operate outside the boundaries of their ethnic and cultural groups. ${ }^{7}$ Golubeva also points out that Druviete's and Gavrilina's approach is characterized by the postulates of "deficiency theories", in other words, the situation of minority children in Latvian language schools is examined with reference to the children's inability to fit into these schools, while underplaying deficiencies in the education system itself as the root of the problem.

In this debate, one can see that Golubeva is guided by the values of education in a multicultural society (freedom of choice in cultural, ethnic belonging), while Druviete and Gavrilina are guided by the ethnic nationalism that is rooted in Latvian politics. The positions represented by these authors illustrate in sharp relief the dominant positions on the issue of the education system's division according to the language principle and the silence of policy documents thereon, suggesting that at least in the short term, there will be neither any policy innovation nor an open debate in society which might mark a change in the prevailing discourse on this issue. At the same time, it is useful to examine the practices which to a certain extent pave the way for the creation of a unified system of education.

In the opinion of Golubeva, it is necessary to adopt policy guidelines or a strategy that would lead to the integration of diversity in Latvia's school

${ }^{3}$ Ina Druviete and Marija Gavriḷina (2003), Minoritātes bērni latviešu mācībvalodas skolās. Riga: Puse, pp. 31-37.

${ }^{4}$ Golubeva, Dažădības integrācija valsts vispārējās izglìtības sistēmā, pg. 37.

${ }^{5}$ Ibid.

${ }^{6}$ Ibid.

7 James Banks (1997), Educating Citizens in a Multicultural Society. 
system. At the base of such a strategy there must be a certain consensus among the persons involved in the school system (parents, teachers, pupils, the school administration, the local education authority, government and policy-makers), and it must be adopted after wide consultations with all stakeholders. ${ }^{8}$

The international research project Divided Education, Divided Citizens, ${ }^{9}$ in which Maria Golubeva participated from the Latvian side, found that a school system divided along linguistic lines influences the creation of a different political culture among the respective group of youth, but also that a certain part of youth and teachers support a separated system. The research found that minority youth are less convinced of their political efficacy than the majority. With regard to the division of schools, the research found that $39 \%$ of Russian-speakers and $23 \%$ of Latvian pupils and $29 \%$ of Russian-speakers and 14\% of Latvian teachers agreed with the statement that "the existence of separate schools is a very good thing." The share of pupils who claimed that they would not want to learn in one class with those belonging to the "other" group was $42 \%$ of Latvians and $56 \%$ of Russian-speakers. These figures show clearly that a divided education system reproduces dissociation from the other sociolinguistic group as well as negatively impacts motivation for political participation.

\section{Bilingual Education as an Integrating Strategy}

One of the goals of introducing bilingual education was to promote the integration of minority youth into the labour market and enhance their prospects for studying in Latvia's institutions of higher education where the language of study at state-funded institutions since 1992 has been Latvian. A significant amount of research has been conducted in Latvia on the introduction of bilingual education, but thus far no research has been done on the impact of bilingual education on school results which would permit the evaluation of this policy in terms of attaining the goals set for it.

The lack of research, as well as the publicly available Ministry of Education and Science data do not permit an evaluation of how learning subjects bilingually has affected school results. In this context, it is interesting to review the analysis conducted by the representatives of the Russian cultural, education and science association "Arkon" Alexandra Malashonok and Nikita Khalyavin of the marks in centralized examinations in all of Riga's state and municipal secondary schools. ${ }^{10}$ The authors compare marks in centralized examinations

${ }^{8}$ Golubeva, Dažādības integrācija valsts vispārējās izglītības sistēmā, pg. 44.

9 Marija Golubeva, Stephen Powell, Elmina Kazimzade, Anca Nedelcu (2009), Divided Education, Divided Citizens? A comparative study of the effects of separate schooling on civil enculturation, available at http://www2.providus.lv/public/27199.html.

10 Aleksandra Malashonok, Nikita Khalyavin (n.d.), 'Podrobnee ob issledovanii rezultatov reforrny obrazovaniya v russkikh shkolakh,' Assotsiatsiya Russkoy kul'tury, obrazovaniya i nauki "Arkon", available at http://www.svoi.lv/userfiles/File/memorandum-svoi.doc. 
by Riga school pupils for the period 2004 to 2007 depending on the language of instruction. For the analysis, they did not choose subjects in which less than $20 \%$ of the pupils took the examinations. Malashonok and Khalyavin compare Russian and Latvian pupils' average marks in mathematics, English and history. The results obtained suggest that Russian pupils do more poorly in English, but that there was no observable worsening of results in the time period covered which could serve as a baseline for comparison with results obtained in subjects in which instruction takes place bilingually.

In comparison with 2005, results in mathematics examinations in 2006 and 2007 worsened by several percentile points. With regard to history examinations, one sees that the results are very inconsistent among both Latvian and Russian pupils. However, a common characteristic is that the average mark for Russian pupils was 3/10 of a point lower (in 2007 7/10 of a point lower) in comparison with Latvians. These results suggest that in examinations where language knowledge is more important, for example, in history, Russian pupils' school results are lower compared to those of Latvians.

At the same time, the 2007 annual report of the Ministry of Education and Science mentions that "2006-2007 school year results are similar in educational institutions that are implementing education programmes in the Latvian language and those implementing minority education programmes." These two materials suggest that without a detailed evaluation of the influence of bilingual education on school results, it is not possible to draw conclusions about the inclusive impact of the education reform with regard to minority youth.

Table 1. Riga state and municipal secondary school student average marks in centralized examinations by language of instruction

\begin{tabular}{|l|c|c|c|c|c|}
\hline \multicolumn{1}{|c|}{ Subject } & Year & Russian & Latvian & Difference & \% \\
\hline Mathematics & 2004 & 2.88 & 3.00 & -0.12 & $-4 \%$ \\
\hline Mathematics & 2005 & 2.68 & 2.82 & -0.14 & $-5 \%$ \\
\hline Mathematics & 2006 & 2.73 & 2.97 & -0.24 & $-8.1 \%$ \\
\hline Mathematics & 2007 & 2.71 & 2.99 & -0.28 & $-9.4 \%$ \\
\hline English & 2005 & 2.73 & 3.26 & -0.53 & $-16.3 \%$ \\
\hline English & 2006 & 2.74 & 3.22 & -0.48 & $-14.9 \%$ \\
\hline English & 2007 & 2.86 & 3.38 & -0.52 & $-15.4 \%$ \\
\hline History & 2005 & 2.62 & 2.91 & -0.29 & $-10.0 \%$ \\
\hline History & 2006 & 3.01 & 3.37 & -0.36 & $-10.7 \%$ \\
\hline History & 2007 & 2.66 & 3.36 & -0.70 & $-20.8 \%$ \\
\hline
\end{tabular}

A certain comparison of academic results can also be obtained from the International Student Evaluation Programme (SSNP 2006) research. The authors of the 2006 research acknowledge that there are practically no differences between the average attainment of pupils studying in Russian language schools (schools implementing minority education programmes) and those in 
Latvian language schools (491 vs. 494 points). ${ }^{11}$ If in 2000 and 2003 pupils in Latvian language schools had slightly better average results, in 2006 there was no longer any difference and attainment levels had equalized. In comparison with 2003 results, those in 2006 decreased for pupils studying in Latvian language schools or dual stream schools. The results of pupils in Russian language schools (schools implementing minority education programmes) did not change compared to the previous research cycle in 2003. ${ }^{12}$ Children from both Latvian and Russian schools in the countryside had significantly lower educational attainment compared to children in the cities, particularly in Riga.

In their article on educational attainment of minorities in the Baltic states, Hazans, Trapeznikova and Rastrigina investigate the issue of the inclusiveness towards minorities of the system of higher education. ${ }^{13}$ The authors stress that among Latvians in the age group $21-45$ there are $7-8 \%$ more persons than among the same age group among minorities. However, in the article in question, there was no possibility of ascertaining the reasons for differences in educational attainment. Taking into consideration that a gradual transition to instruction in Latvian has taken place in state funded institutions of higher education since 1992, the assumption that some Russian-speaking youth have gone to Russia to receive a higher education in their native language is well-founded. This, in turn, suggests the conclusion that the transition to study in Latvian has weakened the reproduction of highly educated human resources in Latvia.

Table 2. The number of pupils studying in general education day schools

\begin{tabular}{|c|c|c|}
\hline & $\begin{array}{c}\text { Pupils in general education day } \\
\text { schools with Latvian as the primary } \\
\text { language of instruction }\end{array}$ & $\begin{array}{c}\text { Pupils in general education day schools } \\
\text { with Russian as the primary language } \\
\text { of instruction }\end{array}$ \\
\hline $2005 / 2006$ & 186,409 & 68,078 \\
\hline $2004 / 2005$ & 193,665 & 73,711 \\
\hline $2003 / 2004$ & 198,295 & 79,302 \\
\hline $2002 / 2003$ & 204,348 & 83,201 \\
\hline $2001 / 2002$ & 208,454 & 89,718 \\
\hline $2000 / 2001$ & 208,185 & 95,850 \\
\hline $1999 / 2000$ & 205,885 & 101,506 \\
\hline $1998 / 1999$ & 198,353 & 105,806 \\
\hline
\end{tabular}

Source: the home page of the Ministry of Education and Science

Ministry of Education and Science data on the changing enrolment in Latvian and Russian language schools shows a relative decrease in the number of pupils

${ }^{11}$ A. Geske, A. Grīnfelds, A. Kangro, R. Kisel̦ova (2006), Kompetence dabaszinātnēs, matemātikā un lasīšanā-ieguldījums nākotnei. Latvija OECD valstu Starptautiskajā skolēnu novērtēšanas programmā 2006, pg. 127.

12 Ibid., pg. 129.

${ }^{13}$ Mihails Hazans, I. Trapeznikova, O. Rastrigina (2008), 'Ethnic and parental effects on schooling outcomes before and during the transition: evidence from the Baltic countries,' Journal of Population Economics, 21(3) 2008, pp. 719-749. 
studying in Russian. From the 1998-1999 school year to the 2005-2006 school year the number of pupils in Latvian day schools has decreased by 11,944 pupils, while the decrease in Russian schools for that period was 37,728.

The impact of the education reform on the political attitudes of schoolchildren was studied in a research project entitled Integration of Minority Youth in the Society of Latvia in the Context of the Education Reform which found a strengthening of the trend among Latvian and Russian-speaking communities towards separation and mutual isolation as a result of the education reform. The impact of the education reform on Latvian language use is documented in the study Language, which was conducted every year from 1996 through 2008. Annual studies on state language acquisition and use among Russian-speakers permit observation of behavioural and attitudinal changes over a period of more than 10 years. Research results suggest that the number of young people with good Latvian language proficiency has increased from about 40\% in 1996 to $73 \%$ in 2008 . At the same time in 2004 , during the most active phase of implementing the education reform, attitudes towards Latvian language use became more negative: in 2003 38\% of Russian-speakers were positively disposed towards speaking in Latvian, while the figure had dropped to 27\% in 2004.

\section{Dual Stream Schools as a Sociolinguistically Inclusive Strategy}

As demonstrated by Ministry of Education and Science data, over the last ten years the number of dual stream schools has diminished significantly. In the 1998-1999 school year there were 145 such schools, but by 2007-2008 there were only 88 , which accounted for only $9.2 \%$ of all general education day schools. About $40 \%$ of such schools are located in Latgale.

Table 3. Changes in the number of dual stream schools 1998-2008

\begin{tabular}{|c|c|c|c|c|c|c|c|c|}
\hline & Total & Latvian & Russian & $\begin{array}{c}\text { Dual Latvian- } \\
\text { Russian }\end{array}$ & Polish & Ukrainian & Belarusian & English \\
\hline $2007 / 2008$ & 958 & 722 & 141 & 88 & 5 & 1 & 1 & 0 \\
\hline $2006 / 2007$ & 974 & 727 & 148 & 92 & 4 & 1 & 1 & 1 \\
\hline $2005 / 2006$ & 983 & 727 & 152 & 97 & 4 & 1 & 1 & 1 \\
\hline $2004 / 2005$ & 993 & 724 & 155 & 108 & 4 & 1 & 1 & $\mathrm{x}$ \\
\hline $2003 / 2004$ & 1009 & 729 & 159 & 115 & 4 & 1 & 1 & $\mathrm{x}$ \\
\hline $2002 / 2003$ & 1017 & 720 & 166 & 124 & 5 & 1 & 1 & $\mathrm{x}$ \\
\hline $2001 / 2002$ & 1029 & 725 & 175 & 122 & 5 & 1 & 1 & $\mathrm{x}$ \\
\hline $2000 / 2001$ & 1037 & 724 & 178 & 128 & 5 & 1 & 1 & $\mathrm{x}$ \\
\hline $1999 / 2000 *$ & 1057 & 727 & 189 & 133 & 5 & 1 & $* 2$ & $\mathrm{x}$ \\
\hline $1998 / 1999$ & 1074 & 728 & 195 & 145 & 5 & 1 & - & $\mathrm{x}$ \\
\hline
\end{tabular}

* incl. one Lithuanian school

Source: the home page of the Ministry of Education and Science at http://izm.izm.gov.lv/ upload_file/Izglitiba/Vispareja_izglitiba/Statistika/2007/skolu_sk_07.xls. 
Dual stream schools were created in Latvia during the Soviet years in the 1960s. In these schools, children from Latvia's two dominant linguistic groups Latvian and Russian - attended in separate classes or "streams". The term "dual stream" continues to be used today, even though the current emphasis is on the distinction between schools according to the educational programme they are implementing. Thus, this term could be replaced with another, given the fact that the education process has become more open and social integration policy has been directed towards making cooperation between children of different language groups more intensive. ${ }^{14}$

At the very end of the 1980s and the beginning of the 1990s, many "dual stream" schools, especially in Riga, were liquidated. Then, in the mid- and late1990 s the number of "dual stream" schools increased, as many were created on the basis of Russian schools. In 2003, researchers at the Baltic Institute of Social Sciences (BISS) concluded that there are basically two different types of "dual stream" schools.

In the first group are those to which was added a Latvian "stream" - children whose native language was Latvian began to learn at the school in separate classes. In this case, the school became a dual stream school in relation to the concrete local government's strategy to optimize schools taking into account the demographic situation and the ability of the local government to ensure effective use of the finances allocated for education. It is the local government's area of authority to open or close a general education institution, as the state budget covers only expenses related to paying teacher's salaries.

The second group is comprised of schools with children whose native language is Russian, but which have licensed educational programmes in the Latvian language alongside minority education programmes. Schoolchildren who are learning according to Latvian programmes create so-called Latvian classes or "streams." Such a model in creating a "dual stream" school can be characterized as initiative "from below" based on the requests of parents who want their children to learn in Latvian starting from grade one.

The research conducted by the BISS in 2003 points to a number of social gains for various target groups (schoolchildren, teachers, local governments) provided by "dual stream" schools. Textual analysis of focus groups with schoolchildren, teachers and local government representatives permits the following conclusions. First, "dual stream" schools increase the freedom of choice of minority schoolchildren in the field of general education. The co-existence of two linguistic groups opens up opportunities for inter-ethnic communica-

${ }^{14}$ In this chapter, the term 'dual stream' school is used for all general education day secondary schools implementing general education programmes in either the Latvian language of minority education programmes. If necessary, the type of dual stream school is specified. 
tion, develops understanding among both Latvian and minority children about cultural diversity, and creates a store of experience in intercultural contact.

Second, multicultural teacher teams develop in "dual stream" schools, furthering cooperation between Latvian and Russian schools in implementing bilingual education. The social and pedagogical environment at "dual stream" schools promotes interethnic dialogue not only among children, but among teachers as well. Third, in Latvia local governments are institutionally charged with opening, closing and unifying schools. For smaller local governments in particular, "dual stream" schools are a way to resolve the effective distribution of financial resources allocated for education, taking into account the demographic situation when there are not enough children to fill a school and the desire to acquire an education in Latvian in an environment with both a Latvian and a Russian cultural environment.

Notwithstanding the social gains derived from such schools, their academic attainment is on average lower than that in other schools. As demonstrated by the SSNP 2006 research results, the academic results of children from "dual stream" schools in Riga and other big cities are significantly lower than those in other urban schools. The results of children from rural "dual stream" schools are similar to those in rural Latvian schools. ${ }^{15}$ No analysis has been conducted as to the reasons for the different levels of attainment in urban schools. At the same time, it should be acknowledged that the results of the BISS research testify to the inclusive social impact of "dual stream" schools, which is interesting, given the fact that the decisive consideration in creating such schools was economic.

\section{Inclusive Strategies in Educational Institutions}

Implementing an inclusive schools policy also means preparing children who are characterized by a socially inclusive orientation and tolerance towards representatives of various social groups. Although there is some concern in Latvia, as elsewhere, about intolerance in contacts among teachers or students, there is very little research about the issue of tolerance in schools. For example, research entitled Drop Outs from Primary School: Solutions to the Problem points to the necessity of creating an inclusive environment. Experts discovered instances in which a teacher had exhibited a very intolerant attitude towards a child or his family: "you are from such a family and you can't do anything". As a result, the children "have enormous fear of the teachers, since they have had a very negative experience in their previous school - "are you stupid, are you an idiot, that you can't keep up with the others" he feels absolutely dark.

\footnotetext{
15 A. Geske, A. Grīnfelds, A. Kangro, R. Kisel̦ova, Kompetence dabaszinātnēs, matemātikāa un lasī̌̌anā-ieguldījums nākotnei, pg. 128.
} 
They are marked by it, and they proceed with the conviction "I am dumb, I am an idiot" (a social pedagogue).

At the same time, the research by Austers, Golubeva and Strode entitled $A$ Barometer of Teacher Tolerance shows that there is a definite incompatibility between teachers' stances about the necessity of cultivating tolerance in children and the practices used to implement this goal. ${ }^{16}$ On the other hand, teachers often understand tolerance in a very restricted manner, relating it only towards a few social groups. Basically, teachers link the necessity of tolerance with the arrival into Latvia of people of different cultural backgrounds, which could happen "some time in the future". Teachers do not see manifestations of tolerance in everyday situations, including in relations with poorer classmates or physically or mentally challenged children. The research suggests that teachers base their discussions on tolerance with children on their own experience, do not utilize the insights that could be gained from courses, training materials or policy documents, such as the National Programme for the Promotion of Tolerance. This limited understanding often prevents teachers from preparing young people for life situations that will differ from their own. At the same time, the teachers admit that they would not know what to do if children from different cultural backgrounds came into their classrooms. The research also shows that teachers rely more on authority and less on cooperation and mutual respect with schoolchildren. In nurturing such values in young people, teachers reproduce the values typical of authoritarian communication, reducing children's self-confidence and their possibilities for addressing personal and social issues through democratic communication.

In a dissertation entitled $A$ Comparative Analysis of Teachers' Pedagogical Activity in Latvian and Minority Primary School Classes, ${ }^{17}$ Liesma Ose concludes that "in schools with Latvian language instruction with many children with different native languages, the pedagogical activity of the teacher often lacks tolerance towards the children's varied sociocultural experiences and its manifestations in the learning process. When two sociocultural experiences meet, the teacher tries to dominate, since she does not trust the child's sociocultural experience. Thus, the future dimension in pedagogical activity - outgrowing today's culture and creating internal democracy within classrooms - is missing. One way to ensure that teachers were aware of the need to create an inclusive environment in the school is by envisaging intercultural and inclusive education modules in teachers' training. ${ }^{18}$

${ }^{16}$ Ivars Austers, Maria Golubeva, Ieva Strode (2007), Skolotāju tolerances barometrs. Riga: Providus.

${ }^{17}$ Liesma Ose (2007), Skolotāju pedagogiskās darbības salīdzinoša analīze latviešu un mazākumtautību sākumskolu klasēs," Unpublished dissertation, Riga.

${ }^{18}$ Maria Golubeva, Dažādības integrācija valsts vispārējās izglìtīibas sistēmāa, pg. 26, available at http://www.providus.lv/public/26462.html. 


\section{Dialogue Between Parents and the School}

Among Latvian school directors polled in a comparative study (SSNP, 2006), 54\% feel almost no interest or desire from parents that the school guarantee high educational quality. This is a relatively high indicator among the countries included in the study. The authors conclude that in many other countries parents show their interest about educational institutions more actively and are more demanding. These data permit the conclusion that parents' passivity in relation to educational quality does not provide any incentive for schools to improve quality. ${ }^{19}$

Kārlis Boldiševics and Maija Upmane in their article "Insights and Prospects for Dialogue between Parents and the School" 20 stress the necessity of involving social partners in the development of the education system and the improvement of quality and conclude that in contemporary society, parents' participation in education policy is necessary. However, currently at the level of the school, local and national government, participation rates are every low. The authors explain this with reference to the centralized nature of the education system, which creates a great distance between parents and education policy. Legislation is to blame as well, as it envisages parental initiative and participation only in economic matters. ${ }^{21}$ While the public lacks participation skills, schools have insufficiently developed skills in dealing with people of various opinions, sometimes do not perceive parents as social partners, and perceive negatively any attempts to influence school life. The authors stress that parents are dissatisfied with their experience of participation to date in the school and outside of it, suggesting that issues affecting the education process and education quality are virtually impossible to affect. Parents perceive other parents, children, and sometimes teachers as their main cooperation partners, but rarely mention NGOs, representatives of state or local governmental institutions or parliamentary deputies. Parents who live outside of Riga mentioned the local government as a cooperation partner. ${ }^{22}$

Parents indicate that parents' councils basically help the school administration in resolving economic and organizational issues, for example, by deciding about the use of resources donated by parents, addressing issues linked with feeding the children or security. But the council's influence on other essential issues (e.g., evaluating the quality of education, preparing proposals for improving the teaching process) is very limited and depends on the make-up of the school council and its leadership.

\footnotetext{
${ }^{19}$ Geske, Grīnfelds, Kangro, Kiselova, Kompetence dabaszinātnēs, matemātikā un lasīšanā ieguldījums nākotnei, pp. 130-131.

${ }^{20}$ Kārlis Boldiševics and Maija Upmane (2007), 'Vecāku un skolas dialoga atzinnas un perspektīvas,' in Izglìtība zināšanu sabiedrības attīstībai Latvijā. Riga: SAK, pp. 108-121.

${ }^{21}$ Ibid., pg. 111.

${ }^{22}$ Ibid., pg. 112.
} 
Research conducted by the BISS in 2002 entitled Analysis of the Implementation of Bilingual Education showed that parents were not involved in preparing a significant education reform. Parents were informed about bilingual education reform only when it began to be implemented in schools, but even at that level, discussions did not take place. Admittedly, certain school directors did indicate that they were ready to take parents' opinions into consideration in organizing the learning process: "If parents request it, we are ready to adopt a different model which would further the knowledge of the children" (school director in Zemgale). ${ }^{23}$

\section{Diversity in Latvian Textbooks}

The content of textbooks can be seen as one element which shapes the schoolchild's conception of the outside world. Krupnikova's research on "Diversity in Latvian Textbooks" shows that the portrayal of social life in Latvian and Russian language textbooks is rather different. The author concludes that the textbooks analysed have almost no representations of Latvian minorities except for Russians, and that the contribution of minorities in Latvian culture and history is largely ignored. ${ }^{24}$ Russians are mainly portrayed in textbooks in the Russian language, which make almost no mention of Latvians or other Latvian minorities. The author concludes that textbooks in both Latvian and Russian are ethnocentric with regard to other groups and their social and cultural contribution. They are more open to "Western culture", though each has its own "most popular country". The textbooks do not reflect any interaction between Latvians and Russians. Moreover, in translating Latvian language books into Russian, Latvian proper names are changed into typical Russian names, but Latvian books have no characters with Russian names. Latvian language books create a monocultural information space without minorities, but Russian characters in Russian language books are divorced from the Latvian social scene. Minorities are mainly mentioned in those sections which deal with specifically minority themes (ethnic composition of the population, citizenship, the naturalization process), but not in other sections. Minority representatives are not used as illustrations of loyalty towards the country, demonstrations of civic participation, and other positive examples. These roles are reserved for ethnic Latvians. Little attention is given to the other Baltic countries Estonia and Lithuania, their culture and traditions, ignoring the close historical, political and economic ties in the Baltic Sea region.

${ }^{23}$ Baltic Institute of Social Sciences (2002), Bilingvālās izglītības ieviešanas analīze. Riga: BISS, pg. 73.

${ }^{24}$ Marina Krupņikova (2004), Daudzveidība Latvijas mācību grāmatās. Riga: Latvian Human Rights Centre, pp. 80-81, avalable at http://www.politika.lv/temas/izglitiba_un nodarbinatiba/6125/. 


\section{The Advantages and Possibilities of the Critical Thinking Approach - a Strategy to Motivate Schoolchildren}

Research conducted by the BISS entitled Utilization of the Critical Thinking Approach in the Education System in Latvia 2008 shows that the critical thinking approach is one of the most successful alternative ways of organizing the teaching process in the contemporary school. It has a positive impact on the schoolchild's motivation to learn, it develops skills of analysis, structuring information, comparing various opinions and arguments, working in a group, cooperating in solving problems and more. After using the critical thinking approach, teachers have observed positive changes in the models of interaction between teachers and students in the classroom and outside it, with more open, less hierarchical relations. The teacher is a confederate, an ally, a helper, not the "vessel of absolute truth".

Another benefit is a diversification of models of interaction. As teachers have observed, the classical models (teacher - student, student - teacher student) are supplemented with other models (student - student; teacher student - student - teacher). Teachers mentioned various situations, when, for example, a student helped a classmate understand new material or when the teacher acquainted the students with a certain strategy for solving a problem and the students worked out additional strategies.

As suggested by the results of a survey of schoolchildren conducted for the research, they too support such an approach in the learning process. Students like the fact that various forms of cooperation and interaction are used. For example, $73 \%$ like to participate in discussions with classmates, $67 \%$ like to study materials given by the teacher with other classmates and $56 \%$ mentioned that they like to discuss problems for which there is no one best solution. These are all typical working methods of the critical thinking approach, but at the same time, schoolchildren are divided over whether they like the forms of interaction where they have to use the skills that should be the results of the critical thinking approach.

In the assessment of teachers, the critical thinking approach permits improving the interaction skills of all schoolchildren regardless of their psychological peculiarities. The experience of teachers suggests that the ability to become involved in a discussion and express one's opinion not only creates and develops the child's self-confidence, but also nurtures tolerance towards diversity and different attitudes, which is a very important ability in contemporary society. The observations of teachers suggest that using the critical thinking approach can contribute to creating and solidifying a sense of community in the classroom, giving students the opportunity to get to know one another and cooperate with classmates with whom they would have no contact outside the classroom. 


\section{Inclusive Strategies in Schools: Examples of Best Practice in Europe}

Based on an investigation of schools in four countries, the project "Youth and ethnically diverse schools" provides examples of best practice in various conflict resolution strategies in multicultural school environments in schools and in promoting inclusive policy. ${ }^{25}$ The goal of these strategies is to help schoolchildren better resolve conflict situations, to promote skills of expressing, discussing and harmonizing their interests.

Mediator training foresees teaching students to become mediators in discussions between students or between students and teachers. Participants in the training learn effective conflict resolution methods, as well as learn about issues of cultural difference.

Class contracts involve coming to an agreement about good and unacceptable forms of behaviour with the goals of preventing racism and conflicts due to cultural differences. Students themselves try to create regulations to help prevent such problems and to improve the atmosphere in the classroom. In such discussions, students talk about exclusion, violence, racism and conflicts due to cultural differences.

Clear, known and participatory regulations are formulated within the school about what is and is not acceptable in the school and what to do if the regulations are violated. Violence, and ethnic violence in particular, are one of the main issues in such regulations.

A capability raising strategy has the goal of strengthening the self-respect of students, raising their confidence in their abilities. To implement this, it is first of all necessary to perceive the child as an individual. This strategy is based on the creation of an individual learning plan in accordance with the child's language knowledge, as well as socialization activities with the goal of strengthening the child's self-confidence.

Strategies for fostering a sense of belonging have the goal of promoting the student's sense of belonging at two different levels. At the individual level, the strategy is linked to the individual life experience of each student. At the social level, the essence of the strategy is to create belonging to a group based on common goals, not ethnic belonging (in various working groups or in the class group at school). The goal of this strategy is to raise awareness that a person's life is very diverse and that a person's identity (religious, national, cultural, political or gender) creates belonging to very diverse groups. This strategy is implemented primarily in extracurricular activities.

Separate training for girls and boys groups involves discussions about issues of personal and social importance: the prevention of violence, various

25 Baltic Institute of Social Sciences (2006), Jaunieši un etniski neviendabīgas skolas. Pasākumi pret etnisku vardarbību skolēnu vidū. Rokasgrāmata praktiķiem. Riga: BISS. 
forms of dependence, substance abuse, conflict resolution strategies, as well as personal life, future plans related to professional and work choice, friendship, love and sexuality. The goal of this training is not to create a static "male" or "female" identity, but to ponder and evaluate conceptions linked with certain roles and expectations, as issues about gender and cultural difference are closely related. Cultural norms determine gender roles, and children have to learn how to unite diverse perspectives about gender held by their parents, friends, at school and in the surrounding society.

Multicultural education in general education elementary teaching programmes involves discussions about various issues linked with multiculturalism.

Abstract training about cultural diversity has the advantage that all students are spoken to in a similar way, the children evaluate a problem from the same position - as observers. In evaluating a situation and creating conflict resolution strategies, one does not pay particular attention to the origin of each individual schoolchild.

School cooperation in teaching cultural diversity has at its base the creation of a network of school cooperation with the goal of exchanging methodological materials and practical experience.

\section{"School Failure"}

Although Latvian education policy has chosen inclusive education and one of the basic postulates of education development policy is "access," meaning all members of society should have equal opportunities to get an education, ${ }^{26}$ researchers have pointed out that many young people in Latvia do not acquire even an elementary education and that Latvia has one of the lowest shares of young people with a secondary school education in the EU. In order to characterize the effectiveness of an education system's inclusive of exclusive practices, both the academic literature and policy documents use the term "school failure." Research on school failure permits assessing the education system's influence on the integration of youth in society, including integration's social and ethnic aspects. In OECD documents, the analysis of school failure takes place in three directions:

1) low academic results,

2) early abandonment of school, and

3) preparedness for the labour market. ${ }^{27}$

Research conducted in Latvia and elsewhere suggests that the issue of school failure is usually addressed in two ways: how the education system

${ }^{26}$ Izglīitibas attīstības pamatnostādnes 2007.-2013. gadam, pg. 23.
${ }^{27}$ OECD (1998), Overcoming Failure at School. Paris: OECD. 
engenders school failure and what is the role of educational practices in promoting social inclusion. Academic results are characterized by the educational attainment level of the population and school academic results in comparison with those in other countries. Early abandonment of school is characterized by institutional and individual reasons for school abandonment and strategies that promote social inclusion. Poor preparedness for the labour market is analysed with reference to professional education as an inclusive strategy in the labour market.

The education system is comprised of education levels (primary, secondary, higher) and programmes (special, professional), as well as agents (schoolchildren, families, teachers, administrators, policy-makers, communities and NGOs). The goal here is to explore the structures and social agents (activities), which reduce school failure and overcome social exclusion, to discover strategies that promote inclusive education, social cohesion and the creation of a knowledge society.

\section{The Level of Educational Attainment in Society}

Data from research conducted by the BISS in 2006 on life-long education suggest a trend towards a reduction in educational attainment among youth - these are youth who have acquired an education since the restoration of independence. ${ }^{28}$ Research shows that a portion of the age group 15 to 24 does not continue education although their educational level is rather low. For example, among those who have not received a primary education, $10 \%$ of the respondents did not continue studies; among those who acquired only a primary education, $15 \%$ do not continue studies (see Diagram 1). Most people in the 25-34 age group have usually acquired a primary and secondary education. Among respondents aged 25-34, 1\% have not finished primary school, but $14 \%$ have only acquired a primary education. Every fifth person in this age group $(20 \%)$ does not have a secondary education. At the same time, in the age groups 35 to 44 and 45 to 64 , there are fewer poorly educated people: those with only a primary education are $6 \%$ in the 35 to 44 age group and $7 \%$ in the 45 to 54 age group. Insofar as only about $10 \%$ of those aged 25 to 34 with only a primary education continue to study, it can be predicted that the education level of most in this group will remain unchanged.

Though poorly educated youth enter the job market early, their low education level lowers their competitiveness. The life-long education research data suggest that $22 \%$ of respondents in the 25 to 34 age group without a secondary education are unemployed (the average unemployment rate in this age group

28 Baltic Institute of Social Sciences (2006), Mūžizglītības pieejamība un iespējas izglītoties Latvijā. Riga: BISS. 
overall was $9 \%$ ), while $30 \%$ without a secondary education are employed compared to $60 \%$ employed in the age group overall

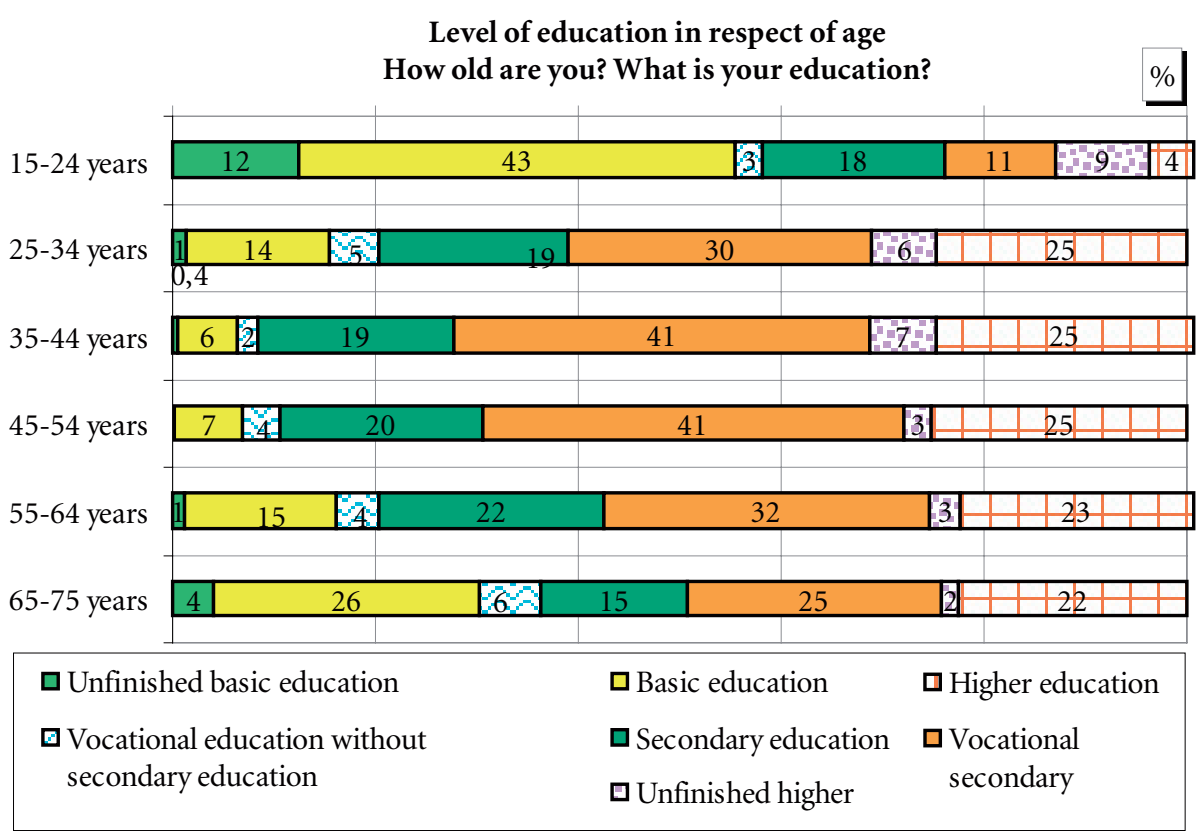

Base: all respondents, $\mathrm{n}=4012$

Source: Baltic Institute of Social Sciences (2006), Mūžizglītības pieejamība un iespējas izglītoties Latvijā. Riga: BISS.

The educational attainment level of 35 to 54 year-old inhabitants is the highest compared to other groups. This age group has the smallest share which has received only a primary education ( $6 \%$ of respondents in the 35 to 44 age group and $7 \%$ in the 45 to 54 age group), but the share of respondents with an unfinished primary education does not reach $1 \%$. This can be explained with reference to the abolition of obligatory secondary education (in 1992), as young people who acquired an education when secondary education was no longer mandatory and primary school could be finished without a diploma are now aged 29-30 or younger. However, in examining research conducted in this field, one acquires a wider view of the circumstances contributing to the growth in under-education.

It is characteristic that in the age groups 35-44 and 45-54 there are more people with a secondary professional education than in the 25-34 age group. This suggests that obligatory secondary education spurred people to acquire a higher professional education level, compared to young people in recent decades who have entered the labour market having attained only a primary education. Research in Latvia on under-education draws attention to the circumstances contributing to the problem, such as missed lessons, poor results, repeat years 
and drop out rates, ${ }^{29}$ but also on the limited ability of these youth to enter the labour market. ${ }^{30}$

\section{Latvian School Academic Results in Comparative Research}

Since 1998 Latvia has participated three times in the Programme for International Student Assessment SSNP (PISA), which permits international comparisons of the effectiveness of Latvian schools. ${ }^{31} 4719$ fifteen year old schoolchildren from 177 education institutions (basic schools, secondary schools, gymnasia, professional schools, technical schools, art schools and others) and the heads of these institutions in Latvia participated in the basic research of the 2006 PISA study. ${ }^{32}$ The authors of the research suggest that Latvia's results are satisfactory, as they almost reach the average indicators among 30 OECD countries. In Latvia $17.4 \%$ of schoolchildren have not attained the $2^{\text {nd }}$ level, which is the basic level in the SSNP at which children demonstrate competence in natural science that permits them to become active in life situations related to natural sciences and technology and to fully participate in social life and the labour market in the future. The average indicator among 30 OECD countries was $19.2 \%$. However, the attainment levels in Latvia's neighbouring countries suggest that there is much room for improvement. In Lithuania the figure is $20.3 \%$, in Russia - $22.2 \%$, but in Estonia - only $7.7 \%{ }^{33}$ The 2006 research reveals very different levels of achievement in different types of schools.

The best attainment is among schoolchildren in Riga's schools, but the lowest is among schoolchildren in the countryside (the difference is 23 points). The results in other big city (Daugavpils, Jelgava, Jūrmala, Liepāja, Rēzekne, and Ventspils) schools are similar to those in smaller cities and differ from those in Riga by 11 points. ${ }^{34}$ Schoolchildren in classes $7-9$ attending gymnasia have average attainment levels 54 points higher than those of children in basic school and 36 points higher than those in high schools.

${ }^{29}$ Indra Dedze, Maiga Krūzmētra, Ingrīda Mikiško (2004), Savlaicīgu pamatizglītības apguvi traucējošo faktoru kopums. Available at http://www.politika.lv/index.php?f=409; see also Brigita Zepa, ed., (2007), Skolēnu atbiršana pamatskolās. Problēmas risinājumi. Riga: BISS.

${ }^{30}$ Brigita Zepa, ed. (2006), Mazizglītoto mazākumtautību jauniešu integrācija darba tirgū. Riga: BISS.

${ }^{31}$ A. Geske, A. Grīnfelds, A. Kangro, R. Kisel̦ova (2006), Kompetence dabaszinātnēs, matemātikā un lasī̌sanāa-ieguldījums nākotnei.

${ }_{32}$ Ibid., pg. 125.

${ }^{33}$ Ibid., pg. 126.

${ }^{34}$ Ibid., pg. 127. 
These differences in attainment are considerable. In comparison with the results of 2003, the achievement distribution in natural science according to school type is virtually unchanged. ${ }^{35}$ At the same time, schoolchildren from primary schools in big cities have very low achievement levels, which evokes concern about the inequality of opportunity in education - as early as the primary school level elite schools and low level schools are created where children have limited opportunities for further education. ${ }^{36}$ There are significant differences between the attainment levels of rural and urban schools in reading skills: rural schools still lag behind the achievement levels of schools in Riga and other big cities. No longer can one see the previous evening out trend. ${ }^{37}$ The average difference in reading competence between boys and girls is quite large in Latvia - 50 points. There are big differences in other countries as well, but considering our schoolchildren's overall attainment (below the OECD average), the low reading competence of boys evokes great concern. Almost a tenth of all boys are in the group with the lowest attainment under level one. Their further success in secondary education is at risk. ${ }^{38}$ It is significant that schoolchildren at the end of primary school in Latvia have skills in natural sciences, mathematics and reading which are almost at the average level of the world's most advanced countries. ${ }^{39}$ At the same time Latvia has few primary school children with good or excellent attainment in mathematics or natural sciences, which can hinder the attainment of the goals enshrined in various state development documents in the realm of science, technology and other spheres. There is more a tendency to work intensively with weaker schoolchildren, which of course, is also important. ${ }^{40}$ The SSNP shows that Latvia's 15 year old schoolchildren's attainment is not very dependent on the family's welfare and the availability of educational and cultural resources at home in comparison with average levels in other countries in the OECD and outside it. The authors of the research think that the Latvian education system can compensate the influence of these negative factors to a certain degree. ${ }^{41}$

The results of research conducted by the BISS in 2007 entitled The Influence of the Cost of Education on School Drop Out Rates in Primary Schools do not coincide with those of the OECD SNNP research results for 2006, which concluded that "the economic and social status of the schoolchildren's family does not have a substantial impact on his attainment in study, which means that schools also fulfil social functions by evening out differences between needy and more well-to-do children." The difference in conclusions can be

\footnotetext{
35 Ibid.

${ }^{36}$ Ibid., pg. 130.

${ }^{37}$ Ibid., pg. 129.

${ }^{38}$ Ibid.

${ }^{39}$ Ibid., pg. 131.

${ }^{40}$ Ibid.

${ }^{41}$ Ibid.
} 
explained with reference to at least two circumstances: first, the international student assessment does not include drop-outs or those who miss classes often and are on the verge of dropping out; second, student fees can affect academic success indirectly, depending on the extent to which the local government can support parents in covering school expenses. The BISS research shows that the inability of low-income parents to cover education costs (textbooks, notebooks, stationary, clothes, and other goods and services necessary for school) has a negative influence on the child's academic results and increases the risk of dropping out in primary schools. In the current situation, local government social assistance has a vital role in integrating the children of low-income families into the education system. However, it should be noted that the ability of local governments to cover school expenses is dependent on their financial means. This situation exacerbates social inequality, as those living and working in poorer local governments have relatively lower incomes than those living in richer local governments.

\section{Early School Leavers}

In accordance with Eurostat data, the share of youth aged 18 to 24 who had acquired a primary education and did not continue their studies in 2006 was $19 \%$, which is the highest rate of the three Baltic States (Lithuania 10.3\%, Estonia 13.2\%). ${ }^{42}$ At the same time, it should be stressed that in 2004 the European Council set the goal of reducing the share of youth who receive only a primary education to $10 \%$ by 2010 , as well as reducing the share that leave primary school without finishing it. ${ }^{43}$

Imprecise registration makes it difficult to ascertain the share of youth who leave school early and do not acquire a primary education. Jānis Eglītis draws the conclusion that about $10 \%$ of youth in Latvia do not acquire a primary education. ${ }^{44}$ Research conducted by the BISS in 2007 entitled Dropouts from Primary School: Solutions to the Problem concludes that there is no clarity about the scale of the school dropout problem, as there is a lack of statistics about those who leave school and the registration of school-age children is imprecise. The authors refer to statements by experts who mention cases from their own experience when they have encountered children who remained unregistered: "Currently, illiterate teenagers are appearing. There are children who

42 Eurostat (2007), Early school leavers. Available at http://epp.eurostat.ec.europa.eu/portal/ page?_pageid=1996,39140985\&_dad=portal\&_schema=PORTAL\&screen=detailref\&lang uage=en\&product=STRIND_SOCOHE\&root=STRIND_SOCOHE/socohe/sc051.

43 Commission of the European Communities (2004), Progress Towards the Common Objectives in Education and Training: Indicators and Benchmarks, available at http://ec.europa.eu/ education/policies/2010/doc/progress_towards_common_objectives_en.pdf.

44 Jānis Eglītis (2007), 'Izglītība zināšanu ekonomikai,' in Izglītība zināšanu sabiedrības attīstībai Latvijā. Riga: SAK, pp. 142-163. 
are seventeen years old, who have no family doctor, no education, they are not registered as living anywhere, they migrate throughout the country." 45

The importance of the problem of school dropouts is confirmed by much research that shows that a low education at the beginning of a professional career increases the risk of unemployment, poverty and the risk of anti-social behaviour. ${ }^{46}$ At the same time, it should be acknowledged that there is often great demand in the labour market for workers, which creates the impression of the irrelevance of education (this was evident in Latvia after accession to the EU, which opened the door to labour out-migration and increased demand for labour within Latvia).

Several studies have been conducted in Latvia about dropouts. Usually, this research uses an institutional approach, which explains the impact of various institutions - the school, the family, society - on the behaviour of the child. In the aforementioned study by the BISS, an institutional approach is combined with an individual perspective, which also examines the individual schoolchild and his resources, involvement in school life, and academic results. The research analyses the interaction of factors from both perspectives and reveals a wide array of circumstances contributing to dropouts.

The research suggests that many circumstances have changed, and this requires the appropriate action: if the planned economy and the totalitarian regime envisioned strict control over the population, including over school attendance, the new circumstances provide greater freedom of choice, but also require greater responsibility from the individual. This responsibility pertains to both the schoolchild and his or her parent, including registering one's residence, taking responsibility for the education of one's child. As a social pedagogue noted, "I want to mention the good old Soviet times, which many would condemn. Back then, in my opinion, there were fewer children who did not go to school. Concretely, in my class there were children who did not learn well, but they were transferred on to the next class, and they came to school. Now it's more like this - if the child does poorly at school, if he thinks he does not understand, he doesn't come to school. ${ }^{\prime 47}$ One expert notes that the problem of school dropouts has gradually become more topical since the restoration of independence and this is due not only to changing social values, but also to the fact that insufficient attention is paid to problem children, resulting in insufficient supervision of various processes taking place in the system. Experts draw attention to the fact that the current education system is not oriented towards lessening failure, bad school attendance or early school leavers: "the

45 Ibid., pg. 23.

46 For example, E. Eemer et al. (2000), Characteristics of Early School Leavers: Results of the Research Strand of the 8-to 15-Year Old Early School Leavers Initiative. Dublin: Educational Research Centre of St. Patrick's College, pp. 4-7.

47 Brigita Zepa, ed. (2007), Skolēnu atbiršana pamatskolās. Problēmas risinājumi. Riga: BISS, pg. 54. 
number has grown in the past 15 years, as in the early 1990s the old system was destroyed and a new one had not yet been created, social values changed a lot. To a large extent the education system was oriented (..) towards talented children, disregarding children with social or family problems. During these years the system became unmanageable and to a certain degree slipped out of control with regard to school attendance, the evaluation of academic results, and such matters" (municipal social worker). ${ }^{48}$

One can see in the remarks of experts that both education workers and local government officials recognize and understand the downward spiral effect which cumulatively leads the schoolchild to leave school early. However, according to one expert, "Currently, schools are not doing anything. They say that they are integrating these children, but in reality, schools want to get rid of them, because as soon as the school has bad academic results, the director gets criticized or people say 'see what a bad school.' In words, we are for an inclusive school, one that integrates everyone, but in reality, it is to the contrary - we exclude people. Yes, we might integrate a child in a wheelchair who calmly and quietly sits in class, but not a teenager from a group at risk who has problems, who is loud, and who does not learn. Schools try very hard to be free of such things" (school psychologist). ${ }^{49}$ Experts indicate that the activities of schools are in contradiction to the idea of an inclusive school, as the school is evaluated according to schoolchildren's academic results, and thus, does not have an interest in integrating young people with learning or behavioural difficulties, as that will be reflected first of all in their bad grades: "Schools do not address this problem. They simply do not pay any attention to it. They know that there are such children, that they are somehow getting by. If he comes to school, and sits there, even if he does nothing, that's fine" (school director). ${ }^{50}$

A similar stance can be discerned with regard to remedial classes in a school which specialized in the intensive acquisition of the German language: "we do not have a remedial class and that is school policy. We have intensive German language acquisition and the school's stance is that children who have problems with languages cannot learn a second foreign language. Thus, one cannot speak of any remedial action" (social pedagogue). ${ }^{51}$

The reasoning and statements of experts reveal the social construction of interaction involving students and how their relations with parents and teachers create a chain of negative experiences leading to a lack of success, negative attitudes towards interaction with teachers, resulting in negative attitudes towards schools and high dropout rates. Labelling and extremely liberal demands towards children in primary schools create a situation in which children leaving

\footnotetext{
48 Ibid., pg. 55.

49 Ibid., pg. 79.

50 Ibid.

51 Ibid., pg. 62.
} 
primary school and entering classes with more complex subjects are unprepared for the next academic level. As an NGO representative put it, "The child is simply transferred on from primary school - 'go ahead wherever I put you, there will be problems with you wherever.' He simply gets pushed ahead. He enters the $5^{\text {th }}$ grade a smoker, drinker and truant. But the problem begins as early as the first grades. He hasn't been to school in a long time. It all seemed normal then, because what could one expect - the family was disadvantaged, you just have to let him move ahead, let him go." 52

The Basic guidelines for education development 2007-2013 declare that "in the knowledge society a person's knowledge and skills have a decisive importance in attaining a high level of welfare." ${ }^{53}$ At the same time, statistical analysis and research suggests that the share of young people in Latvia who have acquired a secondary education is one of the lowest in the EU. In an article entitled "The Paradox of the School: A High Value Attributed to Education and a Low Motivation to Learn," Vera Boronenko points to the contradiction between how the public and people involved in the education process evaluate the value of education and the low motivation to learn. ${ }^{54}$

At the same time, research conducted by the BISS reveals the falling value of education among families in a certain segment of society. In the future vision for their children constructed by poorly educated parents, there are very low educational ceilings. A social worker noted that "Parents say: 'our son will work, because the family needs financial support. I myself have finished the eighth grade, do I earn a poor wage? In construction it's 500 lats a month?" 55 A low level of education is reproduced, poorly educated parents cannot imagine the opportunities a higher education would provide their children, they don't understand their children's problems. Another social worker notes: "Often the parents' self-esteem is low - if we don't have an education, our child will not be able to get one either." Thus, the results of a survey of schoolchildren are no surprise: $38 \%$ do not know about their father's education and $24 \%$ do not know about their mother's education.

\section{Repeat Learning in the Same Grade}

One of the strategies used by schools to improve the academic results of children encountering difficulties is requiring them to repeat the same grade. The home page of the Ministry of Education and Science contains data about the number of children repeating grades in general education day schools, which

52 Brigita Zepa, ed. (2007), Skolēnu atbiršana pamatskolās, pg. 30.

53 Izglītības attīstības pamatnostādnes 2007.-2013. gadam. http://izm.izm.gov.lv/normativieakti/politikas-planosana/1016.html

54 Vera Boroņenko (2007), 'Skolas paradokss: augsta izglītības vērtība un zema motivācija mācīties,' in Izglìtība zināšanu sabiedrības attīstībai Latvijā. Riga: SAK, pg. 77.

55 Brigita Zepa, ed., (2007), Skolēnu atbiršana pamatskolās, pg. 58. 
has shown an upward trend in recent years. A novel trend is that this obtains not only for boys, but for girls as well. The number of those repeating grades has increased significantly since the $2003 / 2004$ school year: it has doubled for girls and increased by a factor of 2.7 for boys. The 2003/2004 school year is the year that those who began school in the 1999/2000 school year are in fifth grade. The Ministry website does not have data broken down by language of instruction, thereby precluding verification of the hypothesis that links the problem of repeating grades to teaching subjects bilingually.

The Ministry's 2007 annual report mentions that the number of those repeating grades from the first through the ninth grade decreased in the 2005/2006 school year compared to the previous year, but increased again by $1.68 \%$ in the $2006 / 2007$ school year. These figures suggest a trend towards increasing repeat grades compared to the end of the 1990s. Comparing those repeating grades by class, it can be seen that those repeating grades has decreased from the first through the third grades, but has increased significantly from the fifth through the ninth grades, especially in the 2003/2004 school year. The number of those repeating grades increases in classes with more teaching hours, with more differentiated subjects, and where the subject matter becomes more complicated in a word, in those subjects that Russian schoolchildren learn bilingually. Possibly, the improvement in results among first graders was promoted by the requirement that five and six-year-old children be prepared beforehand. ${ }^{56}$

In analysing the positive and negative aspects of repeating grades, the authors of the research Drop Outs from Primary Schools: Solutions to the Problem point to the divergent evaluations of experts of the legislative norm which states that a child with more than three failing marks cannot be transferred to the next grade level. Some experts believe that repeating the same grade changes nothing in the child's achievement unless additional assistance is given to the child. At the same time, other experts suggest that the large number of those repeating grades is the consequence of the legislative change, as schoolchildren had accepted as normal the fact that they could not study and not get good grades, but still progress to the next grade and finish school. In the future, in accordance with the new demands, the number of those repeating a grade should decrease. As a social pedagogue noted, "I would guess that a few years will pass and those who are in school now already know that that will not work in the future and they will not get ahead." 57

Experts believe that repeating a grade is not an acceptable practice in primary school, where learning difficulties are probably the outcome of a previously unnoticed and neglected lack of understanding of the teaching programme which cannot be remedied by repeating a grade. As a social pedagogue noted, "The gap is not created in the sixth grade. (..) the gaps in the seventh

\footnotetext{
56 Ibid., pg. 30.

57 Ibid., pg. 66.
} 
and eighth grade are of such an order that he simply cannot keep up. (..) For example, he can't read! I make him try to solve a problem, but he stumbles along. He concentrates on reading, not the meaning of the text. When did the problem begin? Not in the seventh grade. And what good will it do if I leave him in the seventh class." ${ }^{58}$

Making children repeat grades in the older classes generally creates additional problems - the schoolchild's behaviour worsens and conflicts begin with teachers. According to experts, that is basically an artificially created interruption in the child's rhythm of life. Because of this interruption, he is not only forced to learn in a class with younger children, but he also has to watch how his peers have rushed ahead of him. Perhaps some are motivated by this, but a majority loses interest in learning. According to a social pedagogue, "It often happens that it is precisely in the second year that the child's behaviour worsens, he feels superior to his classmates. If the teacher has not found a way to reach this child, he often disturbs the teacher and there are conflicts. (..) In a larger class one child was supposed to be in the ninth grade, but now he is in the sixth grade, he is 16 years old. Teachers have a difficult time establishing contact with him, he tries to provoke them in all manner of ways, he ruins the lesson, he feels superior to everyone." ${ }^{59}$ According to the experts, repeating a grade has a positive impact on the child's academic results if the attitude of those around him is supportive and communication is positive. However, in practice, this strategy is more often ineffective.

Table 4. The number and share of second and third time repeat students in general education day schools by sex at the end of the school year

\begin{tabular}{|c|c|c|c|c|c|c|}
\hline & \multicolumn{2}{|c|}{$2^{\text {nd }}$ and $3^{\text {rd }}$ Time Repeat Students } & \multicolumn{3}{c|}{$2^{\text {nd }}$ and $3^{\text {rd }}$ Time Repeat Students (\%) } \\
\hline & Total & Girls & Boys & Total & Girls & Boys \\
\hline $2004 / 2005$ & 8348 & 2377 & 5971 & 2.79 & 1.59 & 3.98 \\
\hline $2003 / 2004$ & 10246 & 2807 & 7439 & 3.28 & 1.81 & 4.74 \\
\hline $2001 / 2002$ & 3932 & 1228 & 2704 & 1.17 & 0.73 & 1.61 \\
\hline $1990 / 2001$ & 4239 & 1266 & 2973 & 1.24 & 0.74 & 1.74 \\
\hline $1998 / 1999$ & 4398 & 1306 & 3092 & 1.27 & 0.75 & 1.81 \\
\hline $1997 / 1998$ & 4870 & 1381 & 3489 & 1.41 & 0.80 & 2.04 \\
\hline
\end{tabular}

Source: Home Page of the Ministry of Education and Science.

58 Ibid.

59 Ibid., pg. 67. 
Table 5. The number of second and third time repeat students in general education day schools from Grade one through Grade 12 at the end of the school year

\begin{tabular}{|c|c|c|c|c|c|c|c|c|c|c|c|c|}
\hline & 1st & 2nd & 3rd & 4th & 5th & 6th & 7th & 8th & 9th & 10th & 11th & 12th \\
\hline $2004 / 2005$ & 934 & 401 & 381 & 527 & 643 & 930 & 1346 & 1665 & 1261 & 132 & 101 & 27 \\
\hline $2003 / 2004$ & 1100 & 407 & 460 & 605 & 799 & 1126 & 1592 & 1953 & 1875 & 172 & 105 & 52 \\
\hline $2002 / 2003$ & 1107 & 437 & 426 & 533 & 593 & 906 & 1146 & 1266 & 303 & 99 & 68 & 36 \\
\hline $2001 / 2002$ & 1096 & 433 & 351 & 361 & 326 & 373 & 334 & 327 & 228 & 52 & 40 & 11 \\
\hline $2000 / 2001$ & 1252 & 457 & 372 & 373 & 315 & 361 & 394 & 345 & 243 & 55 & 38 & 34 \\
\hline $1999 / 2000$ & 1421 & 456 & 432 & 418 & 319 & 377 & 346 & 334 & 265 & 33 & 29 & 14 \\
\hline $1998 / 1999$ & 1642 & 507 & 471 & 413 & 303 & 295 & 294 & 244 & 161 & 34 & 22 & 12 \\
\hline $1997 / 1998$ & 1683 & 586 & 504 & 527 & 371 & 326 & 342 & 280 & 176 & 35 & 22 & 18 \\
\hline
\end{tabular}

\section{Remedial Classes as an Inclusive Strategy}

Experts suggest that an effective means for improving a schoolchild's academic results is learning in a pedagogical remedial class. In a remedial class, the number of children is twice as small and it is possible to work with each student individually, exercising greater social control. At the same time, according to other respondents, the child himself often does not want to continue learning in a remedial class because of the negative associations. As an NGO representative put it, "The class has very few children, the teachers can pay more attention. (..) The teacher works with them, there is no letting up, there is greater supervision. If he misses school one day, the teacher calls home and asks why he's not at school, not like in a regular class, when you believe that the child is ill." 60

However, remedial classes do not always fulfil their tasks of "filling in the knowledge gaps" and providing an opportunity to return to a "normal class". Experts have observed cases where the child does not want to return and the remedial class does not promote inclusion, but segregation. As a school director noted, "These children end up in these classes very late, and when they enter this programme, the children are more or less equivalent, they are from the same group. This creates an isolated environment and it is rather difficult to put them smoothly back into the general mass in the school." 61

$\begin{array}{ll}{ }^{60} & \text { Ibid., pg. } 69 . \\ { }^{61} & \text { Ibid., pg. } 70 .\end{array}$ 


\section{Evening Schools as an Inclusive Strategy}

Table 6. General Education Evening Schools

\begin{tabular}{|c|c|c|c|c|}
\hline & Total & Latvian & Russian & Latvian/Russian \\
\hline Total in the Country & 34 & 18 & 0 & 16 \\
\hline $2006 / 2007$ & 34 & 16 & 0 & 18 \\
\hline $2005 / 2006$ & 34 & 14 & 0 & 20 \\
\hline $2004 / 2005$ & 33 & 13 & 0 & 20 \\
\hline $2003 / 2004$ & 35 & 12 & 0 & 23 \\
\hline $2002 / 2003$ & 35 & 11 & 0 & 24 \\
\hline $2001 / 2002$ & 37 & 10 & 0 & 27 \\
\hline $2000 / 2001$ & 37 & 10 & 1 & 26 \\
\hline $1999 / 2000$ & 38 & 10 & 1 & 27 \\
\hline
\end{tabular}

As suggested by the data of the Ministry of Education and Science, the number of evening schools is decreasing. Changes in various types of evening schools vary: the number of dual stream Latvian-Russian schools decreased from 27 in the 1999/2000 school year to 16 schools by 2006/2007, while the number of Latvian schools has grown. It should be stressed that five Latvian districts (Dobeles, Kuldīgas, Ventspils, Rēzeknes, Daugavpils) have no evening schools whatsoever. On the one hand, it should be acknowledged that the performance of evening schools is rather low, as about a fourth of those attending finish without a diploma, suggesting failing grades in a number of subjects. Moreover, this is an increasing trend: if $15 \%$ of the students finished without a diploma in $1997 / 1998$, by $2005 / 2006$ the figure had increased to $26 \%$. On the other hand, the necessity of evening schools as an opportunity to continue education for those who for various reasons left school early cannot be denied.

Table 7. The number of students who finished Grade 9 in general education evening schools with Latvian as the language of instruction

\begin{tabular}{|c|c|c|c|c|c|}
\hline & Total & $\begin{array}{c}\text { With a report } \\
\text { card }\end{array}$ & $\begin{array}{c}\text { Equivalency } \\
\text { examination }\end{array}$ & $\begin{array}{c}\text { Without a } \\
\text { diploma }\end{array}$ & $\begin{array}{c}\text { \% without a } \\
\text { diploma of the total }\end{array}$ \\
\hline $2005 / 2006$ & 863 & 634 & 0 & 229 & 26 \\
\hline $2004 / 2005$ & 790 & 579 & 1 & 210 & 26 \\
\hline $2002 / 2003$ & 679 & 504 & 4 & 171 & 25 \\
\hline $2001 / 2002$ & 636 & 473 & 8 & 155 & 24 \\
\hline $2000 / 2001$ & 845 & 621 & 2 & 222 & 26 \\
\hline $1999 / 2000$ & 905 & 696 & 2 & 207 & 23 \\
\hline $1998 / 1999$ & 966 & 804 & 1 & 161 & 17 \\
\hline $1997 / 1998$ & 1053 & 889 & 5 & 159 & 15 \\
\hline
\end{tabular}


Table 8. The number of students who finished Grade 9 of general education evening schools with Russian as the language of instruction

\begin{tabular}{|c|c|c|c|c|c|}
\hline & Total & $\begin{array}{c}\text { With a Report } \\
\text { Card }\end{array}$ & $\begin{array}{c}\text { Equivalency } \\
\text { examination }\end{array}$ & $\begin{array}{c}\text { Without a } \\
\text { Diploma }\end{array}$ & $\begin{array}{c}\text { \% without a diploma } \\
\text { out of the total }\end{array}$ \\
\hline $2005 / 2006$ & 199 & 152 & 0 & 47 & 24 \\
\hline $2004 / 2005$ & 222 & 150 & 0 & 72 & 32 \\
\hline $2003 / 2004$ & 189 & 120 & 0 & 69 & 36 \\
\hline $2002 / 2003$ & 243 & 173 & 6 & 64 & 26 \\
\hline $2001 / 2002$ & 282 & 216 & 0 & 66 & 23 \\
\hline $2000 / 2001$ & 301 & 223 & 2 & 76 & 25 \\
\hline $1999 / 2000$ & 446 & 296 & 9 & 141 & 32 \\
\hline $1998 / 1999$ & 532 & 455 & 1 & 76 & 14 \\
\hline $1997 / 1998$ & 584 & 483 & 4 & 97 & 17 \\
\hline
\end{tabular}

\section{Inclusive Strategies for the Most Motivated Students}

In presenting the results of centralized examinations in secondary education programmes, the annual report of the Ministry of Education and Science points out that examination results in state gymnasia are significantly better than the average, while high schools and local government gymnasia results are slightly better than the average. Technical schools, colleges and evening schools have similar centralized examination results, but they are all lower than average. The weakest results are among those in professional education institutions, as only $40 \%$ of teaching time is devoted to general education subjects compared to that in general education programmes. Thus, it is evident that the education system in Latvia reproduces differing academic achievement levels in various education institutions, which limits the educational mobility opportunities of certain categories of children. Choices made in primary school or low academic results clearly limit one's further educational path.

The 2007 annual report of the Ministry of Education and Science mentions that "on the whole, state gymnasium academic achievement levels are higher than in other schools. This attests to the existence of an appropriate learning environment to support talented children." Latvia has created a network of education institutions that is capable of integrating the most able young people and providing them a successful further educational path. Currently, Latvia has 16 state gymnasia. The state's supplementary funding for these state gymnasia is of only symbolic importance: "In accordance with the order No. 820 of 12 September 2007 of the Ministry of Education and Science "On supplementary state budget funding for state gymnasia in 2007," 15 state gymnasia were allocated a total of 30,000 lats (2000 lats each)". ${ }^{62}$ This suggests that school management,

62 For the 2007 annual report of the Ministry of Education and Science, see http://izm.izm. gov.lv/upload_file/Parskats.pdf. 
the educational qualifications of teachers, the criteria for choosing students, and the past work and traditions of the school have resulted in a high quality of education that the education system has legitimized by calling the relevant schools "state gymnasia". At the same time, the contribution of the ministry here should be judged as minimal.

\section{Professional Education as an Inclusive Strategy in the Labour Market}

The integration into the labour market of undereducated youth is hampered by the weakly organized system of professional education. In the 2005/2006 school year, Latvia had 96 professional schools with about 43,000 students. More than half the schools are located in Riga, 80 of them are under the jurisdiction of the Ministry of Education and Science, and 9 are private. The goal of the Law on Professional Education of 1999 is to ensure the implementation of the state's professional education policy and the activities, management and development of the system of professional education. ${ }^{63}$ Regardless of the fact that the goal of the law is to "ensure the comparability of Latvian professional education and professional qualifications with that acquired abroad, creating opportunities for people to continue their education abroad and compete in the international labour market," ${ }^{64}$ experts are rather critical about the quality of professional education in Latvia and point to its incompatibility with the requirements of the market.

In assessing the effectiveness of professional education, Krieviņš and Lesiņš stress that one third of those who finish professional education do not work in their chosen profession, while more than half need additional training. The reasons mentioned for this are, first of all, the ageing technical base of the schools, the incompatibility of the teacher's qualification with the needs of the labour market, as well as the incompatibility of the subjects taught and the content thereof to current requirements. ${ }^{65}$ From the perspective of social and labour market integration, it should be noted that, while professional education is a certain part of the education structure, only a small portion of graduates succeed in continuing on to higher education. This is particularly true of trade school graduates, of whom $76 \%$ do not continue their education. This education is not very successful in integrating youth into the labour market, nor does it pave the way for a higher education. These schools often carry a certain stigma in society, the number of those learning there is decreasing, as parents try to send their children to general secondary schools, as there is a prevailing view

${ }^{63}$ For the Law on Professional Education, see http://www.likumi.lv/doc.php?id=20244.

${ }^{64}$ Ibid.

65 J. J. Brunner (2003), Latvia. Higher Education: Changing Conditions, Problems, Challenges and Policy Options. World Bank, pg. 19. 
that trade schools have a low level of teaching, which limits the opportunities of youth to continue in higher education and prevents them from finding wellpaid work. The prevailing view is that the schools are poorly equipped, the teachers have a low level of qualification, and there is a lack of cooperation with business. Those finishing these schools usually acquire the skills needed on the job.

Table 9. Number of students attending professional education institutions

\begin{tabular}{|l|l|}
\hline $2007 / 2008$ & 37667 \\
\hline $2006 / 2007$ & 40439 \\
\hline $2005 / 2006$ & 42727 \\
\hline $2004 / 2005$ & 44651 \\
\hline $2003 / 2004$ & 46789 \\
\hline $2002 / 2003$ & 46533 \\
\hline $2001 / 2002$ & 47627 \\
\hline
\end{tabular}

Often professional education is viewed not as a purposeful professional choice, but as a solution to the problem of dropping out of school early. In the research Drop Outs from Primary School, the experts surveyed saw one solution to the problem of dropouts in an orientation towards professional education. At the same time, the experts also point to several significant obstacles hindering the integration of children from risk groups and dropouts into the education system through the means of professional education. First of all, usually one can begin to attend a trade school, as with evening school, if one has finished the $8^{\text {th }}$ grade. Thus, if a child has left school earlier, acquiring a trade through the education system is not possible. As a social pedagogue put it, "I have information that there are districts where evening schools and trade schools begin only after the eighth grade. If a child has left the scene after $6^{\text {th }}$ grade, then there is practically no possibility to get him back in. I think this system should be reformed, so the child can acquire a trade after the seventh grade and finish his primary education." 66

Secondly, according to the experts, acquisition of a trade school education is hindered by the incomplete nature of the network of professional schools. Not all districts have such institutions and if they do, they are located in the district capitals, and transportation is not affordable for many youth. As a social pedagogue noted, "In the countryside providing a sufficient choice is definitely a problem. If cities more or less have trade schools, I don't know how big an opportunity there is for parents to send their children after the $7^{\text {th }}$ grade. But I think this problem can be resolved." ${ }^{67}$ The professional orientations of youth and the suitability of the network of professional schools to the needs of the

${ }^{66}$ Brigita Zepa, ed. (2007), Skolēnu atbiršana pamatskolās. Problēmas risinājumi, pp. 101-102.

${ }^{67}$ Ibid., pg. 102. 
labour market are problems stressed by experts. As a local government official stated, "the professional orientation has to be very strong. (..) How many professional schools do we have? Where will they go after the $9^{\text {th }}$ grade, to Ireland or to work as salesclerks? (..) This is a complex question - professional orientation, the development of the network of professional schools and what kind of specialists will be needed." 68

\section{Conclusion}

The analysis of the education strategy in the context of social integration in this chapter leads to a series of conclusions:

- The divided school system reproduces isolation between the two major sociolinguistic groups and negatively affects the motivation to participate politically among minority youth. In public discourse, the dominant discourse is that of ethnic isolation, which determines the existence of the divided school system. It is only in the academic world where one finds a civic discourse aimed at creating values for a unified school system. At the same time, various strategies are being implemented that pave the way to a certain extent for the creation of a unified school system in the future.

- The implementation of bilingual education has promoted the improvement of Latvian language skills among minority youth, which promotes their integration into the labour market. At the same time, the education reform furthered the separation of communities along sociolinguistic lines.

- A good example of youth integration is dual stream schools; interestingly, they were created primarily as a result of economic considerations.

- The level of understanding and the behavioural patterns inculcated in schools are not suitable to the rapid changes taking place in society and for life in a multicultural society. Teachers often understand issues related to tolerance in a very narrow manner, their pedagogical activity often lacks tolerance towards the varied sociocultural experience of students and its manifestations in the learning process. At the same time, textbooks do not reflect the diversity of society, are ethnocentric with regard to minorities and their cultural contribution.

- At the same time, new approaches to teaching, for instance, the introduction of critical thinking, open up big opportunities for strengthening the learning motivation of schoolchildren, as well as promoting tolerance towards various manifestations of social and ethnic diversity. Examples of good practice in promoting tolerance among schoolchildren elsewhere

${ }^{68}$ Ibid., pg. 88. 
in Europe suggest that there is a large unused potential that can be used to promote more inclusive education policy in Latvia.

- While recognizing the necessity of cooperation between various actors and institutions in education, parents usually consider other parents and children to be the primary cooperation partners, but do not see NGOs or state institutions as partners.

- The large number of children who leave school early without acquiring a primary education testifies to serious deficiencies in the field of inclusive, accessible education policy. Another bad sign is the fact that Latvia has the lowest share of those with a secondary education in the Baltic states. What is more, Latvia has old-fashioned, unattractive professional training institutions that are unsuited to meeting the needs of the labour market.

- A portion of the inclusive strategies currently being implemented in Latvian schools, for example, making students repeat grades or attend remedial classes or change schools, do not attain the desired results. The inclusive impact of evening schools is decreasing: the decrease in the number of evening schools has negatively influenced access to education in various regions of Latvia. At the same time, the fact that the number of Russian-language evening schools is decreasing faster has a negative impact on minority access to education.

\section{Greatest Achievement}

The greatest achievement in the context of the education reform lies in the fact that the results of centralized examinations in the exact sciences do not differ in schools and classes where instruction is in Latvian or bilingually. This is the most serious counterargument to critics and opponents of the reform, as it demonstrates the effectiveness of bilingual education in the acquisition of subject matter in the exact sciences.

\section{Most Serious Problem}

The most serious problem in addressing issues of education in the context of social integration remain barriers to creating a unified system of education based on a unified curriculum, textbooks and language of instruction. Barriers are created by prejudices among the public and researchers about the necessity of creating such a system. Militant nationalist forces, in turn, are advocating a complete transition to instruction in Latvian in all schools funded by the state budget without offering a strategy for implementing such a transition. 


\section{Most Urgent Task}

The most important task in the field of education in the context of social integration is the creation of unified system of education through a concrete strategy and steps to implement this goal. A very important task is garnering wide public support and understanding about the necessity of such a system of education. One step in this direction would be introduction of a unified Latvian language examination, a task being addressed by the Ministry of Education and Science. 


\section{The Media and Integration Ilze Šulmane}

\section{Interaction Between the Media, Politics and Economics}

To analyse the role of the media in social integration, it is important to understand which factors have an effect on the media. Journalism as a profession faces various external and internal influences. This interaction can be viewed at the macro-level, focusing on how journalism interacts with politics and economics. We can point to the external agents of influence - the state, media owners, advertisers, sources of information, and the audience. However, we must also speak to internal agents of influence - directors of media organizations, as well as rank-and-file journalists.

The relationship between the media and government is marked by contradictory trends everywhere. There has been a closer relationship between journalists and the political elite, because they share a common socio-political environment. The commercialization of the media has promoted conservatism and defence of the elite in many media organizations, but in others it has encouraged greater media hostility toward the government. When the media feel pressure from the power elite, journalists shift from simple reporting, interpretation and commentary to unmasking, criticizing and defending, thus becoming independent political actors. ${ }^{1}$

Media systems are based on local socio-political and cultural circumstances. The development of media systems, the structure of the media, and the specific content of publications (agendas, represented images, stereotypes, myths, separation between "ours" and "theirs") - all are influenced by existing political culture, by the ethnic division of political parties, the historical and contemporary socio-political situation which prevails, relevant legal regulations, as well as close links to economic groupings in terms of the distribution of the advertising market.

The fact that a country does not financially regulate or support the press can have a positive effect in terms of freedom of expression. However, there can be

1 This trend was noted by the media researcher McNair. See B. McNair (2006), Cultural Chaos: Journalism, News and Power in a Globalised World. London and New York: Routledge, pg. 57. 
undesirable consequences - no nationally declared values such as an Integration Programme can oblige the private media to observe the programme's positions or to demonstrate concern for any group in society if this is not of financial advantage. This can mean the disappearance of media outlets which are meant for smaller groups in society. The content of a publication or programme can become trivialized in an attempt to find as broad an audience as possible.

Competition in a small media market often forces the media to use cheaper content from big countries, because original broadcasts are expensive. This can cause concerns about the preservation of a national or ethnic culture and increase the influence and domination of the information space of another country. Recent changes in relations between the government and the opposition in Latvia have led media outlets to position themselves not just in relation to politicians and media outlets of other languages, but also to newspapers published in the same language - to mark out their political sympathies or antipathies more clearly. On the one hand, this may lead to an intensification of hateful, combative discourse (and create problems for those in power, as they receive a double portion of criticism from both oppositions). On the other hand, this situation can complicate the primitive identification which is based on ethnic elements, forcing the media and their consumers to focus more on substance and less on the political or ethnic status of those who are defending a certain point of view.

The economic crisis, too, can have a dual effect. It can bring society closer together by discussing issues related to survival, as well as social and economic matters, thus forgetting, at least for a period of time, various historical and ideological disagreements. There can also be a search for scapegoats, however, and this role is most often assigned to an "alien."

Then there is the presence of a very large, powerful, active and interested neighbour - Russia. It and its information space ensure the maintenance and exacerbation of confronting viewpoints when this is of political advantage. In the public arena, this encourages ethnic Russians to see Russia as their true homeland, and it helps to convince them that they face great oppression in Latvia.

All of this ensures pluralism in terms of viewpoints and attitudes in the media, but it may also promote entropic processes in which criticism is based not on analysis and constructive solutions, but instead on sarcasm based on the positions of another country, and which questions values that are important for the existence of the state and the unity of society. This, in turn, leads the Latvian news media to put up greater fences against the "aliens." These outlets do not engage in any public discussion of the problems which these "aliens" face, and they suggest that Latvians themselves should feel threatened. Thus, social, political, historical and cultural circumstances join together with external influences on the Latvian media system in objectively promoting the production of disintegrating discourses in the media space. 


\section{Media Accessibility: The Aspect of Language}

The systemic transformations which occurred in the wake of the restoration of independence not only opened the path toward democratization, but also established two subsystems - the Latvian language media and the Russian language media. In Soviet times, the media tended to propagandize the same ideas in two languages. Now there is different content in the media system information in two languages which sometimes interacts, but usually stays apart. In quantitative terms, both subsystems are self-sufficient. While initially unstable, the Russian language press has become stronger, and audiences in both languages have access to several daily and weekly national newspapers, TV programmes, advertising publications, a diversity of weekly and monthly magazines, etc. The Russian language press in Latvia is not a typical example of a minority press - one which speaks only to the needs of a specific culture and exists alongside the national press used by a majority of the population and addressed to the whole community of citizens.

There have been a few failed attempts to bring the two information arenas closer together by offering translated versions of press publications - the newspapers Diena and Rigas Balss both used to offer a Russian language edition. There have also been unsuccessful attempts to produce local newspapers in both languages simultaneously. The only exception to these failures is a newspaper which delivers the same information in both languages - it is the free newspaper $5 \mathrm{~min}$.

The fact that the Russian language press has become more stable and that it can also be read by representatives of other ethnic minorities has not served the interests of other ethnic groups in terms of developing their own media. ${ }^{2}$ This is advantageous to the Russian language press, because it expands the audience, but it also reduces the use of other minority languages, thus diminishing the presence of cultural diversity in the public arena in various languages. The same applies to the book publishing industry.

There have also been efforts to produce television and radio programmes in the Latgalian dialect or for the Livs. There are various cultural organizations for ethnic minorities, but their activities are not reflected too extensively in the mass media, and links to their Internet homepages are not particularly visible. In interviews, representatives of these organizations say that they have not noticed any television broadcasts or press publications that are focused on minority ethnic groups, the only exception being radio. ${ }^{3}$

Latvians and Russians have an equal availability of media that present information in their native languages, but the opportunities for Russian-speakers

2 There are newspapers for Latvia's Lithuanians and Poles, along with a newspaper for the local Armenian community which is offered in Armenian, Latvian and Russian. Copies of these newspapers are available at the Latvian National Library.

${ }^{3}$ Brigita Zepa, ed. (2006), Integrācijas prakse un perspektīvas. Riga: BSZI, pg. 210. 
must nonetheless be seen as more diverse, because they have access to vast media resources from Russia - the electronic media, the Internet, the press, as well as books and movies. The existence of a media system with two languages exacerbates market competition both among advertisers and between the two languages in the media. Rules concerning the proportion of language use in the electronic media have served to extend the reach of the Russian language while simultaneously narrowing people's opportunity to obtain information and entertainment on several TV channels in the Latvian language. ${ }^{4}$

A report from an EU working group on multilingualism emphasizes the importance of television broadcasts which allow people to develop an interest in other cultures, thus strengthening their motivation to learn a language. ${ }^{5}$ Particular attention in the document is devoted to the importance of subtitles, which can be an effective means for learning a language, suggesting that channels which dub their series or have a behind-the-scenes translator must be encouraged to offer subtitles as an option. ${ }^{6}$

In 2003, the EU issued guidelines on the use of minority languages in the electronic media, calling on member states to develop policies aimed at the use of those languages. This means that support for public broadcasting must involve concern for the linguistic needs of ethnic minorities. ${ }^{7}$ In Latvia, such rights might rest not only with Russians, but also Belarusians, Ukrainians, Poles, Lithuanians and Latgalians. ${ }^{8}$

The democratic demand for diversity, the elimination of regulatory norms, and the more widespread use of the Russian language may attract this linguistic group to the Latvian media. However, it can also create tensions and insecurity among members of the other part of society who see it as a threat against a diverse supply and the availability of media that are presented in Latvian. The development of two equal sub-systems does not promote the learning of the Latvian language or its more widespread use; instead it creates a gap between the two linguistic groups, each of them having its own media space.

\footnotetext{
${ }^{4}$ Here we can mention protests against TV broadcasts which viewers expressed in the entertainment section of the newspaper Diena in 2008.

5 The group's final report can be found at http://ec.europa.eu/education/languages/archive/ doct/multishort_lv.pdf.

${ }^{6}$ Ibid.

7 The report 'Thematic Comment N3: The Protection of Minorities in the European Union,' can be found at http://ec.europa.eu/justice_home/cfr_cdf/doc/thematic_comments_2005 en.pdf.

${ }^{8}$ See State Language Commission (2007). Latviešu valoda 15 neatkarības gados. Riga: Zinātne, pg. 125.
} 


\section{Media Accessibility: Regions and Special Needs}

In terms of media accessibility, there are still substantial differences between the countryside and the capital city. Comparative data about accessibility in Riga and in Latvia's regions suggest the situation has improved, but it is still important to increase the availability of the Internet. Also of importance is ensuring TV and radio coverage in Latvia's more peripheral areas so that people in those regions do not feel isolated. Unfortunately, the economic crisis has spurred talk of a reduction in the number of cultural broadcasts of importance to rural residents. TV7 is to shut down its analogue broadcasts, and Radio Klasika is to narrow the territory in which it can be received.

Problems with Internet access in the countryside create a knowledge gap and unequal opportunities in the labour market. Poor people who do not have an Internet connection or multifunctional mobile telephones have fewer opportunities than do people in big cities and those who are wealthier. An increase in the price of press delivery, the fact that the Diena Subscription Centre has narrowed its local services, and that there is a lack of competition against the services that are provided by the Latvian Postal Service - all make it harder to ensure regular and timely deliveries of the press to more peripheral areas.

People with special needs in Latvia have said that it is hard for them to receive information that would reduce barriers against their integration into society. In a study on the situation of hearing-impaired people in Latvia, Germany, the Czech Republic and Slovakia in 2007, respondents in Latvia in particular said that they had problems in obtaining information and communicating with "the world of the hearing." In a 2004 discussion at the Latvian Association of the Hearing-Impaired, participants said that the fundamental rights of hearingimpaired people to take part in the country's political life were constantly violated. There was never a political discussion on Latvian Television which was translated into sign language, interpreters were unavailable at election precincts, and the speeches delivered by Latvia's top officials at the New Year were not translated into sign language. Only $3 \%$ of the programming on Latvian Television was made available to the hearing-impaired. ${ }^{10}$

There have been some discussions in the media about subtitling foreign films, as opposed to dubbing them. People with hearing problems would prefer subtitles to dubbing. The idea was listed by the National Radio and Television Council (NRTC) in its strategy for 2009-2011, although the main stated motivation for the idea was that it would help people to learn foreign languages, not that the hearing-impaired would become more integrated into society.

In 2009, the NRTC included in the national remit an extension in the Latvian Television evening news programme (26 minutes) which ensures sign language interpretation. The programme provides a review of daily events and

\footnotetext{
9 See http://www.lns.lv/public/userimages/Beyond\%20Silence_datu\%20baze.pdf.

${ }_{10}$ See http://www.lns.lv/public/?id=33\&ln=lv\&news_id=140.
} 
includes information from Latvia's regions. Because of the economic crisis and financial problems, it is not possible to predict what will be preserved.

People with hearing problems have also complained about a divergence between text and image on television. The subtitles and images are autonomous, and the subtitles which appear on news programmes on channels such as LTV, LNT and PBK are just a brief and moving line of facts which do not reflect the essence of the news.

Organizations for people with special needs publish their own specialized publications. For people with hearing disorders, there is the newspaper Walking Together, ${ }^{11}$ which is published twice a month and is archived on the Internet. The Latvian Association of the Blind has published its own magazine, Encouragement. The needs of people with vision impairment are met more by specialized libraries than by the mass media - the Latvian Central Library and its branches in Balvi, Daugavpils, Cēsis, Rēzekne, Liepāja and Ventspils. Along with books in Braille, the needs of the visually impaired are satisfied with audio books that are available in Latvian and in Russian.

There have been a few positive trends in the area of mass culture. There is special equipment which allows hearing-impaired people to perceive the content of theatrical performances. The Latvian National Opera was first in this regard, but since November 2007, the Daile Theatre has also offered subtitling. ${ }^{12}$ The universal practice among Latvia's cinemas is to subtitle films.

\section{Trust and the Role of the Media in Establishing Common Values}

Trust in the mass media in Latvia has declined since 2000, but in comparison to the very low level of trust in other institutions, it can still be seen as comparatively high. A survey conducted in November 2008 by the SKDS ${ }^{13}$ company confirmed that the media are seen as an important source of information for the vast majority of respondents (94\%). Researchers compared the answers given by Latvians and Russians and by citizens and non-citizens, finding that the answer that the mass media are an important source of information was given quite equally among the various groups, but in terms of the types of mass media, there were differences - Latvians and Russians were equally likely to cite television as a source of information, but radio, newspapers and magazines were seen as slightly less important sources among Russians than among Latvians.

${ }^{11}$ See http://www.lns.lv/public?id=108\&ln=lv.

12 http://www.leta.1v/archive_item.php?id=153CF77C-996C-4C5B-A61328A75AF5F8AA.

${ }^{13}$ SKDS (2008), Survey commissioned by ASPRI for the Human Development Report. Riga, unpublished. 
It is important here to determine how trustworthy these various sources of information are in the eyes of people in different groups in society. There are substantial differences. $88 \%$ of Latvians, $58 \%$ of Russians, $80.5 \%$ of citizens, and $54.6 \%$ of non-citizens trust Latvian Television, for instance, while $5 \%$ of Latvians, $18 \%$ of Russians, $9 \%$ of citizens and $17 \%$ of non-citizens do not. The differences are less distinct when it comes to commercial channels, except for the First Baltic Channel (PBK) - it is trusted by $27.6 \%$ of Latvians and $62 \%$ of Russians, $39 \%$ of citizens and $58 \%$ of non-citizens. When it comes to Russian television channels that are visible in Latvia, they are trusted by $33 \%$ of Latvians, $73 \%$ of Russians, $45 \%$ of citizens and $77 \%$ of non-citizens. Public radio is trusted by $73 \%$ of Latvians, $49.5 \%$ of Russians, $67 \%$ of citizens and $42 \%$ of non-citizens. Trust in commercial radio stations is fairly even across the board.

The press is traditionally seen as a disintegrating factor, because newspapers tend to be focused on small and differentiated target audiences. People trust "their own" press publications and distrust others. The Latvian language press is trusted by $80 \%$ of Latvians, $41 \%$ of Russians, $71 \%$ of citizens, and only $26 \%$ of non-citizens. The Russian language press, by contrast, is trusted by $27 \%$ of Latvians, $72 \%$ of Russians, $41 \%$ of citizens, and $74 \%$ of non-citizens. Trust in Internet news portals is fairly even, once again, although non-citizens are comparatively less likely than citizens to trust such sources of information.

Approximately one third of the respondents in the aforementioned groups say that they know about the interests defended by specific newspapers in Latvia, and more than one-half of respondents in both ethnic groups know that information in the media tends to be one-sided because of economic interests and that information in the media may be biased because of political sympathies or antipathies.

An interesting issue is how this knowledge affects media use. Respondents were asked: "If a media outlet defends a position with which you do not agree, do you stop reading/listening to/watching it? " The answers were divided fairly equally $-38 \%$ of all respondents said yes, $34 \%$ said neither yes or no, and $28 \%$ said no. Russian respondents and non-citizens are more likely than Latvians and citizens to use only those media outlets which affirm their beliefs, but differences here are not major (35\% of Latvians, $40 \%$ of Russians, $37 \%$ of citizens, and $42 \%$ of non-citizens).

Trust in specific newspapers was also analysed in a study conducted in 2006. The survey showed that Latvians read and trust newspapers in the Latvian language considerably more than others, while Russians and members of other ethnic groups mostly read and trust newspapers that are published in Russian. The level of trust in the newspaper Diena is a bit higher among Russians than is the case with Neatkarig $\bar{a}$ and Latvijas Avizze, and the percentage of Russian 
respondents who read that newspaper is smaller than is the case among others. ${ }^{14}$ Latvians have greater distrust in Russian language newspapers than Russians do in Latvian newspapers - only 3-5\% of Latvians trust them. Russians are most likely to trust the newspaper Vesti Segodnya, then Chas, and only then Telegraf.

These data suggest that the level of trust in the media is linked to the language in which the media work. This is most true in the case of the press, but it is also seen in attitudes vis-à-vis the other media. Trust is a fairly subjective judgment, and it is not always based on usage experience. Instead it has to do with the image of an "alien" media outlet.

\section{The Electronic Media}

In the 1990s, the conceptual approach of Latvian Television and the NRTC and the absence of Russian language broadcasts encouraged viewers to turn to Russian television programmes on cable TV. The number of cable clients increased very rapidly after the Russian channel ORT was no longer broadcast on a terrestrial basis in Latvia - from $28 \%$ in 1998 to $47 \%$ in 2003 . The proportion of Russian speakers watching the channel reached $20 \%$ during this period of time.

Latvian broadcasting organizations compete with Russian television over the local Russian-speaking audience. The proportion of viewers of the Latvian Television evening news programme "Panorama" increased a bit between 2000 and 2003 - from 7\% to $10 \%$. The broadcast "What's Happening in Latvia?" was watched by $11 \%$ of non-Latvians. The proportion of the non-Latvian audience for Radio Latvia 1 was between $7 \%$ and $10 \%$. Commercial channels attracted a greater share of the Russian audience - both LNT and TV3 were watched by $11 \%$ of non-Latvians. ${ }^{15}$

The public electronic media have not tried to become involved in discussions of issues which create conflicts in society. The Integration Programme instructs the media to disseminate information mostly about "ethnic culture." It does not mention the fact that broadcasts in Russian could serve as an instrument for consolidation in society - something that is of key importance, given Latvia's ethnic makeup. Integration in media policy has been dominated by a unidirectional communications model, although public broadcasting organizations today should support programmes which make it possible to express alternative minority identities, to learn about less familiar cultures, or to demonstrate positive examples of interaction. During the first years of independence there

${ }^{14}$ Zepa (2006), Integrācijas prakse un perspektīvas, pp. 88-89.

${ }^{15}$ Sergejs Kruks and Ilze Šulmane (2005), 'Plašsaziṇas līdzekḷi demokrātiskā sabiedrībā.' In Juris Rozenvalds (ed.), Cik demokrātiska ir Latvija? Demokrātijas audits. Rīga: LU, pp. $137-151$. 
were a few Latvian language learning programmes and a soap opera in which characters spoke both languages and had relationships amongst themselves, but, this approach has nearly been forgotten.

A 2008 study (SKDS (2008), survey commissioned by ASPRI for the HDR) involved questions about the three most widely watched television channels, the three most often read press publications, the three most listened to radio stations, and the three most often visited Internet sites. The study confirmed the thesis that Latvia's non-citizens are living in an entirely different information space, and there were great differences in media use in comparison to citizens. $95 \%$ of respondents said that they watch TV. Citizens cited LNT, TV3 and LTV1 as the most often watched channels, while non-citizens were more likely to plump for TV5, TV3+, ORT and PBK.

A similar situation exists with radio. There are stations which are popular among citizens (LR2, SWH, Skonto), while the most popular stations among non-citizens are Russkoye Radio (18\%), SWH+ and MixFM. The Radio Latvia 4 programme "Dome Square" seeks to attract non-citizens, and that is something that should not be forgotten during the economic crisis, when many programmes are simply being eliminated from the schedule.

Integration processes can also be affected by the extent to which nonLatvians use local and foreign media outlets which are presented in Russian. An SKDS study found that PBK was the most popular channel and was watched by $60 \%$ of families in which Russian is spoken at home. ${ }^{16}$ This channel mostly rebroadcasts programming from the leading channel in Russia, but there are also local productions - morning news, as well as an evening news programme called "Latvia's Time" («Латвийское время»). There is also the programme "From the Other Side" ( $«$ другой стороныл»). At the same time, the second most popular channel is local - LNT (35.4\%). Evident changes have occurred at that channel to attract the audience. It has presented an increasing number of soap operas from Russia, including "Liquidation." These broadcasts are subtitled in Latvian, and there is no dubbed voice to eliminate the original language. Commercial television stations broadcast the "New Wave" music competition, which is controversial in Latvia. In order to attract non-Latvians, Russian subtitles are also placed on the original Latvian series "Hope Street." In the media (the Internet site of Diena, and in reader responses sent to the newspaper's television supplement), there have been discussions in which this practice has been denounced. ${ }^{17}$ Recently debate has shifted toward the issue of accepting or rejecting the huge amount of Russian language television output on

16 Ainārs Lerhis, Andis Kudors, and Ivars Indāns (2007), Ārvalstu ietekme uz sabiedrības etniskās integrācijas procesu Latvijā. Rīga: APPC, pg 55.

${ }^{17}$ J. Blūms, (2009), 'Kāpēc Latvijas televīzijās prevalē lēti Krievijas seriāli?' 8 February 2009. See http://www.diena.lv/lat/tautas_balss/lasitaji_raksta/kapec-latvijas-televizijasprevale-leti-krievijas-seriali. 
the part of native Latvian speakers. There have been concerns about the quality of the products and the values which the various series offer.

Behind LNT in terms of popularity is RTR-Planeta (35\%), which does not broadcast any programming from Latvia. ${ }^{18}$ Other popular channels include NTV Mir (30.5\% of respondents from families in which Russian is spoken watch it), TV 3 (25.6\%), LTV1 and LTV 7 (19\% and 21\%). Among Latvians, the most frequently watched channel is LNT (78\%), followed by LTV $1(70 \%)$ and TV3 (61.5\%). ${ }^{19}$

A study in 2006 found that Russians prefer Russian television channels, while Latvians prefer Latvian television channels, and although there are nonLatvians who watch Latvian channels, that does not mean that they watch programmes that are presented in Latvian. An important discovery was that young Latvians also watch Russian television channels, but there is a greater percentage of young Russians who watch such channels than is the case in other age groups. ${ }^{20}$ Families in which Latvian is spoken also watch Russian television channels, but they prefer Latvian ones instead - first of all LNT, and then LTV. It was also found that Latvians watch a news programme on LTV7 that is presented in Russian.

Among Russian news programmes, the unquestioned leader is "Latvia's Time” on the First Baltic Channel. Comparative content analysis of news programmes has shown that there are different approaches to political organizations, experts, subjects and positive or negative news on the various channels. Russian language channels spend more time on interpreting disputed aspects of history than is the case with Latvian language channels. On TV5, too, journalists present Soviet-era military poetry on May 9, send out congratulations to war veterans, etc. ${ }^{21}$

The longest-running news programme in Russian is the one on LTV7. It and the news programme on TV5 have similar ratings. The LTV7 news programme has often been changed in terms of duration and format, but there has been little research about its content or its influence, particularly in terms of integration.

Journalists at public broadcasting organizations are not accustomed to any evaluation of the quality of their work, and their reaction tends to be fairly harsh. The NRTC is perceived as a body which represents politicians and political parties and is not a self-regulating institution. In the background of this

${ }_{18}$ Lerhis et al. (2007), Arrvalstu ietekme uz sabiedrības etniskās integrācijas procesu Latvijā, pg. 54.

19 Ibid. It has to be noted, however, that these data are very malleable. TV3 and LNT are fierce competitors.

20 Zepa (ed.) (2006), Integrācijas prakse un perspektīvas, pp. 87-88.

${ }^{21}$ For more on this see Kruks, S., Juzefovičs, J., Kikuste, E. and G. Kikusts (2007), 'Ziņas Latvijas televīzijās. LTV1, LTV7, TV3, LNT, TV5 un PBK ziņu raidījumu satura analīze. 2007. gada 16.-27. aprīlis.' Riga. 
has been disagreement between the management of Latvian Television and the NRTC on the one hand and the news team on the other.

Analysis of news programmes has found mistakes and shortcomings, such as the use of just some sources and an imbalance in viewpoints. ${ }^{22}$ An NRTCcommissioned study showed a lack of analytical stories in news content, as well as a specific political direction in the news. ${ }^{23}$ It is specifically on public television that quality, balance, a focus on different groups in society and greater thought about broadcasts that could serve as an integrative factor should be an issue. Public broadcasting organizations must have concrete programming in terms of content and language which speaks to all of the minorities in Latvia, because only then will there be a chance to think about a subscription fee collected from all Latvian households.

There has also been analysis of popular news broadcasts in Russia, looking at how Latvia is presented in the Russian media and specifically in news programmes. ${ }^{24}$ Researchers found negative representation of Latvia, as well as a defence of Russian ideology and "national identity" in representing the socalled "compatriots" in Latvia. When the Russian media do report on Latvia, the subjects usually focus on controversial issues which allow the media to present Latvia in an unattractive light - the events of March 16, court cases against Latvia's "liberators", the lack of sufficiently ceremonial presentation of May 9 events in the Latvian media, etc. All of this allows the Russian media to talk about the "rebirth of fascism" in Latvia. ${ }^{25}$

Media discourse in Russia suggests that Latvia has a homogeneous and uniform Russian community, one with identical socio-political problems, one which faces discrimination, one which is humiliated by Latvian government officials, and one which requires Russia's support and assistance. Individual circumstances are generalized, and the media claim that there are various threats to which the Russian community of Latvia is subject. The boundaries of the community are clearly marked in ethnic terms, and links to Russia are presented as an important element on the agenda - one that justifies Russian media interest in events in Latvia. ${ }^{26}$

Students of foreign influence in Latvia have expressed concerns that this space is being flooded with anti-democratic and nationalist content from Russia.

${ }^{22}$ For more on this, see Ilze Šulmane and Sergejs Kruks (2007), 'Plašsaziṇas līdzekḷi demokrātiskā sabiedrībā'. In Juris Rozenvalds, ed., Cik demokrātiska ir Latvija. Demokrātijas monitorings 2005-2007. Rīga: Zinātne, pp. 74-75.

${ }^{23}$ See Kruks S., Juzefovičs J., Kikuste E. and G. Kikusts (2007). Ziņas..., op. cit., pg. 2.

${ }^{24}$ Nils Muižnieks (ed.) (2008), Manufacturing Enemy Images? Russian Media Portrayal of Latvia. Riga: University of Latvia Press. See also Lerhis et al. (2007), Árvalstu ietekme uz sabiedrības etniskās integrācijas procesu Latvijā.

${ }^{25}$ Solvita Denisa (2008), 'The Story with History.' In Muižnieks (ed.), Manufacturing Enemy Images? pp. 79-107.

${ }^{26}$ Dmitrijs Petrenko (2008), 'How Does the Russian Community Live in Latvia?' In Muižnieks (ed.), Manufacturing Enemy Images? pp. 45-77. 
It has also been argued that "media content from Russia rules the information space for Russians in Latvia" and that Russia's government is making use of manifestations of Russian nationalism at home to produce the assumption that it can also hope to manipulate with the emotions of Russian speakers in Latvia, as well. ${ }^{27}$ These authors have noted that Russia's support policy for compatriots abroad has become more intense, and they believe that this will have an increasingly strong effect on ethnic integration in society - an effect which will hinder integration. ${ }^{28}$

Media output from Russia is both accessible and popular. Unfortunately, there is a lack of research in Latvia to measure the true influence, to identify the media effects, or to seek out correlations among media choice, usage intensity and the level of information, values and attitudes toward the country. There have been surveys focusing on what people from both language groups, as well as citizens and non-citizens, think about Russia, loyalty, patriotism and language, ${ }^{29}$ but these indirectly confirm the split in society.

There are no national policies in the area of the electronic media that might have an effect on the representation of integration processes on electronic channels, except for the indirect effect of awarding or refusing frequencies. Nearly the only way to ensure national regulations of representation and to affect integration processes with the help of the media is to issue regulations which apply to public broadcasting. LTV1 broadcasts exclusively in Latvian. LTV7 is a channel with sports and cultural shows, but it also broadcasts in Russian. It was only at the beginning of this century, when the channel was still known as LTV2, that it was positioned as a channel meant for the integration of minorities. It presented shows intended for Russians or for people from both linguistic groups. ${ }^{30}$ Over the last two years the channel has shifted toward sports and entertainment. A more recent plan for three public television channels insists that "LTV7 will be focused on sports, active lifestyles and entertainment." 31

The word "integration" does not appear anywhere in the 2009 conceptual document on the development of public television. ${ }^{32}$ The document speaks to minority audiences only in terms of the radio: "The goal of Radio Latvia 4 is to strengthen its positions as a leader among Russian and minority audiences in all of Latvia, and particularly its regions, by producing high-quality informational,

${ }^{27}$ Lerhis et al. (2007), Árvalstu ietekme uz sabiedrības etniskās integrācijas procesu Latvijā, pp. 56-57.

${ }^{28}$ Ibid., pg. 68.

${ }^{29}$ E.g., comparative data from SKDS that were presented at the conference "Russia's Informational Influence in the Post-Soviet Space", "Views About Patriotism," Riga, 22 May 2009.

30 The National Concept on the Development of Latvia's Electronic Public Media, 2006-2008, pg. 8.

31 The National Concept on the Development of Latvia's Electronic Public Media, 2009-2011, NRTC. See http://www.nrtp.lv/lv/padome/normativie-akti/nacionala-koncepcija.

${ }^{32}$ Ibid. 
analytical and cultural programming. The proportion of national news will be increased in news reports and informational broadcasts, developing cooperation with the regional press, radio and television." ${ }^{33}$ Because of the economic crisis, there may be substantial changes in programming. Among those projects that could be on the chopping block are ones which are focused on integration such as "Dome Square" on Radio Latvia 4.

Overall, broadcasting on minorities in the electronic public media has shrunk. There are several Russian language programmes such as "Сегодня", "Рьгбалка", and "Криминальная информация", but there is no more morning news show in Russian, and evening news programmes are presented only on weekdays. The once important broadcast "Страна.ль", which focused on information and entertainment, is also gone. Analysis of ratings shows that the narrowing or elimination of such broadcasts led people to switch to other channels.

An increase in the proportion of programmes on LTV that are meant for non-Latvians and a broader offer in Russian might attract greater numbers of Russian-speakers to Latvian programming. However, from the perspective of competition among languages, it narrows the use of the Latvian language and reduces resources for original programming and films in Latvia. The logic of the advertising market may also focus on support for channels and programmes that are meant not for specific target audiences or endangered groups in society, but instead for as large a segment of the audience as possible. That is why Latvia's commercial channels offer so many programmes, films and broadcasts in Russian and from Russia. Their quality is not always the best because of commercial considerations, and here we are not even looking at the facts, values and lifestyles which they represent.

\section{The Press}

In the late 1990s, the number of non-Latvian readers of the Latvian daily press had a tendency to increase. In the early 2000s, the share of the non-Latvian audience was proportionally higher than had been the case in the 1990s, but then came confrontations over education reforms, and the trend was reversed.

More Latvians read Russian publications than non-Latvians read Latvian ones. There is greater interest in thematic and specialized publications - the business dailies and women's magazines. The differences are even greater in terms of citizens and non-citizens who read the daily newspapers - Diena has a slightly larger share of non-citizen readers, while their numbers for other newspapers are negligible. Among Russian language dailies, Vesti Segodnya has always had the largest share of non-citizen readers, while Telegraf has been read more by citizens. Up until 2003, the proportion of non-citizens for all three

33 Ibid. 
Russian language dailies was on the rise. Magazines have been affected less by political confrontations, and the share of citizens who read such magazines has remained largely unchanged. ${ }^{34}$

According to a study on integration, $87 \%$ of citizens and $85 \%$ of noncitizens read at least one press publication, and magazines had the largest share of readers. Among newspapers, the largest proportion of citizens (27\%) reads Diena and local newspapers, while among non-citizens, the most popular newspapers at that time were Chas (21\%), Vesti Segodnya (19\%), and local newspapers (16\%). This suggests that the local press, which is less politicized, might be a factor in the integration of non-citizens, helping them to develop stronger identification with a specific territory.

Over the last four years, Latvian and especially Russian language dailies have seen subscription and circulation numbers drop. Over the course of those years, Chas lost half of its subscribers - from 14,313 in January 2006 to 6,464 in January 2009. ${ }^{35}$ The leader in terms of subscription numbers at the beginning of 2009 was Vesti Segodnya, which is published by the Fenster publishing house and had 12,920 subscribers on January 1 of that year. That was half as many readers as the leading Latvian dailies - Latvijas Avize and Diena. The smallest readership is that of Telegraf, although the numbers have increased since a change in ownership at the newspaper. ${ }^{36}$

Several Chas journalists were candidates in the $9^{\text {th }}$ Saeima election in 2006. Among them was the newspaper's editor. Also on a candidate list was the publisher of Vesti Segodnya. This had a very clear effect on the content of the newspapers, which printed much information about the relevant party programmes and sought to polish up the image of the candidates. The newspapers focused on issues raised by "Russian parties" and the electorate toward which those messages were addressed. Still, the intensive publicity for the journalists who were candidates did not ensure their election. ${ }^{37}$

A successful example of an integrative source of information is the aforementioned free newspaper $5 \mathrm{~min}$. It has been very popular among both Latvians and Russian-speakers, and from the perspective of integration, that is of fundamental importance in that both communities receive the same information. A similar role is performed by the official newspaper Latvijas Véstnesis, which ensures that members of both communities have access to laws and decisions.

34 This is starting to worry some Latvians, as seen in reader comments attached to a blog by Dmitrijs Mironovs on the Internet portal of the newspaper Diena. See http://www.diena. lv/lat/tautas_balss/blog/dmitrijs-mironovs/tv-un-latvija?comments=3\#comments.

35 See Kruks and Šulmane (2005), 'Plašsaziņas līdzekḷi demokrātiskā sabiedrībā,' pp. 137-151.

36 For newspaper subscription data, see http://www.leta.lv/search/?phase=abon $\% \mathrm{C} 4 \% 93 \% \mathrm{C}$ 5\%A1\%2A\&id-25E119D9-8980-4199-BE13-BE9003A20B19.

37 Ibid. 
Latvijas Avizze and Vesti Segodnya feed off one another, making reference to each other's content and criticizing it. Press reviews, no matter how combative they might be, often offer the only chance for a reader to find out what has been said in the media environment of the other language. Only Radio Latvia offers press reviews which discuss the most important elements of the agenda of daily newspapers in both languages.

Writing about the Russian language press in Latvia, Zagorovska and Šudnevs have argued that "it has become an important phenomenon in public opinion, and it increasingly influences political processes in the country." They add that "this is the only way in which Latvia's Russian-speakers can express their views to the government and their attitudes about what is happening in this country." 38 One might agree with this judgment if it was applied only to non-citizens. The role of the Russian language press is contradictory. Some have claimed that "the Russian language press is not politically engaged, and it has no interests related to the pursuit of power," but then there is also the idea that leftist politicians are the ones who defend the interests of Russian readers. Authors proudly note that the newspaper Chas is in a global association of Russian press publications, which means that it does not isolate itself and instead moves into a new arena. ${ }^{39}$ The president of the Petits publishing house, Aleksejs Šeininins has also written that he is proud of the local Russian press as a unique and self-sufficient phenomenon - one that is an independent business which competes in the advertising market. ${ }^{40}$

\section{The Internet}

In 2005 it was found that the audience of Internet portals is far more diverse than that of the press. The share of non-citizens who use Latvian language portals is similar to the proportion who read Latvian newspapers (5-9\%), and regarding the linguistic divide, one finds that these Latvian media outlets Delfi.lv, Apollo.lv and Tvnet.lv - have larger shares of the non-Latvian audience. A study conducted in 2003 about the audience of Internet portals over the course of seven days, for instance, found that the non-Latvian audience for the three aforementioned portals was $23 \%, 19 \%$ and $17 \%$, respectively. $30 \%$ of the readers of the Russian version of Delfi, in turn, are Latvians. The Internet version of the newspaper Diena attracts about as large a share of non-Latvians as the newspaper itself does, although in absolute terms, the number of the readers of the newspaper is far smaller.

${ }^{38}$ On the other hand, a journalist from the PBK television channel and his party did win election to Parliament, which apparently shows that for Russian-speakers, the most important source of information is television.

${ }^{39}$ K. Zagorovska, P. Šudṇevs (2006), 'Krievu preses fenomens Latvijā,' in Inta Brikše (ed.), Informācijas vide Latvijā: 21. gs. sākums. Rīga: Zinātne, pp. 167-169.

${ }^{40}$ Ibid., pp. 174-175. 
Citizens cited the Internet as a source of information twice as often as others did. Delfi.lv is visited by approximately one-third of citizens and $16 \%$ of non-citizens. The portal is visited by speakers of both languages, and the Latvian version attracts a larger audience. Articles which have led to the harshest debates and concern topics that are worrisome to people in both linguistic groups receive comments both in Latvian and in Russian on both versions of the portal. The same comments are often posted on the Latvian and the Russian site, and this is one of the few areas of the public media in which "they" and "we" come together to avoid unilateral monologues.

The public policy centre Providus has established a database related to public policy on the Politika.lv portal. The database is in Latvian and English, and it contains sections on media criticism and social integration. Articles in the database focus on integration, media practices related to diversity, research results, evaluation thereof, and reader comments. The portal also presents interviews with foreign experts and politicians on integration policies and minorities. ${ }^{41}$ There are also studies as to how migration affects ethnic relations in Latvia, the integration of immigrants in Latvia and Poland, and integration of new members of society. ${ }^{42}$ The portal presents the idea that Latvia needs new myths which do not promote the consolidation of the electorate of a single political party or a merger on the basis of ethnic principles, but instead ones which can bring the people of Latvia together. ${ }^{43}$ The portal also includes blogs in which authors discuss integration, the interpretation of history and memorial dates.

The portal Dialogi.lv presents articles in both languages. It offers a "Tolerance Library" related to integration issues. There is also a Good Will Memorandum that was signed on November 10, 2008, and was published on Tolerance Day on November 13. The discussion here has to do with aspects of multiculturalism, the integration of disabled people and the unemployed, as well as the rights of homosexuals. ${ }^{44}$ Dialogi.lv is valuable in that it offers the same information in both languages, and that may promote discussions in both languages, as well. These two portals, along with other Internet resources, play a role in the identification, discussion and analysis of integration problems and processes.

${ }^{41}$ Aleksejs Šein̦ins (2003), 'Krievu prese - Latvijas fenomens,' in Ābrams Kleckins (ed.), Dienas kārtība Latvijai 2004. Rīga: Baltijas forums, pp. 343-346.

${ }^{42}$ An example is an interview with Paresh Solanki, presented under the title 'Minorities Need Good Marketing.' See http://www.politika.lv/index.php?id=16787.

${ }^{43}$ See 'Migrācijas ietekme uz etniskajām attiecībām Latvijā', http://www.politika.lv/index. php?id=16689. See also 'Mācāmies uzṇemt. Imigrantu integrācija Latvijā un Polijā', http:// www.politika.lv/index.php?id=16691. See also 'Jauno sabiedrības locekḷu integrācija', http://www.politika.lv/index.php?id=15697.

${ }^{44}$ See http://www.dialogi.lv/article_new.php?id=2787. 
Portals that are visited by the masses, as opposed to specialists, play a positive role in that they present different views, ideologies and values, allow representatives of various ethnic groups to intermingle, offer a place for disputes and dialogues, and make it possible to use both languages, as in real life. On the other hand, comments are left anonymously, and irresponsible people leave comments which offend. In this sense, these portals offer a platform for polarization of viewpoints, and this can promote both intolerance and disintegration.

\section{The Effect of Journalistic Culture on Media Texts}

A quantitative and qualitative study of journalists ${ }^{45}$ conducted in 1998 shows that journalists, particularly those who work for daily newspapers, have diverse opinions as to their role. People working for Latvian newspapers say that they are active and want to influence processes. They are more likely to emphasize their role as objective analysts of events and organizers of public debates. Russian journalists see themselves as fighters for a "Russian renaissance," as representatives of the Russian community and of non-citizens, and as participants in and organizers of political and protest campaigns. Journalists at Russian language newspapers openly admit that they provide support to the largest so-called Slavic parties in advance of elections.

The description of direct competitors and, particularly, of daily newspapers published in the other language, is contradictory and diverse. One can identify various attitudes among journalists vis-à-vis professional values such as neutrality, the separation of fact from opinion, etc. Sometimes observers claim that there are different traditions and practices in Latvian and Russian journalism. There are radical differences in the attitudes of journalists vis-à-vis the ethical issue of conflicts of interest. Specifically, this has to do with journalists who are simultaneously candidates for public office or active politicians. The practice has mostly been denounced in interviews conducted by Latvian journalists. ${ }^{46}$

There have been positive trends, including in the training of journalists, an increasing number of whom are bilingual and can use sources of information from both linguistic environments and work for media in both languages. Accented Latvian can also be heard more often on the radio. A popular LTV

45 The results of a survey conducted in late 1998 by Ilze Šulmane. See Ilze Šulmane (2000), 'Latvijas žurnālisti gadsimta beigās: Sociologiskas aptaujas rezultāti,' in Daudzveid̄̄ba II (Diversity II). Riga: University of Latvia Department of Communications Studies. See also Ainārs Dimants (2004), Pašcenzūra pret paškontroli Latvijas presē: mediju pētījuma atklājumi. Valmiera: Vidzeme University College.

46 Ilze Šulmane (2007), 'Kurš uzraudzīs sargsuni: nacionālo dienas laikrakstu žurnālistu attieksme pret profesionālo ētiku Saeimas vēlēšanu kontekstā.' In Skaidrīte Lasmane (ed.), Politiskā komunikācija, ètika un kultūra Latvijas Republikas 9. Saeimas vēlēšanās. Riga: LU Akadēmiskais apgāds, pp. 207-222. 
soap opera, "The Price of Senselessness" features characters that communicate in both languages, engage in inter-ethnic marriage, represent reality, and both break and, sometimes, reproduce stereotypes. ${ }^{47}$ Language skills alone, however, do not indicate any commonality or similarity in views or values.

\section{The Role of Media Content in Integration and Disintegration}

The media situation in Latvia features external diversity and pluralism. There are many different press publications, television and radio channels, and the Internet, all of which ensure the appearance in the public arena of opposing ideas, viewpoints and ideologies. However, most people have neither the time nor the resources to make use of several or many sources of information so as to learn what other thoughts exist in the public arena. Typical in the Latvian media at this time are polarization and a lack of internal diversity. It is not too often that a television channel or programme, a newspaper or magazine, or even a single article offers a balanced and equal description of various views.

Content analysis of the media has long since shown that the agenda is different for the media outlets of the two languages. This is a trend that has remained quite stable over the course of time. ${ }^{48}$ The main issues may be the same, but their framing can be very different. The widely discussed "umbrella revolution" of 2007, for instance, was presented in Russian language newspapers largely as an "ethnic Latvian" protest or a provocation directed by the US embassy. In Latvian language newspapers, by contrast, the protests were presented as a rebirth of the nation. ${ }^{49}$

Differences in the presentation and interpretation of various events can be seen in relation to domestic politics. The Latvian and Russian press have very different interpretations of Latvia's declaration of independence, its citizenship law, the national language law, education reforms,${ }^{50}$ attitudes vis-à-vis the EU and NATO, the National Development Plan, etc. There are also different views on economic matters such as possible energy sources, banks, the construction of the Latvian National Library, etc.

${ }^{47}$ Because of the financial crisis in Latvia and a lack of support on the part of LTV management, the soap opera was renamed and moved to a private television channel.

48 Brigita Zepa et al. (2005). Etnopolitiskā spriedze Latvijā: konflikta risinājuma meklējumi. Rìga: BISS, pp. 57-70.

49 For more on this, see Solvita Denisa, 'Nerussky bunt,' available at http://www.politika. lv/index.php?id=14804.

${ }^{50}$ For more on this, see Zepa (ed.) (2006), Integrācijas prakse un perspektīvas. 
Analysis of Latvia's two most recent parliamentary elections ${ }^{51}$ shows that the views and messages of politicians and the media are separate in the two linguistic arenas. This relates to the choice of a media outlet for political advertising and also the editorial content of the various media, focused mostly on ethnic or linguistic aspects of their target audiences. In the 2009 European Parliament and local government elections, for the first time, a "non-Slavic" party campaigned very actively in the Russian language media and published information about itself in both languages. ${ }^{52}$ Here the attempt has been to address the Russian-speaking electorate, with intensive use of outdoor advertising.

A comparison of media and political messages shows that the frameworks of various political forces in election campaigns are openly presented in the Russian national press, which positions itself as a participant, allows political actors to present their messages without any critique at all, and identifies itself with the Russian-speaking community. The Latvian language press, by contrast, is less likely to take part in party politics, preserving a certain distance as an observer. ${ }^{53}$

There are also substantial differences in opinions in the Latvian and the Russian media on foreign policy issues such as attitudes toward the United States, the war in Iraq, Kosovo, etc. When the Russian-Georgian war erupted, a battle of interpretations started in the Latvian media. Journalists had diametrically opposite views of the conflict, and depending on the language in which the relevant publication was published, journalists actively tried to identify "comrades" and "enemies" in the Georgian conflict. ${ }^{54}$

There are also differences related to whether Latvia should be focused toward the East or the West, what its relationship with Russia should be like, and who exactly Stalin was and Vladimir Putin is. The presentation of issues related to history, collective memory, collective myths and dates of commemoration has, for a long time, been used by the media of both languages as an effective means for evoking an emotional response and splitting society.

${ }^{51}$ For the 2002 election, see Sergejs Kruks and Ilze Šulmane (2002), Pilsoniskās sabiedrības attīstība un sabiedrības integrācija: 8. Saeimas priekšvēelēšanu kampaņas preses un politiku diskurss. Rīga: SIA JUMI, pp. 3-103; for the 2006 election campaign, see Inta Brikše and Vita Zelče (eds.) (2007), Latvijas Republikas 9. Saeimas vēlēšanu kampaņa: priekšvēelēšanu publiskā telpa. Rīga: Zinātne.

${ }_{52}$ The reference is to the First Party of Latvia/Latvia's Way (LPP/LC), whose leader, Ainārs Šlesers, invested heavily in his ultimately unsuccessful campaign to become the mayor of the Latvian capital city of Rīga. His party placed advertising in both Latvian and Russian language publications and on television channels watched by both Latvians and nonLatvians.

${ }^{53}$ Inta Brikše (2007), 'Preses rāmējumi 9. Saeimas priekšvēlēšanu komunikācijā'. In Brikše and Zelče (eds.), Latvijas Republikas 9. Saeimas vēelēšanu kampaņa: priekšvēlēšanu publiskā telpa, pp. 15-106.

${ }^{54}$ Z. Gorbušina 'Interpretāciju karš', available at http://www.politika.lv/index.php?id$=16725$. 
Of importance in the public arena has been the discourse of liberation and occupation. Views about what happened in Latvia in 1940 are completely polarized, although there have been some periods in which they have drawn closer together. Politicians use these differing experiences, collective memories, and views about history to engage in public political bargaining - the status of the Russian language as an official minority language, the ability of children to pursue their education in Russian, and the awarding of citizenship are all offered in "trade" for a recognition of the fact of the occupation. ${ }^{55}$

Then there are dates of commemoration such as March 16, when the World War II-era Latvian Legion is commemorated, May 9, when the end of World War II is remembered, and March 25, when, in 1949, there were mass deportations of Latvia's residents to Siberia. Confrontational discourse on these dates appears year after year, with particularly intense debates during campaign season. One example is a member of Parliament for PCTVL (For Human Rights in a United Latvia) who is also a working journalist and absolutely rejects the historical nature of Latvia's statehood. ${ }^{56}$ A study of how various events have been presented in the media over a longer period of time suggests that the exacerbation of different views in the media has to do not only with domestic political circumstances, but also with the results of influence by external factors. ${ }^{57}$

When it comes to culture, there are differences in the two types of media. Russian language newspapers in Latvia print columns and inserts with content that has been created in Russia or that is republished from Russian newspapers. That is advantageous from a business perspective, and it may be that the target audience is interested in such content, but this strengthens and maintains two completely different information worlds in Latvia. Publications from Russia as such are not particularly popular, and few people in Latvia subscribe to them. Local and national events in Latvia, meanwhile, are insufficiently reported and analysed in the Russian language press, even though non-Latvians attend performances at the New Riga Theatre and at the Latvian National Opera. A similar situation exists in Latvia's regions. Survey data show that the Russian language media have little or nothing to say about important aspects of culture in Latvia. The Latvian press, for its part, sometimes ignores important cultural events if the performers in question come from Russia. ${ }^{58}$

Because the media focus on popular culture and sometimes provide products that are cheaper (e.g., rebroadcasting of cultural programmes from Russia

${ }^{55}$ For more on what Harmony Centre chairman Nils Ušakovs has said on the Internet, see Vita Zelče (2007), 'Vēsture un 9. Saeimas vēlēšanas.' In Brikše and Zelče (2007), Latvijas Republikas 9. Saeimas vēlēšanu kampaņa: priekšvēlēšanu publiskā telpa, pg. 208.

56 Ibid.

57 An example of this is that at the international level, Russia insists that the date when the Latvian Legion is commemorated represents a "rebirth of fascism" in Latvia.

58 See Aivars Tabuns (ed.) (2006), Kultūras. Jaunieši. Mediji. Riga: University of Latvia, pp. 28-31 and 49-53. 
or the United States), the public media should offer programmes which present local achievements in culture and the arts, not just among Latvians, but among Russians and others as well. They should not merely present Russian (usually classical Russian) culture.

Content analysis has shown that in the traditional media and the press, statements which foment ethnic hatred and biases are uncommon, but they are very common in comments left by readers of Internet portals. Stereotypes most often relate to political evaluations and identification. ${ }^{59}$ Intolerant or stereotypical statements about Latvians or Russians usually appear in the context of specific political forces or groups with specific views. ${ }^{60}$ As such statements accumulate, hatred toward an entire nation can be established, even though the public criticisms may well apply to Latvian politicians, for instance, not the Latvian nation and people. There have also been new stereotypes in both media worlds. One example includes the idea that newly naturalized citizens are a unified community. ${ }^{61}$

The mass press tends to report on extremes, and that is why there is a disproportionate presentation of the views of radicals on both sides. The Latvian press, for instance, rarely reports on Russians who speak several languages, are satisfied with life, are not waiting for Russia to protect them, and do not support Russian policies. Similarly there are few articles which demonstrate an understanding of the subjective feelings of a Russian born in Latvia who has to prove his/her knowledge about history or language. The Russian language press, for its part, has never reported on the fate of a member of the Latvian Legion, or any understanding of the limited ability of Latvians to speak their native language in Latvia's capital city.

On the Internet, there are often hostile descriptions such as "damn Russians," "Nazis," "rebirth of fascism," "Moscow's hand," "fifth column" and "nationalist radicals." Many commentators criticize those who produce this intolerant discourse and demand that they be isolated from the portals in question, but the overall flow of anonymous comments demonstrates a fairly high level of intolerance toward those who have different opinions.

The demonstration on January 13, 2009, and the riot in Old Riga which followed were not represented in media discourse as an ethnic conflict, perhaps specifically because the event represented a departure from Latvia's accustomed

59 Ilze Šulmane and Sergejs Kruks (2002), 'Ethnic and Political Stereotypes in the Latvian and Russian Press in Latvia', Humanities and Social Sciences, Latvia, No. 1(34), pp. 71-90.

60 Ilze Šulmane and Sergejs Kruks (2006). Neiecietības izpausmes un iecietības veicināšana Latvijā: Laikrakstu publikāciju un politiskā diskursa analīze (Diena, Neatkarīgā, Latvijas Avizze, Vakara Ziņas, Telegraf, Čas, Vesti Segodniya). Riga, pp. 4-128.

${ }^{61}$ For more, see Dmitrijs Petrenko (2007), 'Pilsonības naratīvs 9. Saeimas priekšvēlēšanu kampaņā’'. In Brikše and Zelče (eds.) Latvijas Republikas 9. Saeimas vēlēšanu kampaņa: priekšvēēěsanu publiskā telpa, pp. 167-180. 
culture of peaceful demonstrations. ${ }^{62}$ Media polarization was seen in advance of the May 9 events in 2009, particularly in the context of approaching elections. Polarization is by no means linked exclusively to the language of the relevant media outlet. An example here is attitudes toward sexual minorities. Reporting on Latvia's gay pride events, which are known as "Friendship Days," tends to be similar in media outlets in both languages, and it often differs only in terms of whether traditionally conservative or liberal values are being defended.

The Latvian media give voice to people with very different views. This is a good thing from the perspective of individual rights and freedoms, and it promotes the development and representation of a diversity of individual identities. At the same time, however, this can also hinder the emergence of a civil society that is unified and based on common fundamental values.

\section{Regulation and Self-Regulation}

Legal regulations concerning the media in Latvia are usually in line with European Union requirements. In a study on the subject of limitations to freedom of speech on inciting hatred, ${ }^{63}$ Kučs argues that courts in Latvia are increasingly taking into account the principles developed by the European Court of Human Rights. Examples include the separation of opinion from news reporting. However, ensuring this may be quite difficult, because not all of Latvia's press publications observe these principles. The failure to separate among genres and the habit of journalists of expressing subjective and emotional judgments makes it hard for experts to analyse this process of separation in cases when it must be decided whether a statement in the media has been libellous.

There are still legal regulations which excessively limit freedom of speech by failing to take into account whether a disputed statement has been factual or an opinion. Courts evaluate statements grammatically, without taking into account the context of the article or series of articles. It is quite easy in Latvia to sue a journalist even if he has simply quoted the views of a government official, as opposed to making the offensive statement himself. Journalists from regional newspapers have reported that this is the case. ${ }^{64}$

Prior to 2003, the Latvian Security Police launched only a few criminal investigations of racial intolerance or speech which foments discrimination, Kučs reports, adding that such cases were a fairly new phenomenon in court practice. He also emphasizes how important it is to inform the public, also

${ }^{62}$ The events of January 13 were described differently in the media - "revolution of eggs" (Vesti Segodnya), "revolution of empty bottles" (Chas), "revolution of penguins" (Neatkarīgā), "liquored-up revolution" (Diena) and "paving stone revolution" (Telegraf).

${ }^{63}$ Artūrs Kučs (2004), Vārda brīvības robežas: goda un cieñas aizskaršana, naida kurināšana. Riga: Nordik, pg. 7.

${ }^{64}$ Kruks and Šulmane (2005), 'Plašsaziņas līdzekḷi demokrātiskā sabiedrībā'. 
speaking to the role and responsibility of the media in promoting tolerance and in disseminating negative stereotypes.

Latvia has no press council or ombudsman to oversee the process and intervene in those cases when the media publish information which offends a race, nationality, minority or religious group, thus hindering public debate about the validity of a complaint. Such a debate would make it possible to review cases of negative practices and to publish analysis and judgments about disputed issues, thus educating the public at large, as well as the community of journalists. The Latvian Association of Journalists has been insufficiently active in the area of self-regulation and internal critique. Only the Latvian Association of Publishers has organized training and seminars for editors to discuss the two separate information spaces and the different culture of journalists, as well as the role of diversity and pluralism in the media. However, there have been cases in which advertising which may contain racially offensive discourse has been cancelled. Such incidents are reviewed by the industry's self-regulatory institutions, and discussions about them also appear in the press.

In a 2008 survey, the SKDS company posed this question: "Should offensive or inappropriate comments on the Internet be erased (censored)?" More than $60 \%$ of respondents said yes, $11 \%$ said no, and answers among Russians and Latvians were quite similar (5\% more Latvians than Russians agreed with the statement). Non-citizens were slightly more likely than citizens to agree that offensive comments should be erased (69\% versus 64\%). Another question was this: "As long as a journalist observes the law, should he be free to do whatever he wants?" $42 \%$ of Latvians and $35 \%$ of Russians answered in the positive.

Many media outlets in Latvia have signed up to a declaration on tolerance on the Internet, which calls for the erasing of any statements which foment hatred. However, hostile discourse in that environment has not been reduced. Commentators often complain that statements which foment hatred or offend an individual are not being erased sufficiently or quickly enough, while others have accused the management of the various portals of limiting freedom of speech. As the proportion of user-created content in the media increases, the issue of the level of responsibility of the author or publisher of the relevant text has come to the fore.

\section{An Evaluation of the Role of the Media}

The aforementioned BISS study contains important insights about what media consumers, politicians and representatives of public organizations think about the role of the media in the integration process. Participants in focus group discussions said that because of the two separate media arenas in Latvia, there are different interpretations of reality, and these are different than the reality which respondents encounter on an everyday basis: 
There's no conflict at the everyday level, but if you open up a newspaper, it's there, if you close the newspaper it's gone. If you switch on the TV, it's there, but if you switch it off, it's gone. ${ }^{65}$

Similar views in this regard were expressed by Russian and Latvian focus group participants. The conclusion was that different media outlets present different kinds of propaganda, and so one media outlet or channel is not enough to understand what is happening. The researchers found that most respondents had negative opinions about the role of the mass media in the area of integration.

Representatives of non-governmental organizations said that the media promote a polarization of views, use integration issues to sell their product, mostly publish negative information, serve the interests of political parties, and promote ethnic mobilization. Respondents also said that representatives of the radical organizations are most likely to be satisfied with the current situation in the media arena. ${ }^{66}$

Both ordinary individuals and politicians said in interviews that the media do have a role to play in the area of integration. Many spoke of the influence of foreign television channels, cable TV and the Russian media. ${ }^{67}$ Representatives of political parties emphasized the role of the media in shaping of public opinion and defining the agenda. They argued that the press writes about politically sensitive issues in a very diverse way, while the Russian language daily press mostly reports on events in Russia, thus strengthening the identification of readers with Russia, not Latvia. Several respondents said that the Russian language press is closely linked to politics in Moscow. ${ }^{68}$

Representatives of some parties complained that certain newspapers and public TV do not give them a platform. ${ }^{69}$ Asked which newspapers are most intolerant, they pointed to Latvijas Avizze among Latvian and Chas and Vesti Segodnya among Russian language newspapers. The arguments, however, were based on who was talking. Some respondents, for instance, said that Latvijas Avize is the only one which upholds the self-confidence of ethnic Latvians and defends their rights.

Politicians also pointed to the fact that the media are private enterprises, that they are interested in their business, that they express the views of editors and owners, not the public at large, and that "no one pays anything" for the presentation of integration issues, so they are not presented at all. ${ }^{70}$ Asked what to do in order to ensure that the media promote social integration, respondents suggested the establishment of a new media outlet with the support of the

\footnotetext{
${ }^{65}$ Zepa (ed.) (2006), Integrācijas prakse un perspektīvas, pg. 88.

66 Ibid., pp. 208-210.

${ }^{67}$ Ibid., pg. 226.

68 Ibid., pp. 239-242.

69 Ibid., pp. 241-242.

70 Ibid., pg. 241.
} 
state or non-governmental organizations, while others proposed that government financing be provided for special articles in newspapers or broadcasts on TV. Still others called for the establishment of a media regulator to ensure the independence of positions taken. ${ }^{71}$

A study focused on culture, young people and the media ${ }^{72}$ found that even if the issue is an ideologically neutral sphere such as culture, there are still very different representations. It is hard to receive the same information if one only consumes the media in one language. Young people and experts criticized the media, insisting that the cultural spaces are very different, and that the media business maintains this split because integration is not a business project. Experts also said that communications between Latvians and non-Latvians could be facilitated with bilingual publications and broadcast programmes. ${ }^{73}$

A fundamental element in the process of language learning is an understanding of culture. Positive attitudes toward less familiar cultures can be facilitated through study, comparing types of rituals (weddings, funerals) and forms of address. $^{74}$ This might be one of the most important jobs for television - explaining and describing this so as to establish a socially open and unified society which accepts the coexistence of different cultures.

A report from an EU working group on multilingualism noted that the rapid rebirth of regional languages shows that people are happy to learn new languages if the motivation is clear. The authors point to Finland, where the media encourage people to learn languages. Methods include "educational leisure," for instance, which is very different from standard educational techniques. ${ }^{75}$

In Latvia, choices or changes related to language, particularly in the public arena and in the media, are not just a matter of communications. For the most part, they relate to manifestations of power and expressions of identity. Sensitive issues related to language use appear regularly in the media of both languages, with concerns expressed about a decline in the quality of both languages, about the demonstrative refusal to speak one or the other language in contacts with clients, and about imprecision in the translation of people's surnames. ${ }^{76}$

71 Ibid., pg. 243.

72 Tabuns (ed.), Kultūras. Jaunieši. Mediji.

73 Ibid., pg. 103-106.

74 Baker C. (2002) Foundations of Bilingualism and Bilingual Education (Latvian translation). Riga: Nordik, pg. 237.

75 See http://ec.europa.eu/education/languages/archive/doc/multishort_lv.pdf.

76 This latter issue is often discussed in the Russian press, ignoring the fact that both languages are similar in this regard, and proper nouns from other languages are pronounced in a different way. This is a linguistic issue which should be addressed by both communities together. 


\section{Participation}

Public participation is most often manifested through protests, but it is less common to be involved in other ways - voting in elections, working for NGOs, meeting with members of Parliament, or approaching the mass media. In one survey, only 90 of 1,200 respondents said that they had contacted the media in this regard, and even fewer had ever met with civil servants, MPs or government ministers. ${ }^{77}$

A survey conducted in November 2008 to find out how respondents participate in the preparation of media content and what reciprocal links there are in this process found that more than half of respondents (55\%) had never called a newspaper, written a letter, or left comments on the Internet. Russians (59\%) and non-citizens (74\%) were more likely to give that answer than Latvians and citizens. In comparing various forms of participation, differences are even more distinct in an area such as the posting of photographs or videos on the Internet only $27 \%$ of citizens and $14 \%$ of non-citizens reported having done so.

If we look at these data from the regional perspective, we find no direct relationship to the availability of the media (the Internet). Activities such as blogging, chatting, posting of videos on portals, and telephone votes are not the provenance of people in Riga and its metropolitan area alone - respondents from regions where Internet coverage is weaker also do the same. People in Riga, however, are dominant when it comes to writing letters to the editor and ringing newspapers and other media outlets.

Journalists from the Russian language press say that they are more concerned about ordinary people and that they are closer to the people. The reciprocal link of letters to the editor, however, is not too common in this media segment. The number of letters and reports on phone calls from the audience has declined both among the Latvian and the Russian language media. Instead there is often republication of comments left on the relevant newspaper's Internet site, and because such comments are usually anonymous, they tend to be more confrontational.

Overall, public influence on media content is not too substantial. Local residents do have the right to receive a written response from the media to criticisms that have been levelled. They do not, however, have any influence on the content of public radio and television programming. Viewers and consumer

${ }^{77}$ AC Konsultācijas (2008), Kvantitatīvs un kvalitatīvs pētījums par sabiedrības integrācijas un pilsonības aktuālajiem aspektiem. Riga: Īpašu uzdevumu ministra sabiedrības integrācijas lietās sekretariāts. 
organizations do not participate in decision-making, as opposed to the case in

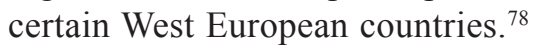

The process of filing complaints with media organizations is largely an individual process, because there are no active organizations which seek to influence media content. Because there are few activities on the part of the audience, the media do not involve viewers in an evaluation of programming - something that would help to learn the views of different groups in society while allowing such groups to become more visible in media content.

\section{Conclusions and Recommendations}

In methodological terms, it is difficult to differentiate between the role and responsibility of the media in promoting processes of integration and disintegration and those of other actors such as political parties, NGOs and the educational system. Latvia's media structure ensures good access to speakers of Latvian and Russian, but the voices of smaller ethnic groups are hardly ever heard. In terms of ideology and content, there are two separate information spaces which offer different political agendas and actors, different collective memories, different views about the future, and different values, as well.

The commercialization of the media, political parallelism and the existence of two different information spaces maintain external diversity and the representation of different voices, but internal diversity within a single media outlet has not been systematically ensured. Without unified ethical norms and a common journalistic culture with effective self-regulation mechanisms, and with harsher competition among media outlets even in the same language, the autonomy of journalists and professional values such as high-quality, analytical and balanced journalism cannot be fully manifested, and that probably has a disintegrating effect on society.

The agenda of the media, and particularly the press, is dominated by political news, and there is little attention to the everyday practices and dialogues of people in society. Co-existence is positively assessed by researchers who study ethnic tensions, but this is a matter which is represented in the media in a fairly fragmentary way.

Competition among so-called rightist parties makes them and the media outlets which support them compete amongst themselves, while the so-called Slavic parties and the media which support them serve to consolidate the Russian-

${ }^{78}$ For instance, there is an audience council in Austria. Representatives of viewer organizations serve on the councils of broadcasting organizations in Luxembourg, Portugal and the Netherlands. The situation in other countries in Eastern and Central Europe is worse. See Holznagel B. and Jungleisch C. (2007), 'The Protection of Viewer Rights in Europe.' In Baldi P. and Hasebrink U. (eds.), Broadcasters and Citizens in Europe. Trends in Media Accountability and Viewer Participation. Bristol: Intellect, pp. 53-74. 
speaking audience. The "normalization" which emerged in advance of educational reforms has given way to a greater proportion of polarized messages.

The effects of politics in Russia can also be seen in the media arena. As political and economic confrontations increase, the media start to produce harsher representations of March 16 and May 9, and the discourse about a "rebirth of fascism" (which has no confirmation in public opinion surveys) becomes more active. This, along with mistakes made by Latvian politicians, does not promote integration.

The economic crisis may mean that national issues and historical confrontations might become less important on the agenda, but crisis traditionally leads people to seek out scapegoats, and since a general election is approaching, members of the political elite are staking out their positions. This brings up subjects that split up voters and audiences to an even greater degree.

There has been no public debate about how to reduce the effects and role of the Russian information space and its propaganda in processes of integration and disintegration, and Latvian media outlets have not identified policy options. There has also been no serious research into media effects from Russia. Other important areas of research - the effects of the media on the public agenda, information, and changes in attitudes and opinions on specific issues - have not been sufficiently developed. The possibly disintegrating role of the media is rooted less in the activities of the media themselves, and more in the representation of the existing situation and the consequences of factors which lie outside of the media themselves.

What should be done to ensure that the media help to integrate society?

1) There must be courses at schools which teach young people to use the media. This might reduce negative effects, because teachers can talk about how stereotypes emerge, how important the choice of information sources is, and how specific problems are framed.

2) There is a need for publications or at least sections of Internet portals which engage in a critique of the media. There should also be a professional publication for media employees to ensure a reciprocal link, along with media critique. This would enhance the responsibility of the media, and the community of journalists could discuss questionable practice and ethical dilemmas which help to disintegrate the audience.

3) Programmes and public media broadcasts which promote civil society and social integration must be planned, financed and produced, ensuring that the needs of specific groups in society are met and that these groups have access to the media.

4) Media policy must define steps to be taken toward a greater sense of security and belief that a group's interests are being taken into account. This applies both to the majority and to minorities. 
5) An attractive language teaching programme is needed on TV, along with programmes for young people in which speakers of both languages interact (competitions on knowledge and skills, games, etc.).

6) There should also be broadcasts which have basic information about Latvia, its geography, culture, history and distinguished individuals (both Latvians and non-Latvians). These would be meant for recent immigrants and for people who are poorly integrated into the Latvian environment - non-citizens and older people.

7) The status of public broadcasting organizations should be clarified and their dependency on state financing should be reduced, to help ensure the survival of public broadcasting in Latvia.

8) The public media should set aside broadcasting time on specific days and at specific times for public discussions, messages from local residents and NGOs, and programmes in minority languages (with subtitles on television).

9) The public and other media must promote themselves in the media outlets of the other language so that people learn about what is on offer, and audiences become larger. This would bring together the fairly limited information and cultural spaces in Latvia.

10) The scientific potential and resources of the Latvian media and interdisciplinary sectors must be coordinated so as to engage in complex research into the issue of whether and how specific types of media consumption and other factors affect the views of people toward Latvia, different groups in society, and their identity, history and citizenship.

Only if policy-makers are truly interested in integration - something that is of key importance in dealing with the economic crisis, political alienation, greater emigration, and a reduction in civic patriotism - will there be more intensive and targeted thinking about how to attract large segments of the audience to a specific information space, as well as about the quality and effectiveness of this process.

\section{Greatest Achievement}

Despite the historical, political and economic circumstances with a disintegrative impact, the Latvian media space is characterized by external pluralism and the media structure guarantees good access and media content for the two largest linguistic communities - Latvians and Russian-speakers - which is a significant achievement.

\section{Most Serious Problem}

The most serious problems are the existence of two parallel media spaces which differ in terms of ideology, values, content, collective memory, political agenda, and future vision. As a result of media commercialization, political 
parallelism and the influence of Russia's media, there is no diversity of opinions within media outlets and the parallel media spaces do not promote the integration of various audiences and social groups.

\section{Most Urgent Task}

The most important tasks are conducting research on media effects, as well as elaborating media policy to determine the minimum level of funding and content which would permit public broadcasters to ensure programming for the integration of all social groups and to define conditions for Latvia's main private commercial broadcasters aimed at promoting high quality, culturally diverse programming that guarantees language acquisition. 


\title{
Identity, Ethnic Relations, Language and Culture ${ }^{1}$
}

\author{
Aivars Tabuns
}

\section{Introduction}

In the late 1990s, there were extensive debates in Latvia about language, culture and identity. Even the need for the restoration of independence was often justified with reference to the idea that such issues can only be addressed properly in an independent country. One of the first politically significant decisions by the Supreme Council of the Latvian SSR was the adoption of a language law in 1989. A later version of the law emphasized the following:

The purpose of this law is to ensure: 1) the maintenance, protection and development of the Latvian language; 2) the maintenance of the cultural and historical heritage of the Latvian nation; 3) the right to freely use the Latvian language in any sphere of life within the whole territory of Latvia; 4) the integration of members of ethnic minorities into the society of Latvia while observing their rights to speak their native language or other languages; 5) the increased influence of the Latvian language in the cultural environment of Latvia, to promote the more rapid integration of society. ${ }^{2}$

Discussions about the status of the Russian language are continuing to this very day. Riga Mayor Nils Ušakovs, for instance, believes that if the Russian language were granted the status of an official language, that would make it possible to use the language in contacts between local residents and local government institutions, to submit documents to the authorities in Russian, and to use the Russian language more extensively in the country's educational system. ${ }^{3}$

Debates about Latvia's history, ethnic relations, ethnic threats, and the country's geopolitical orientation have a similarly long history. Debates about policies related to ethnic and national identity have not been radically

1 The author would like to thank Brigita Zepa, Ieva Strode, Vija Kḷave, Sigita Snikgere, and the Latvian Ministry of Defence for their support in preparing this paper.

2 The State Language Law, in effect as of 1 September 2000. See http://www.likumi.lv/doc. php?id=14740.

3 Nils Ušakovs, "Press Conference.” See http://www.lenta.ru/conf/ushakov (in Russian). 
confrontational in recent years, but these issues still serve as one of the most important factors in the "ethnicization" of political parties, and this is the one aspect of integration which deserves the greatest focus.

Latvia's Integration Programme (2001) states in its introduction that "each resident of Latvia has the right to shape and maintain his or her own national identity." ${ }^{4}$ Further, it states:

The integration of society, in many senses, depends on the opportunities for development not only for Latvians, but also for the country's minorities. This refers to the right to preserve one's ethnic identity, but also to the inevitable need to accept the Latvian language as the only state language and to learn and use it (..) Opposition to integration is based on the fear of losing one's own ethnic identity. In truth, however, this means that the individual does not understand the essence of integration - the integration of society speaks not to the loss of ethnic identity, but rather to its nurturing and expansion (..) Non-Latvians must believe that they can preserve their ethnic identity and be full-fledged members of this country. ${ }^{5}$

The same section of the document contains the claim that one factor which brings the people of Latvia together in the process of integration is "the desire to preserve and develop their ethnic and cultural identity." In the section of the programme that is devoted to culture, there is an emphasis on the need to "ensure the preservation and development of cultural values, to promote dialogue among cultures, and to guarantee the individual's right to freely express, defend and develop his or her ethnic, cultural and religious identity." 7

The Integration Programme often uses the concept of ethnic identity, and only in one sentence does it use the concept of national identity. This is true despite the fact that in the context of theories about integration policies, the statement that "each (author's emphasis) resident of Latvia has the right to preserve and maintain his or her national identity" is conceptually contradictory with the goal of integration that is stated in the programme: "To establish (..) a society that is based on common basic values."

Researchers from the Baltic Institute of Social Sciences have also pointed to the lack of conceptual clarity in the Integration Programme:

Without stating so specifically, the integration programme includes efforts to develop integration policy in two directions. (..) On the one hand, there is the idea of strengthening the nation state. On the other

\footnotetext{
${ }^{4}$ Ministry of Justice (2001), 'National Programme on the Integration of Society in Latvia.' Riga: Ministry of Justice, pg. 8.

${ }^{5}$ Ibid., pg. 9.

${ }^{6}$ Ibid., pg. 11.

7 Ibid., pg. 68.

${ }^{8}$ Ibid., pg. 71.
} 
hand, the integration programme insists that the people of Latvia are joined together by the desire to preserve and to develop their ethnic and cultural identity (..) Integration of the ideas of a nation state and multiculturalism in a single programme is a job that is not only complex, but may also prove to be contradictory. ${ }^{9}$

There are several things which it make it difficult to analyse collective identities and to come to conclusions as to how successful or unsuccessful this process has been in Latvia: 1) collective identities are multidimensional phenomena which can be measured using different indicators which each describe different processes and different trends; 2) various studies focused on the measurement of collective identities use different methods, questions and scales, which makes it difficult to compare the data and to evaluate trends; 3 ) a great deal of research data is not available for secondary analysis, because authors have used different data grouping principles in their research reports; 4) measurements of collective identities are essentially based on indicators which only indirectly describe the studied phenomenon or any aspect thereof; 5) individuals find it hard to recognize and formulate their belonging and the level of its intensity. ${ }^{10}$

The Weatherhead Initiative in International Affairs at Harvard University has classified eight dimensions in the measurement of identities: ${ }^{11}$

1) Recognition - the degree to which a group accepts a particular social identity; and the degree to which a state recognizes a social identity;

2) Exclusivity - the degree to which a given social identity excludes the holding of another social identity;

3) Primordiality - some identities are interpreted as being chosen and others as essential and unchangeable;

4) Entativity ${ }^{12}$ - measures the degree to which groups are perceived (mostly by outsiders) as being "real", as cohering as a natural group, rather than an arbitrary one;

5) Status - the way in which identity is seen as positive, neutral or negative; something to be taken pride in or something to be ashamed of.

${ }^{9}$ Brigita Zepa (ed.) (2006), Integrācijas prakse un perspektīvas. Riga: Baltic Institute of Social Sciences, pg. 7.

${ }^{10}$ A. Von Busekist (2004), 'Uses and Misuses of the Concept of Identity,' Security Dialogue, Vol. 35, No. 1, March, pg. 82.

${ }^{11}$ R. Abdelal, Y. M. Herrera, A. I. Johnston and T. Martin (2001), 'Treating Identity as a Variable: Measuring the Content, Intensity, and Contestation of Identity,' available at http:// www.wcfia.harvard/edu/default/files/Johnston_Treating.pdf, pp. 11-12.

12 The term "entativity" refers to the extent to which a group is perceived as being a coherent unit, one in which the members of the group are bonded together in some fashion. See B. Lickel, D. L. Hamilton and S. J. Sherman (2001), 'Elements of a Lay Theory of Groups: Types of Groups, Relational Styles and the Perception of Group Entativity,' Personality and Social Psychology Review, No. 5, pg. 131. 
Again, this can be measured from the perspective of in-group and outgroup members, and the state as well;

6) In-Group Favouritism/Out-Group Hostility - focuses primarily on this issue, the degree to which "groupness" leads to in-group favouritism and out-group hostility;

7) Claims - the claims that membership in an identity group makes on an individual and the right to hold opinions different from the group on matters of fundamental interest to the group, or what claims are made in terms of sacrifice of one's economic or other interests;

8) Goals/Purposes - the primary goals/purposes of the group. (For instance, does an ethnic identity imply a belief in sovereignty or other less demanding forms of recognition?)

Any evaluation of integration processes is also seriously hindered by the multidimensional nature of the whole concept of integration - it can be interpreted in various ways. Conclusions in research are substantially affected not just by the indicators and methodologies selected, but also by the fact that the collected data offer vast opportunities for interpretation. Accordingly, there will be separate analysis of different aspects of collective identities and how these are formed.

\section{An Evaluation of Integration Policy and Interethnic Relations}

Ever since the late 1980s, researchers in Latvia and elsewhere in the world have been concerned about the prospects for ethnic relations in the country. It should be remembered that the proportion of minority residents in Latvia was higher than in Lithuania and Estonia. Toward the end of the Soviet period, there were more non-Latvians than Latvians in five of Latvia's largest cities (just $36 \%$ of the residents of Riga were Latvians). Most foreign experts, including those who wrote about "ethnic conflict," had to acknowledge, however, that most people in Latvia are seldom involved in conflicts on an everyday basis, and ethnic differences have little effect on changes in the structure of population and employment (see Mihails Hazans' chapter above). Internal migration is not dictated by ethnic factors, there is no ethnic segregation in terms of neighbourhoods, and ethnic under-representation has been seen primarily in the civil service, where most employees are Latvians. ${ }^{13}$ Research on the proportion of minorities in the labour market does not point to widespread discrimination

${ }^{13}$ See Artis Pabriks (2002), Etniskās proporcijas, nodarbinātība un diskriminācija Latvijā. Riga: Providus. 
or ethnic segregation. Indeed, most companies are multi-ethnic in nature. ${ }^{14}$ When it comes to the lack of ethnic parity in the national civil service, the main explanations have been the weak participation of minorities in the restoration of the state, the ongoing lack of Latvian language skills among minorities, a lack of citizenship, scepticism about the work of government institutions, and low wages in the state sector (see also the chapter by Ilze Brands Kehris above). ${ }^{15}$

It is also true that major political protests in recent years have not been ethnically based. Latvians and non-Latvians have taken part in these. The comparatively low number of everyday conflicts that are based on ethnicity, however, is seen as a necessary, but insufficient prerequisite for social integration. In a survey conducted in March 2006, ${ }^{16}$ only 9\% of respondents agreed with the statement that "all in all, society can be considered to be consolidated and integrated," while $65 \%$ disagreed with the statement. A comparatively high percentage of respondents $(27 \%)$ were undecided on the matter. Data from the study entitled Integration Practice and Perspectives illustrate how difficult it is to evaluate processes of integration. The taxonomy of the acculturation strategies used by the researchers is based on two dimensions - identification with an ethnic group (ethnic identity), and subjective identification with a state (civic identity). If respondents accept both identities, then there is reason to talk about integration, but if they reject both identities, then one can speak of marginalization. If one of the identities dominates over the other, then there is reason to think about assimilation and strategies of separation. ${ }^{17}$ One of the possible strategies to be identified in the research was fusion, which leads to the emergence of an entirely new identity.

$80 \%$ of Latvians, $83 \%$ of Russians and $81 \%$ of people of other nationalities expressed support for the strategy of integration in this study. ${ }^{18}$ Latvians and Russians had different views of the strategy of separation in which individuals attach a great deal of importance to the preservation of their culture, but avoid contacts with members of other ethnic groups and feel no sense of belonging to Latvia. $9 \%$ of Latvians and $27 \%$ of Russians supported this strategy. The researchers found that young people were more likely to support the strategy of separation than were older respondents. ${ }^{19}$

${ }^{14}$ Baltic Institute of Social Sciences, Latvian Academy of Sciences, Institute of Economics (2004), Society Integration and Business: The Ethnic Dimension. Riga: BISS, LAS IE, pg. 81, available at http://www.bszi.lv/downloads/resources/ekonIntegr/Ekon_integr_EN.pdf.

15 Pabriks, Etniskās proporcijas, nodarbinātība un diskriminācija Latvijā.

${ }^{16}$ SKDS (2006), 'Sabiedrības integrācijas aktuālākie aspekti,' Riga: SKDS, pg. 36.

${ }_{17}$ Zepa (ed.) (2006), Integrācijas prakse un perspektīvas, pg. 36.

${ }^{18}$ Respondents were asked to read five stories which were based on five different types of acculturation strategies - assimilation, integration, separation, marginalisation, and fusion. Then they were asked to rate each story on a five-point scale, with 1 meaning no support at all, and 5 meaning full support. Ibid., pg. 19.

19 Ibid., pg. 20. 
Non-Latvian respondents were far less likely to identify themselves with the integration strategy (65\% said that they "largely" or "completely" corresponded to that type of person). ${ }^{20} 20 \%$ of respondents identified with the strategy of separation, $9 \%$ with the strategy of marginalisation, and 30\% with the strategy of fusion. Respondents were asked to evaluate each strategy separately, and the data show that most non-Latvian respondents identified themselves with several models, sometimes ones which excluded one another entirely.

When we look at how many non-Latvians chose one of the proposed strategies, we can conclude that there is no single strategy for acculturation in Latvia. Instead, all five strategies of acculturation are represented to a more or less similar degree. It is also true that the answers given by Latvian and Russian respondents differed quite substantially. ${ }^{21}$ Latvians, on average, believed that $25.5 \%$ of non-Latvians would choose the strategy of integration, while non-Latvians felt that there would be more people who would do that (38\% of Russians and $34 \%$ of members of other ethnic groups, on average). The spread of the strategy of separation, by contrast, was quite similar (36\% among Latvians, 33\% among Russians).

We may ask which of these indicators best characterizes the integration process - the fact that more than $80 \%$ of non-Latvians support this model, that $65 \%$ of non-Latvians identify themselves with it, or that there is a considerably lower public assessment of the spread of this model of behaviour (25-38\%). If we analyse answers given by those people who support the integration model, we find that approximately one-quarter say that for the most part, they do not particularly feel any sense of belonging to Latvia's society. Nearly one-third says that their Latvian language skills are quite poor (the choices included the statements "I speak no Latvian or very little Latvian" and "I speak a bit, and I can converse only about simple issues"). Asked about the language which they speak in contacts with friends and acquaintances, nearly one-half of respondents chose the response "Nearly always in Russian." Even when it comes to government institutions, some $20 \%$ of people in this group mostly speak Russian, at least as far as they themselves have reported. Nearly $20 \%$ only watch television channels from Russia (more than 60\% said "mostly Russian TV"). Some not only have not become Latvian citizens themselves, but they also don't want their children to become Latvian citizens. In the group of respondents who identified themselves with the strategy of separation or marginalization, all of these indicators of social integration were even less favourable.

At the same time, researchers found that approximately one-half of respondents in Latvia say that everyday relations with people of other nationalities are "good". Approximately one-fourth said that they are very good, and one-fifth said that they are "satisfactory." Only 5\% of respondents said that relations are

\footnotetext{
20 Ibid., pg. 34.

21 Ibid., pg. 35.
} 
bad or very bad. ${ }^{22}$ Similar data have been found in other studies. One that was conducted by the Baltic Institute of Social Sciences ${ }^{23}$ asked respondents to rate their relations with others on a ten-point scale, with 1 referring to hostile relations, and 10 referring to excellent ones. Ethnic Latvians rated their relations with non-Latvians at a level of 7.8, while non-Latvians rated their relations with ethnic Latvians at a level of 8.4. In other words, people believe that they are friendly with others.

People were also asked to answer this question: "What keeps you from feeling patriotic and proud about Latvia?" Ethnic relations were not mentioned often as a reason ( $6 \%$ of Latvians and $10 \%$ of Russians). For the purpose of comparison, we can note that the system of governance was rated far more critically (37\% and 33\%).

If we compare these data to data from the late $1990 \mathrm{~s}$, then we see that there has been a substantial increase in the number of respondents who say that interethnic relations are good (two-thirds say that they are "satisfactory", while one-fifth said that they are "good"). ${ }^{24}$ Back then there were quite a few respondents who felt that there was a threat of interethnic conflict. Approximately one-third of Russian-speaking respondents denied that this was so, but more than one-fifth of respondents in that group said that there could "definitely" or "possibly" be such conflicts. ${ }^{25}$

The study Ethnic Tolerance and the Integration of Latvia's Society used five indexes to describe ethnic identities and evaluations thereof (ethnic separation, positive social identities, dogmatism, contacts, social distance). ${ }^{26}$ The index of ethnic separation shows that Latvians are more likely than non-Latvians to be ethnically cautious to the point of separating themselves from other ethnic groups. Latvians are also less likely to have a positive social identity in terms of wanting to emphasize and maintain that identity. Most respondents in Latvia claim to enjoy contacts with people from other ethnic groups (81\% of Latvians, $87 \%$ of non-Latvians). ${ }^{27}$ The dogmatism index shows that many Latvians and non-Latvians (around $25 \%$ in each case) tend to see the world in black-andwhite terms; these are people who believe in a single truth. ${ }^{28}$ Ethnic stereotypes

${ }^{22}$ AC Konsultācijas (2008), 'Kvantitatīivais un kvalitatīvais pētījums par sabiedrības integrācijas un pilsonības aktuāliem aspektiem,' pg. 28.

${ }^{23}$ Brigita Zepa (ed.) (2004), Etniskā tolerance un Latvijas sabiedrības integrācija. Riga: BISS, pg. 76.

${ }^{24}$ Baltijas datu nams (1998), 'Cẹ̦ā uz pilsonisku sabiedrību,' Riga: Baltijas datu nams, pg. 129.

25 Centre for the Study of Public Policy (1997), New Baltic Barometer III, Studies in Public Policy, No. 284, Glasgow: University of Strathclyde, pg. 34.

${ }^{26}$ Zepa (ed.) (2004), Etniskā tolerance un Latvijas sabiedrības integrācija, pg. 48.

${ }^{27}$ Ibid., pg. 61.

${ }^{28}$ Ibid., pg. 78. 
are more common among Latvian respondents, but both they and non-Latvians believe that one group wants to force others to accept its views. ${ }^{29}$

The fact that ethnic stereotypes are more common among Latvians was seen in a study that was conducted in the early 1990s - The Formation of New Political Systems and the Question of Democratic Stability: The Case of Latvia (1993). ${ }^{30}$ Researchers believe, however, that the ethnic distance between the two communities is not great, which is seen in data about mixed marriages, experience with interethnic conflicts, as well as in ethnic stereotypes. ${ }^{31}$ The fact that interethnic relations have not deteriorated during this period is best seen in dynamics related to the number of mixed marriages (unlike the evaluations or self-evaluations presented by respondents in sociological surveys, this is an indicator that cannot be falsified). At the beginning of the 1990s, approximately $18 \%$ of Latvian men were marrying non-Latvian women, and a slightly higher percentage of Latvian women were marrying non-Latvian men. In 2008, the proportion of such marriages was $19.8 \%$ among Latvian men, and $20 \%$ among Latvian women. ${ }^{32}$ Survey data show that Latvians are less likely to accept close relationships with Russians than the other way around, ${ }^{33}$ but at the same time, two-thirds of Latvian respondents $(66 \%)$ say that they would accept the marriage of their son or daughter to a Russian. ${ }^{34}$

These data show, all in all, that the support of non-Latvians for integration strategies is higher in the public arena than is the preparedness of respondents to identify themselves with such practices, let alone pursuing them in real life. The identification criteria of non-Latvians have not become stabilized. Ethnic relations have improved a bit over the last decade, but the process is hindered by the fact that many people distance themselves from members of other ethnic groups and are prejudiced against them. Moreover, this is more often true among Latvians than among others.

\section{Ethnic Identity and Linguistic Integration}

The Latvian and Russian languages are of decisive importance in the process of establishing collective identities, as this is the main criterion in marking out the boundaries between ethnic and linguistic groups. Competition between languages increases the sense of endangerment in the two groups. That is exactly why there are harsh discussions about the use of the two languages, with

\footnotetext{
29 Ibid., pg. 72.

30 G. Ozolzīle, T. Tisenkopfs, A. Tabuns, J. Broks and J. Ozolins (1993), The Formation of New Political Systems and the Question of Democratic Stability: the Case of Latvia. Riga: Baltic Studies Centre.

31 Ibid., pg. 28.

${ }^{32}$ Data from the Central Statistical Board, http://www.csb.gov.lv.

33 Zepa (ed.) (2004), Etniskā tolerance un Latvijas sabiedrības integrācija.

34 Ibid., pg. 66.
} 
a more active ethnic discourse in the media. This refers to issues such as the State Language Law and reforms in the minority education system. ${ }^{35}$ Latvians have extensive expectations vis-à-vis non-Latvians in the country - they must accept the Latvian language and culture, and they must dissociate themselves from the Russian cultural heritage. At the same time, however, "the strategy of assimilation seems exaggerated and unbelievable for respondents in the Latvian context, because the Russian community in Latvia is very large, and to a great degree it is self-sufficient. ${ }^{36}$ Because the spread of ethnic fears has an effect on the understanding of group identities, ${ }^{37}$ politicians use linguistic fears to polarize society and increase distrust and suspicions. ${ }^{38}$

Ilga Apine and Vladislavs Volkovs have argued that

Many Russians in Latvia link their identity to the preservation of the social functions of the Russian language in civil society. The strengthening of the collective identity of Russian residents of Latvia cannot be described unambiguously. Of importance in the collective linguistic identity of the Russian minority is a shift in the value orientations of Russians from the Soviet (imperial) identity to the identity of a national minority. The collective identity of Russians who do not have close links to the civic identity which exists in Latvia can also be stimulated by negative trends such as self-sufficiency and self-segregation. For a certain part of the Russian minority, the collective linguistic identity has become the only foundation and resource for social self-organization. ${ }^{39}$

Sociologists use different indicators in the attempt to identify the importance of ethnic identity. In the early 1990s, people were asked this question: "How much do you have in common with Russians?" $48 \%$ of non-Latvian respondents gave the answer "a great deal," 29\% gave the response "some," and only $5 \%$ and $2 \%$ respectively answered "not much" or "nothing at all." Asked the same question with reference to Latvians, $13 \%$ and 3\% of non-Latvians chose "not much" or "nothing at all," 24\% said "a great deal," and 40\% gave the answer "some." Of key importance is the fact that a fairly substantial proportion of respondents (16\% in the former case and $19 \%$ in the latter) had no answer to the question. ${ }^{40}$

${ }^{35}$ Zepa (ed.) (2006), Integrācijas prakse un perspektīvas, pg. 29.

${ }^{36}$ Ibid., pp. 47-48.

${ }^{37}$ Leo Dribins (ed.) (2007), Mazākumtautības Latvijā. Vēsture un tagadne. Riga: LU FSI, pg. 134.

${ }^{38}$ Zepa et al. (2005), Etnopolitiskā spriedze Latvijā: Konfliktu risinājumu meklējumi, pg. 6.

39 Ilga Apine and Vladislavs Volkovs (2007), Latvijas krievu identitāte: vēsturisks un sociologisks apcerējums. Riga: LU FSI, pp. 215-216.

${ }^{40}$ Centre for the Study of Public Policy (1994), Nationalities in the Baltic States: A Survey Study, Studies in Public Policy, No. 222. Glasgow: University of Strathclyde, pg. 55. 
The ethnic identity of respondents is also characterized by answers given to this question: "How important in your life is the fact that you are a Latvian/ Russian/member of another ethnic group?" The Baltic Institute of Social Sciences found that Latvians are more likely than non-Latvians to say that this fact is important or very important ( $74 \%$ of Latvians and $51 \%$ of Russians gave that response in a study in 2006). ${ }^{41}$ In 2004, the same answers were given by $53 \%$ of Latvians and $32 \%$ of Russians. ${ }^{42}$

In 2008 respondents were asked this question: "Are you concerned about the possibility that you might lose your ethnic identity?" $71 \%$ of respondents said no, 22\% said yes, and 7\% said that they did not know. ${ }^{43}$ In the 2006 study Integration Practice and Perspectives Latvian respondents were far more likely that Russian respondents to be concerned about threats against the Latvian language and culture (53\% of Latvians and $78 \%$ of Russians said that there are hardly any threats or that it is more likely that there are no threats than that there are threats. ${ }^{44}$ This indicates a fairly high level of a sense of ethnic endangerment in both groups, but the people in each group have different views as to their own endangerment and that of the other group.

The Integration Programme states more than once that the cornerstone of integration is people's readiness to accept the Latvian language as the state language. It also emphasizes the need to strengthen the situation of the Latvian language. ${ }^{45}$ Because linguistic identity is the most important component in the ethnic self-understanding of the Russian minority, ${ }^{46}$ the linguistic aspects of the Integration Programme are perceived by many Russians as potentially being discriminatory, this despite the fact that "the Russian language is almost completely dominant among Russian families and in informal communications. There are Russian language media and educational institutions." ${ }^{47}$

Between 1996 and 2008, 13 surveys of Latvia's residents have been taken to observe the results of the country's language policies, changes in language skills, the extent to which Latvian is spoken, as well as attitudes toward that language. The results have shown the consequences of language policy. The level of language skills and speaking habits have changed rather slowly over the course of time, although the Latvian language skills of non-Latvians have improved considerably. The segment of the population which speaks no Latvian at all diminished from 22\% in 1996 to just 7\% in 2008, and the use of the language in various areas of life is on the rise, particularly in the public

${ }^{41}$ Zepa (ed.) (2006), Integrācijas prakse un perspektīvas.

42 Etnopolitiskā spriedze, pg. 30.

43 AC Konsultācijas (2008), 'Kvantitatīvais un kvalitatīvais pētījums,' pg. 29.

44 Zepa (ed.) (2006), Integrācijas prakse un perspektīvas, pp. 76-77.

45 Ministry of Justice (2001), 'National Programme on the Integration of Society in Latvia,' pp. 7 and 63 .

46 Apine and Volkovs (2007), Latvijas krievu identitāte, pg. 215.

47 Ibid. 
arena. Speaking the Latvian language is promoted by the formal language environment, as well as the language law, which particularly applies to public situations. The decline in the self-sufficiency of minority languages can be seen as significant proof of the consolidation of the majority language's status. Respondents increasingly feel that it is necessary to have a command of both the Russian and the Latvian language. ${ }^{48}$

Data from the study called Integration Practice and Perspectives however, show that Russian respondents mostly speak Russian on the street, at shops and at work (more than two-thirds of respondents said that they mostly or exclusively speak Russian in such situations or that they speak Russian more than they speak Latvian). In government institutions, too, Russian respondents are more likely to speak Russian. Approximately one-quarter of Russian respondents "mostly or only watch Russian television channels," more than half watch Russian channels more often than Latvian ones, and fewer than one-fifth watch Latvian channels more than Russian ones.

The linguistic situation for other minority groups in Latvia is considerably worse, because it is harder for children to get an education in their native language (there were 1,432 students in non-Russian minority schools in the $2007 / 2008$ school year, and the language of teaching at most of those schools was Latvian and/or Russian anyway). ${ }^{49}$ There are also fewer mass media resources for other minority languages, and the same is true with respect to cultural products such as books, recordings of music, films and theatrical performances. Most Russian respondents agreed with the statement that "Russians must understand that the Latvian language is the state language in Latvia, and so if one wants to live in Latvia, one must learn the language" (the statement was supported by $94 \%$ of all residents and $86 \%$ of Russians, with $50 \%$ saying that they completely agree with it; $11 \%$ of Russians and $5 \%$ of people of other nationalities disagreed with the statement. ${ }^{50}$ Despite this fact, researchers found in 2005 that "communications between a Latvian and someone of another nationality are usually based on Russian, because the level of Latvian language skills among Russians and representatives of other ethnic groups tends to be far lower than the level of Russian language skills among Latvians." ${ }^{51}$ Asked about their Latvian language skills, $9 \%$ of Russian respondents said that they speak no Latvian or hardly any Latvian, while $26 \%$ said that they are only able to discuss simple issues in Latvian. ${ }^{52}$ At the same time, some of the Russian respondents

${ }^{48}$ Baltic Institute of Social Sciences (2008), Language. Riga: BISS, pp. 5-7.

${ }^{49}$ Classes are taught in Polish at five schools, in Ukrainian at one school, and in Belarusian at one school. There is one Estonian and one Lithuanian school at which some subjects are taught in the minority language. Two schools teach the Romani language as a separate subject. http://www.am.gov.lv/lv/latvia/integracija/mazakumtautibu-izglitiba/?print=on.

${ }^{50}$ Zepa (ed.) (2006), Integrācijas prakse un perspektīvas, pg. 79.

${ }^{51}$ Etnopolitiskā spriedze, pg. 30.

${ }^{52}$ Unpublished data from Zepa (ed.) (2006), Integrācijas prakse un perspektīvas. 
who said that they have a complete command of the Latvian language nevertheless admitted that on the street, in shops and at government institutions, they mostly speak Russian (around 10\% of Russian respondents said so). ${ }^{53}$

Generally speaking, the conclusion here is that the integration-based principle of allowing ethnic groups to maintain and develop their ethnic identities and to speak their native language is not being violated. At the same time, the Integration Programme states that "the integration of society in many ways depends on the ability of Latvia's minorities to develop, which refers not only to the right to preserve their ethnic identity, but also to the need to accept the Latvian language as the only state language, to learn the language, and to speak it in public situations." The latter part of this statement remains a problem. In 2008 approximately one-third of respondents considered the language barrier as something which divides society (only social and material stratification were mentioned more often in this regard). ${ }^{54}$

\section{National Identity}

The protection and maintenance of ethnic identities can be a necessary prerequisite for political stability and a reduction in the level of ethnic fears. That alone, however, is not enough to ensure no confrontations in a civil society in which ethnic corporativism doesn't dominate over the long-term interests of the public at large. Societies in which ethnic groups have different ideas about the fundamental principles of national identity are often subject to political crisis. They find it hard to find solutions to economic and political crises, because the initial ideas of ethnic groups about politics, the state and its relationship with the citizenry have not been harmonized on the basis of fundamental principles.

In a study that was called Shifting Identities: Mobilization of Ethnic Groups and the Effects of Changes in the Ethnic Structure of Society on Social Integration, researchers found that the consolidation and mobilization of ethnic groups such as Russians, Belarusians, Ukrainians, Poles, Lithuanians and Jews in pursuit of their ethnicity and of a strengthening in their ethnic identity are often not balanced out with the emergence of a civic identity and support for processes of integration. ${ }^{55}$

National identity can be analysed in many different ways, but researchers often study the "proximity" of respondents to the state (including geopolitical identity), national pride, and support for the basic political positions of the

${ }^{33}$ Ibid.

${ }^{54}$ AC Konsultācijas (2008), 'Kvantitatīvais un kvalitatīvais pētījums,' pg. 30.

${ }^{55}$ Elmārs Vēbers (2004), Main̄̄gās identitātes: etnisko grupu mobilizēšanas un sabiedrības etniskas struktūras izmainu ietekme uz sabiedrības integrāciju. Riga: University of Latvia. See http://www.politika.lv/print.php?id-3995. 
state. ${ }^{56}$ In many studies conducted in Latvia, respondents have been asked how closely they feel they are related to their country, city, region or Europe. ${ }^{57}$ The word "closeness" in English is synonymous to "proximity", which comes from the Latin and refers to that which is closest and most tightly bound. ${ }^{58}$ In this chapter, a high level of territorial proximity refers to a specific environment which respondents consider to be important and comfortable. ${ }^{59}$ Several studies in Latvia have shown that indicators related to national proximity have remained more or less stable, with a slight decline in some cases. The difference between evaluations given by Latvians and by Russians has not changed to any statistical degree between 1995 and 2008.

\section{Table 1. Proximity to the state}

(Average arithmetic indicator: 1 = "very close links", $0=$ "no links at all")

\begin{tabular}{|c|c|c|c|}
\hline Proximity to the state & $\mathbf{2 0 0 8}^{* *}$ & $\mathbf{2 0 0 3}^{*}$ & $\mathbf{1 9 9 5}^{*}$ \\
\hline Latvians & 0.75 & 0.76 & 0.80 \\
\hline Russians & 0.68 & 0.61 & 0.73 \\
\hline Arithmetic difference & $\mathbf{0 . 0 8}$ & $\mathbf{0 . 1 5}$ & $\mathbf{0 . 0 7}$ \\
\hline
\end{tabular}

Sources: * International Social Survey Programme data; ** SKDS (2008).

The International Social Survey Programme (ISSP) survey posed two questions to Russian respondents: "How close do you feel to Latvia?", and "How important for being truly Latvian is it to respect the political institutions and laws?" The data show that there are correlations among these variables. $16 \%$ of Russians who think that they are closely linked to Latvia also feel that this does not mean that they have to respect the government and the country's laws. Younger Russian respondents (29 and under) were less likely than older respondents to say that the government and the law must be respected. ${ }^{60}$

There was also an analysis of the correlation between these two questions: "How close do you feel to Latvia?" and "Would I rather be a citizen of Latvia

${ }^{56}$ R. Sinnott (2005), 'An Evaluation of the Measurement of National, Sub-National and Supranational Identity in Major Cross-National Surveys,' Geary Discussion Paper Series, February 2005, pg. 34. See http://www.ucd.ie/geary/publications/2005/GearyWp200502. pdf. See also A. Rawi, Y. M. Herrera, A. I. Johnston and R. Mcdermott (2005), "Identity as a Variable," available at www.wcfia.harvard.edu/misc/initiative/identity/publications/ ID050722.pdf.

${ }^{57}$ In a study conducted by the International Social Survey Programme, the concept of "feel close to..." must be interpreted as "emotionally attached to" or "identifying with."

${ }^{58}$ The concept of proximity is used by social psychologists and anthropologists in terms of concepts such as "social proximity" and "cultural proximity." The first to make widespread use of the term was Edward T. Hall (2006), The Hidden Dimension. Garden City, N.Y.: Doubleday.

59 Territorial proximity is usually evaluated on a scale, with 1 referring to "very close links" and 0 referring to "no links at all."

${ }^{60}$ Aivars Tabuns, (2007), 'Nacionālā identitāte un integrācija.' In Aivars Tabuns, ed., Droš̃̄ un tiesiskums Latvijā. Riga: University of Latvia Institute of Philosophy and Sociology, pg. 116. 
than of any other country in the world?" The data show correlation between these two variables, but $29 \%$ of Russians who feel closely linked to Latvia would prefer to be another country's citizens. At the same time, Latvian citizenship is attractive for $11 \%$ of Russians who do not feel close to Latvia. ${ }^{61}$

The geopolitical identities of non-Latvians are characterised quite well by data from other studies, including We, Celebrations, The State: A Sociological Study of How National Holidays are Celebrated. In it, researchers found that $20 \%$ of non-Latvians respondents feel linked or closely linked to Europe, $31 \%$ to Russia, and $78 \%$ to Latvia. ${ }^{62}$ In another study, the question was a bit different: "How close do you personally feel to Russia?", with 44\% of Russian respondents saying "close" or "very close", while 39\% don't feel very close, and $16 \%$ don't feel close to Russia at all. ${ }^{63}$

It is of key importance here that non-Latvian schoolchildren are more likely than respondents from other age groups to indicate closer links to Europe and Russia (39\% and 45\% respectively), with weaker links to Latvia (52\%). ${ }^{64}$ In another study, The Emergence of Identity and the Participation of Young People, students from the $9^{\text {th }}$ and $11^{\text {th }}$ grade and from the second year of professional trade schools were surveyed $(\mathrm{n}=3,046) .64 \%$ of the Russian respondents in that study said that they felt linked or closely linked to Russia, while only $31 \%$ said the same about Latvia. ${ }^{65}$

When asked about their sense of belonging in different social groups, young people again revealed their sense of identity. $63 \%$ of Russian respondents felt very close or closer to a certain extent to Russians in Latvia, while only $14 \%$ felt close to Latvia's Latvians. Similar responses came from Latvians - the sense of belonging with Latvians was declared by $61 \%$, while only $21 \%$ said the same about Latvia's Russian residents. Most non-Latvian young people (54\%) said that they belong in the Russian community of Latvia, as opposed to belonging among Latvia's Latvians $(28 \%){ }^{66}$

The ISSP study showed that Russian respondents who were asked about Latvia's national achievements in 2003 thought less about them then than was the case in 1995. In 2003, Russians had a more positive view only of Latvia's achievements in sports. The attitude of these respondents did not change in relation to Latvia's economic achievements or the country's social security system. There is less pride now in the armed forces, democracy, scientific achievements, accomplishments in the arts and literature, the country's political influence in

61 Ibid.

62 Brigita Zepa (ed.) (2008), Mēs. Svētki. Valsts. Valsts svētku svinēšanas socioloǵiska izpēte. Riga: Baltic Institute of Social Sciences, pg. 73.

${ }_{63}$ Zepa (ed.) (2006), Integrācijas prakse un perspektīvas, pg. 73.

64 Ibid., pg. 99.

${ }_{65}$ Ritma Rungule (ed.) (2005), Jauniešu identitātes veidošanās un līdzdalība. Pētījuma pārskats. Riga: LU FSI, pg. 70.

66 Ibid., pg. 72. 
the world, and the idea of a just and equal attitude toward all social groups in society. Russian respondents have particularly lost a sense of pride about Latvia's history. ${ }^{67}$

Similar data were received in a 2008 study. Russian respondents were most often proud of Latvia's environment and the country's achievements in sports. The greatest difference between Russian and Latvian respondents in this regard relates to the country's cultural heritage and folk songs (67\% of Latvians and $39 \%$ of Russian respondents felt proud about these), to achievements in art and culture (44\% and 26\%), and accomplishments in science and technology (35\% and 18$) .11 \%$ of Russian and $3 \%$ of Latvian respondents say that they are not proud about anything.

In $2008,77 \%$ of Latvians and $50 \%$ of Russians fully or mostly agreed with the statement "I am a patriot of Latvia." $36 \%$ of Russians disagreed, and 14\% did not answer. When asked "Which is the country with respect to which you feel patriotic?", 29\% of Russian respondents cited Russia, 19\% said that they don't feel patriotic about any country, and 6\% did not answer. It is necessary to emphasize here that the two answers are not mutually exclusive - in an SKDS study, $61 \%$ of those who feel that they are patriots of Russia do not feel that they are patriots of Latvia, but 39\% do. Among those Russian respondents who do not feel that they are patriots of Russia, a greater percentage believe that they are patriots of Latvia (61\%).

In comparison to an ISSP study in 1995, Russian respondents in a 2003 study run by SKDS were less likely to agree with the statement that "there are things in Latvia today which make me feel ashamed about Latvia." The thinking of Russian respondents is also seen in attitudes toward the statement that "I would rather be a citizen of Latvia than of any other country in the world." In 2003 , only $25 \%$ of Russian non-citizens preferred Latvian citizenship to that of any other country, while in 2008 , the answer came from $39 \%$ of respondents who were not Latvian citizens (36\% would choose another country's citizenship, while $25 \%$ did not answer. On the other hand, only $33 \%$ of Russian citizens in 2003 thought that it was better to have Latvian citizenship than to have any other, but in 2008, fewer thought so - 20\% disagreed, and $31 \%$ did not answer (SKDS). These changes indicate an increasing level of nationalism in the views which Russians have about Latvia.

These data show that the people of Latvia have a great many fragmented and often contradictory identities. A low level of proximity to the state, disrespect for Latvia's government and laws, and no desire to obtain Latvian citizenship - all of these phenomena are linked. Many citizens feel no ties with Latvia and would prefer to be some other country's citizen. These are people whose thinking and lifestyle are not oriented toward a territorial community or its needs and values.

${ }^{67}$ Tabuns (2007), 'Nacionālā identitāte un integrācija,' pg. 110. 
Weakly expressed proximity to the state does not encourage the emergence of a national identity. A deficit in roots, a sense of instability, a sense of insecurity, and contradictory identities - all of these provoke disloyalty and damage social contacts among people. The situation in Latvia is considerably more complicated than is the case in other countries, although ISSP data show that analogous problems are also faced by Israel and Russia.

Table 2. Proximity to the state

\begin{tabular}{|c|c|c|c|c|}
\hline & \multicolumn{4}{|c|}{ How close do you feel to the state? } \\
\hline Cohort of respondents & Very close & Close & Not too close & $\begin{array}{c}\text { Not close } \\
\text { at all }\end{array}$ \\
\hline Jews in Israel (1,061) & $80 \%$ & $14 \%$ & $4 \%$ & $2 \%$ \\
\hline Latvians in Latvia (592) & $36 \%$ & $49.5 \%$ & $12.5 \%$ & $2 \%$ \\
\hline Russians in Russia (2,266) & $26 \%$ & $41 \%$ & $23 \%$ & $10 \%$ \\
\hline Russians in Latvia (305) & $13 \%$ & $55 \%$ & $27 \%$ & $5 \%$ \\
\hline $\begin{array}{c}\text { Average among 35 countries } \\
(43,285)\end{array}$ & $48 \%$ & $40 \%$ & $9 \%$ & $2 \%$ \\
\hline
\end{tabular}

Source: ISSP, 2003.

A 2008 SKDS study posed the question a bit differently - "To what extent to you feel a sense of belonging in Latvia?", with $1=$ "not at all" and 5 = "very much." $64 \%$ of Russian respondents chose 5 or 4 . Many studies show that substantial numbers of non-citizens have no plans to seek citizenship in Latvia (51\% of them said so in the study Integration Practice and Perspectives, with $15 \%$ saying that they also don't want their children to become citizens of Latvia).

Another question was this: "If Latvia's independence were threatened, would you be prepared to defend it?" $68 \%$ of Latvians, $38 \%$ of Russians, and $52 \%$ of people from other ethnic groups said "yes." $8 \%$ of Latvians, $23 \%$ of Russians, and $18 \%$ of people from other ethnic groups said "no." The remaining couldn't say. ${ }^{68}$ In another SKDS survey, respondents were asked whether they would take up arms in defence of Latvia during an armed conflict. Among men aged 45 and younger, $69 \%$ of Latvians and 33\% of Russians said that they probably or certainly would, while $39 \%$ of Russians said that they probably or certainly would not ( $28 \%$ did not answer the question). Russian respondents who were citizens were more likely than those who were non-citizens to say that they would defend Latvia, but in the latter group, too, $35 \%$ did not answer, and $23 \%$ said that they would not do so.

In December 2005, the DATA Serviss research firm conducted a survey in which it found that $33 \%$ of non-Latvian and $70 \%$ of Latvian respondents thought positively about Latvia's accession to NATO. ${ }^{69}$ Similar results were found in another study - The Emergence of the Civil Society in Latvia's Largest Cities

${ }^{68}$ AC Konsultācijas (2008), Kvantitatīvais un kvalitatīvais pētījums, pg. 40.

69 Ibid. 
and the Most Ethnically Heterogeneous Regions of Latvia. ${ }^{70} 700$ respondents, half of them citizens and half of them non-citizens, were surveyed in Latvia's larger cities and ethnically heterogeneous regions. Nearly twice as many Russian respondents said that they trust the Commonwealth of Independent States (CIS) than those who said that they trust NATO (41\% and $22 \%$ respectively).

I have argued that

All in all, it can generally be said that many non-Latvians still identify themselves with Russia, and so they are not satisfied with the government's pro-Western policies. Latvians, for their part, think that such non-Latvians are disloyal toward the state. Differences in the geopolitical values of the two groups do not help in facilitating political integration in Latvia. The fact is, however, that non-Latvians have relatively few opportunities to change Latvia's foreign policy, and so the political differences of opinion between the two groups are primarily of a latent nature..$^{71}$

One element in national identity is a unified perception of political history. Latvia's Integration Programme states that

It is important to establish an objective understanding of the past in order to reach agreement about Latvia's future. Of particular importance is the history of Latvia's period of independence, along with the causes which led the independent republic to be occupied and violently incorporated into the USSR in 1940. The people of Latvia did not voluntarily choose the Soviet system or lives in a totalitarian system. Of fundamental importance is a unified position vis-à-vis the unlawfulness of the Soviet regime - deportations and all manner of other repressions against the Latvian people, nationalization of private property, forced collectivization and industrialization, and demographic policies. Denunciation of this must be based on an in-depth and objective understanding of historical events if different ethnic communities - and younger generations in particular - are not to find that historical understandings are an obstacle against integration processes. ${ }^{72}$

Historical memories are seen as a factor which splits society by nearly onethird of respondents (less often mentioned phenomena included the mass media, foreign propaganda, and the interpretation of citizenship issues, while phenomena that were mentioned more often included social and material stratification,

70 Ibid.

71 Aivars Tabuns (2006), 'Attitudes Toward the State and Latvian Foreign Policy.' In Nils Muižnieks, ed., Latvian-Russian Relations: Domestic and International Dimensions. Riga: University of Latvia Press, pg. 32.

72 Ministry of Justice (2001), 'National Programme on the Integration of Society in Latvia,' pg. 9. 
as well as the language barrier). ${ }^{73}$ Data from several other surveys indicate the same. A study of history teachers and high school students, for instance, found that most students at schools where classes are taught in Russian do not believe that Latvia was reoccupied in $1945 .^{74}$

Students from Latvian and Russian language schools have different views about the Soviet period (1994-1990). This period of history was rated positively or mostly positively by $63 \%$ of respondents from schools where classes are taught in Russian (only 6\% rated it mostly or totally negatively). At schools where classes are taught in Latvian, the responses were quite the opposite - 9\% and $62 \%$ respectively. ${ }^{75}$ Asked whether knowledge about Latvian history is a factor in the shaping of civic identity, $35 \%$ of Russian students and $56 \%$ of Latvian students replied in the affirmative. ${ }^{76}$

The We, Celebrations, The State: A Sociological Study of How National Holidays are Celebrated study found that $66 \%$ of Latvians and $46 \%$ of nonLatvians take part in celebrations of Latvia's Independence Day, November 18. $65 \%$ of Latvians said that the holiday is very important or mostly important to them, while the same was said by only $35 \%$ of non-Latvian respondents. ${ }^{77}$ $91 \%$ of those who said that the holiday is important did things to celebrate it, which was also true among $18 \%$ of those who find the holiday to be "completely unimportant." Latvians celebrate the holiday at home and at public events, while non-Latvians mostly celebrate it at public events alone. ${ }^{78}$

The authors of the same study also found that the Latvian language press publishes much more information about the national holiday. In Russian language newspapers, there are usually just brief snippets of information about events that have already happened. The authors of the study report that "planned events are described in a highly alienated way, as if the discussion were about some other country. Nothing is said about the participation of local residents in the celebrations. (..) Russian language newspapers have far more information about negative phenomena related to the holiday." The authors also found that Internet portals which are presented in the Latvian and the Russian language mostly rely on information from the LETA news agency, but Russian language portals are far more laconic about the events, or they do not reflect them at all. ${ }^{79}$

${ }^{73}$ AC Konsultācijas (2008), 'Kvantitatīvais un kvalitatīvais pētījums,' pg. 30.

${ }^{74}$ Leo Dribins (2008), 'Latvijas vēstures faktors sabiedrības integrācijas procesā.' In Ilga Apine et al. Pretestība sabiedrības integrācijai: cēloṇi un pārvarēšanas iespējas. Riga: LU FSI, pp. 12-13.

75 Viktors Makarovs and Ilze Boldāne (2008), '20. gadsimta vēstures pretrunīgo jautājumu pasniegšana Latvijas skolās un muzejos.’ Riga: SFL, pp. 12-13.

${ }^{76}$ Ibid., pg. 76.

${ }^{77}$ Zepa (ed.) (2008), Mēs. Svētki. Valsts, pg. 72.

${ }^{78}$ Ibid., pg. 88.

79 Ibid., pg. 17. 
Leo Dribins has argued that in Latvia, "the influence of totalitarian ideology has not been overcome when it comes to the elements of people's memories." At the same time, however, $60 \%$ of Russian and $48 \%$ of Latvian respondents fully or partly agree with the statement that "it would be better if there was less talk in Latvia about historical issues with respect to which unified views do not exist in society" (Unpublished data from SKDS). This brings up a question: Why are discussions about history so important to people, and what makes that so? Participants in discussions most often are motivated not only by the desire to establish positive ideas about their ethnic group and its contribution to Latvia's economic and social development, but also by the readiness to emphasize the losses which have been caused to the group by various political regimes and to claim that the group has exclusive political rights. Some respondents dispute the legitimacy of the country's independence and deny that there can be ethnic coexistence in Latvia without any conflicts at all. Also of great importance is the fact that many Latvians take an uncritical approach to various aspects of history, while the understanding of history among non-Latvians is substantially affected by the mass media in Russia. These try to present Latvians as people who support fascist ideology and have a fascist understanding of history (it is important that Russian propaganda still replaces the concept of National Socialism with the concept of fascism when discussing Latvia). Because the ideas of many non-Latvians in Latvia are based on the influence of the Russian media, it is no surprise that these people ignore the importance of the Molotov-Ribbentrop Pact while, at the same time, approving of Soviet aggression against Latvia as a means for self-defence.

If there can be questions about the precision of data from sociological surveys, then there can be no question about the validity of the results of the 2009 European Parliament Election. In Latvia's voting system, people cast ballots for a certain party, but they can either place a plus mark next to an individual candidate's name or cross out that name to signify favour or disfavour - these are taken into account when determining which candidates from a list have been elected. In the EP election, former Soviet Latvian Communist Party leader Alfrēds Rubiks from the Concord Centre party got 66,603 pluses and was stricken from the ballot by 8,848 voters. Also on the list was Latvian MP Boriss Cilevičs, who received far fewer pluses - 36,358. Euro-MP Tatjana Ždanoka from For Human Rights in a United Latvia (FHRUL) got 55,759 pluses and was stricken 1,049 times. ${ }^{81} 231,330$ citizens of Latvia voted either for Concord Centre or for FHRUL, and only $4 \%$ or so struck the names of Rubiks and Ždanoka from the ballots. The fact that more than 124,000 voters gave pluses to two people who actively fought against the restoration of Latvia's

${ }^{80}$ Dribins (2008), 'Latvijas vēstures faktors sabiedrības integrācijas procesā,' pg. 61.

${ }^{81}$ Central Statistical Bureau data. See http://www.cvk.lv/cgi-bin/wdbcgiw/base/eiro9. Veles9_REZultati.pers_statist? $\mathrm{sec}=7$. 
independence and gave far fewer pluses to other candidates who did not do so - that is an indicator that cannot be falsified, and it should be important both to researchers and to the Latvian electorate.

It can be concluded from all of this that processes of shaping a national identity must be viewed critically. The people of Latvia have different views about the past, ${ }^{82}$ as well as the present. Different ethnic groups also have different ideas about the country in which they wish to live. The bottom line is that there are substantial differences between the geopolitical identities of the various ethnic groups.

\section{Culture}

The introduction to the section of Integration Programme devoted to culture states that it is necessary to increase the state's care for the preservation, study and development of the cultural heritage of Latvians and the country's minority nationalities, to create conditions for integration in the area of culture, to promote the understanding of the people of Latvia about the cultural values of the Latvian nation and the ethnic groups which reside in the country, to encourage respect and tolerance toward the cultures of other nations, and to encourage all of the people of Latvia to be involved in cultural life. ${ }^{83}$ Even though the programme admits that "the common cultural space has aspects of functioning that are typical of it alone, and information about the system, its structures and changes therein can be obtained by cultural and sociological research," there have been few studies of this particular aspect of integration, and so conclusions must be based on fragmentary data (young people have been studied more often, which makes it possible to understand conditions for changes in social values).

The main areas of cultural policy have included a more precise identification and expansion of cultural rights, improved financing for culture, improvements in the accessibility of culture, increased information about cultural life, and expanded cultural dialogue. I believe that the most appropriate allegory in describing culture is Janus, the Roman god of doorways and time - a symbol of every beginning and every end. Janus is usually portrayed with two faces pointing in opposite directions. The suggestion is that he is simultaneously looking at the future and the past, while his 365 fingers encircle our present. It is important, too, that one of the faces is always that of a youth, while the other is that of an old man. Culture, too, is distinctly dual in nature: it is both open

${ }^{82}$ Aivars Tabuns, 'Comments on David Laitin's Book.' In Changing, Overlapping and Interacting Identities: Acta Universitatis Latviensis, Vol. 680, "Political Science," pp. 179-181.

${ }^{83}$ Ministry of Justice (2001), 'National Programme on the Integration of Society in Latvia,' pg. 68. 
to the future and locked up in the past in a way that limits freedom. Culture can maintain that which is sacred, or it can deny it. ${ }^{84}$

The idea that Russian culture is under threat is often linked to the idea that the everyday use of the Russian language may diminish. Even sociologists often fail to distinguish these phenomena. In the study Integration Practice and Perspectives, respondents were asked whether the existence of the Russian language and culture in Latvia was under threat. $11 \%$ of Russian respondents said that it is in grave danger, $34 \%$ said that it is more threatened than not, $34 \%$ said that it is less threatened, and $17 \%$ said that it is not threatened at all. ${ }^{85}$ At the same time, results from surveys and focus group discussions show that many Russians perceive Latvians to be a "less important" ethnic group, one which does not even have its own culture. ${ }^{86}$ Faced with the statement that "Russian culture is superior to Latvian culture, and so Russians do not have to learn the Latvian language," $16 \%$ of respondents whose native language is not Latvian agreed fully or in part. ${ }^{87}$

The same study also offered two other statements which helped to show the readiness of Latvians and Russians to accept the other culture. One related to the readiness of Latvians to accept multiculturalism: "Latvians must understand and accept the fact that there are different ethnic groups in Latvian society, including Russians, Belarusians, Ukrainians, Roma, Lithuanians, and others." Most residents of Latvia agree ( $85 \%$ of Latvians and even more non-Latvians agree with the statement, while $11 \%$ of Latvians do not). ${ }^{88}$

Culture and traditions as a factor of closeness to Latvia are more important among young Latvians than among young Russians (the idea that they are a factor of closeness was supported by $31 \%$ of Russian and $72 \%$ of Latvian young people). ${ }^{89}$ When asked what makes them feel patriotic and proud about Latvia, $29 \%$ of Latvian and 14\% of Russian respondents said that it is culture (Unpublished data from SKDS). Young Russians are less likely than young Latvians to say that the study and acceptance of Latvian culture is a factor in the shaping of civil identity (31\% and $73 \%$ respectively). ${ }^{90}$ The majority of young Latvians $(48 \%)$ believe that people who do not accept local traditions and habits cannot fully belong to Latvia, while $44 \%$ of young Russians disagree. ${ }^{91}$

${ }^{84}$ Aivars Tabuns (2004), 'Culture and Integration of Society.' In Cultural Dilemmas During Transition: East Central Europe Versus Taiwan. Conference papers. Munster: National Science Council of Taiwan and LIT Verlag, pp. 268-269.

${ }^{85}$ Zepa (ed.) (2006), Integrācijas prakse un perspektīivas, pg. 76.

${ }^{86}$ Ibid., pg. 78.

${ }^{87}$ Ibid., pg. 79.

${ }^{88}$ Ibid.

${ }^{89}$ Rungule (ed.) (2005), Jauniešu identitātes veidošanās un lìdzdalība, pg. 75.

${ }^{90}$ Ibid., pg. 76.

${ }_{91}$ Ibid. 
The sense of ethnic belonging has a substantial effect on the cultural activities of just some young people. Far fewer Russian schoolchildren than Latvian schoolchildren (5\% vs. 16\%) sing in a choir or are involved in various extracurricular clubs (11\% vs. 17\%). 54\% of Latvian, $52 \%$ of Russian, and $49 \%$ of other non-Latvian young people take part in clubs, cultural groups, etc. ${ }^{92}$ The fact is that quantitative indicators about the cultural activities and consumption of culture in the two largest ethnic groups do not indicate the existence of a gap in the terms of the culture of the two. This is seen, for instance, in a study on the cultural activities and national integration of young people. ${ }^{93}$

The Russian language and Latvian language mass media tend mostly to reflect the artistic activities of their own ethnolinguistic group. The Russian language mass media often present information about the events of other ethnic minorities while seldom discussing the cultural activities of young Latvians. The Latvian language mass media, for their part, very seldom pay any attention at all to Ukrainian, Belarusian and other minority cultural activities. ${ }^{94}$ In a study of the two types of newspapers and Internet portals over the course of two months in 2005, it was found that nearly 100 cultural events in Liepāja, Daugavpils, Jūrmala and Valmiera (all are regional centres) were mentioned, but there were only two about which there was information in both the Latvian and the Russian language media (a concert staged by a Romani group from Lithuania and a reality show produced at the Karosta facilities in Liepāja). ${ }^{95}$

Even when it comes to the visual arts, there are substantial differences in the way in which they are presented in Latvian and Russian news media - this despite the fact that there are no linguistic barriers against the perception against such artworks. ${ }^{96}$ The study focused on Russian and Latvian university students to analyse their cultural consumption, values, communications and activities, finding that students are mostly unified in their interest about Western culture (mostly pop culture). Both Latvian and non-Latvian students watch foreign films and download foreign music. Young people in both groups praise Western musicians, authors and artists, as well as certain Latvian musicians. Latvian students are more likely than non-Latvian students to make use of Latvian cultural products - they read the works of Latvian authors, listen to the music of Latvian musicians and watch films that have been produced in Latvia more often than non-Latvians do. At the same time, however, young people in the two groups have a fairly different communicative environment, and the same is true when it comes to their competence about and interest in cultural life in Latvia. Many non-Latvians do not feel competent in evaluating the profession-

\footnotetext{
92 Ibid., pg. 59.

93 Aivars Tabuns (ed.) (2006), Kultūras. Jaunieši. Mediji. Riga: University of Latvia, Faculty of Social Sciences.

94 Ibid.

95 Ibid., pg. 33.

96 Ibid., pp. 38-43.
} 
alism of Latvian cultural workers, and if they assess it, they are more critical than Latvian students are. ${ }^{97}$

It must be stressed, however, that apart from ethnic music, cultural groups are usually not homogeneous in ethnic terms. Some 35\% of Russian students take part in cultural activities in which the proportion of Latvian participants is equal to or exceeds the share of Russian participants. Cultural activities represent an environment in which young people learn about members of other ethnic groups - something that helps them to get rid of mistaken stereotypes. ${ }^{98}$

At the same time, however, young Russians are considerably less likely to take part in the Latvian Song and Dance Festival, to attend concerts and other cultural events, or to watch such events on TV. ${ }^{99}$ Young Russians quite often think that the Song Festival is important to foreigners (28\% say that it is important or very important), but they are far less likely to say that it is important for non-Latvians (18\% say that it is important or very important for Russians, and $15 \%$ say the same about other nationalities in Latvia). The conclusion here is that the integration of society in Latvia is affected more substantially by the global cultural arena than by cultural processes which occur in Latvia.

\section{Ethnic Studies}

Latvia's Integration Programme claims that

The interest of people in their own ethnic identity will always be a sensitive component in the multi-national Latvian society. Civic integration in a democratic nation state relates to ethnic identities. Social integration can be endangered by ethnic disharmony and conflicts. From the perspective of ethnic policy, such tensions and conflicts can be caused by two types of causes. First of all, they can be caused by an increased sense that Latvian identity is endangered, and secondly, they can be caused by members of national minorities who feel that their own ethnic identity is under threat. The goal for ethnic policy research is to identify and forecast the causes of ethnic disharmony in a timely way so that recommendations can be developed on how to prevent them. ${ }^{100}$

The studies cited in this chapter and many others show that research has been the most successful specifically in this sub-section of the Integration

\footnotetext{
97 Ibid., pp. 57-70.

98 Ibid., pg. 107.

99 Rungule (ed.) (2005), Jauniešu identitātes veidošanās un lìdzdalība, pg. 60.

${ }^{100}$ Integration Programme, op. cit., pg. 92.
} 
Programme, ${ }^{101}$ although cultural processes and their effects on integration have been studied to a lesser degree.

\section{Summary}

The authors of a recent study on opposition to social integration believe that contradictions among the ethnic groups in Latvia have recently been manifested in several forms - at the symbolic level, in politics, as a result of the divided information space, negative interethnic stereotypes, and the increased activities of radically nationalist organisations. The authors argue that "the press disseminates ideas and views which are in confrontation with the very essence of integration." 102 Studies show that many people believe that a greater contribution to social integration is made by people outside of politics - athletes, musicians and artists. ${ }^{103}$

The authors of a study conducted by the Baltic Institute of Social Sciences agree:

Generally speaking, there are radically different discourses and very different collective identities in Latvian language and Russian language newspapers, which are read by Russian and Latvian speakers. The separate media spaces cause a gap between the two ethnolinguistic groups, which makes it more difficult to engage in mutual discussions, exchange viewpoints, and shape unified identities. This gap is closely linked to the polarization of political identities, because parties, too, represent the interests of one group or the other, and the ethnic identities of parties dominate over ideological differences related to economic, social and other issues. In terms of discourse, people who think differently are marginalized in both the Latvian and the Russian language press. These people are presented as individuals who do not represent the majority view, and the papers do what they can to discredit them as being selfish, criminal or radically nationalist. ${ }^{104}$

Deniss Hanovs and Irina Vinnika have proposed the hypothesis that "transformations in the collective memory of Latvia's Russian speaking community may overcome trends of self-isolation, weaken the idea that the community has been alienated, and increase participation in the civil society." ${ }^{105}$ The results of

\footnotetext{
${ }^{101}$ For more on this, see the homepage of the Providus public policy research centre (http:// www2.providus.lv/public/petijumi.html), as well as the homepage of the Latvian Centre for Human Rights (http://www.humanrights.org/lv/html/lv/jomas/datu_baze/29355.html).

${ }^{102}$ Dribins (ed.), Pretestība sabiedrības integrācijai, pp. 6 and 26.

${ }^{103}$ Ibid., pg. 28.

${ }^{104}$ Zepa (ed.) (2006), Integrācijas prakse un perspektīvas, pp. 29-30.

${ }^{105}$ Denis Hanovs and Irina Vinnika (2005), 'Krievvalodīgie Latvijā: diasporas kultūras atmiņas saturs un veidošanas tehnologijas.' Proceedings of an international conference, Riga: University of Latvia, 2005, pg. 188.
} 
sociological surveys confirm that there are several issues with respect to which Latvians and Russians have fairly different collective memories. It is also true that their judgments about historical facts differ significantly.

It was hoped at one time that increased welfare and a more inclusive citizenship policy would facilitate consolidation among ethnic communities, but integration processes are developing very slowly. There is evidence of the mutual isolation of the Russian and the Latvian segments of civil society. ${ }^{106}$ The geopolitical self-identification with Latvia is not too extensive among nonLatvians, but interethnic relationships at the personal level have improved to a certain extent. Another positive fact is that "by any standard, racist extremism in Latvia has been quite weak" - there are few such organizations in Latvia, and support for them amidst the electorate is weak. ${ }^{107}$ Even though Latvians and Russians have different views as to the country's ethnic policies, moreover, "the conflict is not likely to turn violent or create an ethnopolitical crisis." 108

If we take into account the eight potential dimensions for measuring identity that have been identified by Rawi, Herrera, Johnston and Martin, ${ }^{109}$ then we can conclude that the level of acceptance of other ethnic identities is high in all ethnic groups, and government institutions ensure the preservation and development of ethnic identity. At the same time, the people of Latvia do not agree as to how and whether many different identities can co-exist. ${ }^{110}$ Most people in Latvia think that identities are "chosen," but they also perceive other ethnic groups as being "real." Each ethnic group says that its identity is one about which pride, not shame can be felt. Ethnic hostilities are not common, but neither is ethnic favour. Ethnic groups do not issue strict requirements to their members - more typical is voluntary ethnic self-isolation (particularly among Latvians), as well as symbolic ethnic confrontation. The goals and intentions of ethnic groups are disharmonious, but resources brought to bear in addressing this fact are not violent.

Latvia's Integration Programme sought to promote understanding and cooperation among individuals and different groups in Latvia, saying that "the goal of integration is to establish a democratic and consolidated civil society which is based on common fundamental values."

${ }^{106}$ Ivars Ijabs (2006), 'Russians and Civil Society.' In Muižnieks N. (ed.), Latvian-Russian Relations, pg. 83.

${ }^{107}$ Nils Muižnieks (2005), 'Latvia.' In Cas Muddle (ed.), Racist Extremism in Central and Eastern Europe. London: Routledge, pg. 102.

${ }^{108}$ Brigita Zepa and Inese Šu upule (2006), 'Ethnopolitical Tension in Latvia: Factors Facilitating and Impeding Accord.' In Muižnieks N. (ed.), Latvian-Russian Relations, pg. 83.

${ }^{109}$ See Rawi, A., Herrera, Y. M., Johnston, A. I. and T. Martin. "Treating identity...”, op. cit., pp. 11-12.

110 Aivars Tabuns (1998), 'Mūsu mainīgās un daudzveidīgās identitātes,'Diena, 17 January 1998.

${ }^{111}$ Ministry of Justice (2001), 'National Programme on the Integration of Society in Latvia,'pg. 4. 
however, that the Integration Programme and its instruments have facilitated the achievement of these goals very much - integration processes have largely been based on the activities of non-political agents, this despite the fact that the process has been hindered by the mass media. It is the everyday experience of individuals that has served as the foundation for the emergence of ethnic trust and integration that is based upon it.

\section{Greatest Achievement}

The greatest achievement in this area is that all ethnic groups have been ensured the opportunity to preserve and develop their identities. Most inhabitants of Latvia are not concerned about losing their ethnic identity. The group that does not know the Latvian language at all is slowly decreasing.

\section{Most Serious Problem}

Efforts to create a civic/political nation have not been successful - ethnic groups still very have divergent notions of the kind of country they would like to live in and their geopolitical identities and perceptions of history are starkly different, which is furthered by the ethnically segregated party system.

\section{Most Urgent Task}

The most important task in the near future is to promote debate and public understanding about ethnic tolerance and respect, a feeling of togetherness and the risks of ethnic strategies of self-isolation. To weaken ethnic stereotypes and promote a "we" feeling, it is necessary to support the non-segregated and non-political activities of cultural, sport, educational, environmental and other organizations, as well as intercultural contact and communication. 


\section{Conclusion}

Nils Muižnieks

This volume has sought to provide answers to the question posed in the title "How integrated is Latvian society?" This question, in turn, contains within it several related questions. What do we understand by the term "integrated"? How should one measure integration? What are the various factors affecting the extent and nature of social integration in Latvia, including the historical legacy, government policy, the economic situation, Latvia's international position, and others? What is the overall picture and what are recent trends?

In seeking to answer these questions, this volume began by delving into the intellectual history of the idea of social integration. Most European discourse on social integration deals with either immigrant integration or Roma integration, whereas the Latvian context also requires an approach that captures the specific character of ethnopolitical and linguistic disunity bequeathed by Soviet rule and, sometimes, exacerbated by Latvian policy. After reviewing social theory, human rights approaches and new European policy frameworks, Nils Muižnieks identifies the consensus understanding of social integration as being a process of unifying society by promoting participation, non-discrimination and intercultural contact. He suggests that these three mechanisms are interdependent and that each has a corollary: participation needs to be supplemented by representation, non-discrimination by the pursuit of equality in outcomes, and intercultural contact by intercultural competence. While such an approach can be extended to encompass "new" migrants and Roma, in the Latvian case, the core cleavages generally revolve around differences between ethnic Latvians and "old" Russian-speaking Soviet-era migrants and their descendants.

A sound conceptual approach to social integration must be supplemented by a nuanced understanding of the Latvian historical and cultural context, which is provided by Juris Rozenvalds. Rozenvalds points to a number of legacies from the Soviet era, the period of the "Awakening" in the late 1980s, and the early post-independence period in the 1990s - and identifies several lingering "habits of mind" which have hindered integration policy development. These include the widespread belief in the uniqueness of the Latvian situation and an ingrained minority consciousness among Latvians. While the "Awakening" period featured inter-ethnic cooperation on the road to independence, Rozenvalds also highlights the subsequent damage caused by mistakes in citizenship, 
language and education policy. These mistakes often derived from a lack of Latvian elite interest in minority issues, mistrust of minorities and an unwillingness and inability to engage in sustained dialogue. When integration policy was adopted, it was a messy compromise formed largely as the result of international pressure in a context of crisis.

Ilona Kunda examines the role of the Society Integration Foundation and the impact of the projects it has supported in addressing ethnopolitical and linguistic cleavages in society. She notes that the Foundation, which has been one of the primary funders of integration-related projects since its creation in 2001, is widely recognized as an efficient, transparent and well-governed agency. The weaknesses of the Integration Programme as a guide for action combined with the desire to develop the Foundation into a serious, but neutral money-administering machine prevented it from becoming a pro-active player in integration policy development. Inspired by a somewhat misplaced faith in the self-organizing capacity of society and its ability to generate integration policy solutions "from below," the Foundation has often supported "monologue" projects lacking sustained face-to-face contact between persons belonging to different cultural groups. This was not only a politically safe path to tread in the political minefield of integration policy, it also reflected the preferences of many inhabitants of Latvia, who sought support for maintaining and reproducing familiar strategies of separation.

Subsequent chapters assess the nature and extent of integration in a wide array of life realms: 1) citizenship, participation and representation; 2) the labour market; 3) the social sphere of welfare, health, housing and the integration of ex-prisoners; 4) education; 5) media; and 6) culture, language and identity. The chapter authors were provided with suggested indicators reflecting participation and representation, intercultural contact and competence, non-discrimination and equality (see the appendix). Moreover, chapter authors were asked to identify the greatest achievements, most serious problems and most important tasks in their respective policy realms. These can be found at the end of each chapter.

In assessing the role of citizenship, participation, and representation in integration, Ilze Brands Kehris notes that, with non-citizens still representing $15 \%$ of the population 20 years after independence, it is difficult to claim huge progress in political integration. Naturalization rates recently hit an all-time low, while failure rates in the naturalization examinations hit record highs. This does not reflect any changes in legislation or in the administration of the law, but rather the low levels of motivation, scarce resources and limited social capital of applicants. Laws excluding certain groups (ex-Soviet military and KGB personnel) from naturalization and limiting others from standing for office appear increasingly anachronistic as immediate post-independence security concerns have faded. Minorities are slightly under-represented at the national political level and in some local governments, but well-represented in others, e.g., in 
Riga. With some partial exceptions, political parties remain largely oriented towards one ethnolinguistic group and most minority activists and politicians perceive their participation as being ineffective in both legislative politics and through advisory bodies.

During the economic boom years from 2002 through 2007, the labour market was quite successful in promoting the integration of ethnic and linguistic minorities and ethnic disparities in employment and unemployment rates largely disappeared. Mihails Hazans demonstrates that the labour shortage led to the de facto easing of Latvian language requirements during the boom years, which led to many minority workers learning Latvian on the job. Moreover, this led to increased inter-ethnic contact in the workplace and a decrease in the already modest levels of sectoral and occupational segregation. Latvia has only a small ethnic pay and earnings gap, though the gap is more pronounced among female public sector workers. The existing survey evidence on labour market discrimination suggests that Roma are the group most at risk of differential treatment. Unfortunately, the onset of economic crisis in 2008 was accompanied by a reversal of previous positive trends in the labour market integration of ethnic minorities.

In assessing social policy and integration, Feliciana Rajevska finds that the share of the population at risk of poverty is large and growing, but that there is no intimate link between ethnicity and poverty. However, she does find that ethnic Latvians are better informed about their social rights. In a February 2009 ruling, the European Court of Human Rights found that Latvia's pension policy has discriminated against some non-citizens (who are almost all members of ethnic minorities), in that time worked outside of the territory of Latvia is counted in calculating pensions for citizens, but not for non-citizens. ${ }^{1}$ The privatization of health care, combined with economic crisis, means that many will be unable to afford care and the health situation will deteriorate significantly. There is a serious dearth of cheap and social housing. Rates of incarceration and recidivism are very high, though the creation of the State Probation Service was a step forward.

The link between the education system and integration, as analysed by Brigita Zepa, is a complex one. Some progress has been made in overcoming the Soviet legacy of two parallel educational sub-systems operating in the Latvian and Russian languages through bilingual education reform, dual-stream schools and other strategies. However, a significant share of Latvian and minority pupils and teachers support separate education, teachers are often unprepared to cope with diverse classes and many textbooks are ethnocentric. Participation

1 The practice affects 16,850 non-citizen pensioners. See the ruling of the European Court of Human Rights in the case Andrejeva vs. Latvia, pg. 16, available at http://cmiskp.echr. coe.int/tkp197/view.asp?item=1\&portal=hbkm\&action=html\&highlight=55707/00\&sessi onid $=28048028 \&$ skin $=$ hudoc-en . 
by parents in education policy decision-making is low. According to international comparative studies, Latvia's overall education achievement levels are satisfactory, though overall figures mask great diversity within the system and significant urban-rural differences. A serious problem is the low quality of professional education and the mismatch with the needs of the labour market, which hinders subsequent integration into the labour market.

While separation is sometimes still the norm in education, the same holds true in the media world, which is characterized by external diversity (many media outlets) and internal uniformity (a lack of diversity in viewpoints within media outlets) and limited interaction. The chapter by Ilze Šulmane finds that Latvia has two stable, self-sufficient media sub-systems based on the Latvian and Russian languages using different sources and featuring divergent content and stances towards important aspects of socio-political life, such as history and international affairs. While there are examples of audience overlap (the newspaper $5 \mathrm{~min}$, the internet portal dialogi.lv), the rule is coexistence in parallel worlds. With the partial exception of Latvian Radio, the Latvian authorities have not exploited the opportunities inherent in public broadcasting to systematically inform, involve and entertain minorities in their native languages. While local Russian-speakers have wide access to local Russian language media outlets, they also use the vast array of media originating in Russia. Smaller non-Russian minorities, in turn, have considerably less access to media in their own language. Other groups with limited media access include persons living in rural or border areas without internet access or public broadcasting coverage, as well as the hearing and sight impaired.

Aivars Tabuns finds a very contradictory situation in the realm of identities, ethnic relations, language and culture. On the positive side of the ledger, more than three-quarters of both Latvians and minorities believe that ethnic relations are satisfactory or good and that ethnic conflict has become less likely over time. Latvia has relatively high and stable rates of ethnic intermarriage, while studies find that ethnic distance is not very great. Latvian language knowledge among Russian-speakers has improved significantly since independence. These positive characteristics, however, are accompanied by more negative ones: persistent threat perceptions among both Latvians and minorities about their identities, continued use of Russian as the "language of interethnic communication," a very weak sense of attachment to Latvia by Russian-speakers and deep differences in geopolitical identities.

Thus, the overall picture and recent trends are very contradictory, with elements of separation, marginalization and integration within each of the life realms. Latvia has become more integrated in some realms (Latvian language knowledge, progress towards a unified education system), but the economic crisis has set back progress in other realms (the labour market, social policy). Patterns of separation and exclusion in the media and in public and political life are stable and deep-rooted. In analysing the situation in different life realms, 
the authors generally employed the triadic framework of analysis stressing nondiscrimination, intercultural contact, and participation. Some chapter authors were able to find the suggested data for most of the suggested indicators (e.g., Mihails Hazans on the labour market and Ilze Šulmane on the media). However, other authors (e.g., Feliciana Rajevska on social policy and integration) were clearly asked to accomplish an unrealistic task, given the frequent lack of disaggregated data and space constraints. Several chapter authors present only limited data on perceptions of policy, participation opportunities or inequalities in their respective realms and the existence and effectiveness of advocacy groups. Often, such data are simply not available.

With the liquidation of a separate ministry responsible for integration in 2009, a small department (6 persons) within the Ministry of Justice and the Society Integration Foundation are all that remain in integration policy-making in 2010 outside specialized units within sectoral ministries. As has been the case since the beginning of policy dialogue on integration in the late 1990s, political disagreements continue to hamper the adoption of a (new) policy document to guide decision-making and frame public debate. While waiting for the policy elite to come to a new consensus, the Society Integration Foundation could make internal changes to ensure that projects it supports more often contain an element of inter-ethnic contact and cooperation. Another institution - the Ombudsman's Office - has not been a player in integration policy, though its role as Latvia's equality body gives it the potential to assume a more active stance by commissioning research on discrimination, reviewing complaints, conducting public awareness raising campaigns, and providing policy advice. ${ }^{2}$

There are risks inherent in the current integration policy drift. ${ }^{3}$ The Latvian state and its representatives have largely withdrawn from the integration policy field - no agreement has been reached on a new policy document after several years of debate, institutions responsible for integration are being done away with one after another (the latest casualty of budget cuts has been the Naturalization Board), government money is no longer being allocated to NGOs in general and minority NGOs in particular, and an increasing number of Latvian politicians refuse to speak Russian in public. At the same time, the Russian Federation has become much more active in seeking to win the hearts and minds of Russian-speakers in general and non-citizens in particular. The Russian government has adopted several policy documents in the realm of "compatriots"

2 See the Ombudsman's home page at www.tiesibsargs.lv. On the role of equality bodies in Europe more generally, see Rikki Hotlmaat (2006), Catalysts for Change? Equality bodies according to Direcitve 2000/43/EC - existence, independence and effectiveness. Brussels: European Commission, DG Employment, Social Affairs and Equal Opportunities.

3 For an elaboration of various future scenarios, including "disintegration," see Nils Muižnieks (2008), 'Ethnic Relations in Latvia in 2020: Three Scenarios.' In Žaneta Ozoliņa and Inga Ulnicāne-Ozoliṇa (eds.), Latvija 2020: Nākotnes izaicinājumi sabiedrībai un valstij. Riga: LU Akadēmiskais apgāds, pp. 155-172. 
policy, created new institutions to implement them, and allocated increasing amounts of funding to diaspora NGOs and Russian diaspora media, including in Latvia. ${ }^{4}$ As a result, in 2009, for the first time since the early 1990s, the Russian ambassador to Latvia was able to report that the number of Latvian non-citizens to apply for Russian citizenship (about 4000) exceeded that applying for Latvian citizenship. ${ }^{5}$ Latvia needs to "restart" its integration policy.

A "restarted" integration policy would need to take several circumstances into account. For one, effective, targeted policy measures require data disaggregated by ethnicity, native language, citizenship, gender, age, and region. ${ }^{6}$ The planned 2011 census will provide a good opportunity not only for data collection, but also for public debate about the use of simplistic categories that do not always reflect many people's identities. Furthermore, new policy documents and policy initiatives need to envision a Latvia that is not only losing many people to outmigration, but that is also attracting labour migrants, asylum-seekers and refugees. As argued in other research, Latvia needs to craft social integration policy with a view to immigrant and refugee integration as well. ${ }^{7}$ Otherwise, new European integration problems will compound old integration challenges bequeathed by Soviet rule. Latvian society is not very integrated now, but the lack of policy and future migration in this policy vacuum could undermine progress already made.

4 For a historical overview of Russian policy towards the diaspora in Latvia, see Nils Muižnieks (2006), 'Russian Foreign Policy Towards 'Compatriots' in Latvia.' In Nils Muižnieks (ed.), Latvian-Russian Relations: Domestic and International Dimensions. Riga: University of Latvia Press, pp. 119-130; for recent developments see Gatis Pelnēns (ed.) (2009), The 'Humanitarian Dimension' of Russian Foreign Policy Toward Georgia, Moldova, Ukraine, and the Baltic States. Riga: SIA Apgāds "Mantojums", pp. 137-190.

5 See the interview with Russian ambassador to Latvia Aleksandr Veshnakov in Baltic News Service, 7 January 2010, 'Vešnakovs: krīzes smagums Latvijā ir pat lielāks nekā Krievijā.'

6 On the importance of such data and obstacles to collecting it, see Patrick Simon (2007), 'Ethnic' statistics and data protection in the Council of Europe countries. Strasbourg: Council of Europe, ECRI, and European Commission, DG Employment, Social Affairs and Equal Opportunities (2006), European handbook on equality data. Brussels: European Commission.

7 See Dace Akule (ed.) (2008), Learning to welcome: the integration of immigrants in Latvia and Poland. Riga: Providus; Nils Muižnieks (ed.) (2009), Immigrant Integration in Latvia. ASPRI Working Paper No. 1, September 2009, Riga: ASPRI, available at http://www.szf. lu.lv/eng/petnieciba/sppi-instituts/petijumipublikacijas/working-paper/; and Brigita Zepa and Inese Šūpule (eds.) (2009), Imigranti Latvijā: Ieklaušanās iespējas un nosacījumi. Riga: BSZI. 


\section{Draft Integration Indicators}

\section{Ilona Kunda and Nils Muižnieks}

\begin{tabular}{|c|c|c|c|}
\hline & $\begin{array}{c}\text { Equal rights in the relevant } \\
\text { area of life (non-discrimination, } \\
\text { recognition) }\end{array}$ & $\begin{array}{l}\text { Contact between various social } \\
\text { groups }\end{array}$ & $\begin{array}{c}\text { Participation, } \\
\text { involvement, shared } \\
\text { responsibility, influence } \\
\text { on public affairs } \\
\end{array}$ \\
\hline $\begin{array}{l}\text { Citizenship, } \\
\text { representation, } \\
\text { defence of } \\
\text { interests }\end{array}$ & $\begin{array}{l}\text { 1. The phenomenon as } \\
\text { a whole: where is there } \\
\text { inequality? } \\
\text { What is the proportion of } \\
\text { citizens and non-citizens? } \\
\text { (trends, reasons) } \\
\text { To what extent are minorities } \\
\text { and women represented in the } \\
\text { structures of power? } \\
\text { 2. Quality of the phenomenon } \\
\text { To what extent is there } \\
\text { dissatisfaction with one's } \\
\text { citizenship status? } \\
\text { How many naturalization } \\
\text { applicants pass the } \\
\text { examination on the first try? } \\
\text { Are there disparities between } \\
\text { citizens and non-citizens, } \\
\text { ethnicities and genders in } \\
\text { trust in government? } \\
\text { 3. Most vulnerable groups } \\
\text { and risks } \\
\text { Who wants to naturalize } \\
\text { but cannot? Are there social } \\
\text { groups without any NGOs? }\end{array}$ & $\begin{array}{l}\text { 1. The phenomenon as a whole: } \\
\text { is there contact? } \\
\text { To what extent are mechanisms } \\
\text { of participation (parties, NGOs) } \\
\text { multiethnic or mono-ethnic? } \\
\text { How intensively do mono-ethnic } \\
\text { parties and NGOs engage in } \\
\text { contact with others? } \\
\text { 2. Quality of the phenomenon } \\
\text { How great is ethnic distance? } \\
\text { In which realms is there } \\
\text { cooperation and the lack thereof? } \\
\text { What are the consequences? } \\
\text { 3. Most vulnerable groups and } \\
\text { risks } \\
\text { How serious a problem is } \\
\text { extremism - individuals and } \\
\text { groups that are non-democratic } \\
\text { and deny equality? }\end{array}$ & $\begin{array}{l}\text { 1. The phenomenon as } \\
\text { a whole: what are the } \\
\text { most important forms } \\
\text { of participation? } \\
\text { To what extent are } \\
\text { individuals involved } \\
\text { in NGOs? Political } \\
\text { parties? How actively } \\
\text { do citizens participate } \\
\text { in elections? } \\
\text { Have other modes of } \\
\text { participation become } \\
\text { more important? } \\
\\
\text { 2. Quality of the } \\
\text { phenomenon } \\
\text { To what extent are } \\
\text { people satisfied } \\
\text { with their ability to } \\
\text { influence decisions? } \\
\text { 3. Most vulnerable } \\
\text { groups and risks } \\
\text { What are the major } \\
\text { barriers to participation } \\
\text { and advocacy? Which } \\
\text { groups are in the } \\
\text { most disadvantaged } \\
\text { position? }\end{array}$ \\
\hline
\end{tabular}




\begin{tabular}{|c|c|c|c|}
\hline & $\begin{array}{l}\text { Equal rights in the relevant } \\
\text { area of life (non-discrimination, } \\
\text { recognition) }\end{array}$ & $\begin{array}{l}\text { Contact between various social } \\
\text { groups }\end{array}$ & $\begin{array}{c}\text { Participation, } \\
\text { involvement, shared } \\
\text { responsibility, influence } \\
\text { on public affairs }\end{array}$ \\
\hline $\begin{array}{l}\text { Economic } \\
\text { participation } \\
\text { (employment) }\end{array}$ & $\begin{array}{l}\text { 1. The Phenomenon as a } \\
\text { whole } \\
\text { What is the share of those } \\
\text { employed? } \\
\text { What is the level of } \\
\text { unemployment? } \\
\text { Are there significant } \\
\text { differences on the basis of } \\
\text { region, ethnicity, gender, age? } \\
\text { 2. Quality of the phenomenon } \\
\text { How many working people } \\
\text { are below the poverty line? } \\
\text { To what extent are people } \\
\text { with disabilities employed? } \\
\text { To what extent are youth } \\
\text { employed? } \\
\text { What is the average } \\
\text { difference in wages between } \\
\text { women and men? } \\
\text { Do people think that all have } \\
\text { equal opportunities in the } \\
\text { labour market? } \\
\text { 3. Most vulnerable groups } \\
\text { and risks } \\
\text { Who are the long-term } \\
\text { unemployed? }\end{array}$ & $\begin{array}{l}\text { 1. The Phenomenon as a whole } \\
\text { To what extent is there ethnic } \\
\text { segmentation in the labour } \\
\text { market by profession or sector? } \\
\text { 2. Quality of the phenomenon } \\
\text { With whom do people not want } \\
\text { to work? Whom do they not want } \\
\text { to hire? } \\
\text { How many people could not } \\
\text { work in a job requiring Latvian } \\
\text { language skills? } \\
\text { 3. Most vulnerable groups and } \\
\underline{\text { risks }} \\
\text { What is the level of employment } \\
\text { among Roma and immigrants? }\end{array}$ & $\begin{array}{l}\text { 1. The Phenomenon as } \\
\text { a whole } \\
\text { To what extent } \\
\text { do trade unions } \\
\text { and professional } \\
\text { associations include } \\
\text { those employed? } \\
\text { 2. Quality of the } \\
\text { phenomenon } \\
\text { To what extent } \\
\text { do inhabitants } \\
\text { trust trade unions } \\
\text { and professional } \\
\text { associations? } \\
\text { 3. Most vulnerable } \\
\text { groups and risks } \\
\text { Are there sectors/ } \\
\text { professions in which } \\
\text { there is no organized } \\
\text { advocacy or interest } \\
\text { representation? }\end{array}$ \\
\hline Poverty & $\begin{array}{l}\text { Gini coefficient } \\
\text { How many people are below } \\
\text { the poverty threshold (by } \\
\text { region, gender, age, ethnicity, } \\
\text { etc.) }\end{array}$ & $\begin{array}{l}\text { To what extent are the poor } \\
\text { concentrated in a district or } \\
\text { region? }\end{array}$ & $\begin{array}{l}\text { To what extent are } \\
\text { poor people organized } \\
\text { to defend their } \\
\text { interests? } \\
\text { To what extent does } \\
\text { the public support such } \\
\text { activities? }\end{array}$ \\
\hline
\end{tabular}




\begin{tabular}{|c|c|c|c|}
\hline & $\begin{array}{c}\text { Equal rights in the relevant } \\
\text { area of life (non-discrimination, } \\
\text { recognition) }\end{array}$ & $\begin{array}{l}\text { Contact between various social } \\
\text { groups }\end{array}$ & $\begin{array}{c}\text { Participation, } \\
\text { involvement, shared } \\
\text { responsibility, influence } \\
\text { on public affairs }\end{array}$ \\
\hline $\begin{array}{l}\text { Social } \\
\text { security } \\
\text { (housing, } \\
\text { health, social } \\
\text { protection) }\end{array}$ & $\begin{array}{l}\text { 1. The Phenomenon as } \\
\text { a whole: where is there } \\
\text { inequality? } \\
\text { Is there equal access to social } \\
\text { protection? } \\
\text { Is there equal access to } \\
\text { housing and health care? } \\
\text { 2. Quality of the phenomenon } \\
\text { To what extent is accessibility } \\
\text { guaranteed to the disabled? } \\
\text { To what extent are } \\
\text { risk groups provided } \\
\text { with alternatives to } \\
\text { institutionalized care? } \\
\text { To what extent are the } \\
\text { specific health care needs of } \\
\text { old people, youth, and women } \\
\text { met? } \\
\text { 3. Most vulnerable groups } \\
\text { and risks } \\
\text { Are persons of a certain } \\
\text { ethnic group or gender } \\
\text { overrepresented in risk } \\
\text { groups? }\end{array}$ & $\begin{array}{l}\text { 1. The Phenomenon as a whole: } \\
\text { is there contact? } \\
\text { To what extent are certain groups } \\
\text { (people with a certain illness, } \\
\text { risk children, old people, etc.) } \\
\text { segregated from society? } \\
\text { To what extent is there ethnic } \\
\text { segregation in the housing } \\
\text { market? } \\
\text { 2. Quality of the phenomenon } \\
\text { Which are the groups people do } \\
\text { not want to have as neighbours? } \\
\text { 3. Most vulnerable groups and } \\
\text { risks } \\
\text { To what extent are social risks } \\
\text { passed on from generation to } \\
\text { generation? } \\
\text { Are certain ethnic groups over- } \\
\text { represented among offenders/ } \\
\text { prisoners? }\end{array}$ & $\begin{array}{l}\text { 1. The Phenomenon as } \\
\text { a whole } \\
\text { Is there advocacy } \\
\text { or interest group } \\
\text { representation in these } \\
\text { spheres? } \\
\text { 2. Quality of the } \\
\text { phenomenon } \\
\text { How does the public } \\
\text { perceive activists in } \\
\text { these realms? } \\
\begin{array}{l}\text { Do the advocates feel } \\
\text { they are effective? }\end{array} \\
\text { 3. Most vulnerable } \\
\text { groups and risks } \\
\text { Which groups do } \\
\text { not have any interest } \\
\text { representation? }\end{array}$ \\
\hline
\end{tabular}




\begin{tabular}{|c|c|c|c|}
\hline & $\begin{array}{l}\text { Equal rights in the relevant } \\
\text { area of life (non-discrimination, } \\
\text { recognition) }\end{array}$ & $\begin{array}{c}\text { Contact between various social } \\
\text { groups }\end{array}$ & $\begin{array}{c}\text { Participation, } \\
\text { involvement, shared } \\
\text { responsibility, influence } \\
\text { on public affairs }\end{array}$ \\
\hline Education & $\begin{array}{l}\text { 1. The Phenomenon as a } \\
\text { whole: is there inequality? } \\
\text { To what extent is education } \\
\text { equally accessible to all? } \\
\text { How many young people fall } \\
\text { out of the education system? } \\
\text { What is the percentage of } \\
\text { youth with a low level of } \\
\text { basic skills? } \\
\text { 2. Quality of the phenomenon } \\
\text { To what extent are students } \\
\text { satisfied with the quality } \\
\text { of education? With the } \\
\text { regulation of language use in } \\
\text { the education system? With } \\
\text { their career opportunities } \\
\text { after school? } \\
\text { 3. Most vulnerable groups } \\
\text { and risks } \\
\text { Who are those who leave } \\
\text { school early? What is the } \\
\text { background (by region, native } \\
\text { language, etc.) of youth with } \\
\text { low levels of basic skills? }\end{array}$ & $\begin{array}{l}\text { 1. The Phenomenon as a whole: } \\
\text { is there contact? } \\
\text { What is the ethnic and social } \\
\text { make-up of students at various } \\
\text { levels of education? } \\
\text { What is the share of dual stream } \\
\text { institutions? } \\
\text { 2. Quality of the phenomenon } \\
\text { Do Latvian and minority schools } \\
\text { have any contact? } \\
\text { To what extent do schools teach } \\
\text { civic education and intercultural } \\
\text { competence? } \\
\text { 3. Most vulnerable groups and } \\
\text { risks } \\
\text { How serious a problem in } \\
\text { schools is violence based on } \\
\text { ethnicity, language or other } \\
\text { grounds? }\end{array}$ & $\begin{array}{l}\text { 1. The Phenomenon } \\
\text { as a whole: is there } \\
\text { participation? } \\
\text { To what extent do } \\
\text { parents participate in } \\
\text { decision-making? } \\
\text { To what extent is } \\
\text { internal democracy } \\
\text { (self-government, etc.) } \\
\text { developed in schools? } \\
\text { 2. Quality of the } \\
\text { phenomenon } \\
\text { To what extent are } \\
\text { parents and youth } \\
\text { satisfied with their } \\
\text { ability to influence } \\
\text { decisions? } \\
\text { 3. Most vulnerable } \\
\text { groups and risks } \\
\text { Are there groups about } \\
\text { whom decisions are } \\
\text { taken without any } \\
\text { consultation? }\end{array}$ \\
\hline
\end{tabular}




\begin{tabular}{|c|c|c|c|}
\hline & $\begin{array}{c}\text { Equal rights in the relevant } \\
\text { area of life (non-discrimination, } \\
\text { recognition) }\end{array}$ & $\begin{array}{l}\text { Contact between various social } \\
\text { groups }\end{array}$ & $\begin{array}{c}\text { Participation, } \\
\text { involvement, shared } \\
\text { responsibility, influence } \\
\text { on public affairs }\end{array}$ \\
\hline $\begin{array}{l}\text { Media and } \\
\text { Information }\end{array}$ & $\begin{array}{l}\text { 1. The Phenomenon as a } \\
\text { whole } \\
\text { To what extent is there equal } \\
\text { access to ICT and the media } \\
\text { (the press, radio, TV, the } \\
\text { Internet, telephone service)? } \\
\text { 2. Quality of the phenomenon } \\
\text { To what extent do public } \\
\text { radio and television reflect } \\
\text { the diversity of society? } \\
\text { 3. Most vulnerable groups } \\
\text { and risks } \\
\text { To what extent are } \\
\text { stereotypes prevalent in } \\
\text { the media? Against which } \\
\text { groups? } \\
\text { How frequent is incitement to } \\
\text { hatred? }\end{array}$ & $\begin{array}{l}\text { 1. The Phenomenon as a whole } \\
\text { To what extent do the media } \\
\text { audiences of Latvian and other } \\
\text { language outlets overlap? } \\
\text { To what extent are there } \\
\text { discussions in the media between } \\
\text { different language groups? } \\
\text { To what extent have journalists } \\
\text { working in different language } \\
\text { media united in professional } \\
\text { associations? } \\
\text { 2. Quality of the phenomenon } \\
\text { To what extent do people } \\
\text { believe that the media promote } \\
\text { understanding between people? } \\
\text { 3. Most vulnerable groups and } \\
\text { risks } \\
\text { How many people live outside } \\
\text { of Latvia's information } \\
\text { environment? }\end{array}$ & $\begin{array}{l}\text { 1.The Phenomenon as } \\
\text { a whole } \\
\text { To what extent do the } \\
\text { media promote civic } \\
\text { participation? } \\
\text { 2. Quality of the } \\
\text { phenomenon } \\
\text { To what extent do } \\
\text { people trust the media? } \\
\text { To what extent do } \\
\text { people believe that the } \\
\text { media are a serious } \\
\text { social force? } \\
\text { 3. Most vulnerable } \\
\text { groups and risks }\end{array}$ \\
\hline
\end{tabular}




\begin{tabular}{|c|c|c|c|}
\hline & $\begin{array}{c}\text { Equal rights in the relevant } \\
\text { area of life (non-discrimination, } \\
\text { recognition) }\end{array}$ & $\begin{array}{c}\text { Contact between various social } \\
\text { groups }\end{array}$ & $\begin{array}{c}\text { Participation, } \\
\text { involvement, shared } \\
\text { responsibility, influence } \\
\text { on public affairs } \\
\end{array}$ \\
\hline $\begin{array}{l}\text { Culture, } \\
\text { Language, } \\
\text { Identity }\end{array}$ & $\begin{array}{l}\text { 1. The Phenomenon as a } \\
\text { whole } \\
\text { To what extent is there equal } \\
\text { access to culture: what is } \\
\text { the average cost of a book, a } \\
\text { theatre ticket, museum entry } \\
\text { in relation to the minimum } \\
\text { wage? How often do cultural } \\
\text { events take place nearby in } \\
\text { various regions, in the city/ } \\
\text { countryside? } \\
\text { To what extent are there equal } \\
\text { opportunities to preserve and } \\
\text { develop all the cultures in } \\
\text { the country (through specific } \\
\text { cultural events, museums, } \\
\text { publications, etc.) at the local, } \\
\text { regional and national levels? } \\
\text { To what extent does cultural } \\
\text { policy satisfy the cultural } \\
\text { needs of all inhabitants? } \\
\text { 2. The quality of the } \\
\text { phenomenon } \\
\text { What is the share of people } \\
\text { who believe that government } \\
\text { policy does not pose a threat } \\
\text { to their identity? What is the } \\
\text { share of people who believe } \\
\text { that other groups do not pose } \\
\text { a threat to their identity? To } \\
\text { what extent are minorities } \\
\text { satisfied with language } \\
\text { policy? } \\
\text { 3. Most vulnerable groups } \\
\text { and risks } \\
\text { How many people cannot } \\
\text { speak in the state language? } \\
\text { Which groups feel } \\
\text { stigmatized because of their } \\
\text { identity? }\end{array}$ & $\begin{array}{l}\text { 1. The Phenomenon as a whole } \\
\text { What is the share of mixed } \\
\text { marriages? } \\
\text { To what extent do issues of } \\
\text { history divide Latvian society? } \\
\text { What is the share of public } \\
\text { intercultural events? What } \\
\text { is the rate of participation in } \\
\text { intercultural events? } \\
\text { How accessible are places/centres } \\
\text { were intercultural dialogue can } \\
\text { take place on a regular basis? } \\
\text { How regularly do public } \\
\text { discussions take place on } \\
\text { language, culture and identity? } \\
\text { 2. The quality of the phenomenon } \\
\text { What is the share of inhabitants } \\
\text { who believe that minority culture } \\
\text { is part of Latvia's cultural } \\
\text { heritage? That it should be } \\
\text { funded from the state budget? } \\
\text { What is the share of people who } \\
\text { feel a sense of belonging to more } \\
\text { than one culture? } \\
\text { What is the share of persons } \\
\text { belonging to a minority who feel } \\
\text { a sense of belonging to Latvia? } \\
\text { (by age group) } \\
\text { What is the share of people who } \\
\text { can freely use two or more local } \\
\text { languages? How many people do } \\
\text { not know Latvian and Russian? } \\
\text { 3. Most vulnerable groups and } \\
\text { risks } \\
\text { What is the share of inhabitants } \\
\text { who believe that there are } \\
\text { insurmountable differences in } \\
\text { values in society? }\end{array}$ & $\begin{array}{l}\text { 1. The Phenomenon as } \\
\text { a whole } \\
\text { What is the share } \\
\text { of inhabitants who } \\
\text { participate in amateur } \\
\text { cultural events? } \\
\text { Are there social } \\
\text { initiatives to defend or } \\
\text { develop languages or } \\
\text { cultures? } \\
\text { 2. The quality of the } \\
\text { phenomenon } \\
\text { To what extent are } \\
\text { inhabitants satisfied } \\
\text { with their ability to } \\
\text { influence cultural } \\
\text { (language, history) } \\
\text { policy? } \\
\text { 3. Most vulnerable } \\
\text { groups and risks } \\
\text { Are persons belonging } \\
\text { to certain cultures or } \\
\text { identities excluded } \\
\text { from activities in the } \\
\text { public sphere? }\end{array}$ \\
\hline
\end{tabular}




\section{Contributors}

Ilze Brands Kehris is director of the Latvia Human Rights Centre, chairperson of the management board of the European Union's Fundamental Rights Agency and Vice-president of the Advisory Committee of the Council of Europe Framework Convention for the Protection of National Minorities. Her research interests include human rights (civic and political rights), minority rights, majority-minority relations and social integration, citizenship, racism, xenophobia and discrimination, and international influences on domestic human rights developments.

Mihails Hazans is Professor of economics at the University of Latvia. He has published widely on migration, commuting, the economics of education, ethnic minorities, job search, unemployment risk, working conditions, job satisfaction, active labour market policies, and regional disparities. He has served as an expert or consultant for the OECD, the World Bank, USAID, the European Commission, the ILO, the European Agency for Reconstruction, and the European Training Foundation.

Ilona Kunda is researcher at the Advanced Social and Political Studies Institute of the Faculty of Social Sciences and a doctoral student in the Department of Sociology, University of Latvia. Her research interests include social cohesion, policy evaluation, and social aspects of knowledge production.

Nils Muižnieks is director of the Advanced Social and Political Research Institute at the University of Latvia and chairman of the European Commission against Racism and Intolerance (ECRI). He was director of the Latvian Centre for Human Rights from 1994-2002, then served as Latvia's first Minister for Social Integration from 2002-2004. He has published widely on integration policy, minority rights, and Russian-Latvian relations.

Feliciana Rajevska is Associate Professor at Vidzeme University of Applied Sciences and director of the Master's programme "Governance and Communication". Her research interests include social policy making in Latvia, social exclusion and inclusion policies. She has participated in Council of Europe projects, European Union projects and bilateral projects. She was editor-in-chief of Issues in Political Science (I-IV) published by the University of Latvia in 2002-2005. 
Juris Rozenvalds is Professor of political theory in the Department of Political Science and Dean of the Faculty of Social Sciences, University of Latvia. His recent works include three edited volumes: How Democratic is Latvia: Audit of Democracy (2005), How Democratic is Latvia: Monitoring of Democracy 2005-2007 (2007), and Latvia Human Development Report 2008/2009: Accountability (2010). His research interests include democratic theory, the political role of intellectuals, and measuring the quality of democracy.

Ilze Šulmane is researcher at ASPRI and lecturer in the Department of Communication Studies, University of Latvia. Her main research interests include journalistic cultures and the two information spaces in Latvia, stereotyping in the media, the media system in Latvia and its relationship with socio-economic, historical and integration processes.

Aivars Tabuns is Professor of Sociology at the Faculty of Social Sciences at the University of Latvia. He is the author of numerous publications on ethnicity and national identity, including an edited volume Culture. Youth. Media. (2006). His research interests include national identity, science funding, and culture.

Brigita Zepa is Professor of Sociology at the Faculty of Social Sciences of the University of Latvia and director of the Baltic Institute of Social Sciences. She has been the head of numerous international and local research projects and is the author of more than 40 publications on ethnopolitics, civil society, the integration of society, social identity, collective memory and education politics. 